\title{
The Role of the p75 Neurotrophin Receptor in Experimental Inflammation of the Central Nervous System
}

\author{
Dissertation \\ for the award of the degree \\ “Doctor rerum naturalium" (Dr. rer. nat.) \\ Division of Mathematics and Natural Sciences \\ Georg August University Göttingen
}

submitted by

\section{Tobias Dallenga \\ from Oldenburg, Germany}

Göttingen, 2010 


\section{Thesis Committee}

\section{$1^{\text {st }}$ Reviewer}

Prof. Dr. Wolfgang Brück

Institute of Neuropathology

University Medical Center Göttingen

Georg August University Göttingen

$2^{\text {nd }}$ Reviewer

Prof. Dr. Eberhard Fuchs

Clinical Neurobiology

German Primate Center

Leibniz Institute for Primate Research Göttingen

\section{$3^{\text {rd }}$ Member of the Thesis Committee}

Prof. Dr. Mikael Simons

Cellular Neuroscience

Max Planck Institute for Experimental Medicine

Göttingen

\section{Supervisor}

\section{Prof. Dr. Christine Stadelmann-Nessler}

Institute of Neuropathology

University Medical Center Göttingen

Georg August University Göttingen 
Meinen Eltern 


\section{Declaration}

I hereby declare that I have written my Ph.D. thesis entitled "The Role of the p75 Neurotrophin Receptor in Experimental Inflammation of the Central Nervous System" independently and with no other sources and aids than quoted. This thesis has not been submitted elsewhere for any academic degree. 


\section{Abstract}

The extent of the permanent clinical disability in multiple sclerosis patients emerges from axonal damage and loss. In this study, we show a major role of the low affinity neurotrophin receptor $\mathrm{p} 75^{\mathrm{NTR}}$ for axonal damage in experimental autoimmune encephalomyelitis (EAE). After EAE induction by active immunization with the myelin oligodendrocyte glycoprotein peptide $\mathrm{MOG}_{35-55}, \mathrm{p} 75^{\mathrm{NTR}}-/-$ mice suffer from a more severe disease course, demyelination, and axonal loss. To elucidate whether the increased disability derives from a more aggressive inflammation or a more vulnerable central nervous system (CNS), I examined both, the immune system during peripheral disease generation and the overt disease phase, and cells of the CNS in vivo, ex vivo, and in vitro. No difference with regard to the quality of inflammation was found using immunohistochemical, flow cytometric, ELISA, and mRNA analysis, ruling out a major role of the immune cell populations examined. However, constitutive expression of $\mathrm{p} 75^{\mathrm{NTR}}$ by B cells suggests a role for $\mathrm{p} 75^{\mathrm{NTR}}$ during immune response generation within lymph nodes, since $\mathrm{p} 75^{\mathrm{NTR}}-/-$ mice show increased disease scores from the very beginning on.

To circumvent the effects of $\mathrm{p} 75^{\mathrm{NTR}}$ deficiency during peripheral priming, EAE was also induced by adoptive transfer of an encephalitogenic $\mathrm{MOG}_{35-55}$-specific $\mathrm{T}$ cell clone in $\mathrm{p} 75^{\mathrm{NTR}}-/-$ and wild type (wt) animals with similar disease incidence, onset and kinetics. Comparable degree and quality of inflammation were found by immunohistochemical and mRNA analysis in both strains at the peak of disease. However, $\mathrm{p} 75^{\mathrm{NTR}}$ deficient animals suffered from significantly more severe disease in the chronic disease stage due to increased axonal damage and loss. This suggests a protective role for $\mathrm{p} 75^{\mathrm{NTR}}$ within the CNS. In this work it is shown that astrocytes, but not microglia, express the $\mathrm{p} 75^{\mathrm{NTR}}$ constitutively. However, no $\mathrm{p} 75^{\mathrm{NTR}}$ mediated regulation of cytokine/chemokine and respiratory oxygen species (ROS) production by astrocytes was found in vitro. These data lead to a neuroprotective role of $\mathrm{p} 75^{\mathrm{NTR}}$ on neurons and axons in inflammatory CNS disease.

Active immunization of bone marrow chimeric mice, in which only immune or CNS parenchymal cells, respectively, carry a functioning $\mathrm{p} 75^{\mathrm{NTR}}$ confirm these results. However, while both, p75 $5^{\mathrm{NTR}}-/-\rightarrow$ wt and wt $\rightarrow$ p $75^{\mathrm{NTR}}$-/- chimeras suffer from a more severe disease course than wt $\rightarrow$ wt at peak of disease, only wt $\rightarrow$ p $75^{\mathrm{NTR}}-/-$ animals exhibit increased early axonal damage and loss.

In summary, our data suggest a role of $\mathrm{p} 75^{\mathrm{NTR}}$ towards a more aggressive inflammation within the peripheral immune system (namely mediated by B cells) as well as 
neuroprotective properties within the CNS (namely by neurons) in experimental inflammatory conditions of the CNS. 


\section{Contents}

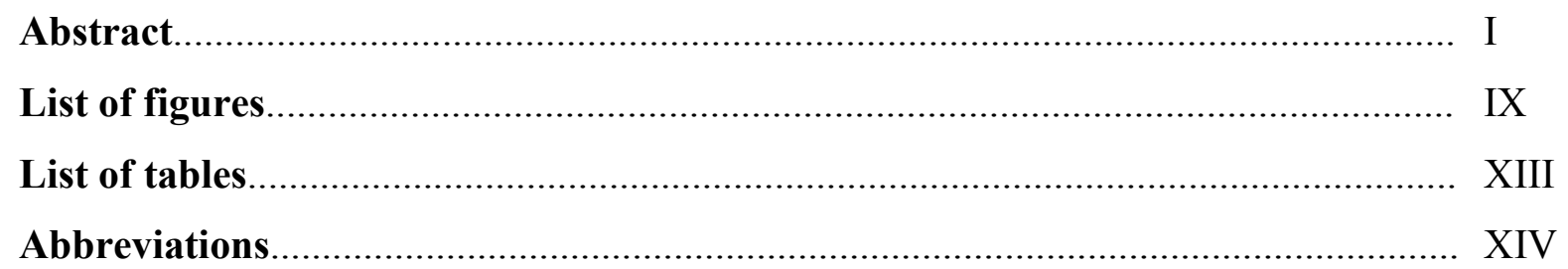

\section{Introduction}

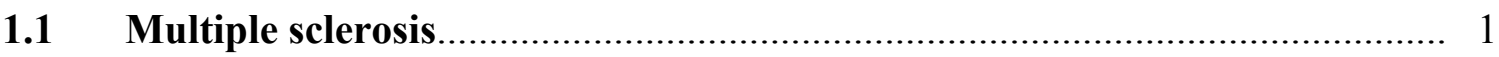

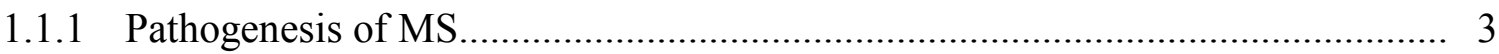

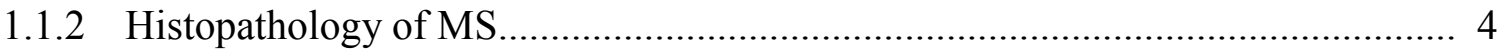

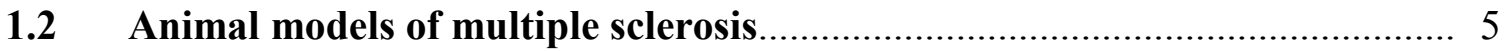

1.2.1 Experimental autoimmune encephalomyelitis.............................................. 6

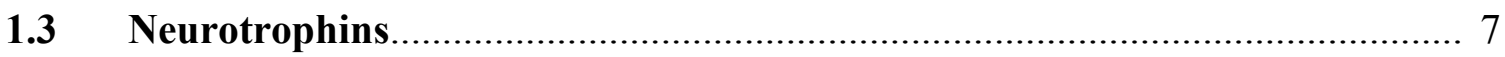

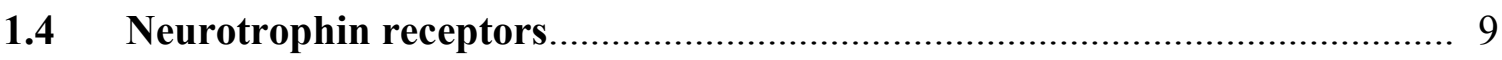

1.4.1 The p75 low affinity neurotrophin receptor.................................................. 9

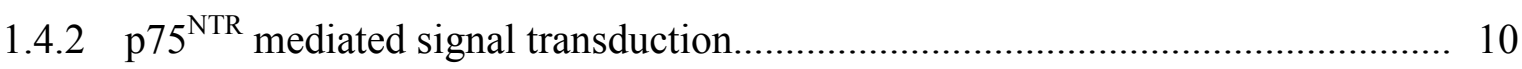

1.4.3 Processing and regulation of $\mathrm{p} 75^{\mathrm{NTR}}$ by cleavage............................................ 14

1.5 Neurotrophin mediated interactions between the immune system

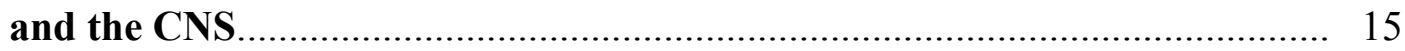

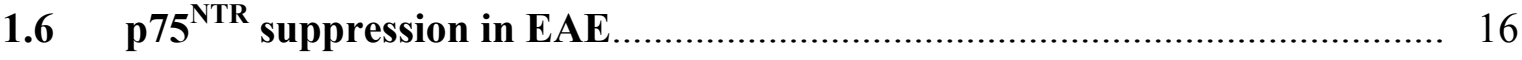

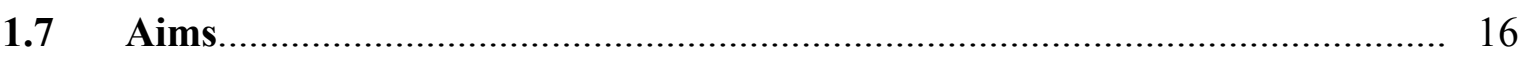

\section{$2 \quad$ Materials \& Methods}

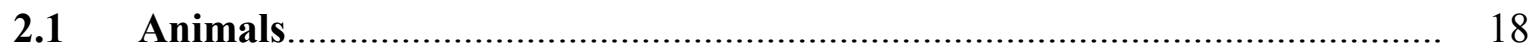

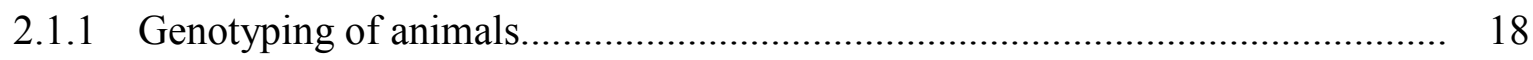

2.2 Generation of bone marrow chimeras..................................................... 20

2.3 Induction of experimental autoimmune encephalomyelitis (EAE)

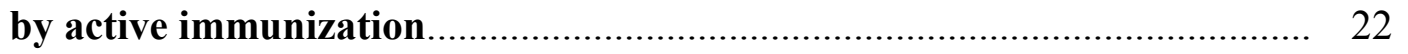




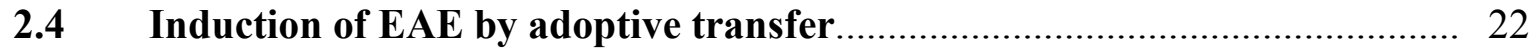

2.4.1 Expansion and restimulation of $\mathrm{T}$ cell clones................................................. 22

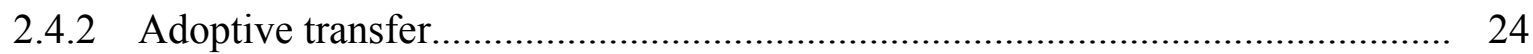

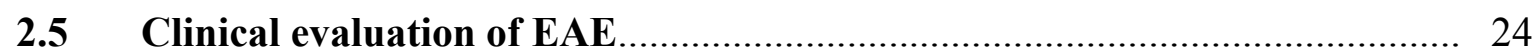

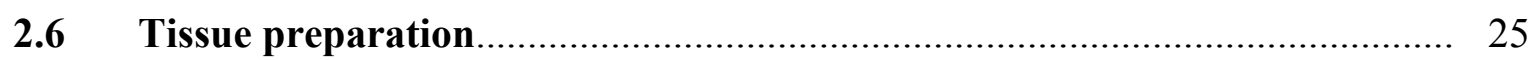

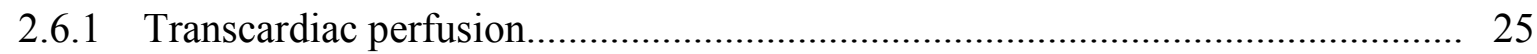

2.6.1 Tissue processing for histological analysis.................................................. 25

2.6.2 Tissue processing for RNA analysis............................................................ 26

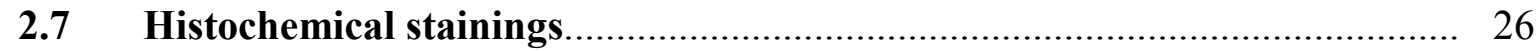

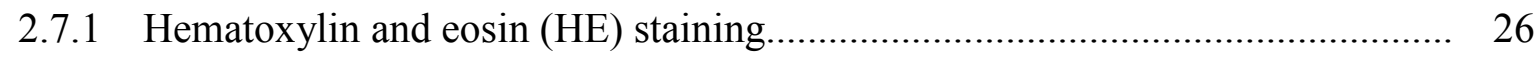

2.7.2 Luxol fast blue / periodic acid Schiff (LFB/PAS) staining.............................. 27

2.7.3 Bielschowsky silver impregnation............................................................. 28

2.7.4 Immunohistochemical stainings.............................................................. 28

2.7.5 Microscopic analysis of histochemically stained tissue slices.......................... 32

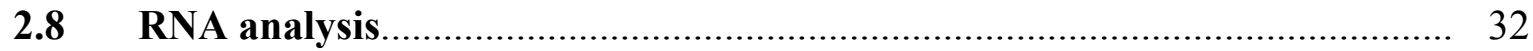

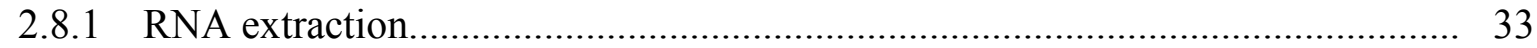

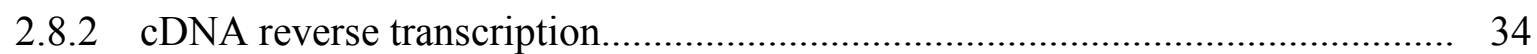

2.8.3 TaqMan quantitative real time PCR (qRT-PCR)........................................ 34

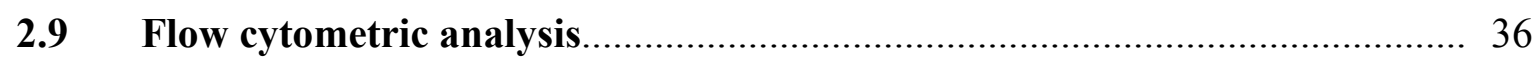

2.9.1 Preparation of lymph nodes for flow cytometric analysis................................ 37

2.9.2 Preparation of spinal cords for flow cytometric analysis................................. 38

2.9.3 Preparation of blood for flow cytometric analysis......................................... 39

2.9.4 Staining cells for flow cytometric analysis................................................. 40

2.10 Enzyme-linked immunosorbent assay (ELISA) ..................................... 43

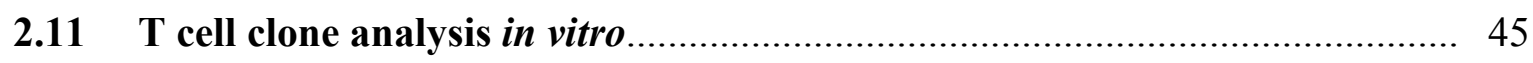

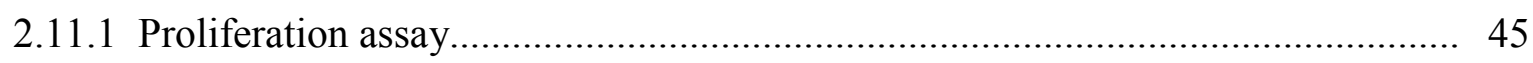

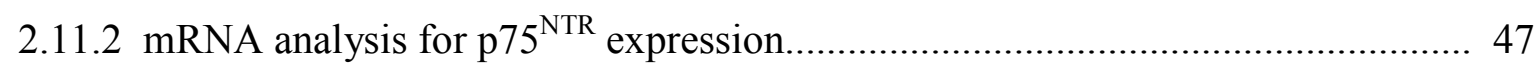

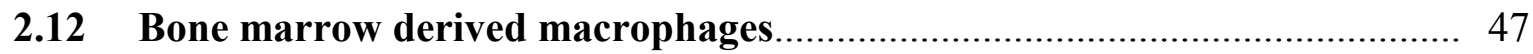

2.12.1 Preparation and differentiation of BMDM................................................ 48

2.12.2 Measurement of nitric oxide (NO) production after stimulation of BMDM....... 49

2.12.3 Measurement of reactive oxygen species (ROS) production after stimulation of BMDM............................................................................... 49

2.13 Astrocyte primary cell culture............................................................ 50

2.13.1 Measurement of ROS production after stimulation of astrocytes..................... 51 


\section{$3 \quad$ Results}

3.1 Induction of EAE by active immunization in $\mathrm{p}^{\mathrm{NTR}}-/-$ mice. 53

3.1.1 More severe disease in $\mathrm{p} 75^{\mathrm{NTR}}$-/- mice after active immunization..................... 53

3.1.2 Increased demyelination in $\mathrm{p} 75^{\mathrm{NTR}}-/$ - mice after active immunization.............. 54

3.1.3 Quantification of inflammation: Increased meningeal B cell numbers in $\mathrm{p} 75^{\mathrm{NTR}}-/-$ mice after active immunization.

3.1.4 Neuronal damage and regeneration: Increased axonal loss in $\mathrm{p} 75^{\mathrm{NTR}}$-/- mice after active immunization.

3.1.5 Quantity and quality of inflammation during peripheral priming and during disease after active immunization in $\mathbf{p}^{\mathrm{NTR}}-/-$ and wt mice..... 58

3.1.5.1 Inflammatory infiltrates in spinal cords at the peak of disease after active immunization in $\mathrm{p} 75^{\mathrm{NTR}}$-/- and wt mice.

3.1.5.2 Regulation of inflammatory related genes after active immunization in $\mathrm{p} 75^{\mathrm{NTR}}-/-$ and wt mice.

3.1.5.3 Leukocyte subpopulations in naïve and immunized lymph nodes of p $75^{\mathrm{NTR}}$-/- and wt mice.

3.1.5.4 Immunization response of lymph node cells to $\mathrm{MOG}_{35-55}$

3.1.5.4.1 No difference in the expression of $\mathrm{T}$ cell activation and maturation markers in naïve and immunized lymph nodes of $\mathrm{p} 75^{\mathrm{NTR}}-/-$ and wt mice.

3.1.5.4.2 T cell adhesion molecules naïve and immunized lymph nodes of p $75^{\mathrm{NTR}}$-/- and wt mice.

3.1.5.4.3 Cytokine profile of $\mathrm{MOG}_{35-55}$ immunized $\mathrm{CD}^{+} \mathrm{T}$ cells in $\mathrm{p} 75^{\mathrm{NTR}}-/-$ and wt mice.

3.1.5.4.4 Similar numbers of IFN $\gamma$ and IL-17 producing $\gamma \delta$ T cells in lymph nodes of $\mathrm{MOG}_{35-55}$ immunized $\mathrm{p} 75^{\mathrm{NTR}}$-/- and wt mice.

3.1.5.4.5 No difference in numbers of macrophages expressing MHC class II and $\mathrm{T}$ cell costimulatory molecule CD80 in lymph nodes of naïve and immunized $\mathrm{p} 75^{\mathrm{NTR}}-/-$ and wt animals. 76

3.1.5.4.6 No difference in the cytokine/chemokine production of lymph node cells of $\mathrm{MOG}_{35-55}$ immunized $\mathrm{p} 75^{\mathrm{NTR}}$-/- and wt mice

3.2 $\quad \mathrm{p}^{\mathrm{NTR}}$ deficiency has no effect on $\mathrm{T}$ cell proliferation and antigen presentation to $T$ cells.

3.2.1 No $\mathrm{p} 75^{\mathrm{NTR}}$ expression by $\mathrm{T}_{\mathrm{H}} 1$ cells 81 
3.3 $\mathrm{p}^{\mathrm{NTR}}$ deficiency has no effect on NO, ROS, and cytokine/chemokines production in bone marrow derived macrophages.................................. 81

3.3.1 No effect of $\mathrm{p} 75^{\mathrm{NTR}}$ deficiency on NO release by BMDMs.............................. 82

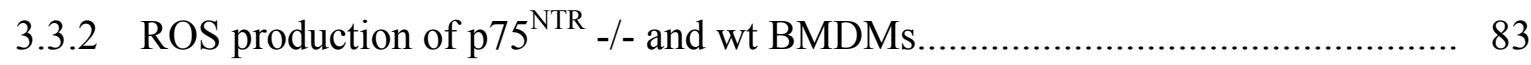

3.3.3 Cytokine/chemokine production of $\mathrm{p} 75^{\mathrm{NTR}}$-/- and wt BMDMs....................... 83

$\begin{array}{lll}3.4 & \mathrm{p}^{\mathrm{NTR}} & \text { expression in naïve lymph nodes and after priming with } \mathrm{MOG}_{35-55} \quad 84\end{array}$

3.5 Active EAE in bone marrow chimeras............................................... 86

3.5.1 Effects of irradiation on immune cell infiltration and cytokine/chemokines production in the CNS................................................................................ 86

3.5.2 Effects of irradiation on the infiltration of macrophages and $\mathrm{T}$ cells

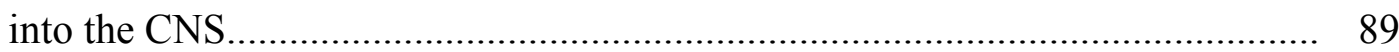

3.5.3 Reconstitution efficiency of bone marrow chimeras.................................... 89

3.5.4 Significantly reduced incidence and less severe disease course in wt $\rightarrow$ wt chimeras in the acute stage after active immunization...................................... 92

3.5.5 Histopathological disease correlates in bone marrow chimeric mice................. 94

3.6 Induction of EAE by adoptive transfer of encephalitogenic $T$ cells in p75 ${ }^{\mathrm{NTR}}$-/- and wt mice.

3.6.1 Similar disease onset and severity in the acute disease stage after adoptive transfer of $\mathrm{MOG}_{35-55}$ specific $\mathrm{CD} 4^{+} \mathrm{T}$ cells

3.6.1.1 Similar quantity and quality of inflammation in the acute disease stage after adoptive transfer of a $\mathrm{CD} 4^{+} \mathrm{T}$ cell clone. 98

3.6.1.2 Increased axonal damage and loss in $\mathrm{p} 75^{\mathrm{NTR}}-/-$ mice in the acute disease stage after adoptive transfer.

3.6.1.3 No difference in the expression of inflammation related genes in the acute disease stage after adoptive transfer between $\mathrm{p} 75^{\mathrm{NTR}}-/-$ and wt mice.. 101

3.6.2 More severe disease course in $\mathrm{p} 75^{\mathrm{NTR}}$-/- mice in the chronic disease stage after adoptive transfer of encephalitogenic $\mathrm{T}$ cells.

3.6.2.1 Less $\mathrm{T}$ cell infiltration in $\mathrm{p} 75^{\mathrm{NTR}}-/-$ mice in the chronic disease stage after adoptive transfer.

3.6.2.2 Similar extent of demyelination and oligodendroglial damage in $\mathrm{p} 75^{\mathrm{NTR}}$-/- and wt mice in the chronic disease stage after adoptive transfer of encephalitogenic T cells. 105

3.6.2.3 Increased axonal damage and loss in $\mathrm{p} 75^{\mathrm{NTR}}-/-$ mice in the chronic disease stage after adoptive transfer. 
3.7 No $\mathbf{p 7 5}^{\mathrm{NTR}}$ expression in primary microglia cultures................................. 107

3.8 Constitutive $\mathbf{p 7 5}^{\mathrm{NTR}}$ expression in primary astrocytes cultures..................... 108

3.8.1 No difference in the ROS production by primary $\mathrm{p} 75^{\mathrm{NTR}}$ deficient and wt astrocytes 108

3.8.2 No difference in the cytokine/chemokine production of $\mathrm{p} 75^{\mathrm{NTR}}-/-$ and wt astrocytes. 109

\section{Discussion}

4.1 The role of $\mathrm{p}^{\mathrm{NTR}}$ in experimental CNS inflammation.

4.1.1 Similar cellular composition of infiltrates and only minor differences in the quality of inflammation in $\mathrm{p} 75^{\mathrm{NTR}}-/-$ and wt mice

4.1.2 More severe disease course in $\mathrm{p} 75^{\mathrm{NTR}}$-/- mice after active immunization with $\mathrm{MOG}_{35-55}$

4.2 The role of $\mathrm{p}^{\mathrm{NTR}}$ in the naïve immune system and during

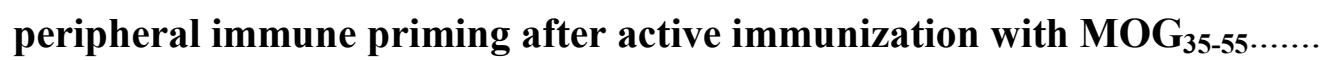

4.2.1 Similar cellular composition and activation states of naïve and $\mathrm{MOG}_{35-55}$ immunized lymph nodes in $\mathrm{p} 75^{\mathrm{NTR}}-/-$ and wt mice.

4.2.2 No differences in the numbers of $\alpha \beta$ and $\gamma \delta \mathrm{T}_{\mathrm{H}} 1$ and $\mathrm{T}_{\mathrm{H}} 17$ cells with and without PMA stimulation in immunized lymph nodes

4.2.3 No role for $\mathrm{p} 75^{\mathrm{NTR}}$ in antigen-specific $\mathrm{T}$ cell proliferation

4.2.4 No role for $\mathrm{p} 75^{\mathrm{NTR}}$ in the production of proinflammatory mediators by bone marrow derived macrophages.

4.2.5 Constitutive $\mathrm{p} 75^{\mathrm{NTR}}$ expression by B cells in lymph nodes in vivo.

4.3 Similar inflammation but more axonal damage in EAE induced by adoptive transfer.

4.3.1 Constitutive expression of $\mathrm{p} 75^{\mathrm{NTR}}$ by astrocytes, but not by microglia.

4.4 Dissecting the roles of $\mathrm{p}^{\mathrm{NTR}}$ in the immune system and the CNS: Active immunization of bone marrow chimeras.

4.4.1 Increased axonal damage in chimeras deficient for $\mathrm{p} 75^{\mathrm{NTR}}$ within the CNS.

4.5 Is $\mathrm{p}^{\mathrm{NTR}}{ }^{\mathrm{NTR}}$ relevant to the human inflammatory demyelinating disease, MS? 


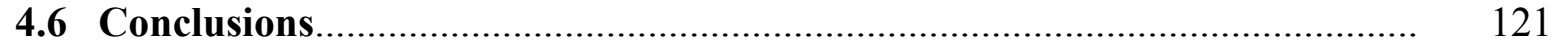

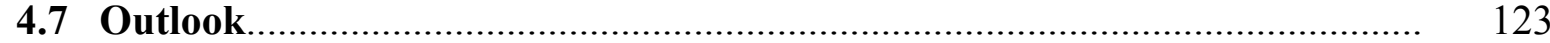

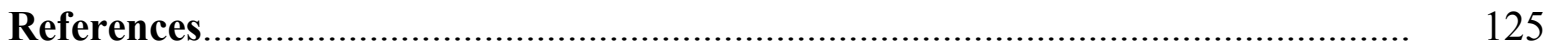

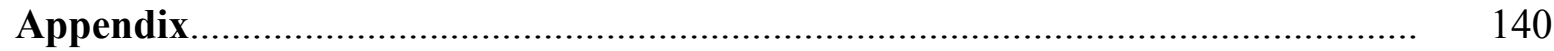

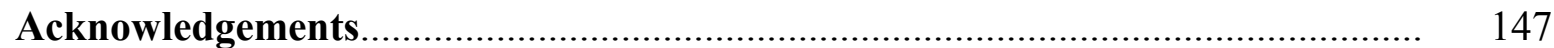

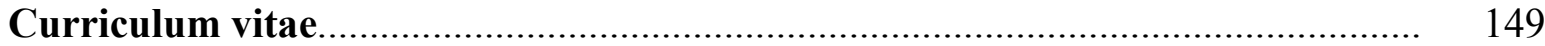




\section{List of figures}

\section{$1 \quad$ Introduction}

Fig. $1.1 \quad$ Clinical course of MS.................................................................... 3

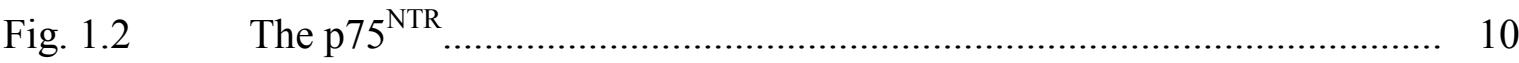

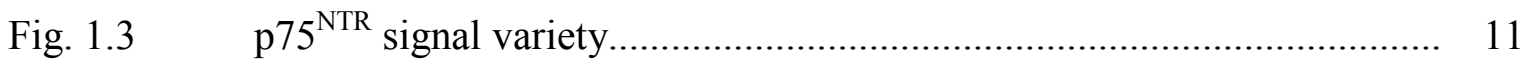

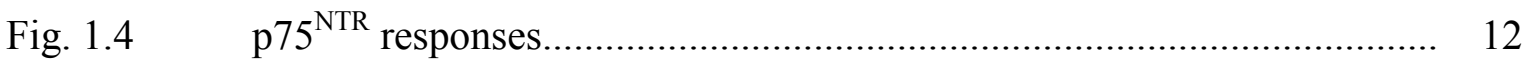

Fig. $1.5 \quad \mathrm{p} 75^{\mathrm{NTR}}$ signal transduction............................................................ 13

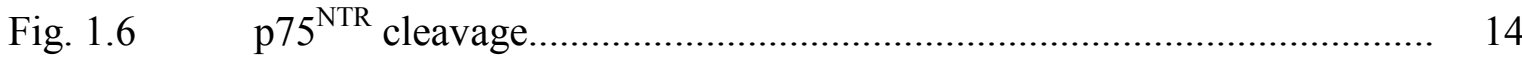

\section{$2 \quad$ Materials \& Methods}

Fig. 2.1 Scheme of bone marrow chimera generation....................................... 21

Fig. 2.2 Scheme of detection in immunohistochemistry by using the avidin biotin method....................................................................... 30

Fig. 2.3 Scheme of the TaqMan qRT-PCR principle......................................... 35

Fig. $2.4 \quad$ Scheme of the ELISA principle............................................................... 45

\section{$3 \quad$ Results}

Fig. 3.1 Disease course of $\mathrm{p} 75^{\mathrm{NTR}}-/-$ and wt mice after active immunization...... 53

Fig. 3.2 Demyelination in the chronic disease stage after active immunization... 54

Fig. 3.3 Oligodendroglial damage in the chronic disease stage after active immunization.................................................................. 54

Fig 3.4 Inflammatory CNS infiltration in the chronic disease stage after active immunization

Fig. 3.5 Axonal damage and loss in the chronic disease stage after active immunization......................................................................... 56

Fig. 3.6 Neuronal damage in the chronic disease stage after active immunization 57

Fig. 3.7 Neuroaxonal regeneration in the chronic disease stage after active immunization

Fig. 3.8 Flow cytometric analysis of T cell populations in EAE spinal cords at the peak of disease.

Fig. 3.9 Flow cytometric analysis of $\mathrm{CD} 11 \mathrm{~b}^{+}$cells in spinal cords at the peak of disease. 
Fig. 3.10 Similar expression of CD4 and CD68 in naïve and actively immunized $\mathrm{p} 75^{\mathrm{NTR}}-/$ - and wt mice.

Fig. 3.11 Expression of cytokines and chemokines in naïve and actively immunized mice.

Fig. 3.12 Expression of NGF and $\mathrm{p} 75^{\mathrm{NTR}}$ in naïve and actively immunized mice. 63

Fig. $3.13 \quad$ FSC/SSC properties of lymph node cells.............................................. 64

Fig. 3.14 Flow cytometric analysis of $\mathrm{T}$ helper and cytotoxic $\mathrm{T}$ cell populations in naïve and immunized lymph nodes

Fig. 3.15 Flow cytometric analysis of the $\gamma \delta \mathrm{T}$ cell population in naïve and immunized lymph nodes.

Fig. 3.16 Flow cytometric analysis of NK cell and NK T cell populations in naïve and immunized lymph nodes.

Fig. 3.17 Flow cytometric analysis of the $\mathrm{T}_{\text {reg }}$ cell population in naïve and immunized lymph nodes

Fig. 3.18 Flow cytometric analysis of the B cell population in naïve and immunized lymph nodes.

Fig. 3.19 Flow cytometric analysis of the T cell activation markers CD62L and CD44 in naïve and immunized lymph nodes.

Fig. 3.20 Flow cytometric analysis of the T cell activation marker CD69 in naïve and immunized lymph nodes 70

Fig. 3.21 Flow cytometric analysis of the T cell adhesion molecule CD11a........ 71

Fig. 3.22 Flow cytometric analysis of the T cell adhesion molecule CD29.......... 72

Fig. 3.23 Flow cytometric analysis of IFN $\gamma$ and IL-17 producing $\mathrm{CD}^{+} \mathrm{T}$ cells in immunized lymph nodes with and without stimulation.. 73

Fig. 3.24 Frequencies of IFN $\gamma$ and IL-17 producing $\mathrm{CD}^{+} \mathrm{T}$ cells in immunized lymph nodes with and without stimulation 74

Fig. 3.25 Flow cytometric analysis of IFN $\gamma$ and IL-17 producing $\gamma \delta$ T cells in immunized lymph nodes with and without stimulation. 75

Fig. 3.26 Frequencies of IFN $\gamma$ and IL-17 producing $\gamma \delta \mathrm{T}$ cells in immunized lymph nodes with and without stimulation. 76

Fig. 3.27 Flow cytometric analysis of antigen presenting macrophages in immunized lymph nodes.

Fig. 3.28 Flow cytometric histograms for MHC class II and CD80 expression by $\mathrm{CD} 11 \mathrm{~b}^{+}$cells in naïve and immunized lymph nodes. 
Fig. 3.29 ELISA analysis of lymph node cells (dpi 10) after

$\mathrm{MOG}_{35-55}$ restimulation 79

Fig. $3.30 \quad \mathrm{~T}$ cells proliferation after $\mathrm{MOG}_{35-55}$ restimulation 80

Fig. 3.31 Macrophage morphology of BMDMs. 81

Fig. 3.32 Flow cytometric analysis of BMDM showed a distinct macrophage phenotype.

Fig. 3.33 NO production by $\mathrm{p} 75^{\mathrm{NTR}}-/-$ and wt BMDMs after LPS

and Zymosan stimulation.

Fig. 3.34 ROS production by $\mathrm{p} 75^{\mathrm{NTR}}-/-$ and wt BMDMs in vitro. 83

Fig. 3.35

Cytokine/chemokine release of $\mathrm{p} 75^{\mathrm{NTR}}-/-$ and wt BMDM in vitro 84

Fig. 3.36 Expression of inflammation related genes in naïve and irradiated spinal cords

Fig. 3.37 Expression of inflammation related genes in naïve and irradiated brains 88

Fig. 3.38 Flow cytometric analysis of CD $45^{+}$immune cells in the peripheral blood in bone marrow chimeras 8 weeks after reconstitution. 90

Fig. 3.39 Flow cytometric analysis for blood T and B cells in bone marrow chimeras

Fig. 3.40 Visualization of chimerism: Immunohistochemical analysis of spinal cord sections at the peak of disease after active immunization.....

Fig. 3.41 Acute disease course and cumulative scores after active immunization of bone marrow chimeric mice

Fig. 3.42 EAE Incidence in bone marrow chimeric mice after active immunization with $\mathrm{MOG}_{35-55}$

Fig. 3.43 Inflammatory index in the acute stage after active immunization of bone marrow chimeric mice.

Fig. 3.44 Demyelinated area in spinal cords of chimeras in the acute disease stage after active immunization.

Fig. 3.45 Early axonal damage in bone marrow chimeric mice in the acute disease stage after active immunization 96

Fig. 3.46 Disease course in the acute disease phase after the transfer of $\mathrm{MOG}_{35-55}$ specific CD4+ T cells in $\mathrm{p} 75^{\mathrm{NTR}}-/-$ and $\mathrm{wt}$ animals. 97

Fig 3.47 Inflammatory infiltration in the acute disease stage after adoptive transfer of $\mathrm{CD} 4^{+} \mathrm{T}$ cells. 
Fig. 3.48 Early activated and NO producing macrophages /microglia at the peak of disease after adoptive transfer.

Fig. 3.49 Axonal damage and loss in the acute disease stage after adoptive transfer.

Fig 3.50 mRNA expression levels of inflammation related genes in naïve mice and after adoptive transfer of encephalitogenic $\mathrm{T}$ cells. 102

Fig. 3.51 Disease course in the chronic stage after adoptive transfer. 103

Fig. 3.52 Inflammation in the chronic disease stage after adoptive transfer. 104

Fig. 3.53 Demyelination in the chronic disease stage after adoptive transfer....... 105

Fig. 3.54 GAP $43^{+}$neurons in the chronic disease stage after adoptive transfer 106

Fig. 3.55 Axonal damage and loss in the chronic disease stage after adoptive transfer. 106

Fig. 3.56 ROS production by $\mathrm{p} 75^{\mathrm{NTR}}-/-$ and wt astrocytes in vitro......................... 109

Fig. 3.57 Cytokine / chemokine release of $\mathrm{p} 75^{\mathrm{NTR}}-/-$ and wt astrocytes in vitro.... 110 


\section{List of tables}

Tab. $2.1 \quad$ Scores and clinical correlates......................................................... 24

Tab. 2.2 List of primary antibodies................................................................ 31

Tab. 2.3 List of secondary antibodies......................................................... 31

Tab. 2.4 List of antigen specific FACS antibodies............................................ 41

Tab. $2.5 \quad$ List of isotype control FACS antibodies............................................... 43

Tab. 3.1 No p $75^{\mathrm{NTR}}$ expression by $\mathrm{T}_{\mathrm{H}} 1$ cell clone........................................... 81

Tab. $3.2 \quad$ p75 ${ }^{\mathrm{NTR}}$ expression in lymph nodes after priming with $\mathrm{MOG}_{35-55 \ldots \ldots \ldots \ldots . . .} 85$

Tab. $3.3 \quad$ No p $75^{\mathrm{NTR}}$ expression in primary microglia cultures.............................. 107

Tab. 3.4 Constitutive $\mathrm{p} 75^{\mathrm{NTR}}$ expression in primary astrocyte cultures................. 108 


\section{Abbreviations}

$\begin{array}{ll}\text { APC } & \text { antigen-presenting cell } \\ \text { APC } & \text { allophycocyanin } \\ \text { APP } & \text { amyloid precursor protein } \\ \text { BAX } & \text { B cell lymphoma } \\ & \text { associated X protein } \\ \text { BBB } & \text { blood brain barrier }\end{array}$

Bcl-xL B cell lymphoma-extra large

BDNF brain derived neurotrophic factor

dGTP desoxyriboguanosinetri-

phosphate

DMSO dimethyl sulfoxide

DNA desoxyribonucleic acid

dNTP desoxyribonucleotide

Dpi days post immunization

dTTP desoxyribothymidinetri-

phosphate

EAE experimental autoimmune

BMDM bone marrow derived macrophages

EDTA ethylenediaminetetraacetic acid

BME basal medium eagle

CAM cell adhesion molecule

ELISA enzyme linked immuno-

CCL CC motif ligand

CD cluster of differentiation

CFA complete Freund's adjuvant

CIS clinically isolated syndrome

CM-H2DCFDA 5-(and-6)-chloromethyl2',7'-dichlorodihydro-

fluorescein diacetate, acetyl ester

CNS central nervous system

CSF 1. cerebrospinal fluid

2. colony stimulating factor

CXCL CXC motif ligand

Da Dalton

DAB diaminobenzidine

dATP desoxyriboadenosinetri-

phosphate

dCTP desoxyribocytidinetri-

phosphate

sorbent assay

EtOH ethanol

FACS fluorescence activated cell sorting

FCS fetal calf serum

Fig. figure

FITC fluorescein isothiocyanate

FoxP3 forkhead box P3

GAPDH glyceraldehyde 3-phosphat dehydrogenase

GM-CSF granulocyte macrophage colony stimulating factor

GTPase guanosine triphosphatase

Gy Gray

HBSS Hank's buffered salt solution

HCl hydrochloric acid

HE hematoxylin and eosin 


\begin{tabular}{|c|c|c|c|}
\hline HEPES & $\begin{array}{l}\text { hydroxyethyl piperazine- } \\
\text { ethanesulfonic acid }\end{array}$ & $\begin{array}{l}\mathbf{N}_{2} \\
\mathbf{N a}\end{array}$ & $\begin{array}{l}\text { nitrogen } \\
\text { sodium }\end{array}$ \\
\hline HRP & horse radish peroxidase & Na-P & sodium pyruvate \\
\hline IFN & interferon & NADE & p75 ${ }^{\mathrm{NTR}}$-associated cell death \\
\hline Ig & immunoglobulin & & executor \\
\hline IL & interleukin & NBT & nitroblue tetrazolium \\
\hline iNOS & inducible nitric & NF-H & heavy neurofilament \\
\hline & synthase & $\mathbf{N F - \kappa B}$ & nuclear factor $\kappa \mathrm{B}$ \\
\hline i.p. & intraperitoneal & NGF & nerve growth factor \\
\hline IPA & isopropanol & NGF-R & nerve growth factor receptor \\
\hline i.v. & intravenous & NO & nitroc oxide \\
\hline JNK & c-Jun N-terminal kinase & Nogo & neurite outgrowth inhibitor \\
\hline $\mathbf{k B}$ & kilo bases & NogoR & neurite outgrowth inhibitor \\
\hline LFB/PAS & $\begin{array}{l}\text { Luxol fast blue / periodic } \\
\text { acid-Schiff }\end{array}$ & NOS2 & $\begin{array}{l}\text { receptor } \\
\text { nitric oxide synthase } 2\end{array}$ \\
\hline LINGO-1 & $\begin{array}{l}\text { leucine rich repeat and } \mathrm{Ig} \\
\text { domain containing } 1\end{array}$ & NRAGE & $\begin{array}{l}\text { neurotrophin receptor- } \\
\text { interacting MAGE homolog }\end{array}$ \\
\hline LNGFR & $\begin{array}{l}\text { low affinity nerve growth } \\
\text { factor receptor }\end{array}$ & $\begin{array}{l}\text { NT-3 } \\
\text { NT-4/5 }\end{array}$ & $\begin{array}{l}\text { neurotrophin } 3 \\
\text { neurotrophin } 4 \text { / } 5\end{array}$ \\
\hline LPS & lipopolysaccharide & NT-R & neurotrophin receptor \\
\hline MAG & $\begin{array}{l}\text { myelin associated } \\
\text { glycoprotein }\end{array}$ & OPC & $\begin{array}{l}\text { oligodendrocyte precursor } \\
\text { cell }\end{array}$ \\
\hline $\begin{array}{l}\text { MAGE } \\
\text { MBP }\end{array}$ & $\begin{array}{l}\text { melanoma antigen gene } \\
\text { myelin basic protein }\end{array}$ & p75 ${ }^{\text {NTR }}$ & $\begin{array}{l}\text { p75 low affinity neuro- } \\
\text { trophin receptor }\end{array}$ \\
\hline M-CSF & $\begin{array}{l}\text { macrophage colony } \\
\text { stimulating factor }\end{array}$ & $\begin{array}{l}\text { PBS } \\
\text { PCR }\end{array}$ & $\begin{array}{l}\text { phosphate buffered saline } \\
\text { polymerase chain reaction }\end{array}$ \\
\hline МHC & $\begin{array}{l}\text { major histocompatibility } \\
\text { complex }\end{array}$ & $\begin{array}{l}\text { PE } \\
\text { Pen/Strep }\end{array}$ & $\begin{array}{l}\text { phycoerythrin } \\
\text { penicillin / streptomycin }\end{array}$ \\
\hline MMP & matrixmetalloprotease & PerCP & chlorophyll \\
\hline MOG & $\begin{array}{l}\text { myelin oligodendrocyte } \\
\text { glycoprotein }\end{array}$ & PFA & $\begin{array}{l}\text { protein } \\
\text { paraformaldehyde }\end{array}$ \\
\hline $\begin{array}{l}\text { MRI } \\
\text { mRNA }\end{array}$ & $\begin{array}{l}\text { magnetic resonance imaging } \\
\text { messenger ribonucleic acid }\end{array}$ & PMA & $\begin{array}{l}\text { phorbol 12-myristate 13- } \\
\text { acetat }\end{array}$ \\
\hline MS & multiple sclerosis & PNS & peripheral nervous system \\
\hline
\end{tabular}




\begin{tabular}{|c|c|c|c|}
\hline PP-MS & $\begin{array}{l}\text { primary progressive } \\
\text { multiple sclerosis }\end{array}$ & TNFRSP & $\begin{array}{l}\text { tumor necrosis factor } \\
\text { receptor superfamily }\end{array}$ \\
\hline PR-MS & $\begin{array}{l}\text { progressive relapsing } \\
\text { multiple sclerosis }\end{array}$ & TRAF & $\begin{array}{l}\text { TNF receptor associated } \\
\text { factor }\end{array}$ \\
\hline $\begin{array}{l}\text { PTX } \\
\text { qRT-PCR }\end{array}$ & $\begin{array}{l}\text { pertussis toxin } \\
\text { quantitative real time }\end{array}$ & Tris & $\begin{array}{l}\text { tris-(hydroxymethyl)- } \\
\text { aminomethane }\end{array}$ \\
\hline RhoA & $\begin{array}{l}\text { polymerase chain reaction } \\
\text { Ras homolog gene family } \\
\text { member A }\end{array}$ & $\begin{array}{l}\text { Trk } \\
\text { UV } \\
\text { WM }\end{array}$ & $\begin{array}{l}\text { tropomyosin-related kinase } \\
\text { ultra violet } \\
\text { white matter }\end{array}$ \\
\hline ROS & reactive oxygen species & & \\
\hline RPMI & $\begin{array}{l}\text { Roswell Park Memorial } \\
\text { Institute }\end{array}$ & & \\
\hline RR-MS & $\begin{array}{l}\text { relapsing remitting multiple } \\
\text { sclerosis }\end{array}$ & & \\
\hline RT & room temperature & & \\
\hline SDS & sodium dodecyl sulphate & & \\
\hline SP-MS & $\begin{array}{l}\text { secondary progressive } \\
\text { multiple sclerosis }\end{array}$ & & \\
\hline TBE & tris/borate/EDTA & & \\
\hline TBS & tris buffered saline & & \\
\hline TMB & tetramethyle benzidine & & \\
\hline TNF & tumor necrosis factor & & \\
\hline
\end{tabular}




\section{Introduction}

\subsection{Multiple sclerosis}

Multiple sclerosis (MS), first described by Jean Martin Charcot in 1868, is thought to be an autoimmune, chronic inflammatory, demyelinating disease of the central nervous system (CNS). Besides destruction of myelin sheaths and loss of oligodendrocytes resulting in circumscribed demyelinated areas of the white matter (WM), another hallmark of MS pathology is axonal damage and subsequent loss of axons as well as neuronal cell death (Sospedra \& Martin, 2005). Various neurological symptoms can be observed in MS patients depending on the localization of these lesions within the brain and / or spinal cord.

MS is the most common neurological disease with persistent disability in young adults with an incidence of 60 to 200 per 100000 people in industrialized countries. Women are more often affected then men (Sanders \& De Keyser, 2007).

Even though the cause of disease has not been clarified yet, among others potential roles of genetic predisposition, environmental influences, changes in the hormonal balance, viral infections and other pathogens are discussed (Sospedra \& Martin, 2005).

The disease course is highly heterogeneous from patient to patient and not predictable. However, four different prototypic disease courses are distinguished (Lublin \& Reingold, 1996):

\section{1) $\quad$ Relapsing remitting MS (RR-MS)}

$\begin{aligned} & \text { About } 80 \text { to } 85 \% \text { of } \\ & \text { patients suffer }\end{aligned}$
$\begin{aligned} & \text { unpredictable } \\ & \text { followed by }\end{aligned}$
relapses
remission.

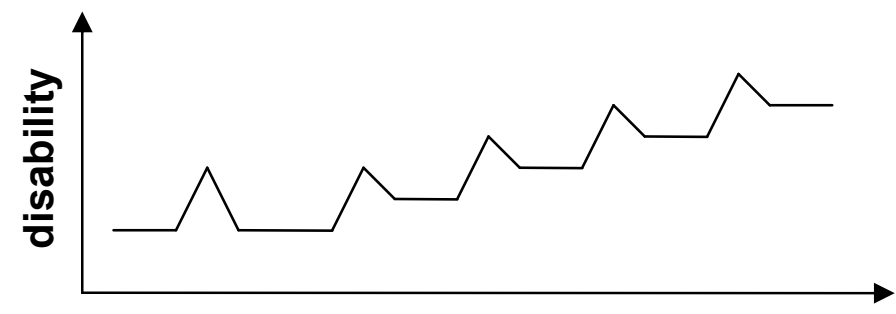

time 
2) Secondary progressive MS (SP-MS)

RR-MS usually transforms into SP-MS with a steady worsening of symptoms without clear phases of remission.

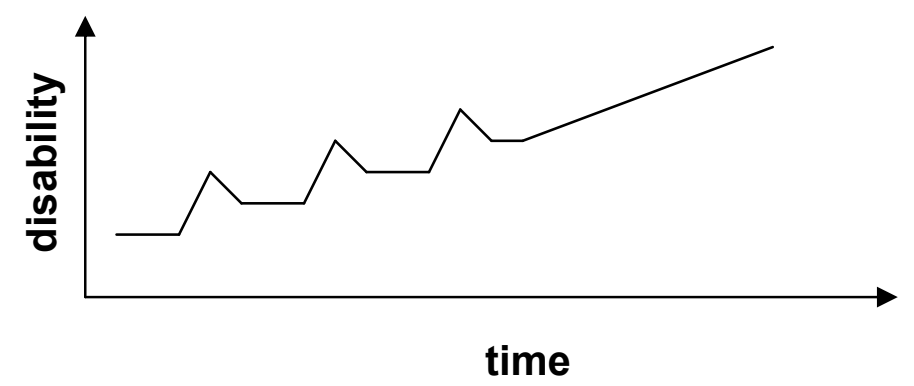

3) $\quad$ Primary progressive MS (PP-MS)

PP-MS is characterized by a steady progression of disability from the onset.

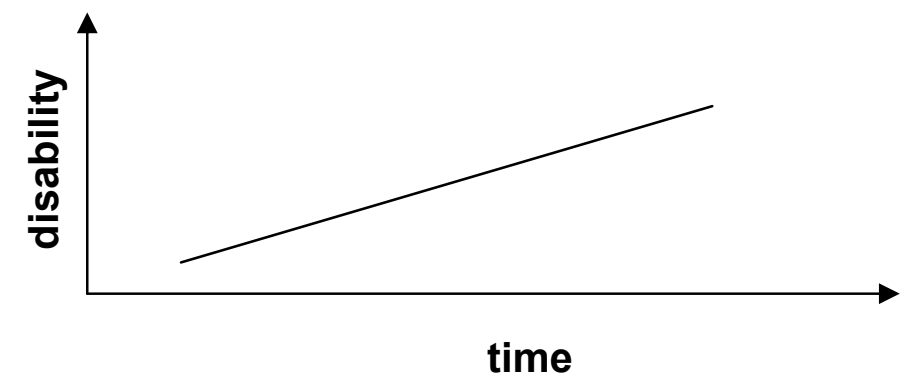

4) $\quad \underline{\text { Progressive relapsing MS (PR-MS) }}$

The disease course of PRMS is the same as PP-MS but with superimposed attacks and partial remissions.

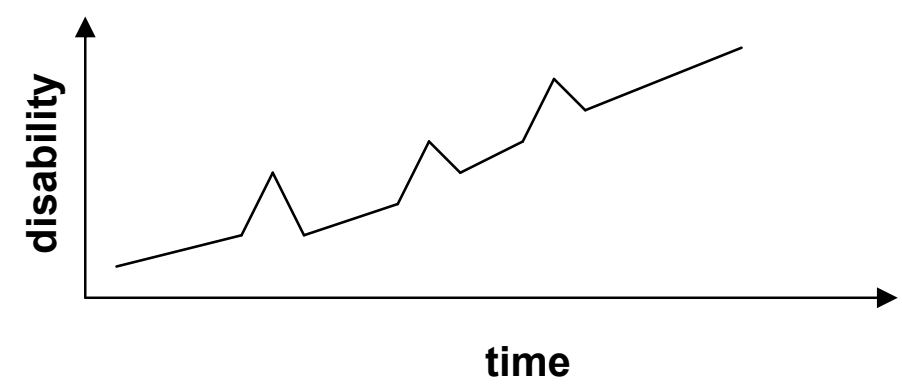

A typical MS disease course (Fig. 1.1) begins with an initial episode of neurological symptoms, the so called clinically isolated syndrome (CIS), with first symptoms like changes in sensation and impaired vision. After the attack the deficits completely resolve followed by a symptom-free period. During the subsequent relapsing remitting disease stage and due to 
several attacks the CNS takes lasting damage resulting in permanent neurological disabilities like paresis, disturbances of sensation or vision or bladder dysfunction. After several years and relapses the majority of patients enters the secondary progressive disease phase which is characterized by a steady worsening with our without superimposed relapses. During the disease course the cerebral volume is decreasing while the total lesion volume is increasing.

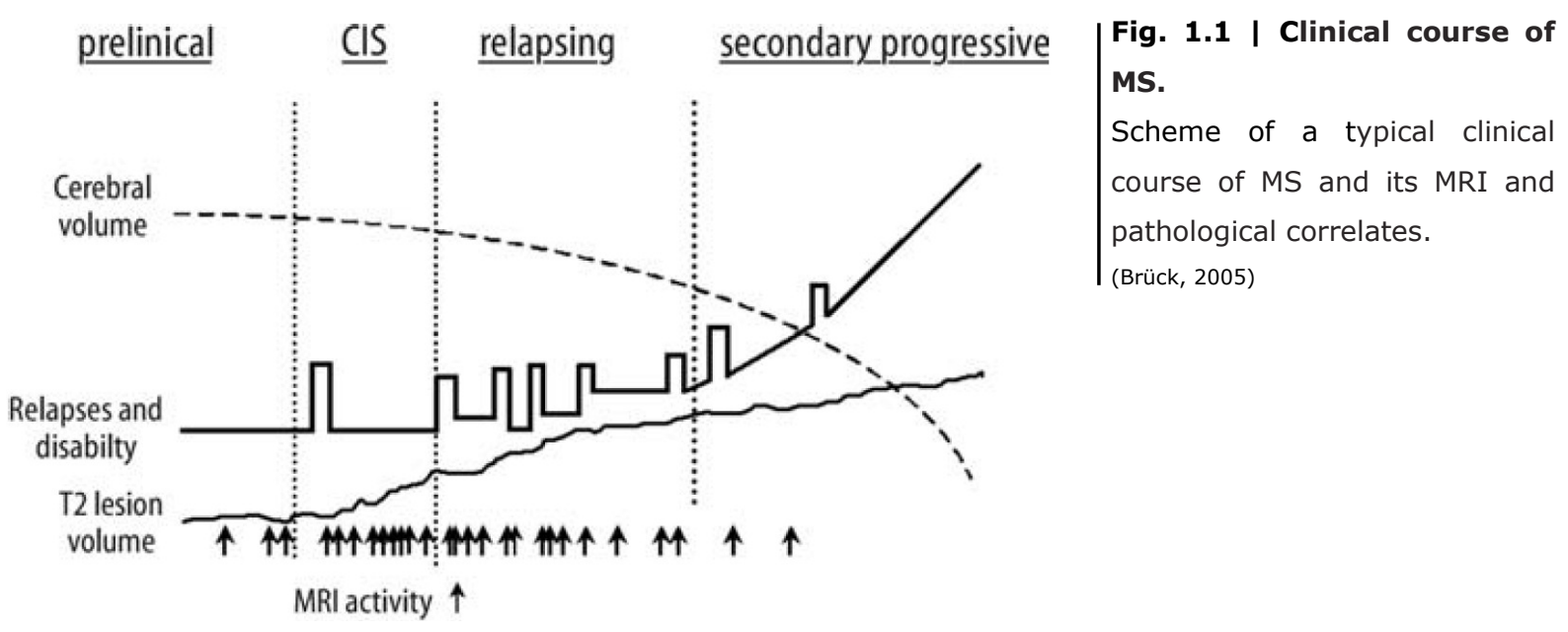

\subsubsection{Pathogenesis of MS}

Even though the exact etiology of MS is still unknown, it is thought that it emerges on the cellular level from autoreactive cluster of differentiation 4 positive $\left(\mathrm{CD} 4^{+}\right) \mathrm{T}$ helper cells that recognize self antigens of the CNS, mainly the myelin sheath (Sospedra \& Martin, 2005), e.g. myelin basic protein (MBP) or myelin oligodendrocyte glycoprotein (MOG). This is confirmed by findings of oligoclonal $\mathrm{CD}^{+} \mathrm{T}$ cells in lesions and in the cerebrospinal fluid (CSF) of MS patients (Sospedra \& Martin, 2005). However, the mechanisms of generation of autoreactive T cells are still unknown.

Potential autoreactive $\mathrm{T}$ cells could possibly be activated in the peripheral immune system, e.g. by viral infection. The cell adhesion molecules (CAMs), like integrins, on the surface of $\mathrm{T}$ cells allow them to adhere to endothelial cells and subsequently pass the blood brain barrier (BBB) to infiltrate the brain and spinal cord parenchyma. Within the CNS the T cells receptors (TCRs) interact specifically with the autoantigen presented by perivascular cells. Consecutively secretion of proinflammatory cytokines like interleukin-2 (IL-2), tumor 
necrosis factor- $\alpha$ (TNF- $\alpha)$ and interferon- $\gamma($ IFN- $\gamma)$ (Navikas \& Link, 1996) and chemokines like CC motif ligand 2 (CCL2) and CXC motif ligand 10 (CXCL10) recruit more resident cells (microglia, astrocytes) as well as cells from the peripheral immune system (macrophages, T and B cells) (Lassmann et al., 2007). Matrixmetalloproteases (MMPs), reactive oxygen species (ROS) and nitric oxides (NO) are produced, which open the BBB. In this inflammatory milieu damage to myelin, oligodendrocytes and axons occur. Excitotoxicity, myelin phagocytosis and apoptosis result in demyelinated axons, damage to axonal transport, axonal transections, loss of neurons and oligodendrocytes, and proliferation of astrocytes and autoreactive immune cells (Sospedra \& Martin, 2005).

In RR MS, after the inflammatory episode a shift to an antiinflammatory $\mathrm{T}$ helper cell 2 (Th2)-mediated immune response occurs, including production of IL-10, TGF- $\beta$ and growth factors, clearance of debris, activation of oligodendrocyte precursor cells (OPCs) and remyelination (Blakemore \& Keirstead, 1999; Sospedra \& Martin, 2005).

Involvements of potential autoreactive antibodies by B cells, complement factors (Parker, 1993) and cytotoxic $\mathrm{CD}^{+} \mathrm{T}$ cells are also discussed (Babbe et al., 2000; Bitsch et al., 2000).

Recent magnetic resonance imaging (MRI) studies could show that the degree of axonal damage and loss directly correlates with the degree of persistent disability in MS patients (De Stefano et al., 2005; De Stefano \& Filippi, 2007; Kornek et al. 2000; Lovas et al. 2000; Hendriks et al. 2005). This emphasizes the importance of maintaining axonal and neuronal function in MS.

\subsubsection{Histopathology of MS}

The clinical heterogeneity of MS is also reflected in the diversity of lesion types. Lucchinetti et al. suggest a classification into four different lesion types:

1) The lesion has a clearly defined border and is characterized by macrophage and $T$ cell infiltration as well as demyelination but only little oligodendrocyte loss. Subsequent remyelination takes place quickly. 
2) Additionally to the characteristics of type 1 lesions, deposits of antibodies and complement factors occur.

3) Although dominated by macrophage and $\mathrm{T}$ cell infiltration like type 1 lesions, type 3 areas of inflammation have a diffuse border. Prominent apoptosis of oligodendrocytes is observed.

4) Type 4 lesions are defined by primary oligodendrocyte damage in the periplaque white matter, and have so far only been observed in autopsy cases.

\subsection{Animal models of multiple sclerosis}

For further investigation and basic research on CNS inflammation under defined and reproducible conditions animal models are indispensable.

Very first observations of accidentally induced encephalitomyelitis resulting in paralytic disease go back to the end of the $19^{\text {th }}$ century. Louis Pasteur used dried rabbit spinal cords as a vaccine against rabies, when in some cases patients developed paralyses (Balaguer, 1888). Being aware of this phenomenon, first experiments were done in rabbits using human spinal cord tissue (Koritschoner \& Schweinburg, 1925). Thomas M. Rivers was the first who linked these findings to neurological complications in other diseases and established the most common model, experimental autoimmune encephalomyelitis (EAE) (Rivers et al. in 1933). Since then, different animal models of MS were established which represent different aspects of the disease. For instance, the cuprizone model is mainly used to analyze mechanisms of demyelination and remyelination (Blakemore, 1972).

Because it shares many immunological similarities with regard to histopathology, EAE became the most studied method. Many MS hypotheses as well as pharmaceutical drugs originate from EAE research. 


\subsubsection{Experimental autoimmune encephalomyelitis}

Back in 1933 CNS tissue homogenate was injected subcutaneously in mammals to induce experimental inflammation of the CNS. Nowadays, purified myelin (or other CNSrelated) proteins as well as short peptides are usually used. EAE has been successfully induced in many different mammals like dogs, cats, pigs, sheep, goats, monkeys, rabbits, hamsters, rats and mice (Gold et al., 2006). Depending on the species and the protein used for immunization, EAE shows different pathology and clinical course (Gold et al., 2006). However, until now there is no model mimicking all aspects of MS.

Because of the great variety of transgenic animals and advantages in breeding possibilities, the most common species used is mouse. Normally, animals are immunized with a small peptide carrying the sequence of MOG from amino acid position 35 to $55\left(\mathrm{MOG}_{35-55}\right)$ emulsified in complete Freund's adjuvant (CFA) (Mendel et al., 1995). This method is termed "active immunization".

The disease that develops in $\mathrm{C} 57 \mathrm{BL} / 6$ mice is a monophasic, mostly self limited form where animals normally do not fully recover from their clinical symptoms. However, in contrast to MS, where also the brain and the neocortex could be affected, mainly the white matter of the spinal cord is affected in these animals (Engelhardt, 2006).

Active immunization of $\mathrm{BL} / 6$ mice with $\mathrm{MOG}_{35-55}$ causes a rather destructive form of EAE with a high degree of axonal damage and subsequent axonal loss. Strong evidence has been collected that the disease is initiated by autoimmune, encephalitogenic $\mathrm{CD}^{+} \mathrm{T}$ cells with a $T_{H} 1$ phenotype (Halachmi et al., 1992). After immunization, the MOG peptide is presented by professional APCs, like dendritic cells and macrophages in peripheral lymph nodes. It is thought that T cells with a specific TCR proliferate and finally invade the CNS by recognizing MOG fragments loaded on major histocompatibility complex (MHC) class II molecules on perivascular APCs, e.g. macrophages. The following activation leads to a release of proinflammatory cytokines like IL-2, TNF- $\alpha$ and IFN- $\gamma$, to an opening of the BBB, and to further recruiting of $\mathrm{T}$ cells and macrophages into the CNS. This inflammatory milieu causes damage to myelin and axons (Wekerle, 1991; Tsunoda \& Fujinami, 1996; Engelhardt, 2008). In contrast to MS, in this model autoantibodies produced by B cells, complement factors and cytotoxic $\mathrm{CD}^{+} \mathrm{T}$ cells are considered to play no relevant role (Sospedra \& Martin, 2005).

EAE is also inducible by transfer of myelin specific (e.g. $\mathrm{MOG}_{35-55}$-specific) $\mathrm{CD}^{+} \mathrm{T}$ cells (Driscoll et al., 1975). This method is termed "adoptive transfer" and it constitutes the 
proof that encephalitogenic $\mathrm{CD}^{+} \mathrm{T}$ cells play the main role in the pathogenesis of $\mathrm{EAE}$ and therefore that EAE is caused by autoimmunity (Ben Nun et al., 1981). Here, the activation and proliferation of specific $\mathrm{CD}^{+} \mathrm{T}$ cells in the peripheral lymph nodes is completely circumvented.

By inducing EAE in different transgenic mouse strains many proteins and their roles during disease generation and maintenance have been analyzed to find potential targets for MS treatment. For instance, the successful and promising MS treatment by natalizumab (Sheremata et al., 1999) arose from early EAE experiments (Yednock et al., 1992). In this therapy an anti-VLA-4 antibody is used to block the interaction of VCAM-1 (on activated T cells and other leukocytes) and VLA-4 (on activated high endothelia cells). This blockade impedes $\mathrm{T}$ cell diapedesis into the CNS and therefore induction of EAE by active immunization and adoptive transfer. Another example is the relative long established treatment of MS with glatiramer acetate, a synthetic, random polymer consisting of four different amino acids (Bornstein et al., 1987). This drug came also from promising results in EAE suppression (Teitelbaum et al., 1971).

\subsection{Neurotrophins}

Neurotrophins (NTs) are small, homodimeric proteins which belong to the family of growth factors (Lewin \& Barde, 1996). Like all growth factors, neurotrophins have the ability to signal for cell survival, differentiation and / or growth upon binding to specific cell receptors (Thoenen, 1995).

Neurotrophins play a major role in the CNS and peripheral nervous system (PNS) during development with regard to cell connectivity and tissue plasticity. Neurons have been shown to compete for neurotrophins in developmental stages. Cells which do not bind enough of these molecules and therefore receive insufficient pro-survival signals undergo apoptosis (Thoenen, 1995). Neurotrophins are also capable of rescuing damaged or dying neurons, initiating sprouting and forming new axons to re-establish connections to a certain degree (Rabizadeh \& Bredesen, 2003).

Neurotrophins originate from proneurotrophins that are cleaved by proteases to become functional. The truncated pro-part plays an important role in forming the correct tertiary structure of the neurotrophin ( $\mathrm{Lu}, 2003)$. 
Nerve growth factor (NGF) is the first discovered growth factor that enhances neuron growth and differentiation (Levi-Montalcini, 1966). Since then four neurotrophins have been classified (Thoenen, 1995):

\section{1) Nerve growth factor (NGF)}

Without binding NGF neurites and neuronal cells degenerate during development. In the presence of NGF dendritic arborisation (Angeletti et al., 1971) and axonal branching is increased (Snider, 1988). Apoptotic neurons can be rescued by NGF (Williams et al., 1986).

\section{2) Brain derived neurotrophic factor (BDNF)}

Because of its pro-survival signalling properties BDNF is required by many neuronal cell populations like midbrain dopaminergic neurons, cerebellar granule cells and hippocampal and cortical neurons during development (Snider, 1994; Hofer \& Barde, 1988).

3) Neurotrophin 3 (NT-3)

NT-3 is secreted by astrocytes to promote survival of OPCs and mature oligodendrocytes (Barres \& Raff, 1994). Also, dorsal root ganglion cells (Hory-Lee et al., 1993) and trigeminal neurons (Ernfors et al., 1994) need NT-3 to survive.

4) Neurotrophin $4 / 5(\mathrm{NT}-4 / 5)$

NT-4/5 is expressed by skeletal muscle cells upon neuronal activation. It supports the generation of neuromuscular function in developmental stages (Funakoshin et al., 1995).

Although it was originally thought that neurotrophins only have "beneficial" effects on neurons, it became soon clear that the cellular response upon binding is defined by the involved receptor complexes and the underlying signalling pathways ( $\mathrm{Lu}$ et al., 2005). 


\subsection{Neurotrophin receptors}

There are two different neurotrophin receptors (NT-Rs):

1) The family of tropomyosin-related kinases (Trks) consisting of $\operatorname{Trk} \mathrm{A}, \operatorname{TrkB}$ and TrkC

2) The p75 low affinity neurotrophin receptor $\left(\mathrm{p} 75^{\mathrm{NTR}}\right)$

Trks bind neurotrophins with high and proneurotrophins with low affinity. TrkA mainly binds NGF, TrkB mainly BDNF and NT-4/5, and TrkC only NT-3 (Meakin \& Shooter, 1992). Upon ligand binding single Trk receptors normally signal for cell survival (Fig. 1.3 d).

p $75^{\mathrm{NTR}}$ binds all neurotrophins with the same affinity. Compared to Trks $\mathrm{p} 75^{\mathrm{NTR}}$ has an overall lower affinity to neurotrophins, but a very high affinity to proneurotrophins (Kaplan \& Miller, 1997). The ligand-receptor complex consisting of a proneurotrophin and a single $\mathrm{p} 75^{\mathrm{NTR}}$ normally leads to an apoptotic cell signal during development (Rabizadeh \& Bredesen, 2003).

\subsubsection{The p75 low affinity neurotrophin receptor}

The $\mathrm{p} 75^{\mathrm{NTR}}$ is a $75 \mathrm{kDa}$ protein consisting of one transmembrane domain, four extracellular immunoglobulin (Ig)-like domains at the N-terminus, which provide the ligand binding site, and six intracellular $\alpha$-helices at the C-terminus (Fig. 1.2). p75 ${ }^{\mathrm{NTR}}$ also features a type II death domain which is able to induce apoptosis. It is posttranslationally modified at an $\mathrm{N}$-linked and an O-linked glycosylation and a palmitoylation site.

The genomic region encoding the $\mathrm{p} 75^{\mathrm{NTR}}$ is located on chromosome 11 in mus musculus and consists of almost 20.000 base pairs. It includes six exons. Exon three encodes three of the four neurotrophin binding Ig-like domains and is essential for a functional $\mathrm{p} 75^{\mathrm{NTR}}$ (Lee et al., 1992).

Because of its structural similarities, $\mathrm{p} 75^{\mathrm{NTR}}$ belongs to the TNF receptor superfamily (TNFRSF). It is also termed TNFRSF16, NGF receptor (NGF-R) and low affinity (L) NGFR. 
p $75^{\mathrm{NTR}}$ is expressed by many different cells of the PNS and CNS as well as other cell populations not belonging to the nervous system, e.g. cells of the immune system (Labouyrie et al., 1997). Most of these cells express $\mathrm{p} 75^{\mathrm{NTR}}$ in developmental stages; however, it is often re-expressed under pathological conditions. During development $\mathrm{p} 75^{\mathrm{NTR}}$ plays a major role for the establishment of neural connections. It induces apoptosis in neurons which do not receive enough neurotrophins or too much proneurotrophins (Volosin et al., 2006).

For the following cell types $\mathrm{p} 75^{\mathrm{NTR}}$ expression has been shown in disease or under activated, disease-like conditions: neurons (e.g. after axotomy, stroke) (Dechant \& Barde, 2002), reactive astrocytes (forming of glial scar) (Hanbury et al., 2002; Oderfeld-Nowak et al., 2003), oligodendrocytes and OPCs (after spinal cord injury, after cuprizone treatment, in MS lesions) (Casha et al., 2001; Beattie et al., 2002; Copray et al., 2005; Chang et al., 2000), rat microglia (Neumann et al., 1998) and monocytes (Dickensheets et al., 1997), activated B cells (Torcia et al., 1996) and dendritic cells (Jiang et al., 2007). Until now, $\mathrm{p} 75^{\mathrm{NTR}}$ was not detected on T cells (Torcia et al., 1996). Some specialized cell populations like Müller cells (Ding et al., 2001), CNS endothelial cells (Kim et al., 2004) and neural stem cells from the subventricular zone (SVZ) (Giuliani et al., 2004) express p75 ${ }^{\mathrm{NTR}}$ constitutively. The constant production of $\mathrm{p} 75^{\mathrm{NTR}}$ by CNS endothelial cells is upregulated in EAE (Copray et al., 2004; Küst et al., 2006).

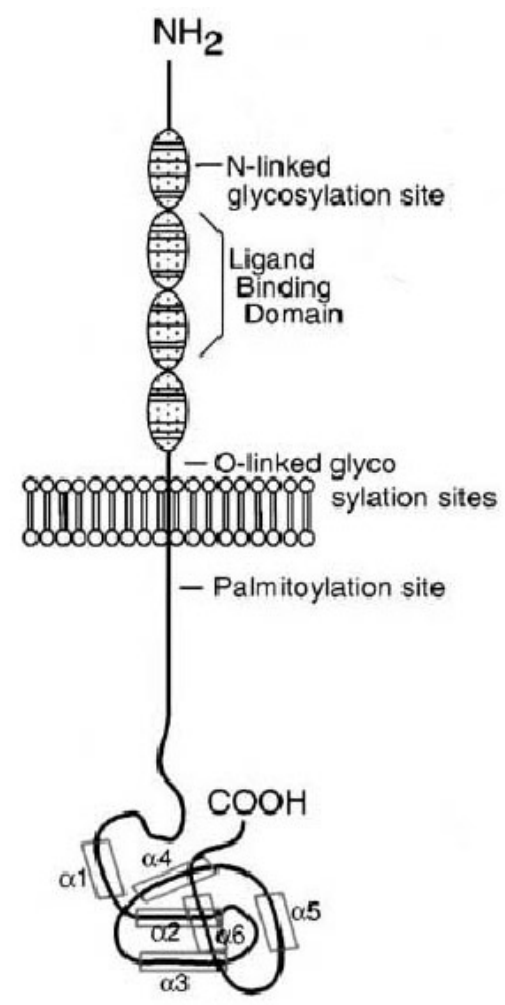

Fig. 1.2 | The $\mathrm{p} 75^{\mathrm{NTR}}$

Schematic drawing of the $\mathrm{p} 75^{\mathrm{NTR}}$ protein. (Rabizadeh \& Bredesen, 2003)

\subsection{2 $\mathrm{p}^{\mathrm{NTR}}$ mediated signal transduction}

The cellular response to the binding of certain neurotrophins by $\mathrm{p} 75^{\mathrm{NTR}}$ is very diverse and strongly depends on associated coreceptors, intracellular adaptor proteins and neurotrophin concentrations (Fig. 1.3 and Fig. 1.4) (Lu et al., 2005). 
Single p75 receptors not associated with any coreceptors induce apoptosis when no neurotrophin is bound (Fig 1.3 a). This happens via activation of the so called "stress kinase" c-Jun N-terminal kinases (JNKs), transcription factor p53-mediated production of the proapoptotic B cell lymphoma 2-associated X protein (BAX), subsequent release of cytochrome $\mathrm{c}$ from mitochondria and finally activation of caspases (Fig 1.3 a) (CasacciaBonnefil et al., 1996; Harrington et al., 2002; Huang \& Reichardt, 2001). When neurotrophins are bound, $\mathrm{p} 75^{\mathrm{NTR}}$ signalling leads to survival via activation of nuclear factor $\kappa \mathrm{B}(\mathrm{NF}-\kappa \mathrm{B})$ and antiapoptotic B cell lymphoma-extra large (Bcl-xL) protein (Fig. 1.3 a and 1.5 a) (Hamanoue et al., 1999; Gentry et al., 2000; Rabizadeh \& Bredesen, 2003).

If $\mathrm{p} 75^{\mathrm{NTR}}$ is associated with Trks it depends on the binding neurotrophins, their concentration and the ratio of $\mathrm{p} 75^{\mathrm{NTR}}$ to Trk molecules on the cell surface whether the response leads to prosurvival or proapoptotic signals (Fig. 1.3 b, c and Fig. 1.4 b) (Rabizadeh \& Bredesen, 2003).

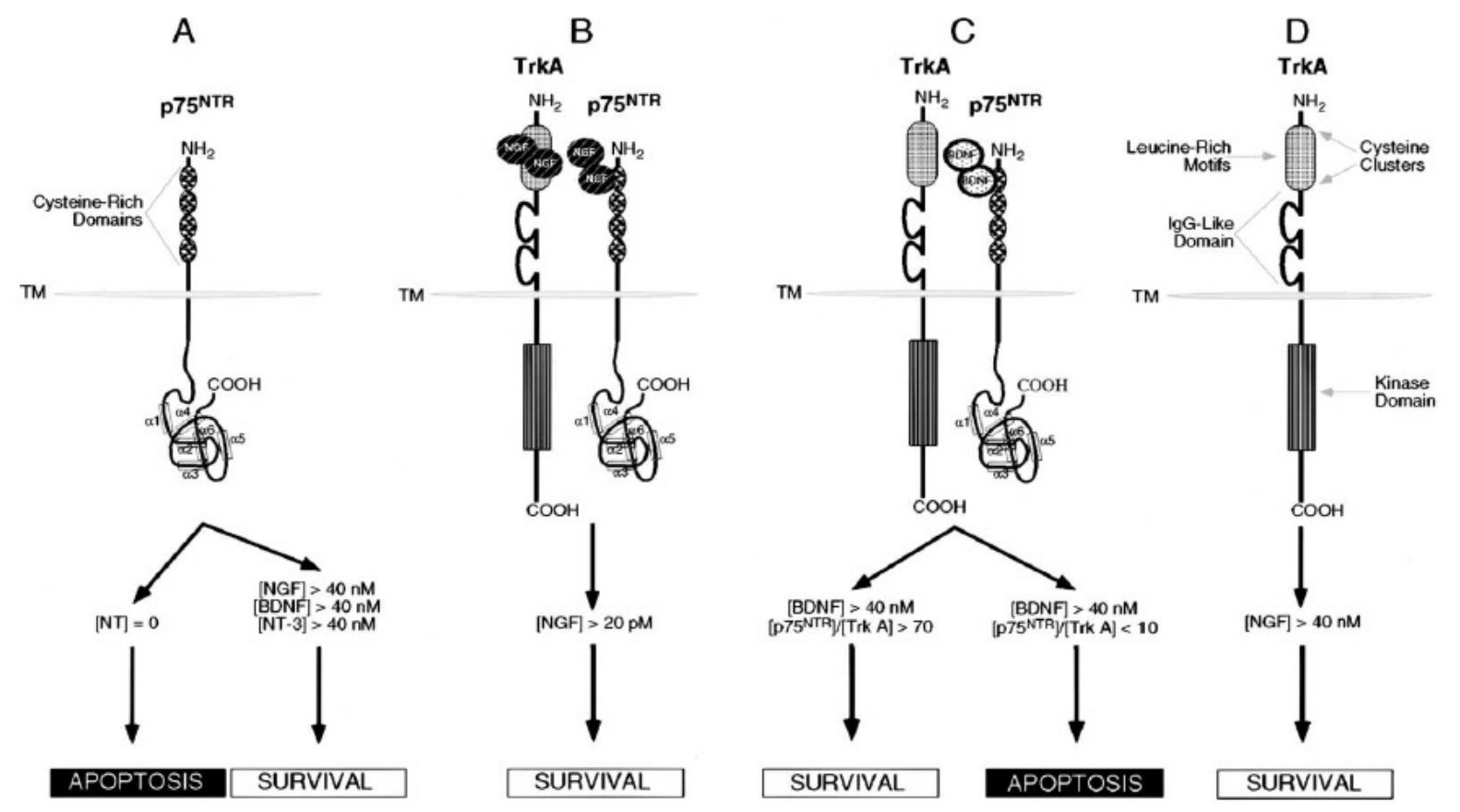

Fig. 1.3 | p75 ${ }^{\text {NTR }}$ signal variety.

Dependence of $\mathrm{p} 75^{\mathrm{NTR}}$ signalling on ligands, ligand concentrations and receptor expression. (Rabizadeh \& Bredesen, 2003) 
A

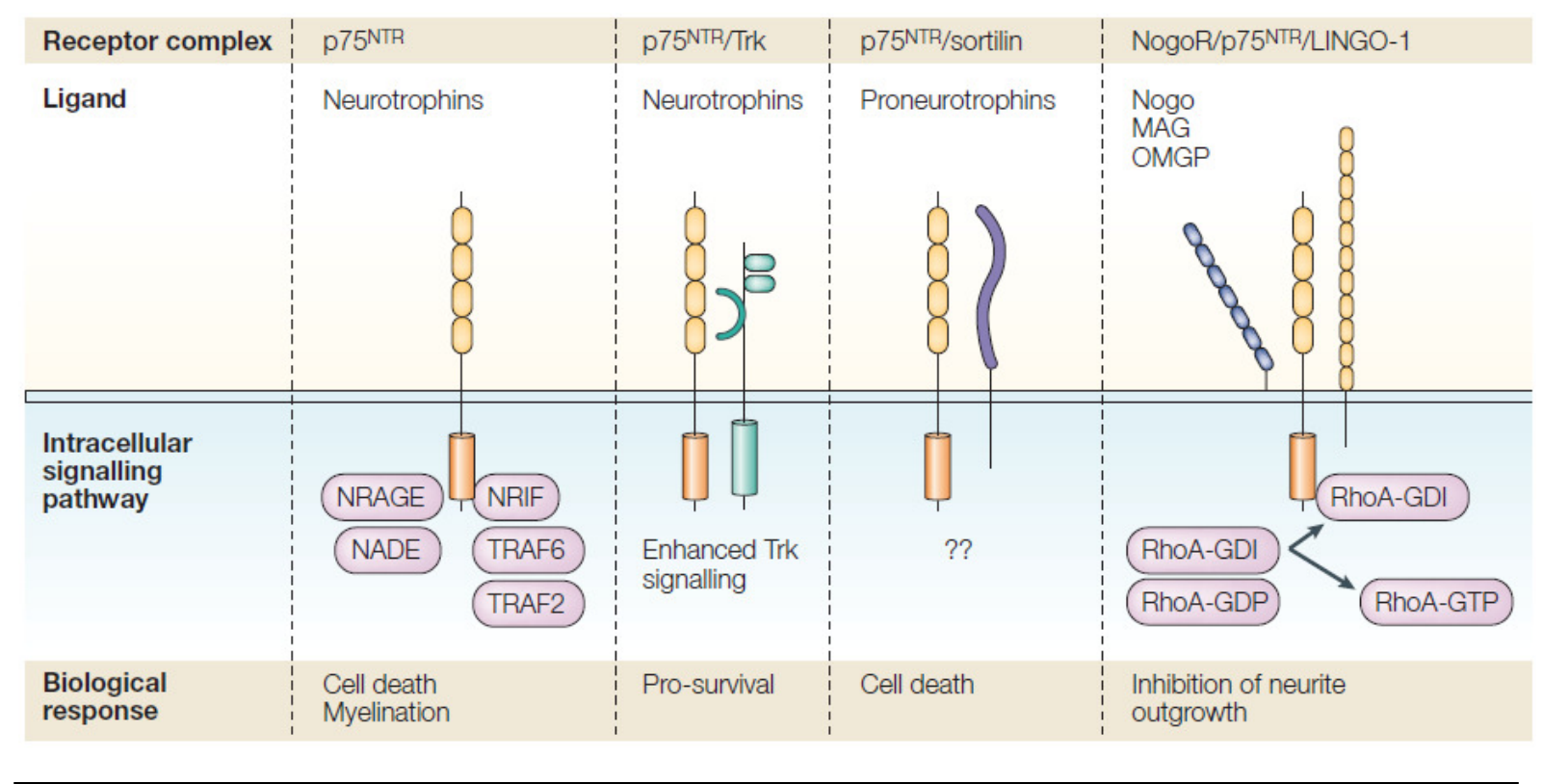

Fig. 1.4 | p75 ${ }^{\mathrm{NTR}}$ responses.

Different responses by $\mathrm{p} 75^{\mathrm{NTR}}$ regarding to receptor composition and intracellular adaptor proteins. (Lu et al., 2005)

In addition, $\mathrm{p} 75^{\mathrm{NTR}}$ is not only able to signal for cell death or survival but also for stabilization of the cytoskeleton by activation of the small guanosine triphosphatase (GTPase) Ras homologue gene family member A (RhoA) (Fig. $1.4 \mathrm{~d}$ ). In this case p $75^{\mathrm{NTR}}$ is part of a receptor complex with neurite outgrowth inhibitor receptor (NogoR) and leucine rich repeat and Ig domain containing 1 (LINGO-1) (Wang et al., 2002; Mi et al., 2004). It binds myelin proteins like myelin associated glycoprotein (MAG) and is thought to mediate the inhibition of neurite outgrowth in neuronal processes approaching a myelin sheath.

$\mathrm{p} 75^{\mathrm{NTR}}$ can also act as a transcription factor via NGF-p $75^{\mathrm{NTR}}$ ligand-receptor complex internalization. In this case p75 is able to increase the expression level of the sodium $\left(\mathrm{Na}^{+}\right)$ channel $\mathrm{Na}(\mathrm{v}) 1.8$ (Damarjian et al., 2004). Enhanced numbers of $\mathrm{Na}^{+}$channels on axons are related to EAE pathology (Renganathan, 2003). 
A

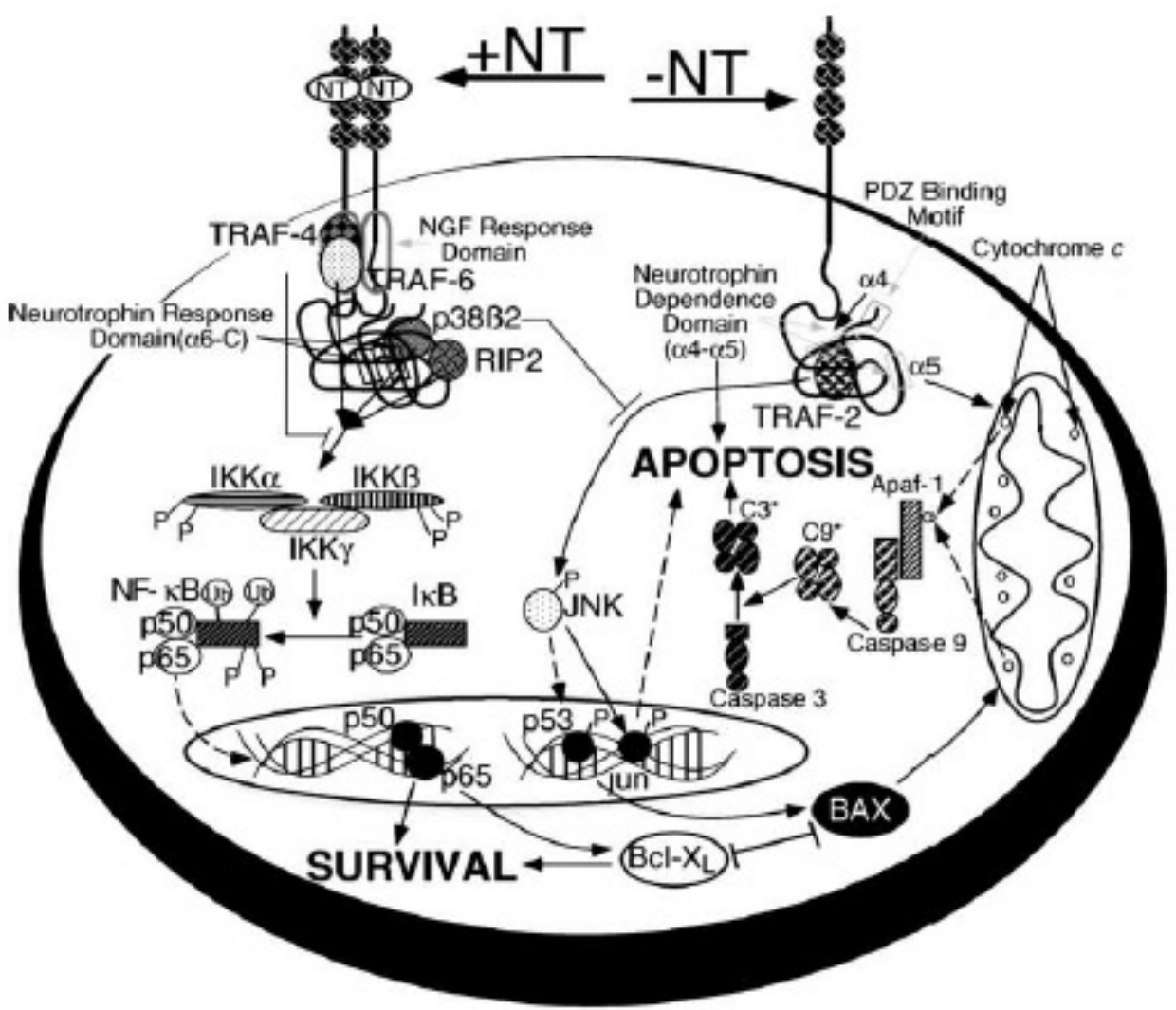

B

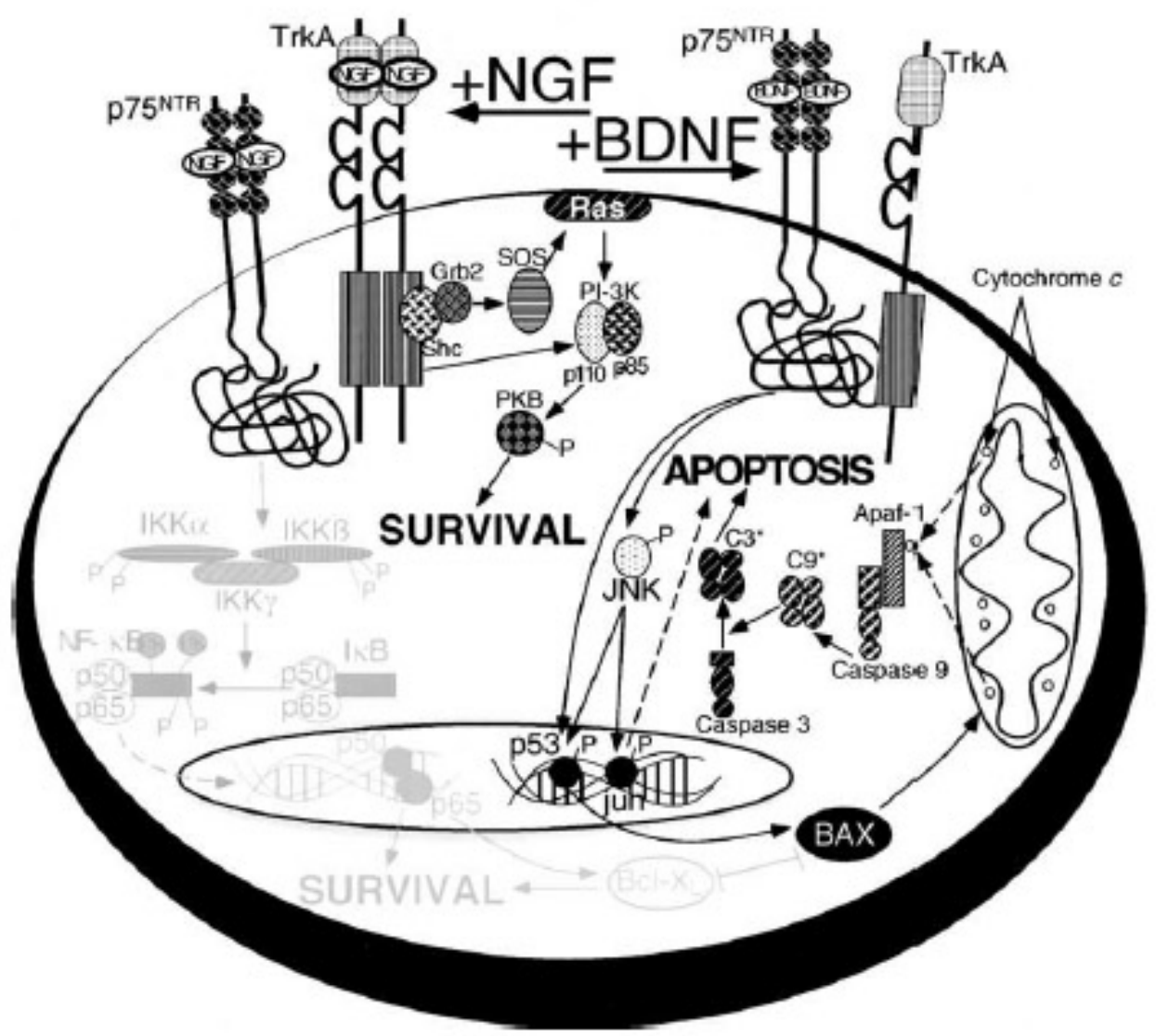

Fig. 1.5 I p75 ${ }^{\mathrm{NTR}}$ signal transduction.

Mediated by $\mathrm{p} 75^{\mathrm{NTR}}$ alone (a) and in combination with the coreceptor Trk (b). (Rabizadeh \& Bredesen, 2003) 


\subsubsection{Processing and regulation of $\mathrm{p}^{\mathrm{NTR}}$ by cleavage}

It has been shown that after ectodomain shedding of the $\mathrm{p} 75^{\mathrm{NTR}}$ and therefore removal of the extracellular NT binding site, the remaining intracellular C-terminal fragment acts as a substrate for $\gamma$-secretase, which also processes amyloid precursor protein (APP) to $\beta$-amyloid in a very similar way (Jung et al., 2003). This fragment is membrane-associated since the transmembrane domain is still functional (Fig 1.6). The latter carries the specific aminoacid target sequence for $\gamma$-secretase. After cleavage the soluble intracellular domain is released and immediately removed by proteasomal degradation. At the time, it is unknown if the released extracellular domain or the soluble intracellular fragment have got any further (signalling) functions. However, it has been suggested that the intracellular domain does not serve as a signalling molecule because of its immediate proteolysis. Nevertheless, the transmembrane cleavage of $\mathrm{p} 75^{\mathrm{NTR}}$ by $\gamma$-secretase could function as an important regulatory mechanism of $\mathrm{p} 75^{\mathrm{NTR}}$ expression and its association with Trks, thus determining the outcome of the cellular response.

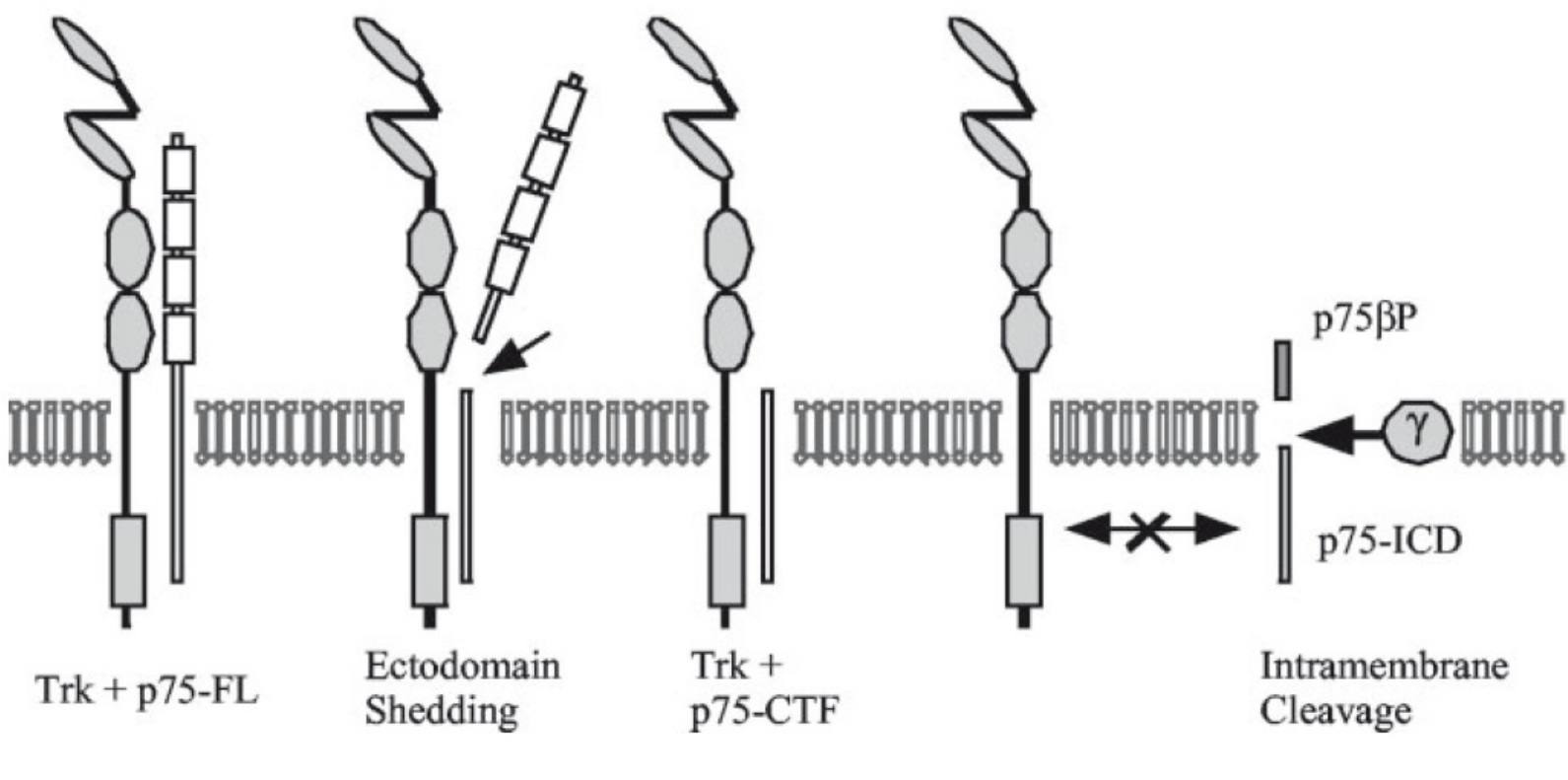

Fig. 1.6 | p75 ${ }^{\mathrm{NTR}}$ cleavage.

Scheme of the $\mathrm{p} 75^{\mathrm{NTR}}$ disassembly by $\gamma$-secretase-mediated cleavage. FL $=$ full length, $\mathrm{CTF}=\mathrm{C}$-terminal fragment, ICD = intracellular domain. (Jung et al., 2003 
In summary, $\mathrm{p} 75^{\mathrm{NTR}}$ is expressed by many different cell populations, like cells of the immune system and the CNS, under various conditions. It seems that $\mathrm{p} 75^{\mathrm{NTR}}$ plays major roles during damage and repair since it is re-expressed by many cell types. Besides cell death and survival, $\mathrm{p} 75^{\mathrm{NTR}}$ can induce a wide range of diverse cellular responses (e.g. inhibition of neurite outgrowth, support of myelination). These responses are mediated by distinct coreceptors as well as different adaptor proteins (e.g. Trk, LINGO-1, NogoR, Sortilin [Nykjaer et al., 2004], RhoA, TNF receptor associated factor [TRAF]-2, TRAF-6, neurotrophin receptor-interacting melanoma antigen gene [MAGE] homologue [NRAGE] [Salehi et al., 2000], p75 $5^{\mathrm{NTR}}$-associated cell death executor [NADE] [Mukai et al., 2003]). Because $\mathrm{p} 75^{\mathrm{NTR}}$ itself does not have an intracellular kinase domain (Lu et al., 2005) and because of its ability to combine with other receptors, crosstalk between various signal transduction pathways might be possible.

\subsection{Neurotrophin mediated interactions between the immune system and the CNS}

Since widespread expression of neurotrophins (Kerschensteiner et al., 1999) and their receptors (Lomen-Hoerth \& Shooter, 1995) has also been found on immune cells, the close connection between the immune system and the CNS under pathological conditions became clear. The increased production of neurotrophins and corresponding receptors by cells of the CNS and the immune system in disease led to the suggestion that neurotrophins might act as alert molecules able to prime tissue defence processes (Weskamp \& Otten, 1987; LeviMontalcini et al., 1996). For instance, neurotrophins are capable of modulating monocyte migration through the BBB (Flügel et al., 2001) via the $\mathrm{p} 75^{\mathrm{NTR}}$. Neumann et al. (1998) show that the MHC class II expression of cultured rat microglia is reduced by NGF - p $75^{\mathrm{NTR}}$ interaction. Furthermore, B cell proliferation, survival and Ig production is increased by NGF in an autocrine manner via $\mathrm{p} 75^{\mathrm{NTR}}$ (Kimata et al., 1991; Torcia et al., 1996). 


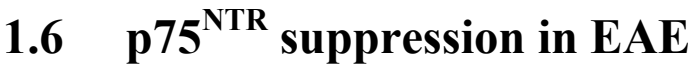

Copray et al. (2004) showed increased clinical deficits and inflammatory infiltrations in spinal cords of $\mathrm{p} 75^{\mathrm{NTR}}$ deficient mice after $\mathrm{MOG}_{35-55}$ EAE induction in comparison to wild type (wt) mice. The composition of the infiltrates regarding macrophages and $\mathrm{T}$ cells numbers however is comparable. They described $\mathrm{p} 75^{\mathrm{NTR}}$ expression on endothelial cells of blood vessels and perivascular astrocytes in the inflamed spinal cord by immunohistochemistry. Copray et al. interpret their findings as suggestive for a role of $\mathrm{p} 75^{\mathrm{NTR}}$ for BBB integrity.

In contrast, Soilu-Hänninen et al. (2000) observed decreased incidence, clinical deficits, inflammation and demyelination in EAE mice in which $\mathrm{p} 75^{\mathrm{NTR}}$ was knocked down by specific antisense oligonucleotides. However, they also show $\mathrm{p} 75^{\mathrm{NTR}}$ expression on CNS endothelial cells.

\subsection{Aims}

The goal of the present work is to elucidate the role of the $\mathrm{p} 75^{\mathrm{NTR}}$ during experimental inflammation and demyelination of the CNS. Most likely, because of the widespread (re)expression, association with diverse coreceptors and initiation of complex signalling cascades, the role of $\mathrm{p} 75^{\mathrm{NTR}}$ in induction and repair of inflammatory demyelination is still a matter of debate.

In this study we examine the effects of a lack of $\mathrm{p} 75^{\mathrm{NTR}}$ signalling after active EAE induction and after adoptive transfer of encephalitogenic $\mathrm{T}$ cell clones by using a $\mathrm{p} 75^{\mathrm{NTR}}$ deficient mouse strain.

First, we compare responses of $\mathrm{p} 75^{\mathrm{NTR}}$ deficient and wt cells and tissues after various stimuli. Second, to further address the question if $\mathrm{p} 75^{\mathrm{NTR}}$ plays the major role within the CNS or in the infiltrating immune system we established a bone marrow chimera system in which the $\mathrm{p} 75^{\mathrm{NTR}}$ is exclusively expressed by cells of the immune system but not by other cell types of the body, namely CNS cells, and vice versa. Third, we measure $\mathrm{p} 75^{\mathrm{NTR}}$ expression levels of diverse immune cell and CNS parenchymal cell populations under various experimental conditions in vitro, ex vivo and in vivo.

We used a variety of techniques and readouts, such as cell culture systems, quantitative real time polymerase chain reaction (qRT-PCR), fluorescence activated cell 
sorting (FACS), enzyme linked immunosorbent assays (ELISA), proliferations assays and immunohistochemistry.

The overall goal of this study is to check under which conditions which cell populations express $\mathrm{p} 75^{\mathrm{NTR}}$, what their contribution to mediating CNS inflammation, damage to axons and clinical outcome is, and possibly to apply new findings to MS treatment. 


\section{Materials and Methods}

For further information on common procedures, reagents, buffers, solutions, chemicals, instruments, equipment, and manufacturers see appendix A.1, A.2, and A.3.

\subsection{Animals}

Young adult $\mathrm{p} 75^{\mathrm{NTR}}-/-$ mice, first generated and described by Lee et al. (1992), aged 6-12 weeks were obtained from our own in-house breeding facility. They were mated heterozygously and, therefore, each mouse was genotyped. $\mathrm{p} 75^{\mathrm{NTR}}-/-$ mice have a C57 BL/6-J background, and we used age-matched wild type C57 BL/6-J mice from Charles River (Sulzfeld, Germany) or our in-house breeding facility as controls.

The murine $\mathrm{p} 75^{\mathrm{NTR}}$ gene is located on chromosome 11 and consists of six exons. In p $75^{\mathrm{NTR}}$-/- mice, exon 3 is knocked out. This exon encodes three of four extracellular, cysteine-rich, Ig-like domains, which are responsible for ligand binding (Welcher et al., 1991; Yan \& Chao, 1991). The truncated version of $\mathrm{p} 75^{\mathrm{NTR}}$ is still expressed in these knock-out mice; however, signalling is impeded (Yan \& Chao, 1991).

The animals had free access to water and food ad libitum and a $12 \mathrm{~h} / 12 \mathrm{~h}$ light/dark cycle. Experiments were carried out in accordance with the guidelines of the Central Department for Animal Experiments, University Medical Center, Göttingen, and the required permissions were obtained from the local authorities, then in Braunschweig, Germany.

\subsubsection{Genotyping of animals}

To genotype the offspring of the heterozygous mating, tissue was obtained during the earmarking procedure.

\section{DNA extraction}

- $\quad 350 \mu 1$ tail lysis buffer $+100 \mu$ g proteinase $\mathrm{K}$ per biopsy

- 2-3h digestion at $56^{\circ} \mathrm{C}$ while shaking 
- $5 \mathrm{~min}$ centrifugation at $8000 \mathrm{~g}$

- collected supernatant $+350 \mu 170 \%$ isopropanol to precipitate DNA

- $5 \mathrm{~min}$ centrifugation at $8000 \mathrm{~g}$

- discarded supernatant, washing pellet with $500 \mu 170 \% \mathrm{EtOH}$

- $5 \mathrm{~min}$ centrifugation at $8000 \mathrm{~g}$

- discard supernatant, let pellet dry

- dissolved dry pellet in $100 \mu$ d distilled $\mathrm{H}_{2} \mathrm{O}$

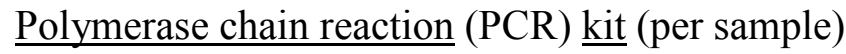

- $2.5 \mu 15 \mathrm{x}$ buffer

- $0.5 \mu 1$ desoxyribonucleotides (dNTPs) (1:4) containing nucleotides of the bases adenine (dATP), cytosine (dCTP), guanine (dGTP), and thymine (dTTP), each $100 \mathrm{mM}$

- $\quad 0.5 \mu 1$ each primer 1 , primer 2 , primer $3(10 \mu \mathrm{M}$ each)

primer sequence 1: GTGTTACGTTCTCTGACGTTGTG primer sequence 2: TCTCATTCGGCGTCAGCCCAGGG primer sequence 3: GATTCGCAGCGCATCGCCTT (synthesized by MWG Biotech AG, Ebersberg, Germany)

- $\quad 0.25 \mu 1$ Taq polymerase

- $\quad 5.75 \mu \mathrm{l} \mathrm{H} \mathrm{H}_{2} \mathrm{O}$

- $2 \mu 1$ sample DNA

\section{$\underline{\text { PCR program }}$}

- $5 \mathrm{~min}$ $95^{\circ} \mathrm{C}$ denaturation

- $1 \mathrm{~min}$ $94^{\circ} \mathrm{C}$ denaturation $1 \mathrm{~min}$ $59^{\circ} \mathrm{C}$ annealing 35 cycles $1 \mathrm{~min}$ $72^{\circ} \mathrm{C}$ elongation

- $10 \mathrm{~min}$ $72^{\circ} \mathrm{C}$ elongation

- forever $4^{\circ} \mathrm{C}$ storage

\section{$\underline{\text { Agarose gel electrophoresis }}$}

- gel: $2 \%$ agarose in tris/borate/EDTA buffer (TBE) $+0.005 \%$ ethidium bromide

- electrophoresis in TBE buffer at $100 \mathrm{~V}$ for $60 \mathrm{~min}$

- Visualization of PCR products by UV light 
homozygous for $\mathrm{p} 75^{\mathrm{NTR}}$ exon 3 deficiency (-/-): one single PCR product at $580 \mathrm{kB}$ heterozygous (+/-): two PCR products at $580 \mathrm{kB}$ and $350 \mathrm{kB}$

A 100bp DNA ladder was used to estimate PCR product length

\subsection{Generation of bone marrow chimeras}

In a bone marrow chimeric animal the original immune system has been destroyed by irradiation and has been reconstituted by transfer of bone marrow from another mouse. Ionizing radiation causes damage of the DNA, resulting in cell apoptosis. Immune cells and hematopoietic stem cells are more susceptible to ionizing radiation than other cell populations of the body. After reconstitution with healthy bone marrow, the stem cells proliferate, differentiate, and repopulate the body compartments.

- $\quad \mathrm{p} 75^{\mathrm{NTR}}$-/- and wt mice were whole body irradiated with 11.5 Gy from top and bottom each using a linear accelerator at the department of radiation therapy and radiooncology (Prof. Dr. Dr. Hess, Prof. Dr. Hille).

- after $1 \mathrm{~d}$ irradiated mice were reconstituted with $6-8 \times 10^{6}$ bone marrow cells in $300 \mu 1$ PBS i.v. (see below).

To be able to distinguish between immune cells which survived the irradiation procedure and ones which repopulated the body after reconstitution, two different markers were used. For flow cytometric analysis a congenic mouse strain was used that expresses another variant of $\mathrm{CD} 45$, called CD45.1, on $\mathrm{BL} / 6$ background. p $75^{\mathrm{NTR}}$-/- mice have the natural CD45.2 gene on BL/6 background. For histological analysis a transgenic BL/6-J strain that expresses the green fluorescent protein (GFP) under the actin promoter was used as bone marrow donor. Thus, all cells express GFP. By means of specific antibodies against CD45.1, CD45.2, and GFP we were able to differentiate donor and acceptor cells.

- 8 weeks after the irradiation and cell transfer, the reconstitution efficacy was checked, and EAE was induced. During the repopulation phase, mice had low germ count acidic drinking water supplemented with neomycin $(0.00016 \%)$ to prevent infections. 


\section{Preparation of bone marrow}

- donor mice were deeply anesthetized and sacrificed by cervical dislocation

- bodies were disinfected with $70 \% \mathrm{EtOH}$

- hind legs were skinned and fleshed and the bones were rinsed in macrophage medium (DMEM + supplements, see appendix A.2)

- bones were cut at both ends under sterile conditions and rinsed from top and bottom with medium using a needle and syringe.

- washed with medium (cell washing see appendix A.1)

- passed through a $40 \mu \mathrm{m}$ cell strainer

- cell counting (see appendix A.1)

- 2x washed with PBS and resuspension of $6-8 \times 10^{6}$ cells in $300 \mu 1$ PBS per animal serum from the medium must not carried over

- i.v. injection (tail vein)

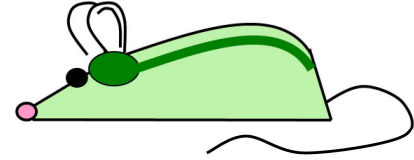

wildtype

CNS p $75+/+$ immune system $\mathrm{p} 75+/+$

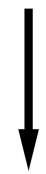

irradiation

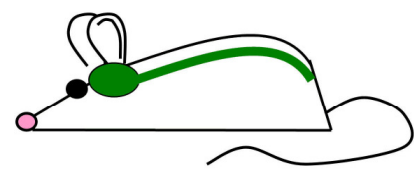

wildtype

CNS p $75+/+$

no immune system

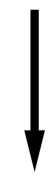

reconstitution

with $\mathrm{p} 75$-/- bone marrow

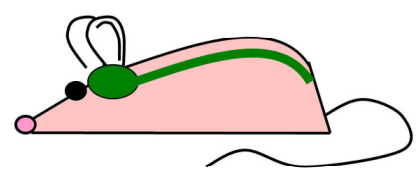

wildtype

CNS p $75+/+$

immune system p75 -/-

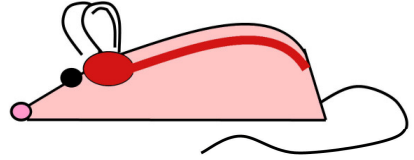

p75 -/-

CNS p $75-1-$

immune system p75 -/-

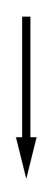

irradiation

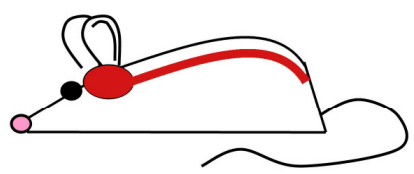

p75 -/-

CNS p75 -

no immune system

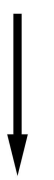

reconstitution

with wildtype $+/+$ bone marrow

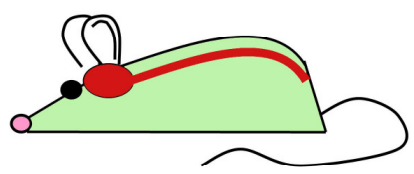

p75 -/-

CNS p75 - I-

immune system p $75+/+$
Fig. 2.1 | Scheme of bone marrow chimera generation.

In wt mice all cells of the body carry a functioning $p 75^{\text {NTR }}$ gene (a). After irradiation and reconstitution with p $75^{\text {NTR }}-/-$ bone marrow p $75^{\text {NTR }}$ signalling is impeded on immune cells but not on CNS cells. In irradiated p $75^{\text {NTR }}$-/- mice reconstituted with wt bone marrow only immune cells are able to express a functioning $p 75^{\mathrm{NTR}}$ whereas CNS cells are not (b). 


\subsection{Induction of experimental autoimmune encephalomyelitis (EAE) by active immunization}

Animals were immunized by subcutaneous injections of $200 \mu 1 \mathrm{MOG}_{35-55}$ emulsion $(2 \mathrm{x}$ $50 \mu 1$ peri-axillary, $2 \times 50 \mu 1$ peri-inguinally; left and right each). The $\mathrm{MOG}_{35-55}$ emulsion contains $1 \mu \mathrm{g} / \mu \mathrm{MOG}_{35-55}$ peptide and $5 \mu \mathrm{g} / \mu 1$ killed mycobacterium tuberculosis in a 1:1 ratio of sterile PBS and incomplete Freund's adjuvant emulsified by sonication. During the immunization animals were anesthetized with diethyl ether per inhalationem. Immediately and $48 \mathrm{~h}$ after immunization 300ng pertussis toxin (PTX) in $300 \mu 1$ PBS were injected intraperitoneally (i.p.) per mice to stimulate the immune response and permeablize the BBB. Some EAE experiments were performed with Dr. med. Wolfgang Jäger and form a part of his medical doctor thesis, which was achieved also at the Institute of Neuropathology.

\subsection{Induction of EAE by adoptive transfer}

EAE was induced by i.p. injection of an encephalitogenic $\mathrm{MOG}_{35-55}$ specific $\mathrm{T}_{\mathrm{H}} 1$ cell clone (clone 5.8, courtesy of Dr. med. Stefan Nessler). Before injection, T cells were restimulated in vitro.

\subsubsection{Expansion and restimulation of $\mathrm{T}$ cell clones}

$\mathrm{T}$ cell clones were stored in freezing medium (see appendix A.2), consisting of $40 \%$ fetal calf serum (FCS) and 20\% dimethyl sulfoxide (DMSO) in Roswell Park Memorial Institute (RPMI) medium, in liquid nitrogen $\left(\mathrm{N}_{2}\right)$. Aliquots of about $10^{7} \mathrm{~T}$ cells were thawed, disseminated, restimulated, and expanded in accordance with the following protocol. All steps were performed under sterile conditions. T cells were cultivated in a cell incubator at $37^{\circ} \mathrm{C}$ and $5 \% \mathrm{CO}_{2}$.

Thawing and dissemination 
- thawed frozen T cells at room temperature (RT)

- $2 \mathrm{x}$ washed with $\mathrm{T}$ cell medium (see appendix A.2) to get rid of the freezing medium (cell washing see appendix A.1)

- cell counting (see appendix A.1)

- dissemination of 750000 cells/ml in $24-w e l l$ plates $+2 \mathrm{ng} / \mathrm{ml} \mathrm{IL-2}$

First restimulation (after 3-4 d)

- collected and washed all cells

- cell counting

- dissemination of 750000 cells $/ \mathrm{ml}$ in 24 -well plates

- added 6-8 x $10^{6}$ irradiated splenocytes (see below) $+10 \mu \mathrm{g} / \mathrm{ml} \mathrm{MOG}_{35-55}$ for specific antigen presentation and restimulation of the $\mathrm{T}$ cell clone

Preparation of irradiated splenocytes

- naïve, female, 6-12 weeks aged mice were sacrificed by cervical dislocation while deeply anesthetized; spleens were extracted under sterile conditions

- washed with T cell medium and meshed through a $70 \mathrm{~nm}$ cell strainer to obtain a single cell suspension

- washed and resuspended with $1 \%$ ammonium chloride in $\mathrm{H}_{2} \mathrm{O}$, incubation for 3 min to lyse the erythrocytes.

- $2 \mathrm{x}$ washed to get rid of the ammonium chloride

- transfer through a $40 \mathrm{~nm}$ cell strainer to get rid of cell debris

- cell counting

- irradiation with $30 \mathrm{~Gy}$ to inhibit proliferation of the splenocytes

\section{Expansion of restimulated $\mathrm{T}$ cells}

- 3-4d after the first restimulation, splited the $\mathrm{T}$ cells by transfer of half of the resuspension in a new well every second day

- refilled the wells with medium $+2 \mathrm{ng} / \mathrm{ml} \mathrm{IL-2}$ to increase proliferation 


\subsubsection{Adoptive transfer}

- second restimulation about 2 weeks after expansion according to the above protocol

- $2 \mathrm{x}$ washed and resuspended in sterile PBS 3-4d after the second restimulation

- cell counting (see appendix A.1)

- i.p. injection of ca. $2 \times 10^{7} \mathrm{~T}$ cells in $300 \mu 1$ sterile PBS per animal

\subsection{Clinical evaluation of EAE}

After EAE induction by immunization or adoptive transfer, animals were weighed and scored daily to measure disease severity. Scores are shown in table 2.1.

\begin{tabular}{cl}
\hline \hline Score & \multicolumn{1}{c}{ clinical symptoms } \\
\hline \hline 0 & none \\
0.5 & partial tail paresis \\
1 & complete tail paralysis \\
1.5 & slight hind limb paresis \\
2 & distinct hind limb paresis, waddle gait \\
2.5 & severe hind limb paresis, no normal gait on soles \\
3 & complete hind limb paralysis \\
3.5 & slight fore limb paresis \\
4 & tetraparalysis \\
4.5 & moribund \\
5 & death \\
\hline \hline
\end{tabular}

Tab 2.1 | Scores and clinical correlates.

Used EAE disease scores and their related clinical symptoms to assess disease severity. 


\subsection{Tissue preparation}

At the end of the experiment mice were deeply anesthetized by i.p. injection of $300 \mu 1$ $14 \%$ chloral hydrate in $\mathrm{H}_{2} \mathrm{O}$. After checking the anesthesia by a pain stimulus on the leg and the eye lid reflex, animals were killed by cervical dislocation or transcardiac perfusion with PBS. No perfusion was done when collecting lymph nodes, spleens, bone marrow, and brains for primary microglia and astrocyte cultures. Animals were perfused when spinal cords and/or brains were dissected for histological, flow cytometric, and RNA analysis.

\subsubsection{Transcardiac perfusion}

The thoraces of deeply anesthetized animals were opened and the mice were anterogradly perfused with PBS through the left heart ventricle until all blood was washed out. For flow cytometric and RNA analysis, the native spinal cord and/or the brain was collected after PBS perfusion. For histological analysis PBS was followed by 4\% paraformaldehyde (PFA) in PBS during the perfusion step to fix the tissue.

\subsubsection{Tissue processing for histological analysis}

After perfusion with PBS and 4\% PFA skulls and spines were dissected and postfixed in $4 \%$ PFA over night at $4^{\circ} \mathrm{C}$ followed by a washing step with PBS over night at $4^{\circ} \mathrm{C}$. Brains and spinal cords were dissected, cut into $3-4 \mathrm{~mm}$ thick slices, dehydrated in an ascending sequence of alcohol solutions and embedded into paraffin (see chapter 2.7) over night using an automated tissue processor. Next day, tissues were embedded in paraffin blocks, cut into $1 \mu \mathrm{m}$ thin serial sections using a sliding microtome, and mounted on glass slides. 


\subsubsection{Tissue processing for RNA analysis}

For RNA analysis, native spinal cords and/or brains were collected after perfusion with cold PBS and stored in RNAlater at $-20^{\circ} \mathrm{C}$ until further processing.

\subsection{Histochemical stainings}

For the following histochemical stainings, tissue sections were deparaffinized and rehydrated. Stained sections were dehydrated after the staining procedures and mounted in DePex medium.

Dehydration and embedding into paraffin

$\mathrm{H}_{2} \mathrm{O} \rightarrow 50 \%$ isopropanol (IPA) $\rightarrow 70 \%$ IPA $\rightarrow 90 \%$ IPA $\rightarrow 100 \%$ IPA $\rightarrow$ IPA/xylene (1:1) $\rightarrow 3 \mathrm{x}$ xylene $\rightarrow$ paraffin

Deparaffinization and rehydration of the tissue sections were done according to the above protocol in reversed order. The duration for every step is $3 \mathrm{~min}$.

\subsubsection{Hematoxylin and eosin (HE) staining}

HE staining provides a general overview of the tissue and facilitates the detection of inflammatory infiltrates. The inflammatory index was determined in HE stained spinal cord cross sections.

Hematoxylin stains cell nuclei blue by binding to basic nucleoproteins like histones. Eosin colours acidophilic and basic extra- and intracellular proteins pink and red (eosinophilic).

- deparaffinization and rehydration

- 8 min Mayer's hemalum

- shortly washed with $\mathrm{H}_{2} \mathrm{O}$

- differentiation by dipping $2-3 \mathrm{x}$ in $1 \% \mathrm{HCl}$ alcohol 
- 10 min blued under flowing tap water

- $6 \min 1 \%$ eosin solution

- shortly washed with $\mathrm{H}_{2} \mathrm{O}$

- dehydration

- mounted in DePeX medium

\subsubsection{Luxol fast blue / periodic acid Schiff (LFB/PAS) staining}

The LFB/PAS staining allows the assessment of demyelination in the white matter of spinal cord cross sections.

LFB stains myelin deep blue by binding to lipoproteins. PAS stains non-myelinated and demyelinated parenchyma pink.

- deparaffinization and rehydration to the $90 \%$ isopropanol step

- LFB solution over night, $60^{\circ} \mathrm{C}$

- washed with $90 \%$ isopropanol

- differentiation in $0.05 \%$ lithium carbonate in $\mathrm{H}_{2} \mathrm{O}$ to release $\mathrm{LFB}, 70 \%$ isopropanol to wash away released isopropanol, and $\mathrm{H}_{2} \mathrm{O}$ to stop the washing step until only the myelin is stained deep blue

- $5 \min 1 \%$ periodic acid in $\mathrm{H}_{2} \mathrm{O}$

- 5 min under flowing tap water

- washed with distilled $\mathrm{H}_{2} \mathrm{O}$

- 20 min Schiff's solution

- 5 min under flowing tap water

- 2 min hemalum

- shortly washed with $\mathrm{H}_{2} \mathrm{O}$

- differentiated by dipping $2-3 \mathrm{x}$ in $1 \% \mathrm{HCl}$ alcohol

- $10 \mathrm{~min}$ blued under flowing tap water

- dehydration

- mounting in DePeX medium 


\subsubsection{Bielschowsky silver impregnation}

Bielschowsky silver impregnation was used to enumerate axons in normal appearing white matter and in lesions and therefore to assess axonal loss.

Axons are argyrophilic (silver salt binding) structures. Insoluble silver nitrate binds to axons and is reduced to elementary silver leading to a black impregnation of axons. Parenchyma is stained yellow to brown.

- deparaffinization and rehydration

- 20 min $20 \%$ silver nitrate $\left(\mathrm{AgNO}_{3}\right)$ solution in distilled $\mathrm{H}_{2} \mathrm{O}$ in the dark

- washed with distilled $\mathrm{H}_{2} \mathrm{O}$

- added $32 \%$ ammonium hydroxide in distilled $\mathrm{H}_{2} \mathrm{O}$ drop by drop to the used silver nitrate solution until all precipitations have cleared up while stirring

- $15 \mathrm{~min}$ in this cleared silver nitrate/ammonium hydroxide solution in the dark

- washed with distilled water with some drops ammonium hydroxide in it

- added 10 drops of developer solution to the used silver nitrate/ammonium hydroxide solution

- developed in this solution until axons are stained black (5-6 min)

- washed with distilled $\mathrm{H}_{2} \mathrm{O}$

- 2 min fixation in $2 \%$ sodium thiosulfate in distilled $\mathrm{H}_{2} \mathrm{O}$ solution

- dehydration

- mounted in DePeX medium

\subsubsection{Immunohistochemical stainings}

Immunohistochemical stainings were done to specifically detect cell marker proteins by antibodies. By means of these markers axonal damage, $\mathrm{T}$ cell infiltration, and other information can be gained.

For this technique, animals, e.g. rabbits, mice, or rats, were immunized with the target protein or peptide, e.g. mouse APP or CD3. The animals produce specific antibodies against certain epitopes. The antibodies are isolated, purified, and used to detect, e.g. APP in mouse tissue. The detection signal is then amplified and visualized by the use of biotin-conjugated 
secondary antibodies, avidin-coupled peroxidase, and e.g., by precipitation of bound diaminobenzidine (DAB) (Fig. 2.2).

- deparaffinization and rehydration

- pretreatment of the tissue slices to unmask the epitopes:

Boiled slices for $5 \times 3 \mathrm{~min}$ in $10 \mathrm{mM}$ citric acid buffer using a microwave (800W).

- cooled down for $30 \mathrm{~min}$ at RT

- washed in $\mathrm{H}_{2} \mathrm{O}$ followed by PBS (except for iNOS detection [see Tab. 2.2])

- 20 min $3 \% \mathrm{H}_{2} \mathrm{O}_{2}$ in $\mathrm{H}_{2} \mathrm{O}$ at $4^{\circ} \mathrm{C}$ to block endogenous peroxidase, which could produce a false positive signal when precipitating DAB during the developing step by $\mathrm{H}_{2} \mathrm{O}_{2}$.

- 3x washed with PBS

- 20 min blocked with $10 \%$ FCS in PBS at RT to prevent unspecific antibody binding (except for iNOS detection [see Tab. 2.2])

- incubation with the specific primary antibody diluted in 10\% FCS in PBS over night at $4^{\circ} \mathrm{C}$ in a wet chamber (for further information on the primary antibodies applied see Tab 2.2).

- 3x washed with PBS

- $1 \mathrm{~h}$ incubation with the secondary antibody diluted in 10\% FCS in PBS at RT in a wet chamber to amplify the detection signal (for further information on the secondary antibodies, see Tab 2.3). The secondary antibody binds specifically to the Fc region of the primary antibody and is, e.g., conjugated with biotin.

- 3x washed with PBS

- $1 \mathrm{~h}$ incubation with $0.1 \%$ streptavidin-horseradish peroxidase (POX) in $10 \%$ FCS in PBS at RT in a wet chamber. Streptavidin is isolated from bacterium streptomyces and binds biotin with high affinity bringing the coupled POX in close proximity to the specific antigen detection site.

- 3x washed with PBS

- development with DAB and $\mathrm{H}_{2} \mathrm{O}_{2}$ in PBS until a clear specific dark brown staining can be seen, preferentially without any background staining. DAB is oxidized by the bound POX using $\mathrm{H}_{2} \mathrm{O}_{2}$.

- 3x washed with PBS

- optional step: the DAB signal may be amplified by incubation with $2 \%$ copper sulphate $\left(\mathrm{CuSO}_{4}\right)$ in $0.9 \% \mathrm{NaCl}$ solution for $10 \mathrm{~min}$.

- washed with $\mathrm{H}_{2} \mathrm{O}$ 
- counter stain of nuclei with $20 \mathrm{~s}$ hemalum, shortly dipping in $\mathrm{H}_{2} \mathrm{O}$, and differentiation by $3-5$ dips in $\mathrm{HCl} / \mathrm{EtOH}$.

- 10 min blued in flowing tap water

- dehydration

- mounted in DePeX medium

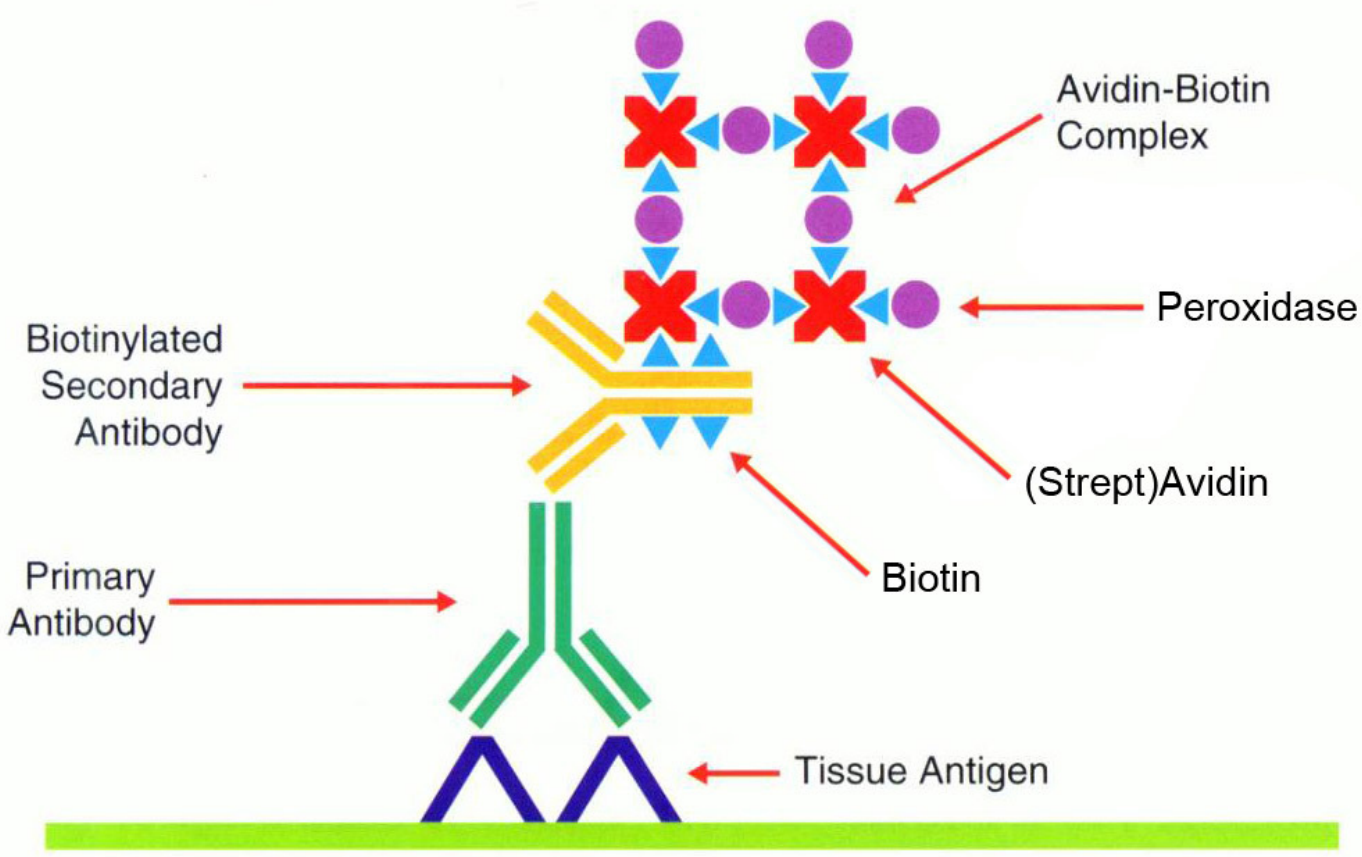

Fig. 2.2 | Scheme of detection in immunohistochemistry by using the avidin biotin method

The specific primary antibody binds to its antigen. Its Fc segment is detected by a biotinylated secondary anti-IgG specific antibody. (Strept)Avidin, coupled to peroxidase (POX), binds to biotin. POX oxidizes DAB by usage of $\mathrm{H}_{2} \mathrm{O}_{2}$. The precipitation of DAB reveals the location of the protein of interest. (from Dako pathology education guide "Immunohistochemical staining 


\begin{tabular}{|c|c|c|c|c|}
\hline antigen & marker for & species & dilution & manufacturer \\
\hline$\overline{\mathrm{APP}}$ & early axonal damage & mouse & $\overline{11: 3000}$ & Chemicon \\
\hline $\mathrm{B} 220 / \mathrm{CD} 45 \mathrm{R}$ & $\mathrm{B}$ cells & rat & $1: 200$ & Becton Dickinson \\
\hline CD3 & T cells & rat & $1: 200$ & Serotec \\
\hline Gap43 & neuroaxonal regeneration & mouse & $1: 5000$ & Chemicon \\
\hline iNOS $^{*}$ & $\begin{array}{l}\text { Upregulation of inductible NO } \\
\text { synthase }\end{array}$ & rat & $1: 500$ & Assay Designs \\
\hline Mac-3 & macrophages / microglia & rat & $1: 200$ & Becton Dickinson \\
\hline NogoA & mature oligodendrocytes & mouse & $1: 20000$ & $\begin{array}{l}\text { Kind gift from M Schwab, } \\
\text { Zürich } \\
\text { (Oertle et al., 2003) }\end{array}$ \\
\hline S100A9 & early activated macrophages & rat & $1: 2000$ & $\begin{array}{l}\text { Kind gift from C Sorg, } \\
\text { Münster } \\
\text { (Nacken et al., 2000) }\end{array}$ \\
\hline SMI35 & early axonal damage & mouse & $1: 7000$ & Sternberger \\
\hline
\end{tabular}

Tab. 2.2 | List of primary antibodies.

Specificy, purpose, origin, dilution, and manufacturer of the used primary antibodies for imunnohistochemical stainings.

* For the detection of iNOS not PBS but tris buffered saline (TBS) was used throughout the whole protocol. Also, for blocking not FCS but donkey serum was used.

\begin{tabular}{cccc}
\hline \hline antigen & species & dilution & manufacturer \\
\hline \hline mouse Ig & sheep & $1: 200$ & Amersham \\
\hline rat Ig & goat & $1: 200$ & Amersham \\
\hline \hline
\end{tabular}

Tab. 2.3 | List of secondary antibodies. Specificy, origin, dilution, and manufacturer of the used secondary antibodies for immunohistochemical stainings. 


\subsubsection{Microscopic analysis of histochemically stained tissue slices}

In HE stained sections the mean number of inflammatory infiltrates per spinal cord cross section was determined at 40x magnification.

In the LFB/PAS stained sections the percentage of lesioned white matter was determined. This was done under 100x magnification by the computer program "cell^^F". The mean for every animal was calculated.

In Bielschowsky stained sections the axonal densities of normal appearing white matter and within lesions of spinal cord cross sections were determined by using an axon counting grid with 25 crossing points. At a magnification of 400x, the number of axons crossing one of these points was determined. The value obtained in the normal appearing white matter was set to $100 \%$. The density of axons within lesions was expressed as the percentage of axonal density in the normal appearing white matter.

All immunohistochemically stained sections were analyzed at a magnification of 400x by using a 10x10 square cell counting grid. Immunoreactive (IR) cells or axons were counted within spinal cord lesions in a given area and given as IR structures $/ \mathrm{mm}^{2}$.

\subsection{RNA analysis}

Quantitative analysis of mRNA transcripts of selected inflammation related genes was done to examine differences in the quality of inflammation between $\mathrm{p} 75^{\mathrm{NTR}}-/-$ and wt mice during EAE. Furthermore, in combination with FACS sorting and primary cell cultures of microglia, bone marrow derived macrophages, and astrocytes we were able to measure p $75^{\mathrm{NTR}}$ expression by different cell subpopulations of the CNS and the immune system ex vivo and in vitro. We also stimulated these subpopulations in vitro to detect changes in the inflammatory response and $\mathrm{p} 75^{\mathrm{NTR}}$ expression.

For RNA analysis of spinal cords and brains, animals were perfused with cold PBS to wash out any remaining blood cells, and native tissues were put in RNAlater on ice to stabilize the mRNA. For RNA analysis of primary cell cultures and FACS sorted cell subpopulations, cell suspensions were centrifuged and directly resuspended in cell lysis buffer (see below). 


\subsubsection{RNA extraction}

The Qiagen RNeasy Mini Kit was used for RNA extraction. All steps were done at RT according to the supplied protocol.

- homogenization of tissue with $500 \mu 11 \% \beta$-mercaptoethanol in supplied RLT lysis buffer with an electric cell crusher;

homogenization of cells from primary cell cultures or after FACS sorting by passing the lysate at least five times through a 20 gauge $(0.9 \mathrm{~mm}$ diameter $)$ needle or through a QiaShredder spin column in $500 \mu 11 \% \beta$-mercaptoethanol in supplied RLT lysis buffer

- centrifugation for $3 \mathrm{~min}$ at $8000 \mathrm{~g}$ to get rid of cellular debris

- collected supernatants and mixing it 1:1 with 70\% EtOH to precipitate nucleic acids

- transfered the sample to an RNeasy spin column

- centrifugation for $1 \mathrm{~min}$ at $8000 \mathrm{~g}$. RNA binds to column. Discarded flow-through.

- Washed with $350 \mu 1$ supplied RW1 buffer. Centrifugation for $1 \mathrm{~min}$ at $8000 \mathrm{~g}$. Discarded flow-through.

- on-column DNA digestion to ensure that only RNA is bound by using the Qiagen RNase-free DNase set:

According to the provided protocol, added $~ 27$ Kunitz units DNase I in $80 \mu 1$ supplied RDD buffer per sample directly onto the column. DNA digestion for $15 \mathrm{~min}$ at RT.

- Washed with $350 \mu 1$ supplied RW1 buffer. Centrifugation for $1 \mathrm{~min}$ at $8000 \mathrm{~g}$. Discarded flow-through.

- Washed with $500 \mu \mathrm{l}$ supplied RPE buffer. Centrifugation for $1 \mathrm{~min}$ at $8000 \mathrm{~g}$. Discarded flow-through.

- Washed with $500 \mu 1$ supplied RPE buffer. Dried the column by centrifugation for $2 \mathrm{~min}$ at $8000 \mathrm{~g}$. Discarded flow-through avoiding carry-over of EtOH.

- Elution of bound RNA by 2 x $30 \mu 1$ RNase-free $\mathrm{H}_{2} \mathrm{O}$ followed by centrifugation for 1 min at $8000 \mathrm{~g}$ each.

- Storage at $-80^{\circ} \mathrm{C}$ 


\subsection{2 cDNA reverse transcription}

An Applied Biosystems High Capacity cDNA Reverse Transcription kit was used to reversely transcribe the mRNA to cDNA. All steps were done according to the supplied protocol.

- reverse transcription PCR (per sample): (All reagents supplied)

$8 \mu \mathrm{l} \quad \mathrm{RT}$ buffer

$3.2 \mu \mathrm{l}$ dNTPs $(100 \mathrm{mM})$

$8 \mu 1 \quad$ random primers

$4 \mu 1 \quad$ reverse transcriptase (Multiscribe)

$16,8 \mu 1 \mathrm{H}_{2} \mathrm{O}$

$40 \mu 1 \quad$ sample RNA

- PCR program:

$\begin{array}{lll}10 \mathrm{~min} & 25^{\circ} \mathrm{C} & \text { annealing } \\ 120 \mathrm{~min} & 37^{\circ} \mathrm{C} & \text { reverse transcription } \\ 5 \mathrm{~s} & 85^{\circ} \mathrm{C} & \text { denaturation } \\ \text { forever } & 4^{\circ} \mathrm{C} & \text { storage }\end{array}$

- determination of cDNA concentration by using $1 \mu 1$ sample cDNA and a NanoDrop analyzer

\subsubsection{TaqMan quantitative real time PCR (qRT-PCR)}

In the TaqMan qRT-PCR technique not only forward and reverse primers complementary to the target gene are used, but also TaqMan probes, which anneal specifically to the target gene, too. These probes carry a fluorophore and a quencher in close proximity, inhibiting the detection of any fluorescence. If the single stranded DNA sequence with a bound primer is now specifically processed, the nucleotides of the TaqMan probes are removed one by one by the exonuclease activity of the Taq polymerase (Fig. 2.3). Therefore, fluorophore and quencher are released. Since the fluorophore is not in close proximity to the 
quencher anymore, it is excitable and fluorescence can be detected. Accordingly, in the TaqMan qRT-PCR method, all measured fluorescence signals are specific.

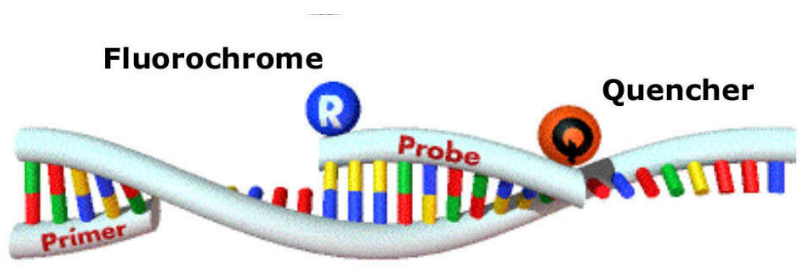

1. Specific binding of Probe and Primers

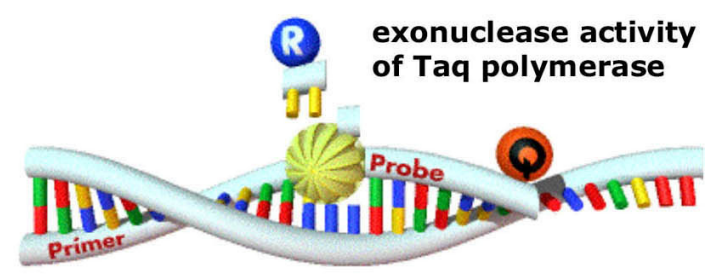

2. strand extention

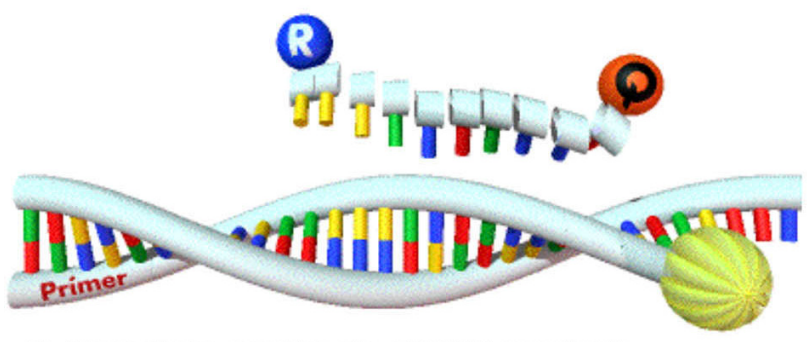

3. Complete synthesis of PCR product

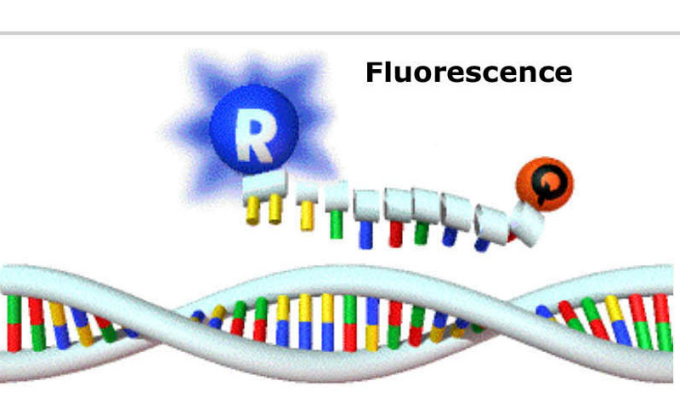

4. Reporter signal

Fig. 2.3 | Scheme of the TaqMan qRT-PCR principle.

Additional to primers, a specific TaqMan probe carrying a fluorophore and a quencher are used (1). In close proximity the quencher inhibits fluorescence detection. During the synthesis of the complementary strand, the probe is released by the exonuclease activity of the Taq polymerase (2). The distance of fluorophore and quencher is increasing (3), and fluorescence signals can be detected (4). (scheme by Ruhr-Universität Bochum)

TaqMan qRT-PCRs were prepared in 96-well-plates. All cDNA samples were also analyzed for the housekeeping gene glyceraldehyde 3-phosphate dehydrogenase (GAPDH), which is constitutively expressed by all cell types.

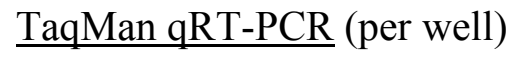

- $10 \mu 1$

- $1 \mu 1$

- $8 \mu 1$

- $1 \mu 1$
TaqMan fast universal master mix gene expression assay mix (specific TaqMan probes)

$\mathrm{H}_{2} \mathrm{O}$

sample cDNA 
$\underline{\text { TaqMan qRT-PCR program }}$

- $20 \mathrm{~s}$

$95^{\circ} \mathrm{C}$

denaturation

- $1 \mathrm{~s}$

$95^{\circ} \mathrm{C}$

$20 \mathrm{~s}$

$60^{\circ} \mathrm{C}$

denaturation

Fluorescence signals were measured in real time by the PCR cycler. The instrument calculated cDNA concentrations (by using the GAPDH expression data) and $\mathrm{C}_{\mathrm{T}}$ and $\Delta \mathrm{C}_{\mathrm{T}}$ values were computed. The cycle threshold $\left(\mathrm{C}_{\mathrm{T}}\right)$ value determines the numbers of cycles needed to get a fluorescent signal significantly above background noise. The less cycles are needed, the higher is the cDNA amount within the sample, the higher was the mRNA amount within the tissue / cells, and the higher was the expression of this gene of interest. To compare expression levels between individuals and groups, the $\Delta \mathrm{C}_{\mathrm{T}}$ value is used. This value is the result of the $C_{T}$ value of the examined gene subtracted by the $C_{T}$ value of GAPDH. A $\Delta C_{T}$ value difference of 1 means a 2-fold up- or downregulation of the gene; a difference of 2 cycles signifies a 4-fold regulation.

Data analysis was done using the StepOne Plus software from Applied Biosystems.

\subsection{Flow cytometric analysis}

Flow cytometric cell analysis was performed to check the frequency of immune cell subpopulations in lymph nodes and infiltrated spinal cords in $\mathrm{p} 75^{\mathrm{NTR}}-/-$ and wt mice. Specific surface markers and intracellular stainings reveal not only different immune cell types, but also their maturation and activation status as well as their cytokine expression patterns. Therefore, flow cytometric analysis gives insights in both the quantity and quality of inflammation.

To see potential differences between $\mathrm{p} 75^{\mathrm{NTR}}$-/- and wt mice during peripheral priming, lymph nodes were analyzed from naïve mice as well as 3, 7, 10, and 14 days after active immunization. Also, spinal cords were examined with regard to infiltrating immune cell populations at peak of disease (score 3.0). Flow cytometric analysis was done by disseminating in vivo primed lymph node cells in culture and checking their activation upon in vitro stimuli.

To see if certain immune cell populations express $\mathrm{p} 75^{\mathrm{NTR}}$ under specific conditions, lymph node cells were sorted and collected for further TaqMan qRT-PCR analysis. 
Furthermore, the reconstitution efficacy of bone marrow chimeras was measured by blood flow cytometry.

\section{$\underline{\text { FACS medium }}$}

$2 \%$ FCS in DMEM (high glucose)

\section{$\underline{\text { FACS buffer }}$}

$1 \%$ FCS in PBS

$\underline{\text { Cell washing }}$

Filled up the tube with specified medium or buffer, centrifugation at $290 \mathrm{~g}, 4^{\circ} \mathrm{C}, 6 \mathrm{~min}$, discarding supernatant, and resuspension of the pellet in an appropriate amount of specified medium or buffer

\subsubsection{Preparation of lymph nodes for flow cytometric analysis}

Naïve mice or mice $3,7,10$, or 14 days after active immunization were deeply anesthetized and sacrificed by cervical dislocation. Bodies were disinfected with $70 \% \mathrm{EtOH}$ and 6 lymph nodes (4x peri-axillary, 2x peri-inguinally) were collected under sterile conditions.

- washed lymph nodes with FACS medium

- $\quad$ passed lymph nodes through a $70 \mu \mathrm{m}$ cell strainer and pipetted the suspension up and down to get a single cell suspension

- washed with FACS medium

- resuspension of the pellet in $500 \mu 1 \mathrm{FACS}$ buffer

- cell counting (see appendix A.1)

- splitting cells to have at least 50000 in a FACS tube for each staining

- Staining of the cells (see chapter 2.9.4) 
For in vitro stimulation of extracted lymph node cells followed by flow cytometric analysis, cells were disseminated in culture. The following additional steps were performed after preparing the single cell suspension according to the protocol above:

- washed with RPMI medium + supplements (same as T cell medium, see appendix A.2)

- resuspension of the pellet in RPMI medium + supplements

- cell counting and dissemination of $10^{6}$ cells per well in 24-well plates

- stimulation with $50 \mathrm{ng} / \mathrm{ml}$ phorbol 12-myristate 13-acetat (PMA) for $6 \mathrm{~h}$. Adding $4 \mu 1$ Golgi block reagent per every $6 \mathrm{ml}$ medium to stop protein transport for intracellular stainings. Golgi stop has to be added to every medium, buffer or solution from this point on to prevent protein release.

- Collected cells and washing with FACS buffer + Golgi stop to end the stimulation

- cell counting (see appendix A.1)

- $\quad$ splited the cells to have at least 50000 in a FACS tube per staining

- $\quad$ surface protein staining of the cells (see chapter 2.9.4)

- fixation (2\% PFA in PBS) over night at $4^{\circ} \mathrm{C}$ in the dark

- washed with FACS buffer

- intracellular staining with fluorochrome labelled antibodies diluted 1:100 in FACS buffer + Golgi stop in a volume of $100 \mu 1$ per FACS tube

30 min incubation at $4{ }^{\circ} \mathrm{C}$ in the dark

- washed with FACS buffer

- resuspension of the pellet in $200 \mu 12 \%$ PFA in FACS buffer

- $\quad$ short-term storage at $4{ }^{\circ} \mathrm{C}$ in the dark

\subsubsection{Preparation of spinal cords for flow cytometric analysis}

At the peak of disease (score 3.0) animals were deeply anesthetized with $300 \mu 114 \%$ chloral hydrate and perfused with cold PBS to wash out any remaining blood cells. Spinal cords were dissected, and collected in FACS medium on ice. Isolation of the immune cells was done by density centrifugation in a 3-phase Percoll gradient. 
- passed the spinal cord tissue through a $70 \mu \mathrm{m}$ cell strainer and pipetted the suspension up and down to get a single cell suspension

- washed with FACS medium

- resuspension of the pellet in $2 \mathrm{ml}$ FACS medium $+20 \mu \mathrm{l}$ DNAse solution $(10 \mu \mathrm{g} / \mu \mathrm{l})$ to avoid DNA clots

15 min incubation at $37^{\circ} \mathrm{C}$

- $\quad$ washed with FACS medium

- resuspension of the pellet in $6 \mathrm{ml} 30 \%$ Percoll in FACS medium

- prepared the Percoll density gradient in a $15 \mathrm{ml}$ Falcon tube $4 \mathrm{ml} \mathrm{45 \%} \mathrm{Percoll} \mathrm{in} \mathrm{FACS} \mathrm{medium} \mathrm{underlain} \mathrm{by} 2 \mathrm{ml} 70 \%$ Percoll in FACS medium Pipetted the cell suspension in 30\% Percoll in FACS medium on top of the density gradient

- density centrifugation: $20 \mathrm{~min}$ at $1065 \mathrm{~g}$ without acceleration and brake

- withdrawal of the uppermost layer containing the myelin by suction

- collecting the immune cells at the two interphases of the Percoll density gradient by using a long needle and a syringe

- passed through a $40 \mu \mathrm{m}$ cell strainer to get rid of cell debris

- washed with FACS medium

- resuspension of the pellet in $500 \mu 1$ FACS buffer

- cell counting (see appendix A.1)

- splitting cells to have at least 50000 in a FACS tube per staining

- Staining of the cells (see chapter 2.9.4)

\subsubsection{Preparation of blood for flow cytometric analysis}

Animals were deeply anesthetized with diethyl ether per inhalationem. Blood was collected retrobulbarly by using a glass capillary and suspended in $1 \% 0.5 \mathrm{M}$ EDTA in FACS buffer. Staining of the blood leukocytes was performed according to the general flow cytometry staining protocol (see chapter 2.9.4). Additionally, erythrocytes were lysed after antibody incubation. 


\subsubsection{Staining cells for flow cytometric analysis}

- washed with FACS buffer

- resuspension of the pellet in $50 \mu \mathrm{Fc}$ receptor blocking solution (1:200 in FACS buffer) to inhibit unspecific binding of the Fc part of the antibodies to Fc receptors on immune cells

10 min incubation at RT

- washed with FACS buffer

- staining with fluorochrome labelled antibodies diluted 1:300 in FACS buffer in a volume of $100 \mu 1$ per FACS tube (Tab. 2.4)

15 min incubation at $4{ }^{\circ} \mathrm{C}$ in the dark

- washed with FACS buffer

- erythrocyte lysis (only for blood flow cytometry): resuspension in $100 \mu 1$ OptiLyse. After incubation for $13 \mathrm{~min}$ at RT in the dark, addition of $1 \mathrm{ml} \mathrm{H}_{2} \mathrm{O}$ and incubation for $1-2 \mathrm{~h}$ at $\mathrm{RT}$ in the dark washed with FACS buffer

- resuspension of the pellet in $200 \mu 12 \%$ PFA in FACS buffer

- $\quad$ short-term storage at $4^{\circ} \mathrm{C}$ in the dark

Flow cytometric analysis was done with a FACSCalibur. Raw data analysis was done with Cell Quest Pro, FlowJo V.7.6.1, and WinMDI 2.9 softwares.

For TaqMan qRT-PCR analysis after cell sorting, separated cell populations were processed according the mRNA analysis protocol in chapter 2.8 . 


\begin{tabular}{|c|c|c|c|c|c|c|}
\hline antigen & marker for & species & isotype & clone & $\begin{array}{l}\text { manu- } \\
\text { facturer }\end{array}$ & $\begin{array}{l}\text { fluoro- } \\
\text { chrome }\end{array}$ \\
\hline \multirow{2}{*}{$\beta$ chain TCR } & \multirow{2}{*}{$\alpha \beta$ T cells } & \multirow{2}{*}{ hamster } & \multirow{2}{*}{$\operatorname{IgG} 2 \lambda 1$} & \multirow{2}{*}{ H57-597 } & $\overline{\mathrm{BD}}$ & FITC \\
\hline & & & & & eBio & FITC \\
\hline \multirow{3}{*}{$\mathrm{B} 220 / \mathrm{CD} 45 \mathrm{R}$} & \multirow{3}{*}{ B cells } & \multirow{3}{*}{ rat } & \multirow{3}{*}{$\operatorname{IgG} 2 \mathrm{a} \kappa$} & \multirow{3}{*}{ RA3-6B2 } & \multirow{2}{*}{ BD } & \\
\hline & & & & & & PerCP \\
\hline & & & & & eBio & $\mathrm{PE}$ \\
\hline \multirow{3}{*}{$\gamma \delta \mathrm{TCR}$} & \multirow{3}{*}{$\gamma \delta \mathrm{T}$ cells } & \multirow{3}{*}{ hamster } & \multirow{2}{*}{$\operatorname{IgG} 2 \kappa$} & \multirow{2}{*}{ GL3 } & $\mathrm{BD}$ & $\mathrm{PE}$ \\
\hline & & & & & eBio & APC \\
\hline & & & $\mathrm{IgG}$ & $\mathrm{GL}-2$ & IT & FITC \\
\hline \multirow{3}{*}{ CD3e } & \multirow{3}{*}{$\mathrm{T}$ cells } & \multirow{3}{*}{ hamster } & \multirow{3}{*}{$\operatorname{IgG1} \kappa$} & \multirow{3}{*}{$145-2 \mathrm{C} 11$} & $\mathrm{BD}$ & PerCP \\
\hline & & & & & Rio & FITC \\
\hline & & & & & (DIO & $\mathrm{PE}$ \\
\hline \multirow{4}{*}{ CD4 } & \multirow{4}{*}{$\mathrm{T}$ helper cells } & \multirow{4}{*}{ rat } & \multirow{2}{*}{$\operatorname{IgG} 2 \mathrm{a} \kappa$} & \multirow{2}{*}{ RM4-5 } & \multirow{3}{*}{$\mathrm{BD}$} & $\mathrm{PE}$ \\
\hline & & & & & & PerCP \\
\hline & & & $\operatorname{IgG} 2 \mathrm{~b} \kappa$ & $\mathrm{GK} 1.5$ & & FITC \\
\hline & & & $\operatorname{IgG} 2 \mathrm{a} \kappa$ & RM4-5 & eBio & FITC \\
\hline \multirow{2}{*}{ CD8a } & cytotoxic & \multirow{2}{*}{ rat } & \multirow{2}{*}{$\operatorname{IgG} 2 \mathrm{a} \kappa$} & $53-67$ & $\mathrm{BD}$ & FITC \\
\hline & $\mathrm{T}$ cells & & & 8.1 & eBio & $\mathrm{APC}$ \\
\hline CD11a & $\begin{array}{c}\mathrm{T} \text { cell adhesion } \\
\text { molecule }\end{array}$ & rat & $\operatorname{IgG} 2 \mathrm{a} \kappa$ & M17/4 & eBio & PE \\
\hline & & & & & BD & FITC \\
\hline CD11b & macrophages, & rat & $\operatorname{IgG} 2 \mathrm{a} \kappa$ & $\mathrm{M} 1 / 70$ & & $\mathrm{APC}$ \\
\hline & microglia & & & & Pis & $\mathrm{PE}$ \\
\hline & & & & & & APC \\
\hline CD11c & dendritic cells & hamster & $\operatorname{IgG} 1 \lambda 2$ & HL3 & $\mathrm{BD}$ & PE \\
\hline$C D 10$ & P colls & rat & 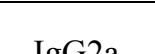 & PeCa1 & IT & APC \\
\hline ( & (D) & tat & $1502 a$ & $1 \mathrm{D} 3$ & $\mathrm{eBio}$ & FITC \\
\hline & activated & & & & & \\
\hline $\mathrm{CD} 25$ & $\begin{array}{c}\mathrm{T} \text { cells and } \mathrm{T}_{\text {reg }} \\
\text { cells }\end{array}$ & rat & $\operatorname{IgG} 1 \lambda$ & PC61.5 & eBio & APC \\
\hline CD29 & $\begin{array}{c}\mathrm{T} \text { cell adhesion } \\
\text { molecule }\end{array}$ & hamster & $\operatorname{IgG}$ & HMb1-1 & eBio & PE \\
\hline CD44 & $\begin{array}{c}\text { T cell } \\
\text { differentiation }\end{array}$ & rat & $\operatorname{IgG} 2 b$ к & IM7 & eBio & APC \\
\hline CD45 & leukocytes & rat & $\operatorname{IgG} 2 b \quad \kappa$ & 30-F11 & $\mathrm{BP}$ & PerCP \\
\hline CD45.1 & $\begin{array}{l}\text { leukocytes } \\
\text { (congenic }\end{array}$ & mouse & $\operatorname{IgG} 2 \mathrm{a} \kappa$ & A20 & eBio & APC \\
\hline
\end{tabular}




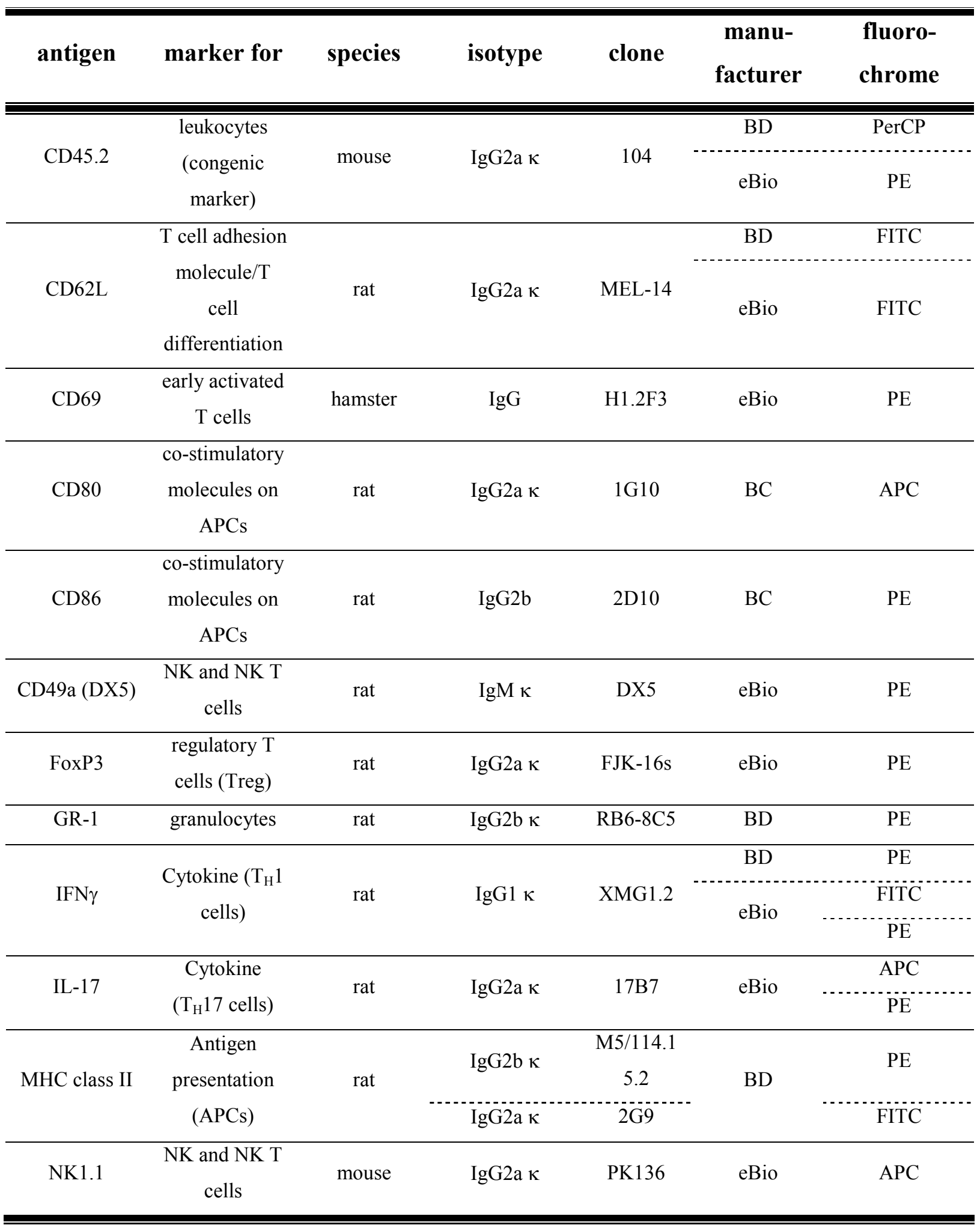

Tab 2.4 | List of antigen specific FACS antibodies.

Antigen specificity, host origin, immunoglobulin isotype, clone, commercial source, and coupled fluorochrome of the antibodies used for flow cytometry stainings. Detectable cell populations by the use of the markers are also indicated. Conjugated fluorophores were allophycocyanin (APC), fluorescein isothiocyanate (FITC), phycoerythrin $(\mathrm{PE})$, and peridinin chlorophyll protein (PerCP). Different fluorophores were used depending on the combination of antibodies applied. $\mathrm{BD}=$ Becton Dickinson Biosciences, $\mathrm{BC}=$ Beckman Coulter, eBio = eBioscience, IT = ImmunoTools 


\begin{tabular}{|c|c|c|c|c|}
\hline species & isotype & clone & $\begin{array}{l}\text { manu- } \\
\text { facturer }\end{array}$ & fluoro-chrome \\
\hline \multirow{4}{*}{ hamster } & \multirow{4}{*}{ IgG } & \multirow{4}{*}{ 299Arm } & \multirow{4}{*}{ eBio } & APC \\
\hline & & & & FITC \\
\hline & & & & $\mathrm{PE}$ \\
\hline & & & & PerCP \\
\hline \multirow{3}{*}{ mouse } & \multirow{3}{*}{$\operatorname{IgG} 2 \mathrm{a} \kappa$} & \multirow{3}{*}{ - } & \multirow{3}{*}{ eBio } & APC \\
\hline & & & & $\mathrm{PE}$ \\
\hline & & & & PerCP \\
\hline \multirow{9}{*}{ rat } & IgG1 $\kappa$ & - & eBio & $\mathrm{APC}$ \\
\hline & \multirow{4}{*}{$\operatorname{IgG} 2 \mathrm{a} \kappa$} & \multirow{4}{*}{ - } & \multirow{4}{*}{ eBio } & APC \\
\hline & & & & FITC \\
\hline & & & & $\mathrm{PE}$ \\
\hline & & & & PerCP \\
\hline & \multirow{3}{*}{$\operatorname{IgG} 2 b \kappa$} & \multirow{3}{*}{-} & \multirow{3}{*}{ eBio } & $\mathrm{APC}$ \\
\hline & & & & FITC \\
\hline & & & & PerCP \\
\hline & $\operatorname{IgM} \kappa$ & - & eBio & $\mathrm{PE}$ \\
\hline
\end{tabular}

Tab 2.5 I List of isotype control FACS antibodies.

Host origin, immunoglobulin isotype, commercial source, and coupled fluorochrome of the antibodies used as isotype negative controls for flow cytometry. Conjugated fluorophores were allophycocyanin (APC), fluorescein isothiocyanate (FITC), phycoerythrin (PE), and peridinin chlorophyll protein (PerCP). eBio = eBioscience

\subsection{Enzyme-linked immunosorbent assay (ELISA)}

ELISA analysis was done to specifically measure the amount of cyto- and chemokines released into the medium by cultured cells. ELISA plates are coated with a primary capture antibody, which is immobilized by binding to the plate surface. After applying the cell culture supernatants, the protein of interest is specifically captured by the antibody. The secondary biotinylated detection antibody binds to another epitope of the protein ("sandwich"). Streptavidin coupled to horseradish peroxidase (HRP) was used as detection system. HRP oxidizes the substrate tetramethyle benzidine (TMB) / peroxide, which then turns blue (Fig. 2.4). 
This technique was used for in vivo primed lymph node cells (dpi10), which were restimulated in vitro, and primary cell cultures in vitro.

All pre-coated plates, solutions, buffers, antibodies, and the protein standard were supplied in the ELISA kits obtained from R+D Systems.

- transfered $100 \mu 1$ of the capture antibody solution per well in a 96-well ELISA plate

- incubation over night at $4^{\circ} \mathrm{C}$

- $3 x$ washed with $400 \mu 1$ wash buffer $(0.05 \%$ Tween 20 in PBS) per well

- $1 \mathrm{~h}$ blocking with blocking buffer at RT

- 3x washing with $400 \mu 1$ wash buffer per well

- added $100 \mu 1$ of the cell culture supernatant sample diluted 1:10 in the specific medium or protein standard per well

$2 \mathrm{~h}$ incubation at RT while shaking. The protein of interest binds specifically to the immobilized primary antibody.

- $3 x$ washed with $400 \mu 1$ wash buffer per well

- added $100 \mu 1$ of the biotinylated secondary detection antibody per well

$2 \mathrm{~h}$ incubation at RT while shaking. The detection antibody binds specifically to another epitope of the protein.

- added $100 \mu 1$ streptavidin-HRP per well

20min incubation at RT in the dark. Streptavidin-HRP binds to the biotin of the detection antibody.

- 3x washed with $400 \mu 1$ wash buffer per well

- added $100 \mu 1$ substrate solution (TMB/peroxide) per well

20-30min incubation at RT in the dark. TMB/peroxide turns blue when modified by the HRP.

- added $50 \mu \mathrm{l}$ acidic stop solution (1M sulphuric acid) per well which turns the solution yellow

- photometric determination of the optical density by an ELISA reader at 540nm and $450 \mathrm{~nm}$ as reference. Specific protein concentrations were calculated according to the supplied protein standards. 


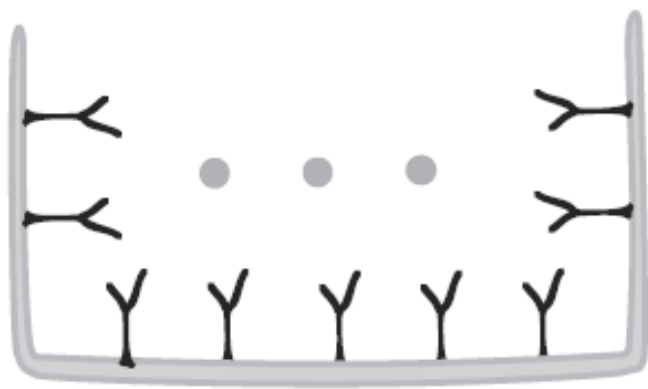

Step 1. Analyte-specific antibody (capture antibody) is pre-coated onto a microplate. The sample is added and any analyte present is bound by the immobilized antibody.

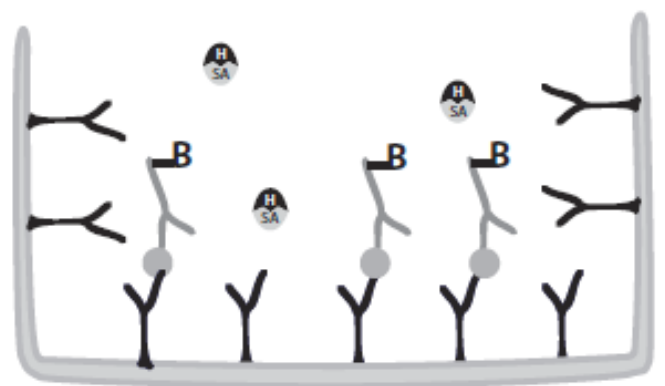

Step 3. Streptavidin-HRP is added and binds to the biotin-labeled detection antibody. Legend
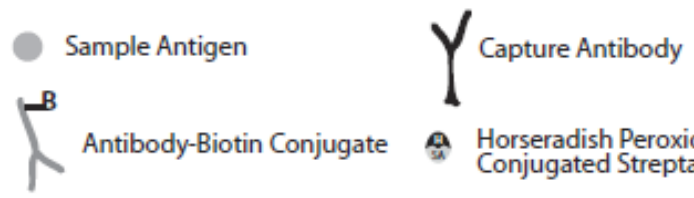

A Horseradish Peroxidase

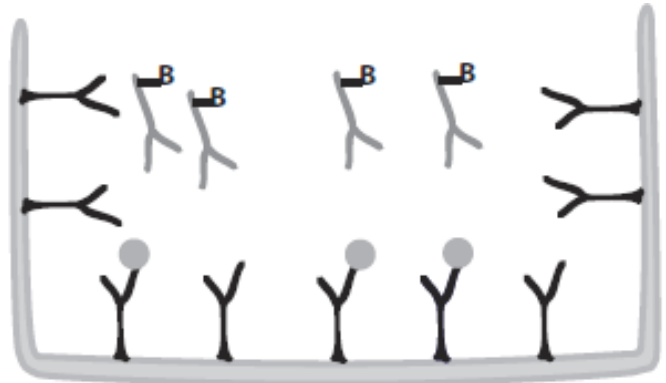

Step 2. A biotin-labeled analyte-specific detection antibody binds to a second epitope on the analyte forming the analyte-antibody complex.

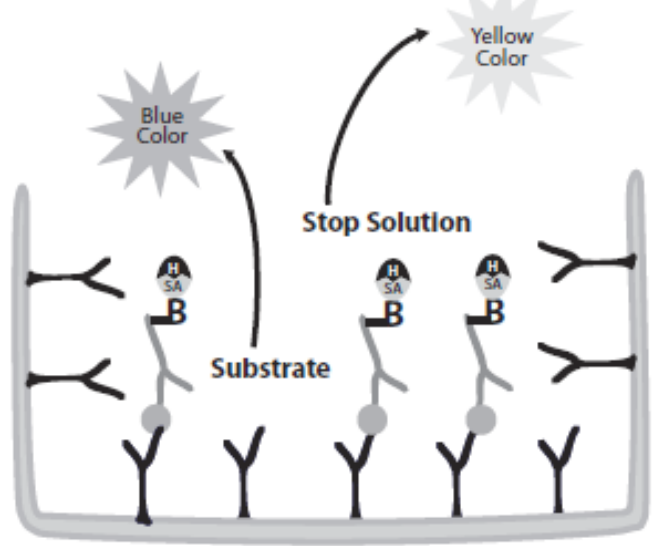

Step 4. TMB/peroxide (substrate) is added and converted by the HRP (enzyme) to a color product (blue) in proportion to the amount of analyte bound (signal increases as analyte concentration increases). The reaction is stopped upon addition of stop solution, changing the solution from blue to yellow.

\section{Fig. 2.4 | Scheme of the ELISA principle.}

Specific capturing and detection of proteins and measurement of protein concentrations by ELISA (from R\&D Systems, Minneapolis, MN, USA).

\subsection{T cell clone analysis in vitro}

\subsubsection{Proliferation assay}

Proliferation assays have been performed to check if impeded $\mathrm{p} 75^{\mathrm{NTR}}$ signalling has effects on antigen specific $\mathrm{T}$ cell proliferation. Therefore, the incorporation of radioactive ${ }^{3} \mathrm{H}$-thymidine into newly synthesized DNA strands was measured. ${ }^{3} \mathrm{H}$-thymidine contains 
heavy hydrogen $\left({ }^{3} \mathrm{H}\right)$ in its methyl group, which is a weak beta emitter with a half-life of $\sim 12.3$ years. 3-4 days after $\mathrm{T}$ cell restimulation, radioactivity was measured as a marker for cell division frequency.

Two different approaches have been followed. First, we restimulated our T cell clone expressing functional $\mathrm{p} 75^{\mathrm{NTR}}$ with $\mathrm{p} 75^{\mathrm{NTR}}-/-$ and wt APCs to dissect the effects of $\mathrm{p} 75^{\mathrm{NTR}}$ deficiency on APCs. Second, we collected lymph node cells from immunized $\mathrm{p} 75^{\mathrm{NTR}}-/-$ and wt animals at dpi 10 and restimulated the $\mathrm{MOG}_{35-55}$ specific $\mathrm{T}$ cells with wt APCs and the MOG peptide. This was done to look at possible differences in $\mathrm{p} 75^{\mathrm{NTR}}-/-$ and wt $\mathrm{T}$ cell proliferation.

- dissemination of 100000 primed (dpi 10) lymph node cells (p75 $5^{\mathrm{NTR}}-/-$ or wt) or T cell clone cells in 50 $\mu 1$ RPMI medium + supplements ( $\mathrm{T}$ cell medium, see appendix A.2) per well in 96-well plates (see chapters 2.3.1 and 2.9.1 for dissemination of the $\mathrm{T}$ cell clone and preparation of primed lymph node cells).

- Added 100000 irradiated APCs (p75 $5^{\mathrm{NTR}}$-/- or wt) in $50 \mu 1$ medium per well to the $\mathrm{T}$ cells (see chapter 2.3.1 for preparation of irradiated APCs).

- Added $10 \mu \mathrm{g} / \mathrm{ml} \mathrm{MOG}_{35-55}$ per well

- After $2 \mathrm{~d}$ added ${ }^{3} \mathrm{H}$-thymidine with a radioactivity of $18.5 \mathrm{kBq}$ in $25 \mu 1$ per well

- After $24 \mathrm{~h}$ determination of cell proliferation by measurement of radioactivity of ${ }^{3} \mathrm{H}$-thymidine incorporated into the DNA by a cell harvester instrument and scintillation counter

\section{$\underline{\text { harvesting protocol }}$}

Proliferating cells containing radioactive DNA are captured on a filter paper, whereas the radioactive medium is washed away.

- pre-wetted the filter paper by $3 \mathrm{x}$ washing (aspirating) with non-radioactive medium (cold)

- $1 \mathrm{x}$ aspirated radioactive cells onto the filter paper (hot)

- $3 \mathrm{x}$ washed by aspirating with medium to get rid of excess radioactivity within the cell medium (hot)

- $3 x$ washed by aspirating with medium (cold)

- dried the filter paper at $60^{\circ} \mathrm{C}$ for $2 \mathrm{~h}$

- fused dry filter paper with a MultiLex film at $100^{\circ} \mathrm{C}$

- measurement of radioactivity by a scintillation counter 


\subsection{2 mRNA analysis for $\mathrm{p}^{\mathrm{NTR}}$ expression}

To check if our $\mathrm{T}_{\mathrm{H}} 1$ cell clone expresses $\mathrm{p} 75^{\mathrm{NTR}}$ under various conditions, mRNA was isolated after different stimuli in vitro.

- dissemination of 750000 cells $/ \mathrm{ml}$ in $\mathrm{T}$ cell medium (see appendix A.2) in a 24-well plate $(2 \mathrm{ml} /$ well $)$

- $\quad$ stimulation for the indicated time periods (3h, $6 \mathrm{~h}, 24 \mathrm{~h})$ :

PMA: 5 or $50 \mathrm{ng} / \mathrm{ml}$ (indicated)

$\alpha-C D 3 / \alpha-C D 28$ antibodies: $0.1 \mu 1 / \mathrm{ml}$ from kit stock

agonistic $\alpha-C D 3 / \alpha-C D 28$ antibodies provide costimulation

NGF: $100 \mathrm{ng} / \mathrm{ml}$

- washed with medium

- $\quad$ mRNA analysis (see chapter 2.8)

\subsection{Bone marrow derived macrophages}

Bone marrow derived macrophages (BMDM) were generated to have access to a pure, non-prestimulated, freshly differentiated primary macrophage culture. In contrast, common cell cultures obtained from peritoneal macrophages are likely prestimulated by thioglycolic acid or by the preparation procedure itself.

By addition of supernatants from L929 cell cultures to the medium, hematopoietic stem cells from the bone marrow differentiate into macrophages within 10 days. L929 is a mouse fibroblast culture, which produces a wide potpourri of cytokines, chemokines, and growth factors, e.g. granulocyte macrophage colony stimulating factor (GM-CSF) and macrophage colony stimulating factor (M-CSF). L929 has been shown to drive hematopoietic stem cells into the macrophage niche (Boltz-Nitulescu et al., 1987). 


\subsubsection{Preparation and differentiation of BMDM}

Cultivated BMDMs were stored in a cell incubator at $37^{\circ} \mathrm{C}$ with $10 \% \mathrm{CO}_{2}$.

- donor mice were deeply anesthetized and sacrificed by cervical dislocation

- bodies were disinfected with $70 \% \mathrm{EtOH}$

- hind legs were skinned and fleshed and the bones were washed in macrophage medium (DMEM + supplements, see appendix A.2)

- under sterile conditions bones were cut open at both ends and washed from top and bottom with medium using a needle and syringe.

- $\quad$ washed with medium (cell washing see appendix A.1)

- passed through a $40 \mu \mathrm{m}$ cell strainer

- cell counting (see appendix A.1)

- dissemination of $10^{6}$ cells $/ \mathrm{ml}$ macrophage medium $+20 \%$ L929 medium in a Teflon coated pot

A Teflon coated pot was used to easily harvest the adhering macrophages without risking a prestimulation, e.g. by trypsin or cell scraping.

- after $5 \mathrm{~d}$ another 20\% L929 was added

- after another $5 \mathrm{~d}$ the cells were used for experiments

- washed with medium

- cell counting

- dissemination of $10^{6}$ cells/well in $500 \mu \mathrm{l}$ in a 24 -well plate

- prestimulation (for 3d):

fibrinogen: $10 \mu \mathrm{M}$

IFN- $\gamma: 10 \mathrm{ng} / \mathrm{ml}$

lipopolysaccharide (LPS): $1 \mu \mathrm{g} / \mathrm{ml}$

- washed with medium

- cell counting

- dissemination of $10^{6}$ cells/well in $500 \mu 1$ in a 24 -well plate

- main stimulation (for indicated time periods)

fibrinogen: $10 \mu \mathrm{M}$

IFN- $\gamma: 10 \mathrm{ng} / \mathrm{ml}$

LPS: $1 \mu \mathrm{g} / \mathrm{ml}$

PMA: $50 \mathrm{ng} / \mathrm{ml}$ 
Zymosan: $100 \mu \mathrm{g} / \mathrm{ml}$

- ELISA analysis (see chapter 2.10), NO analysis (see chapter 2.12.2), or ROS analysis (see chapter 2.12.3)

\subsubsection{Measurement of nitric oxide (NO) production after stimulation of BMDM}

To detect potential differences between $\mathrm{p} 75^{\mathrm{NTR}}$-/- and wt BMDM with regard to NO release, cells were stimulated with the TLR-4 activator lipopolysaccharide (LPS) and the TLR-2 activator Zymosan. The concentration of $\mathrm{NO}_{2}$, being a direct degradation product of NO, was measured by the Griess reaction protocol.

- filled each well of a 96-well plate with $50 \mu 1$ sample supernatant/protein standard and $50 \mu 1$ Griess reagents $\mathrm{A}+\mathrm{B}(1: 1)$

- protein standard: $\mathrm{NaNO}_{2}(80,40,20,10,5,2.5,1.25,0.625,0.313 \mu \mathrm{M})$

- shook

- photometrical measurement at $550 \mathrm{~nm}$ (reference $450 \mathrm{~nm}$ when using phenol red containing medium)

\subsubsection{Measurement of reactive oxygen species (ROS) production after stimulation of BMDM}

ROS, such as NO, have been shown to contribute to axonal damage. Therefore, ROS production by $\mathrm{p} 75^{\mathrm{NTR}}-/-$ and wt BMDM after different (pre-) stimuli was measured.

After stimulation, intracellular ROS were directly bound by membrane permeable nitroblue tetrazolium (NBT), which leads to its precipitation and a blue staining. NBT binds both $\mathrm{H}_{2} \mathrm{O}_{2}$ and $\mathrm{O}^{2-}$. After cell lysis and dissolving of NBT, ROS concentrations can be determined photometrically. 
Before main stimulation:

- cell counting (see appendix A.1)

- dissemination of $10^{6}$ cells/well in $1 \mathrm{ml}$ pure DMEM in a $24-w e l l$ plate

- added1mg NBT/ml (in stock NBT is dissolved in DMSO)

- main stimulation for $6 \mathrm{~h}$ :

PMA: $50 \mathrm{ng} / \mathrm{ml}$

Zymosan: $100 \mu \mathrm{g} / \mathrm{ml}$

- fixation with $1 \mathrm{ml} /$ well $100 \%$ methanol

- washed by aspiration with $70 \%$ methanol

- dried over night at RT under a hood

- lysed cells with $62,5 \mu 12 \mathrm{M}$ potassium hydroxide $(\mathrm{KOH})+75 \mu 1 \mathrm{DMSO}$ per well for ca. $5 \min$

- photometric determination of optical density at $650 \mathrm{~nm}$

\subsection{Astrocyte primary cell culture}

To specifically check the role of $\mathrm{p} 75^{\mathrm{NTR}}$-/- deficiency in astrocytes, primary astrocytes cultures were prepared.

- dissection of the brain from 0-2 d old mice

- removed meninges in Hank's buffered salt solution (HBSS) in a petri dish on ice

- disintegrated the tissue with a razorblade and produced a single cell suspension by pipetting

- disseminating cells of 3-4 brains in astrocyte medium (BME + supplements, see appendix A.2) in a poly-L-lysine coated $75 \mathrm{~cm}^{2}$ flask

poly-L-lysine coating $\left(0.1 \mathrm{mg} / \mathrm{ml}\right.$ in distilled $\left.\mathrm{H}_{2} \mathrm{O}\right)$ by incubation for $1 \mathrm{~h}$ at $\mathrm{RT}$

- after $7 \mathrm{~d}$ changing medium by aspiration and added $200 \mu \mathrm{g} / \mathrm{ml}$ clodronate to deplete microglia cells

- after $2 \mathrm{~d}$ changing medium by aspiration and shook on a shaker at $37^{\circ} \mathrm{C}$ over night to get rid of oligodendrocytes

- washed by aspiration with medium 
- collected cells: 3-5 min treatment with 0.05\% trypsin / EDTA at RT while shook to loosen astrocytes from the flask area

- washed with medium

- cell counting (see appendix A.1)

- dissemination of $10^{6}$ cells/well in $500 \mu 1$ in a 24 -well plate

- prestimulation for $3 \mathrm{~d}$ :

IFN- $\gamma: 10 \mathrm{ng} / \mathrm{ml}$

lipopolysaccharide (LPS): $1 \mu \mathrm{g} / \mathrm{ml}$

- changed medium by aspiration

- main stimulation for indicated time periods or $20 \mathrm{~h}$

IFN- $\gamma: 5 \mathrm{ng} / \mathrm{ml}$

LPS: 10 or $100 \mu \mathrm{g} / \mathrm{ml}$ (indicated)

PMA: 5 or $50 \mathrm{ng} / \mathrm{ml}$ (indicated)

Zymosan: $100 \mu \mathrm{g} / \mathrm{ml}$

NGF: $100 \mathrm{ng} / \mathrm{ml}$

- mRNA analysis (see chapter 2.8), ELISA analysis (see chapter 2.10), or ROS analysis (see chapter 2.13.1)

\subsubsection{Measurement of ROS production after stimulation of astrocytes}

ROS production was measured in $\mathrm{p} 75^{\mathrm{NTR}}$-/- and wt astrocytes.

Intracellular ROS were detected by the fluorescent dye 5-(and-6)-chloromethyl-2',7'dichlorodihydro-fluorescein diacetate, acetylester (CM- $\mathrm{H}_{2}$ DCFDA). This molecule loses its membrane permeability upon ROS binding being trapped intracellularly.

Before main stimulation:

- collected cells: 3-5 min treatment with $0.05 \%$ trypsin/EDTA at RT while shook to loosen astrocytes

- cell counting (see appendix A.1)

- dissemination of $10^{6}$ cells/well in $1 \mathrm{ml}$ pure HBSS in a 24-well plate

- added $10 \mu \mathrm{M}$ CM- $\mathrm{H}_{2}$ DCFDA (dissolved in DMSO)

- incubated for $30 \mathrm{~min}$ at $37^{\circ} \mathrm{C}$ and $5 \% \mathrm{CO}_{2}$ 
- washed by aspiration with HBSS

- main stimulation:

PMA: $50 \mathrm{ng} / \mathrm{ml}$

Zymosan: $100 \mu \mathrm{g} / \mathrm{ml}$

- measurement of arbitrary fluorescence units over time by a fluorescence reader excitation wavelength: $490 \mathrm{~nm}$

emission wavelength: $525 \mathrm{~nm}$ 


\section{Results}

\subsection{Induction of EAE by active immunization in $\mathrm{p}^{2} 5^{\mathrm{NTR}}-/-$ mice}

\subsubsection{More severe disease in $\mathbf{p} 75^{\mathrm{NTR}}$-/- mice after active immunization}

To address the question if $\mathrm{p} 75^{\mathrm{NTR}}$ plays a role during experimental CNS inflammation, EAE was induced by active immunization with $\mathrm{MOG}_{35-55}$ in CFA in $\mathrm{p} 75^{\mathrm{NTR}}-/-$ and wt mice. 13 days post immunization (dpi 13) the mice developed first clinical signs. From the beginning on until dpi 31, when the experiment was terminated, $\mathrm{p} 75^{\mathrm{NTR}}-/-$ mice suffered from a more severe disease course, as has been observed by Copray et al. (2004), (Fig 3.1).

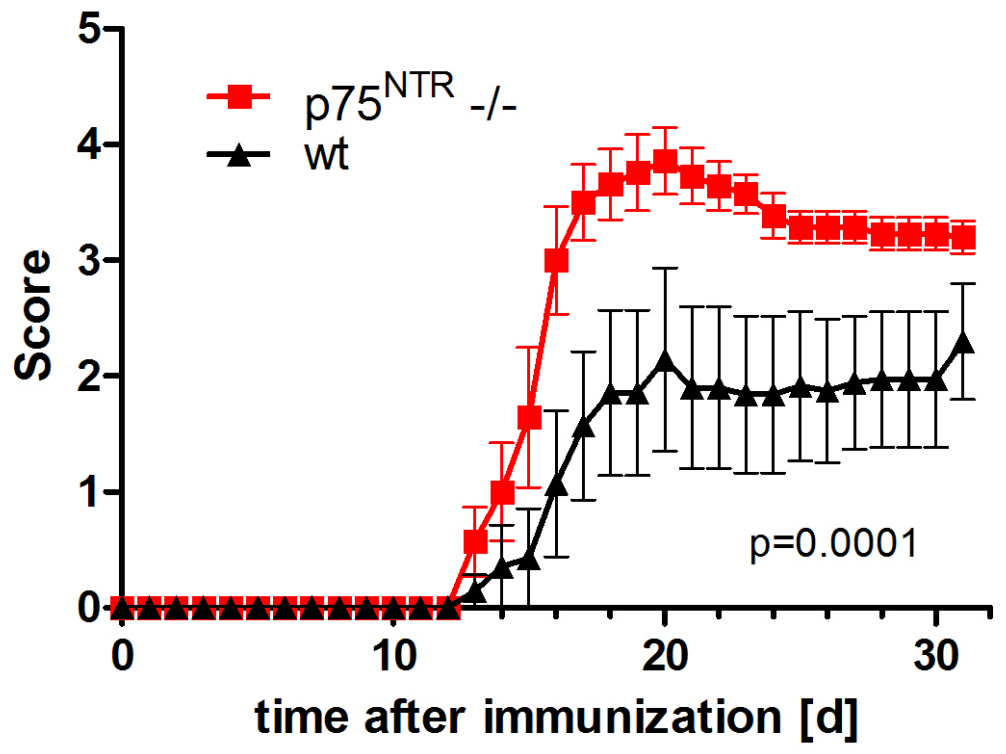

Fig. 3.1 I Disease course
of $\mathbf{p} 75^{\mathrm{NTR}}-/-$ and wt mice
after active immunization.
Significantly higher scores for
p $75^{\mathrm{NTR}}-/-$ mice during the
entire experiment. 


\subsubsection{Increased demyelination in $\mathrm{p}^{\mathrm{NTR}} \mathrm{N}^{\mathrm{NT}}$ - mice after active immunization}

The demyelinated white matter area was measured. In the chronic disease stage after active immunization the extent of demyelination within the spinal cord was higher in p75 ${ }^{\mathrm{NTR}}$-/- mice (p75 $5^{\mathrm{NTR}}-/-9.39+/-3.24 \%$, wt $5.84+/-3.35 \%, \mathrm{p}<0.05$ ) (Fig. 3.2), reflecting the more severe disease course of these mice. However, the density of mature, myelinating oligodendrocytes in the lesions (as indicated by NogoA immunohistochemisry) was similar $\left(\mathrm{p} 75^{\mathrm{NTR}}\right.$-/- $173+/-46$ cells $/ \mathrm{mm}^{2}$, wt $157+/-56$ cells $\left./ \mathrm{mm}^{2}, \mathrm{p}=0.6\right)$, giving no support for an enhanced vulnerability or impaired recruitment of oligodendrocytes in $\mathrm{p} 75^{\mathrm{NTR}}-/-$ mice (Fig. 3.3).
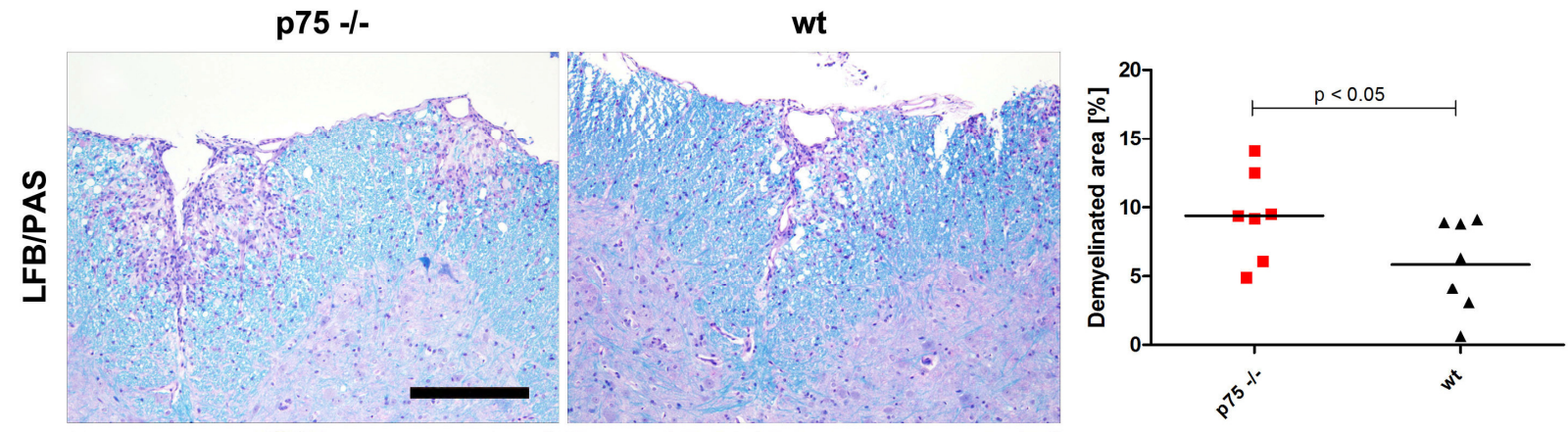

Fig. 3.2 | Demyelination in the chronic disease stage after active immunization.

LFB/PAS staining of spinal cord cross sections showed larger demyelinated areas within the white matter in p $75^{\text {NTR }}$-/- mice. The graph displays the percentage of demyelinated white matter. Scale bar $=200 \mu \mathrm{m}$

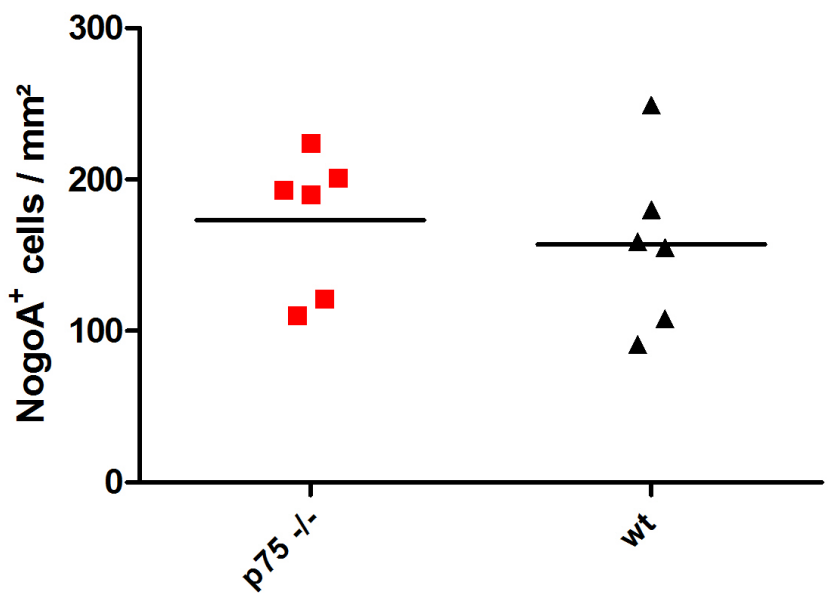

Fig. 3.3 | Oligodendroglial damage in the chronic disease stage after active immunization.

No difference in the density of mature NogoA $^{+}$oligodendrocytes was observed. Scale bar $=100 \mu \mathrm{m}$ 


\subsubsection{Quantification of inflammation: Increased meningeal B cell numbers in $\mathrm{p}^{\mathrm{NTR}} \mathrm{N}-\mathrm{-}$ mice after active immunization}

To assess the quantity of inflammation, cross sections of spinal cords in the chronic disease stage (dpi 36) were stained immunohistochemically. Similar numbers of Mac- $3^{+}$ macrophages/microglia $\left(\mathrm{p} 75^{\mathrm{NTR}}-/-952+/-130\right.$ cells $/ \mathrm{mm}^{2}$, wt $935+/-165$ cells $/ \mathrm{mm}^{2}, \mathrm{p}=$ $0.91)$ and $\mathrm{CD}^{+} \mathrm{T}$ cells $\left(\mathrm{p} 75^{\mathrm{NTR}}-/-192+/-54\right.$ cells $/ \mathrm{mm}^{2}$, wt $242+/-129$ cells $/ \mathrm{mm}^{2}, \mathrm{p}=0.37$ ), but increased numbers of B220/CD45R $\mathrm{R}^{+} \mathrm{B}$ cells within the meninges (p75 $5^{\mathrm{NTR}}-/-3.29+/-2$ cells $/ \mathrm{mm}$ meninges, wt $0.86+/-0.7$ cells $/ \mathrm{mm}$ meninges, $\mathrm{p}=0.01$ ) were counted in $\mathrm{p} 75^{\mathrm{NTR}}-/-$ mice (Fig. 3.4).
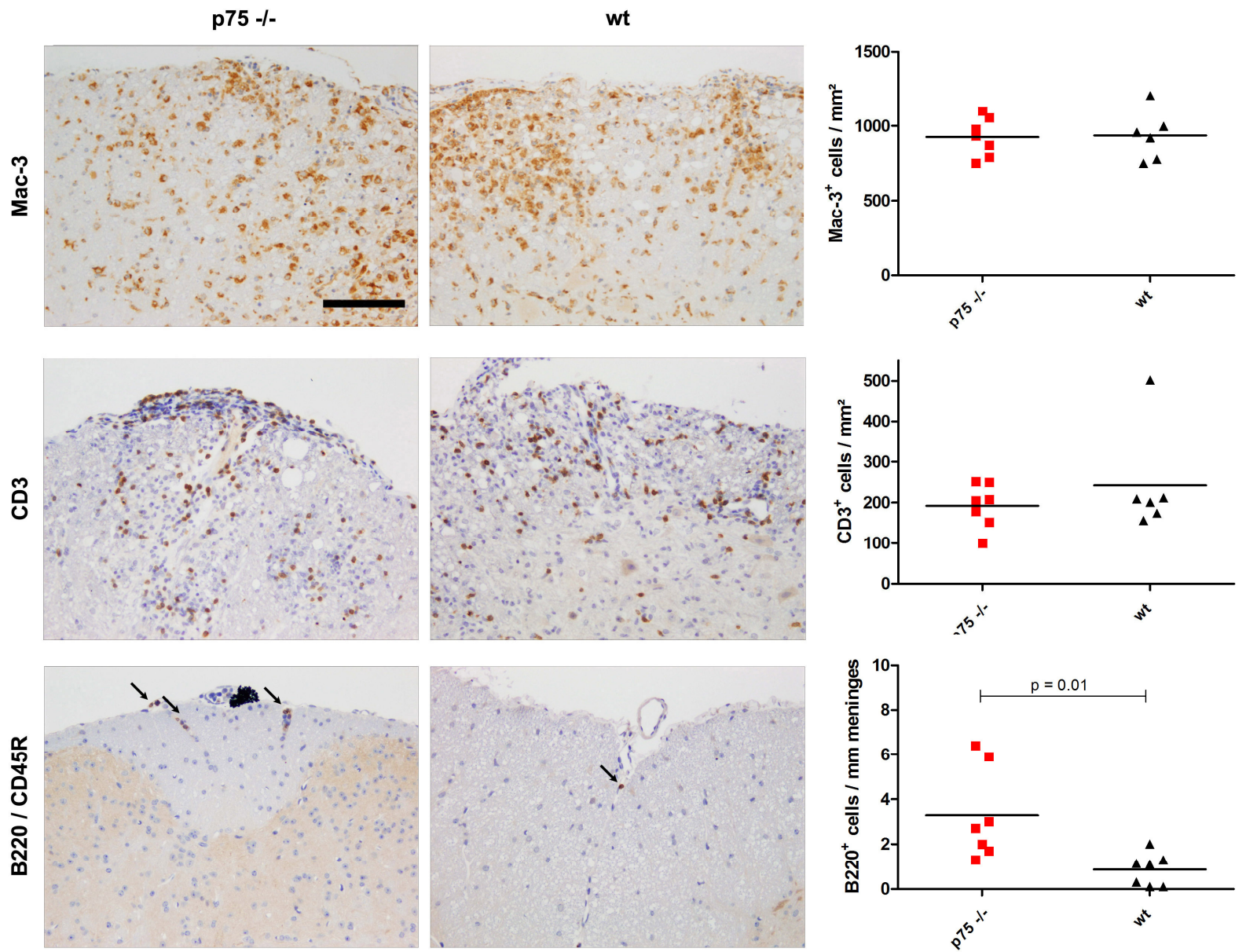

Fig 3.4 I Inflammatory CNS infiltration in the chronic disease stage after active immunization.

Immunohistochemical stainings of spinal cord cross sections revealed similar densities of Mac- $3^{+}$ macrophages/microglia and $\mathrm{CD}^{+} \mathrm{T}$ cells, but increased numbers of meningeal $\mathrm{B} 220 / \mathrm{CD}_{4} 5 \mathrm{R}^{+} \mathrm{B}$ cells in p $75^{\text {NTR }}-/-$ mice. Scale bar $=100 \mu \mathrm{m}$ 


\subsubsection{Neuronal damage and regeneration: Increased axonal loss in p75 ${ }^{\mathrm{NTR}}$-/- mice after active immunization}

The accumulation of axonally transported amyloid precursor protein (APP) was used as an indicator for early axonal damage. Healthy neurons express APP constitutively and deliver it to the presynapse via fast axonal transport. In acutely damaged axons this transport is impeded resulting in accumulation of APP and formation of axonal swellings. This event occurs in the acute disease stage and is thought to be only in part reversible. In the chronic disease stage acute axonal damage plays a minor role, but the degree of axonal damage is more precisely reflected by axonal loss. No differences were observed in the density of $\mathrm{APP}^{+}$ axonal spheroids within chronic lesions (p75 $5^{\mathrm{NTR}}-/-198+/-54$ spheroids $/ \mathrm{mm}^{2}$, wt $222+/-65$ spheroids $/ \mathrm{mm}^{2}, \mathrm{p}=0.48$ ) (Fig. 3.5). However, axonal density was significantly lower within lesions in $\mathrm{p} 75^{\mathrm{NTR}}-/-$ mice compared to wt mice (p75 ${ }^{\mathrm{NTR}}-/-22.5+/-1.6 \%$, wt $27.6+/-2.1 \%$, $\mathrm{p}$ $=0.0004)$. The extent of axonal loss was calculated in relation to the axon density in the normal appearing white matter (set at 100\%).
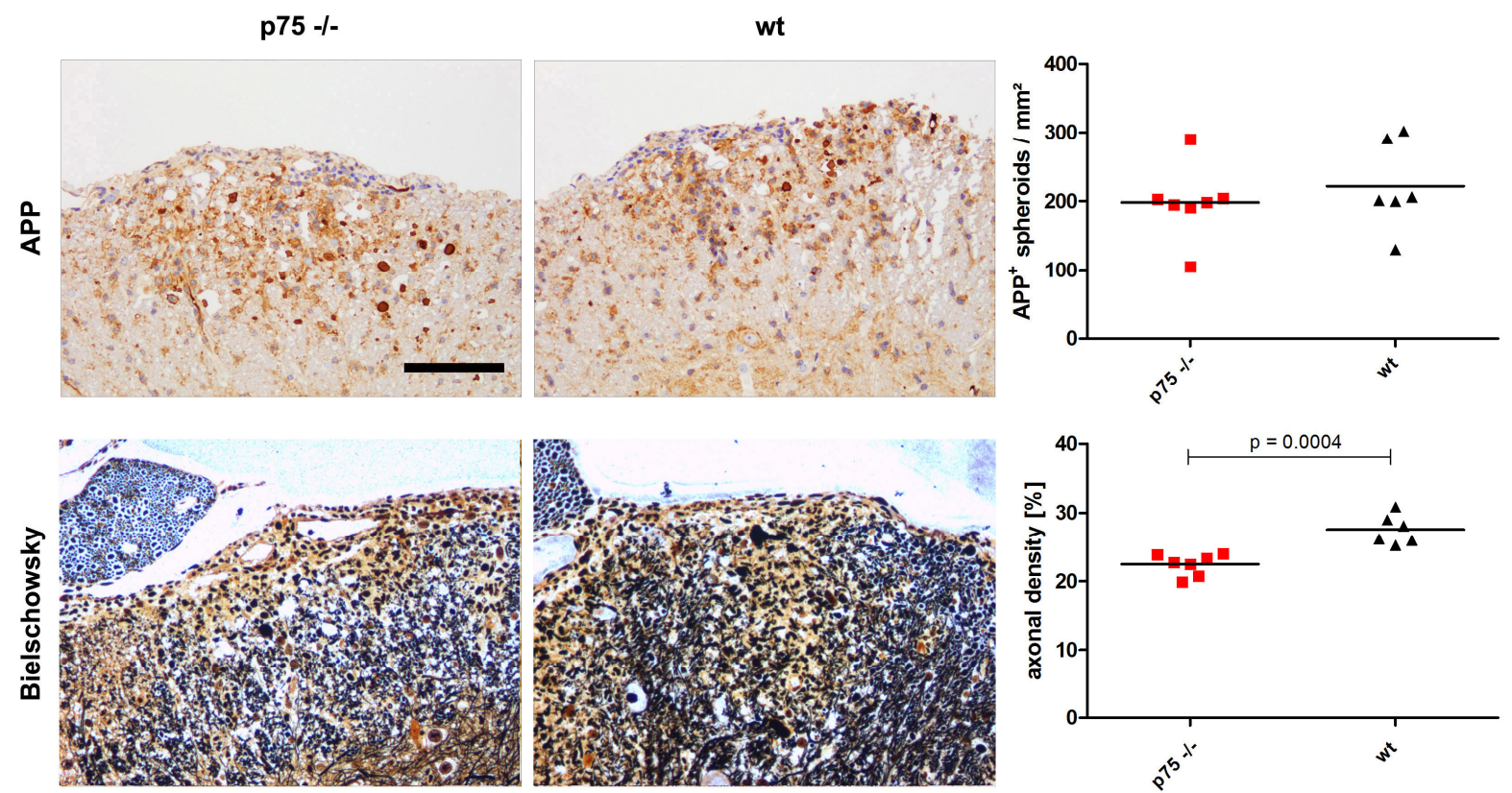

Fig. 3.5 | Axonal damage and loss in the chronic disease stage after active immunization.

Immunohistochemical stainings of spinal cord cross sections showed similar densities of APP ${ }^{+}$axonal spheroids in p75 $75^{\text {TR }}$-/- and wt mice. Bielschowsky silver impregnation showed decreased axonal density in lesion areas of p $75^{\text {NTR }}$-/- mice and therefore increased axonal loss. Axonal density in the NAWM was set to $100 \%$ Scale bar = $100 \mu \mathrm{m}$ 
Neuronal damage was assessed by staining for hypophosphorylated heavy neurofilaments (NF-H), detected by the SMI35 antibody. After axonal transection, a neuronal reaction occurs leading to retrograde chromatolysis and accumulation of $\mathrm{SMI} 35^{+}$ neurofilaments in the neuronal cytoplasm (Fig. 3.6). No significant difference was observed (p75 ${ }^{\mathrm{NTR}}-/-0.84+/-0.86$ neurons/cross section, wt $0.52+/-0.73$ neurons/cross section, $\mathrm{p}=$ $0.52)$.

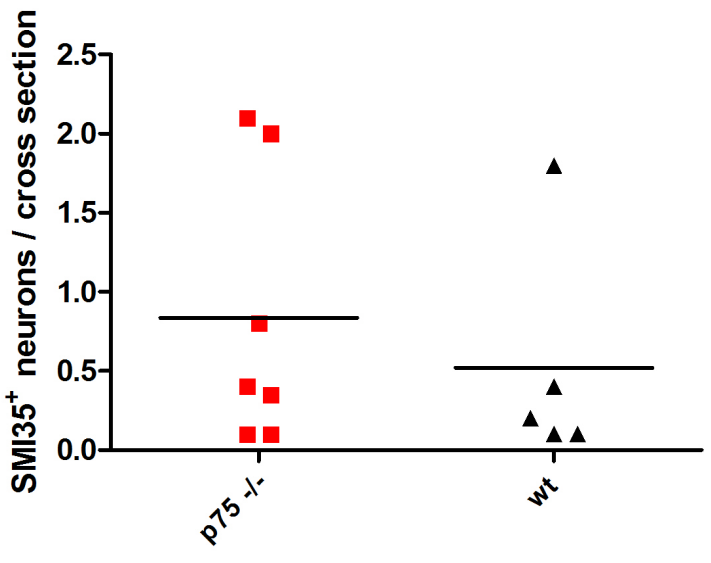

Fig. 3.6 | Neuronal damage in the chronic disease stage after active immunization.

Immunohistochemical stainings of spinal cord cross sections revealed similar numbers of damaged $\mathrm{SMI}^{+} 5^{+}$neuronal cell bodies indicating an accumulation of hypophosphorylated neurofilaments

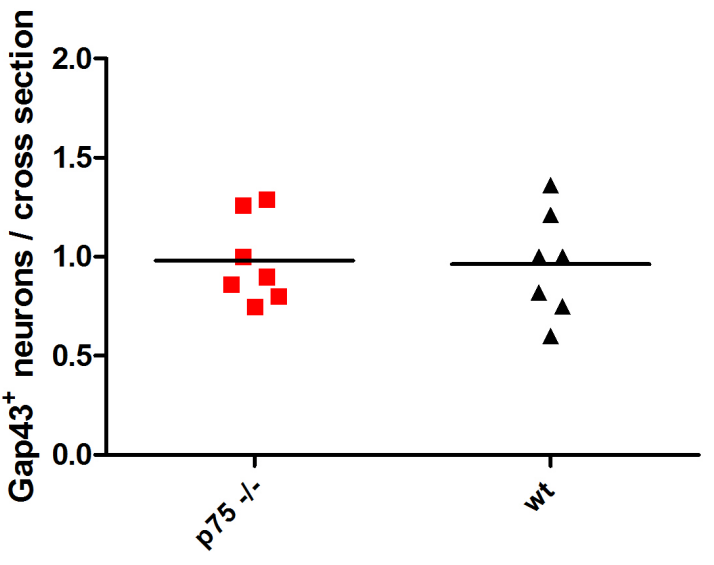

Fig. 3.7 I Neuroaxonal regeneration in the chronic disease stage after active immunization.

Immunohistochemical stainings of spinal cord cross sections revealed similar numbers of Gap43 ${ }^{+}$ neurons.

The capacity for neuroaxonal regeneration was analyzed by staining for growth associated protein 43 (Gap43). Gap43 is expressed by neuronal growth cones during axonal sprouting, but also in neuronal cell bodies after damage. No difference in the number of Gap $43^{+}$neurons was observed between wt $(0.96+/-0.22)$ and $\mathrm{p} 75^{\mathrm{NTR}}-/-$ mice $(0.98+/-0.26)$ at dpi $31(\mathrm{p}=0.9)($ Fig 3.7).

To assess whether the difference in axonal loss was paralleled by a difference in the extent of inflammation, I examined the quantity and quality of the immune response during different disease phases (onset, peak, chronic), during peripheral immune priming at various time points (dpi 3, dpi 7, dpi 10) and under naïve conditions in p $75^{\mathrm{NTR}}-/-$ and wt mice. 


\subsubsection{Quantity and quality of inflammation during peripheral priming and} during disease after active immunization in $\mathrm{p}^{\mathrm{NTR}}$-/- and wt mice

To examine whether any differences exist with regard to inflammation between wt and p $75^{\mathrm{NTR}}$-/- mice after active EAE induction, I studied the effect of p75 deficiency on cellular and molecular level in various immune cell populations in vivo, ex vivo, and in vitro.

\subsubsection{Inflammatory infiltrates in spinal cords at the peak of disease after active immunization in $\mathrm{p}^{\mathrm{NTR}}-/-$ and $\mathrm{wt}$ mice}

To confirm and extend our histological results and assess in more depth the populations of inflammatory cells infiltrating $\mathrm{p} 75^{\mathrm{NTR}}-/-$ and wt spinal cords at the peak of disease, spinal cords were collected at a score of 3.0 after active immunization with $\mathrm{MOG}_{35-55}$. $\mathrm{p} 75^{\mathrm{NTR}}-/-$ and wt animals were score-matched.
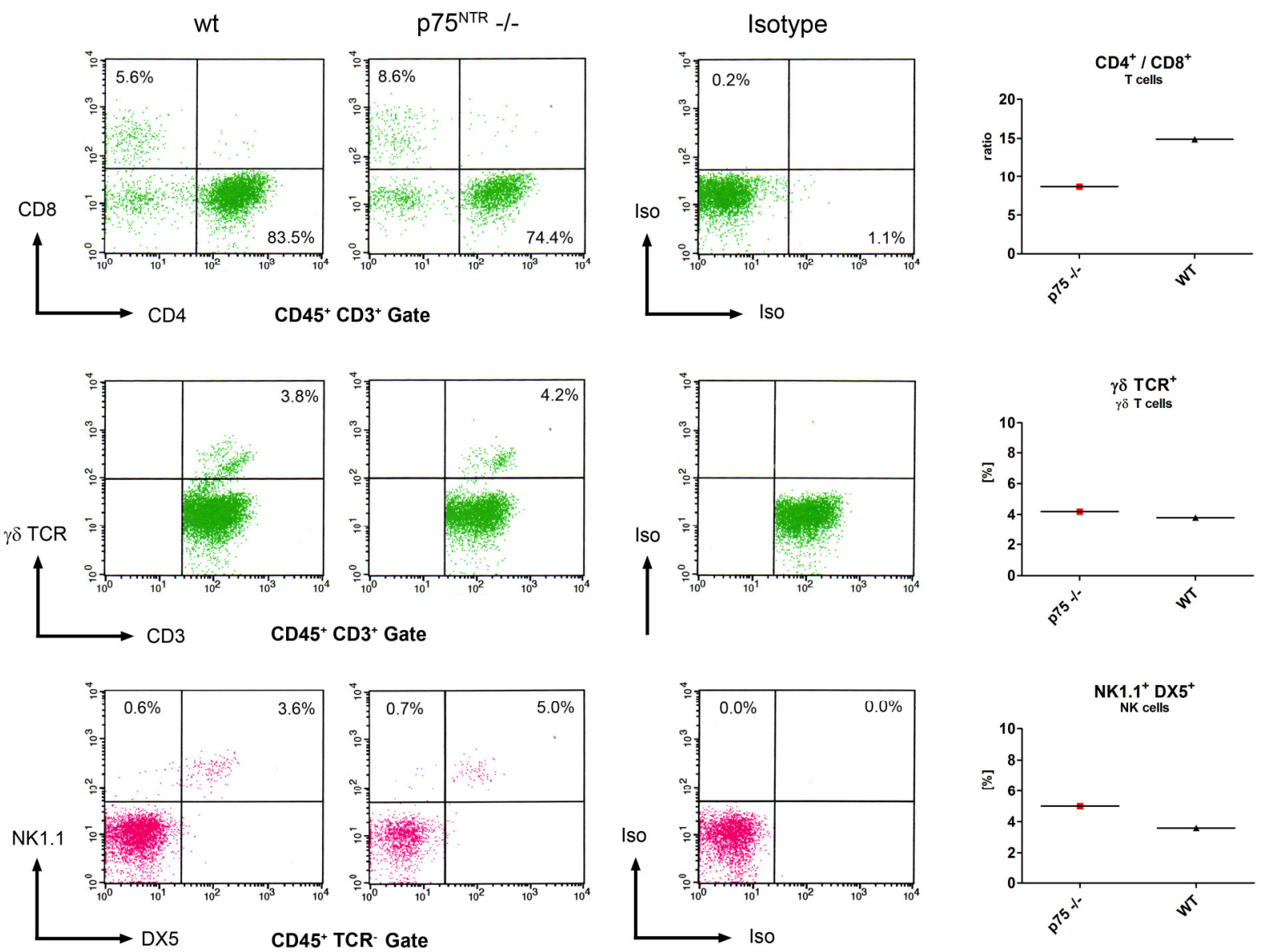

Fig. 3.8 | Flow cytometric analysis of T cell populations in EAE spinal cords at the peak of disease. No differences between $\mathrm{p} 75^{\mathrm{NTR}}$-/- and wt mice with regard to $\mathrm{CD} 4^{+}, \mathrm{CD} 8^{+}, \gamma \delta \mathrm{T}$ cell, and NK cell infiltration were observed. 
The numbers of infiltrating $\mathrm{CD}^{+} \mathrm{T}$ cells were about 10 -fold higher then those of $\mathrm{CD} 8^{+} \mathrm{T}$ cells (Fig. 3.8). Neither the $\mathrm{CD} 4^{+} / \mathrm{CD}^{+}$ratio nor the numbers of $\gamma \delta \mathrm{T}$ cells and NK cells were significantly different between $\mathrm{p} 75^{\mathrm{NTR}}-/-$ and wt mice.

$\mathrm{CD} 11 \mathrm{~b}$ is often used as a marker for infiltrating macrophages whereas $\mathrm{GR} 1^{+}$cells are often referred to as granulocytes. In fact, both markers are expressed by subsets of both cell types as well as CNS residential microglia (Geissmann et al., 2008; Mildner et al., 2007). To distinguish between macrophages/microglia and granulocytes, CD11 $\mathrm{b}^{+} \mathrm{GR}^{+}$cell numbers were checked for MHC class $\mathrm{II}^{\mathrm{hi}}$ and MHC class $\mathrm{II}^{\mathrm{lo}}$ expression (Fig. 3.9 A, B). About $15 \%$ of the flow cytometric analyzed immune cells were GR $1^{+}$inflammatory monocytes $\left(\mathrm{CD} 11 \mathrm{~b}^{+}\right.$ MHC class $\mathrm{II}^{\mathrm{hi}}$ ) and about $30 \%$ were granulocytes $\left(\mathrm{GR} 1^{+} \mathrm{CD} 11 \mathrm{~b}^{+} \mathrm{MHC}\right.$ class $\left.\mathrm{II}^{\mathrm{lo}}\right)$. The total number of all macrophages $\left(\mathrm{CD} 11 \mathrm{~b}^{+}\right.$MHC class $\left.\mathrm{II}^{\mathrm{hi}}\right)$ was by far the largest population of immune cells $(\sim 83 \%)$. No differences between $\mathrm{p} 75^{\mathrm{NTR}}-/$ - and wt mice were found. Activated macrophages and microglia can be distinguished by the expression level of the general leukocyte marker CD45. In both, p $75^{\mathrm{NTR}}-/-$ and wt mice, about $30 \%$ of the immune cells were $\mathrm{CD} 45^{\text {hi }} \mathrm{CD} 11 \mathrm{~b}^{+}$macrophages and another $30 \%$ were $\mathrm{CD} 45^{\text {lo }} \mathrm{CD} 11 \mathrm{~b}^{+}$microglia (Fig. $3.9 \mathrm{C}$ ). By gating on these two populations, their degree of MHC class II expression was assessed (Fig. 3.9 D, E). Expression of MHC class II molecules indicated by a fluorescence intensity histogram was $\sim 3$-fold higher in macrophages compared to microglia. However, no differences between $\mathrm{p} 75^{\mathrm{NTR}}-/-$ and wt were detected. 


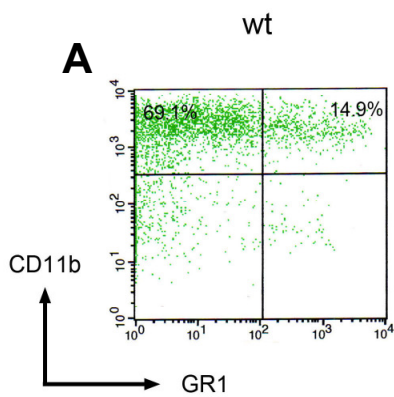

p $75^{\mathrm{NTR}}-/-$

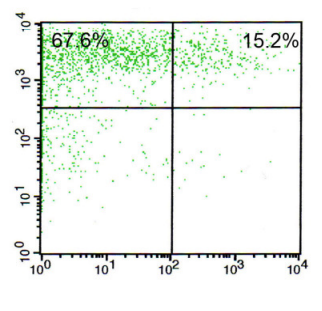

B
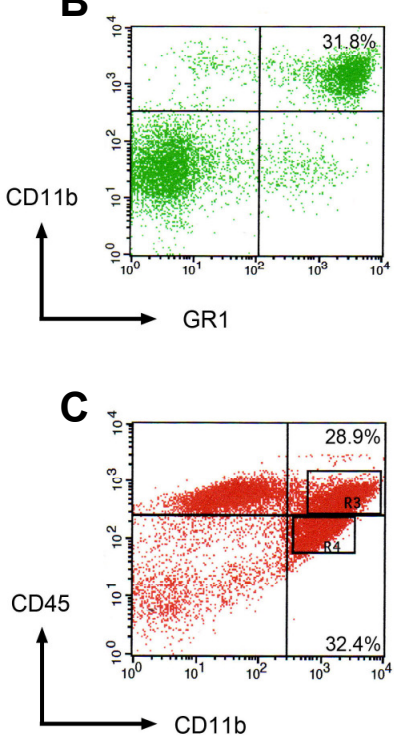

D
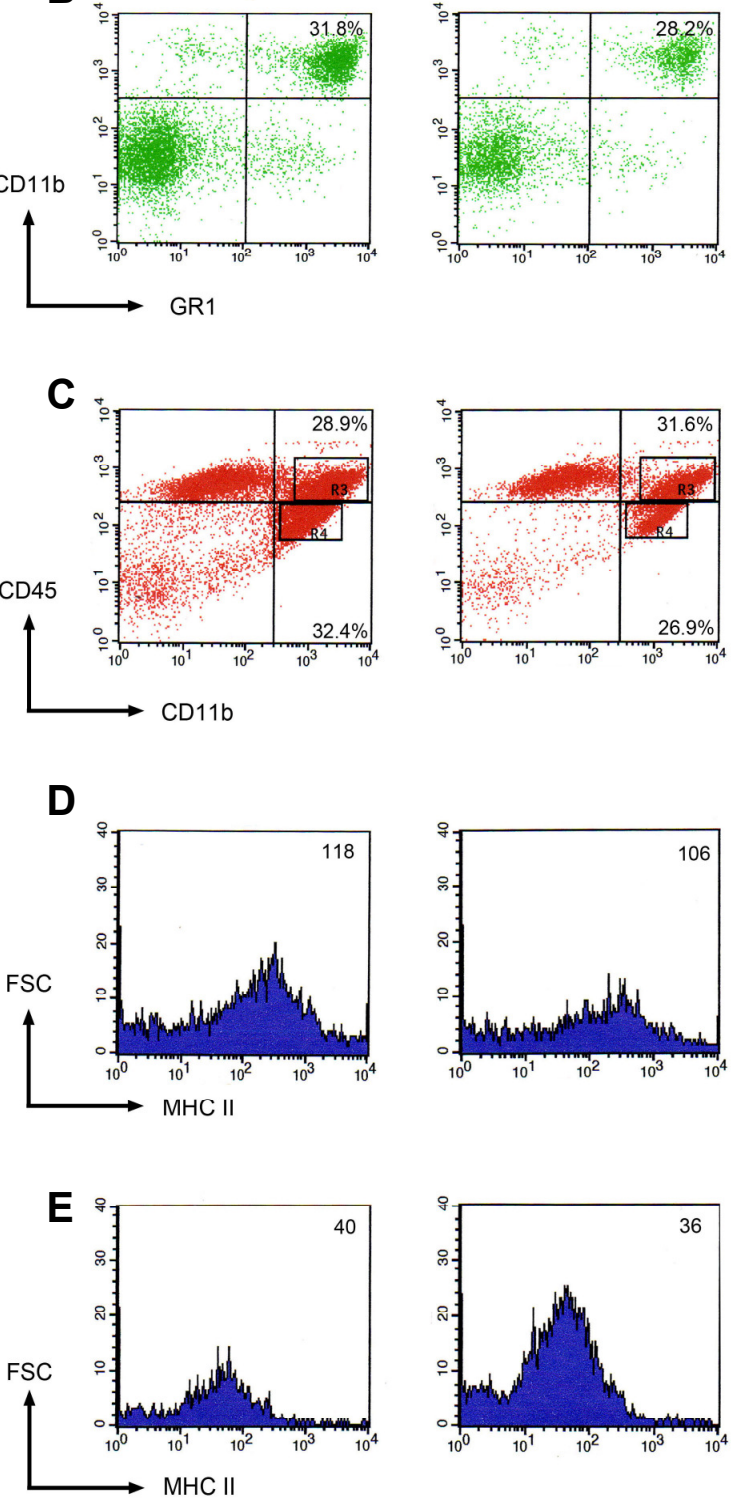
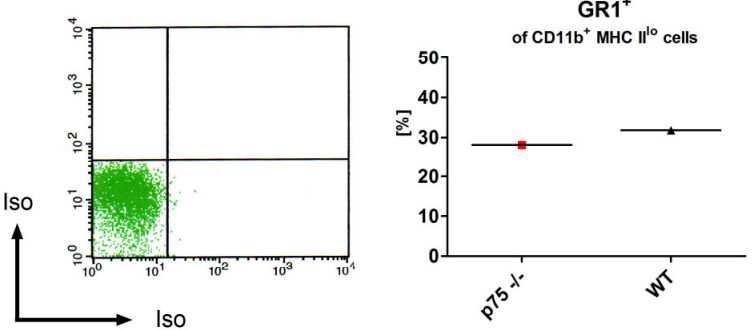

CD45 $5^{\text {lo }} / \mathrm{CD}^{\mathrm{h}} \mathrm{h}^{\mathrm{hi}}$

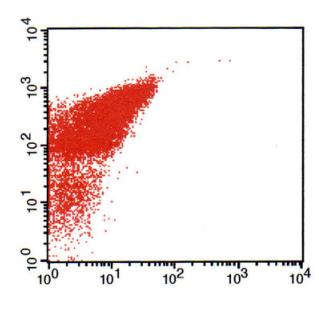

$\longrightarrow$ Iso
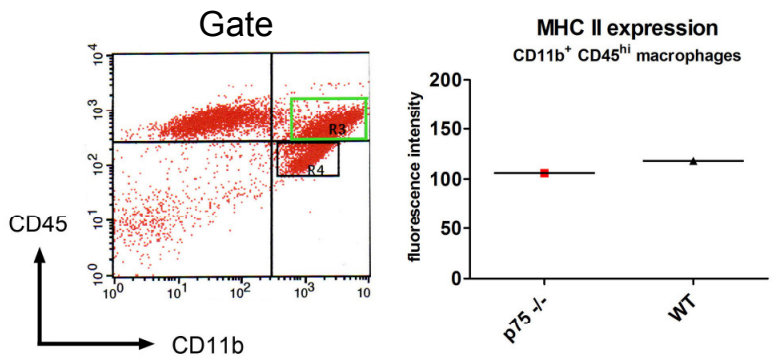

MHC II expression

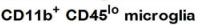

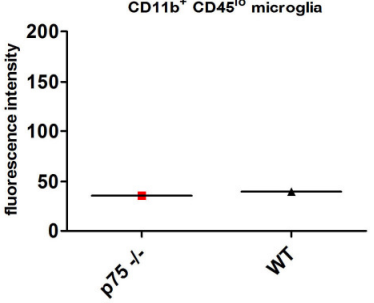

Fig. 3.9 | Flow cytometric analysis of $\mathrm{CD11}^{+}$cells in spinal cords at the peak of disease.

Similar cell counts for inflammatory monocytes (GR1 $1^{+}$CD11 $\mathrm{b}^{+}$MHC class $\left.\mathrm{II}^{\mathrm{hi}}\right)(\mathrm{A})$, granulocytes $\left(\mathrm{GR} 1^{+} \mathrm{CD} 11 \mathrm{~b}^{+}\right.$ MHC class $\left.I^{10}\right)(B)$, macrophages $\left(C D 11 b^{+} C D 45^{\text {hi }}\right)$, microglia $\left(C D 11 b^{+} C D 45^{10}\right)(C)$, and MHC class II expression on macrophages $(D)$ and microglia $(E)$ were found in $p 75^{\text {NTR }}-/-$ and wt mice. 


\subsubsection{Regulation of inflammatory related genes after active immunization in $\mathrm{p}^{75^{\mathrm{NTR}}}$-/- and wt mice}

To examine in more detail the quantity and quality of inflammation in $\mathrm{p} 75^{\mathrm{NTR}}-/-$ and wt mice after active immunization, I studied the expression of inflammation related genes at different time points after peripheral priming and disease onset. Specific TaqMan probes were used to detect mRNA of various chemokines (CCL2, CCL5, CXCL10) and cytokines (IL-1, IL-6) to determine the quality of inflammation. As indicators for $\mathrm{T}$ cell and macrophage/microglia cell numbers, transcripts of cell lineage markers (CD4, CD68) were utilized. Also other molecules of interest, such as NGF, inducible nitric oxide synthase (iNOS), which produces NO, and $\mathrm{p} 75^{\mathrm{NTR}}$ itself were analyzed. The aim of this analysis was to check which genes are regulated at which time points after EAE induction. Inflammation related gene regulations were also measured in the stage of peripheral priming, in which an immune response is generated in peripheral lymph nodes and in the spleen. The time point of this measurement was before disease onset at dpi 10 after immunization with $\mathrm{MOG}_{35-55}$ in CFA or CFA alone (as negative control), respectively. During disease, time points were disease onset (at a score of 0.5), early disease (score of 1.5), peak of disease (score of 3.0), and the chronic disease stage at dpi 35 (score of 2.0). p75 ${ }^{\mathrm{NTR}}-/$ - and wt mice were scorematched.

The $\Delta \mathrm{C}_{\mathrm{T}}$ value represents the number of cycles needed to detect a fluorescence signal significantly higher than the background signal in relation to the housekeeping gene GAPDH. The lower the $\Delta \mathrm{C}_{\mathrm{T}}$ value, the higher the mRNA amount within the sample, in this case the spinal cord.
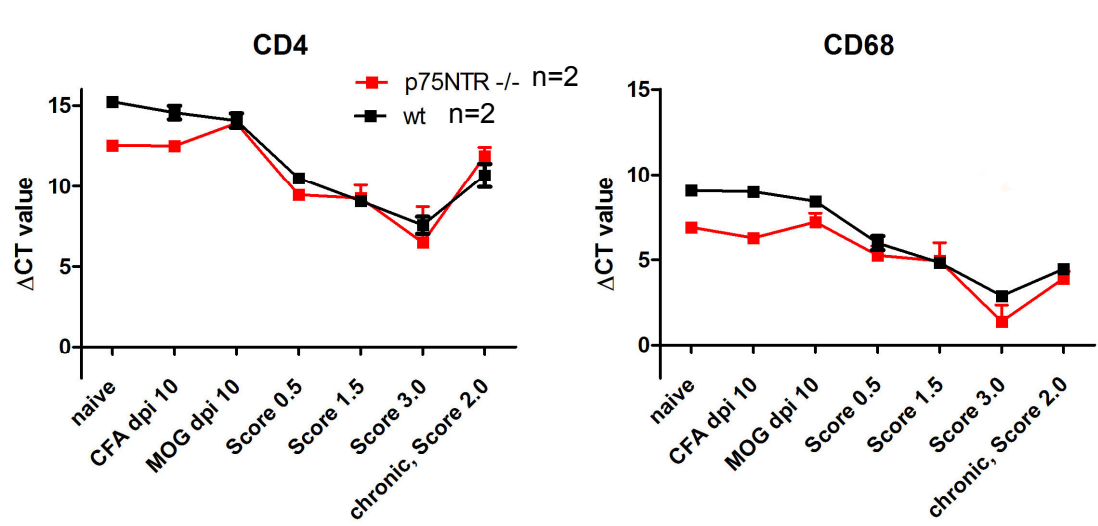

Fig. $\mathbf{3 . 1 0} \quad$ I Similar
expression of CD4 and CD68
in naïve and actively
immunized p75
wt mice.
Increasing CD4 and CD68
mRNA levels during disease
evolution represent macro-
phage/microglia and T cell
infiltration. In the chronic
disease stage inflammatory cell
numbers decrease.
differences between p75
(red) and wt (black) were
observed. 
The amounts of CD4 and CD68 mRNA within the spinal cords increased with disease evolution until the peak of disease (score 3.0), representing the quantity of infiltration by $\mathrm{T}$ cells and macrophages/microglia (Fig. 3.10). In the chronic disease stage the higher $\Delta \mathrm{C}_{\mathrm{T}}$ values indicate that the numbers of $\mathrm{T}$ cells and macrophages have decreased. The mRNA levels were similar in $\mathrm{p} 75^{\mathrm{NTR}}-/-$ and $\mathrm{wt}$ mice at all time points, showing that similar numbers of T cells and macrophages infiltrate the CNS in both mouse strains, when score-matched.

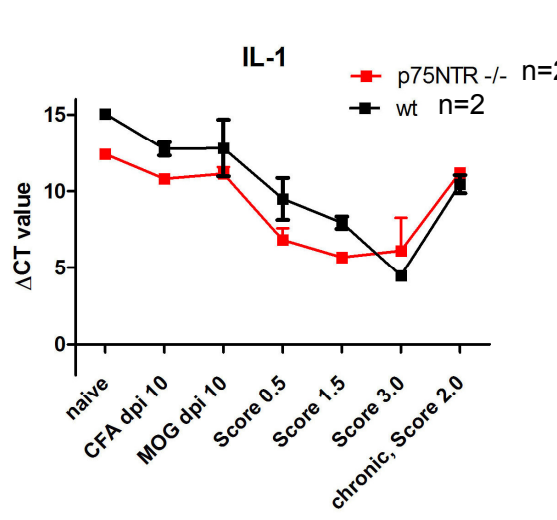

CCL2

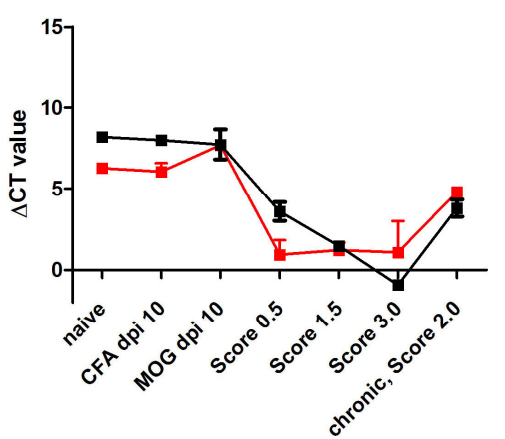

IL-6

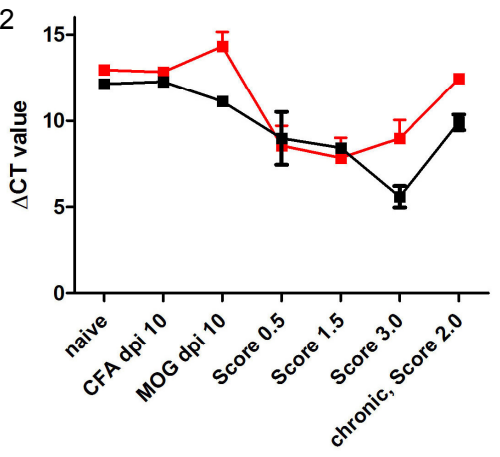

CCL5

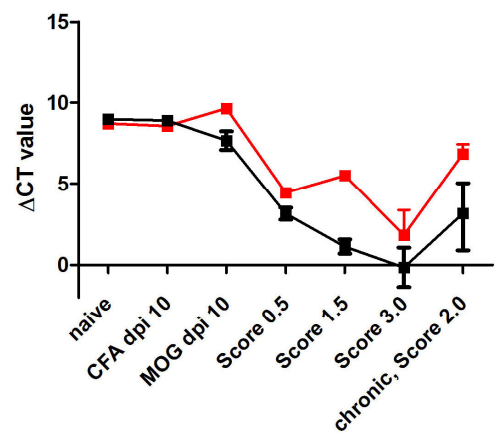

iNOS

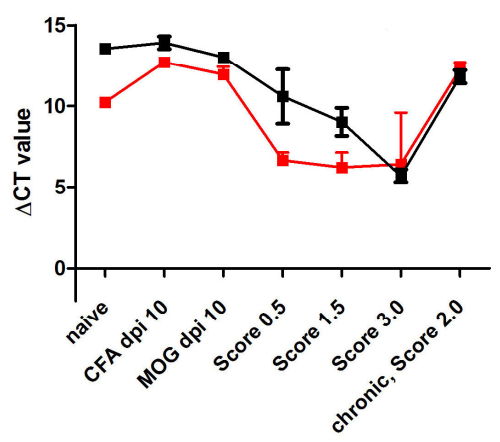

CXCL10

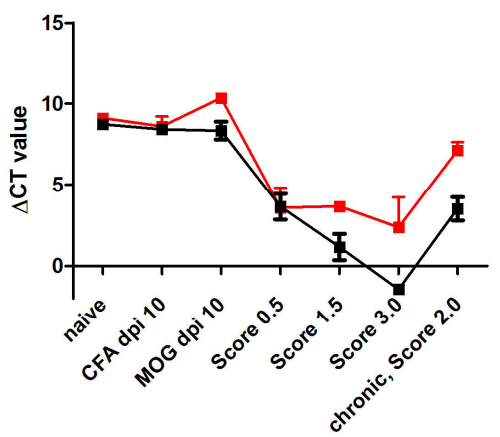

Fig. 3.11 | Expression of cytokines and chemokines in naïve and actively immunized mice.

Increased expression levels of cytokines and chemokines during disease evolution and reduced mRNA levels in the chronic disease stage. No differences in the expression of the examined cytokines and chemokines were observed. The lower the $\triangle \mathrm{CT}$ value, the higher the mRNA amount.

IL-1 and IL-6, which have proinflammatory properties in EAE, are strongly upregulated ( 17-fold) during disease (Fig 3.11). The IL-1 and IL-6 levels showed no significant differences. NO production, indicated by higher expression of iNOS, is boosted during EAE ( 12-fold increased). Similar expression of iNOS in $\mathrm{p} 75^{\mathrm{NTR}}-/-$ mice and wt was 
seen (Fig. 3.11). The chemokines CCL2, CCL5 and CXCL10 have proinflammatory properties and are strongly upregulated during EAE ( 18-fold) (Fig 3.11). No significant differences in chemokine expression were observed at any time point between $\mathrm{p} 75^{\mathrm{NTR}}-/-$ and wt mice.

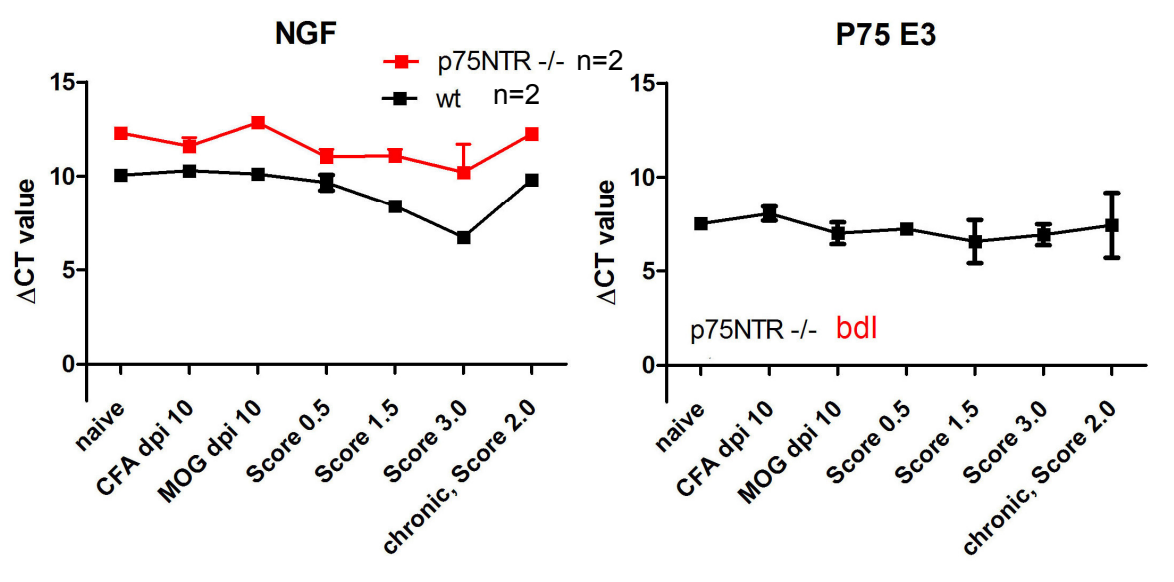

Fig. 3.12 | Expression of NGF and $p 75^{\text {NTR }}$ in naïve and actively immunized mice.

NGF expression is decreased at all time points in $\mathrm{p} 75^{\mathrm{NTR}}-/-$ (red) compared to wt (black) mice. $\mathrm{p} 75^{\mathrm{NTR}}$ expression is not regulated during EAE. The lower the $\triangle \mathrm{CT}$ value, the higher the mRNA amount.

NGF is upregulated during EAE with the highest expression at peak of disease (Fig. 3.12). In naïve lymph nodes, at dpi 10, during early disease evolution (score 1.5), and at the peak of disease (score 3.0) the mRNA levels of NGF are significantly lower in p $75^{\mathrm{NTR}}-/-$ compared to wt mice $(p=0.016) . p 75^{\text {NTR }}$ itself is not regulated during EAE $(p=0.33)$ (Fig. 3.12). Since an exon 3 specific p75 ${ }^{\mathrm{NTR}}$ TaqMan probe was used, no mRNA could be detected in the $\mathrm{p} 75^{\mathrm{NTR}}$ exon 3 deficient mice, validating the genotype on the mRNA level. 


\subsubsection{Leukocyte subpopulations in naïve and immunized lymph nodes of

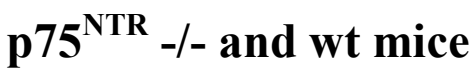

I performed a detailed four colour flow cytometry study of leukocyte subpopulations in the inguinal and axillary lymph nodes of $\mathrm{p} 75^{\mathrm{NTR}}$ deficient animals and wild type controls before and after immunization with $\mathrm{MOG}_{35-55}$. Specifically, I wanted to clarify, if differences in lymphocyte subpopulations were responsible for the earlier disease onset and more aggressive EAE disease course in $\mathrm{p} 75^{\mathrm{NTR}}$ deficient animals. Major leukocyte subpopulations were differentiated by their properties in forward (FSC) and side scatter (SSC) light, which reflect their size and granularity/internal complexity, respectively. The lymphocyte subpopulation is encircled in a correlated measurement of FSC and SSC in Fig. 3.13. Fluorescent antibodies against characteristic surface molecules were applied to further differentiate lymphocyte subsets.

Representative flow cytometry dot plots for CD4 and CD8 T cells (Fig. 3.14), $\gamma \delta \mathrm{T}$ cells (Fig. 3.15), NK and NK T cells (Fig. 3.16), regulatory $\mathrm{T}$ cells $\left(\mathrm{T}_{\text {regs }}\right)$ (Fig. 3.17), and B cells (Fig. 3.18) are depicted.

Since CD4 $\mathrm{T}$ cells are the key players in the pathogenesis of EAE, we started the analysis with this lymphocyte subset. We could not detect any difference in the ratio of $\mathrm{T}$ helper cells $\left(\mathrm{CD}^{+}\right)$to cytotoxic T cells $\left(\mathrm{CD}^{+}\right)$in naïve (Fig 3.14B: p75 $5^{\mathrm{NTR}}-/-1.45+/-0.05$, wt $1.3+/-0.19$ ) or immunized animals (Fig. 3.14C: p75 NTR $_{-/-} 1.36+/-0.16$, wt $1.27+/-0.1$ ).

$\gamma \delta \mathrm{T}$ cells have been shown to enhance autoimmunity by restraining $\mathrm{T}_{\text {reg }}$ responses (Petermann et al., 2010). We therefore analyzed the $\gamma \delta$ T cell subpopulation (Fig. 3.15 A, B) with similar frequencies of $\gamma \delta \mathrm{T}$ cells in naïve (p75 $5^{\mathrm{NTR}}-/-1.03+/-0.1$, wt $0.74+/-0.18$ ) (Fig. $3.15 \mathrm{C}$ ) and immunized animals (p75 $5^{\mathrm{NTR}}-/-0.87+/-0.23$, wt $1.15+/-0.2$ ) (Fig. $3.15 \mathrm{D}$ ) in both genotypes. 
A

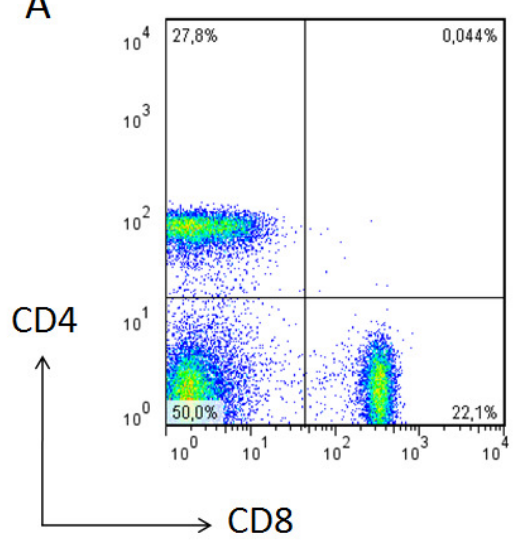

B

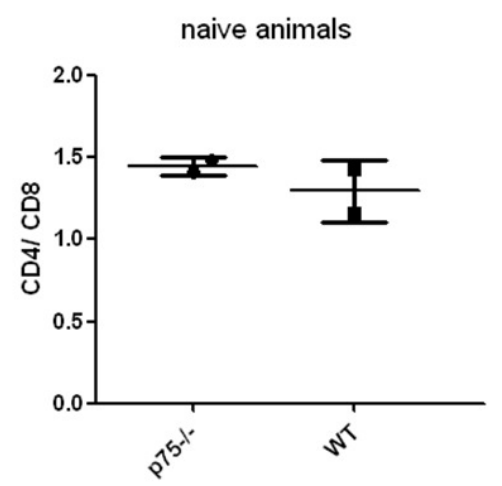

C $\mathrm{MOG}_{35-55}$ immunized animals

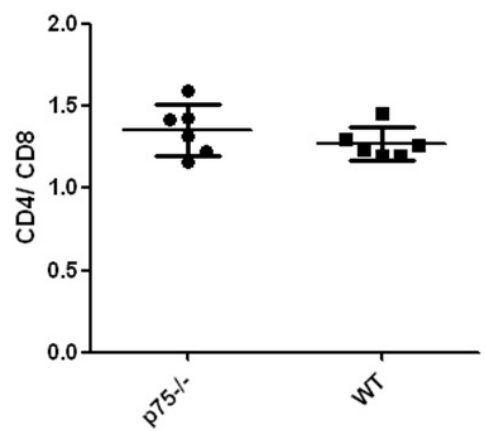

Fig. 3.14 I Flow cytometric analysis of $T$ helper and cytotoxic $T$ cell populations in naïve and immunized lymph nodes.

A representative $\mathrm{CD} 4 / \mathrm{CD} 8$ flow cytometry dot plot of lymph node cells is depicted in $A$. The cells were previously gated on the lymphocyte subpopulation by their FSC/SSC properties. The CD4/CD8 ratio did not differ between the genotypes in naive lymph nodes (B) nor after immunization with MOG $_{35-55}$ (C). Data are presented as mean +/- SD.

A

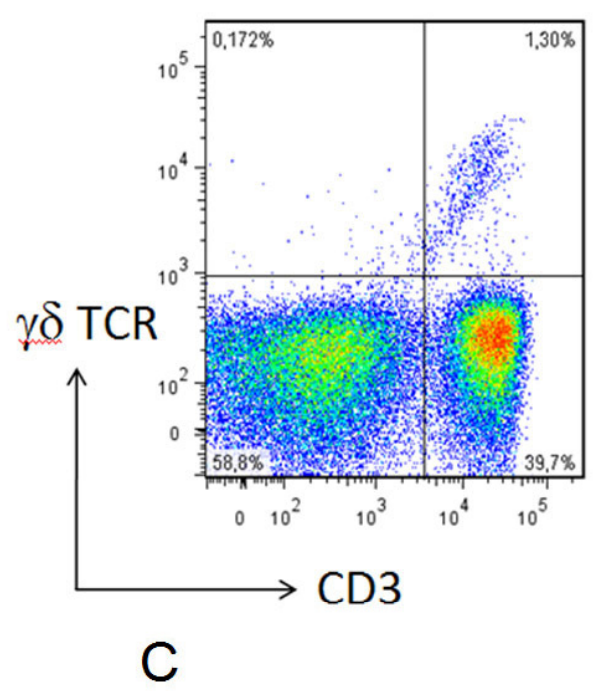

naive animals $\gamma \delta$ T cells

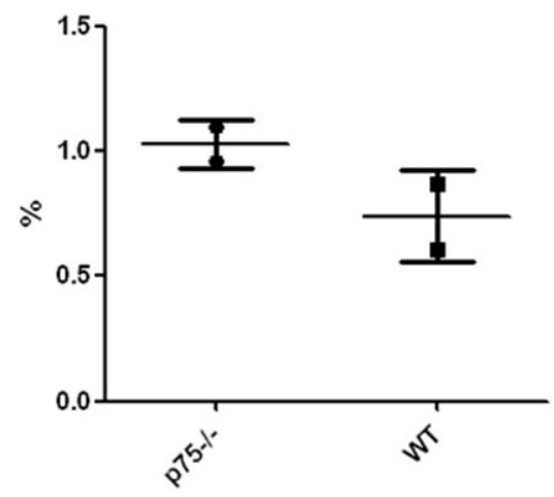

B

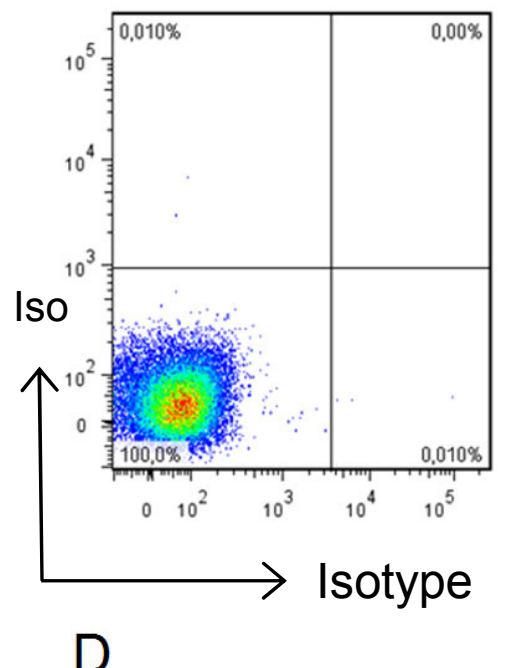

MOG $_{35-55}$ immunized animals:

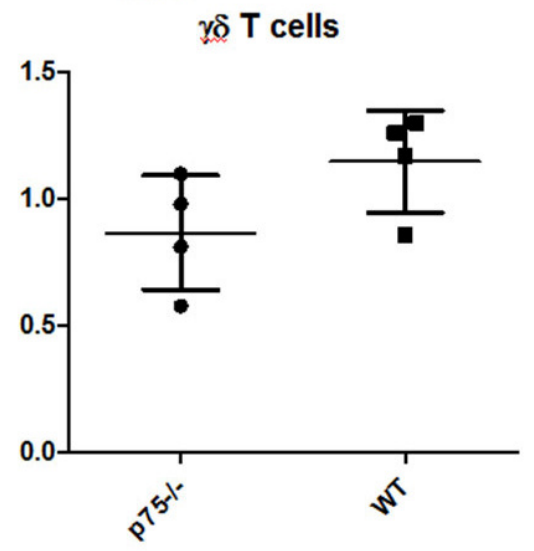

3.15 | Flow cytometric analysis of the $\gamma \delta \mathrm{T}$ cell population in naïve and immunized lymph nodes.

A representative $\gamma \delta$ TCR/CD3 flow cytometry dot plot of lymph node cells is depicted in A. The isotype control staining is shown in B. $\gamma \delta \mathrm{T}$ cells are expressed as percentage of total lymphocytes and did not differ between the genotypes in naive lymph nodes (C) nor after immunization with MOG $_{35-55}$ (D). 
The role of natural killer (NK) and NK T cells in autoimmunity has been studied in a number of animal models, among them EAE. Depletion of NK cells previous to EAE induction resulted in clinically more severe EAE (Zhang et al., 1997) and beneficial effects have been proposed for NK $\mathrm{T}$ cell activation at the time of $\mathrm{MOG}_{35-55}$ immunization (Singh et al., 2001). A typical staining for NK cells (NK1.1 $\left.{ }^{\text {hi }}, \mathrm{CD}^{\circ}{ }^{-}\right)$and NK T cells (NK1.1 ${ }^{\text {intermediate }}$, $\left.\mathrm{CD} 3^{\text {intermediate }}\right)$ is demonstrated in Fig. 3.16 A.
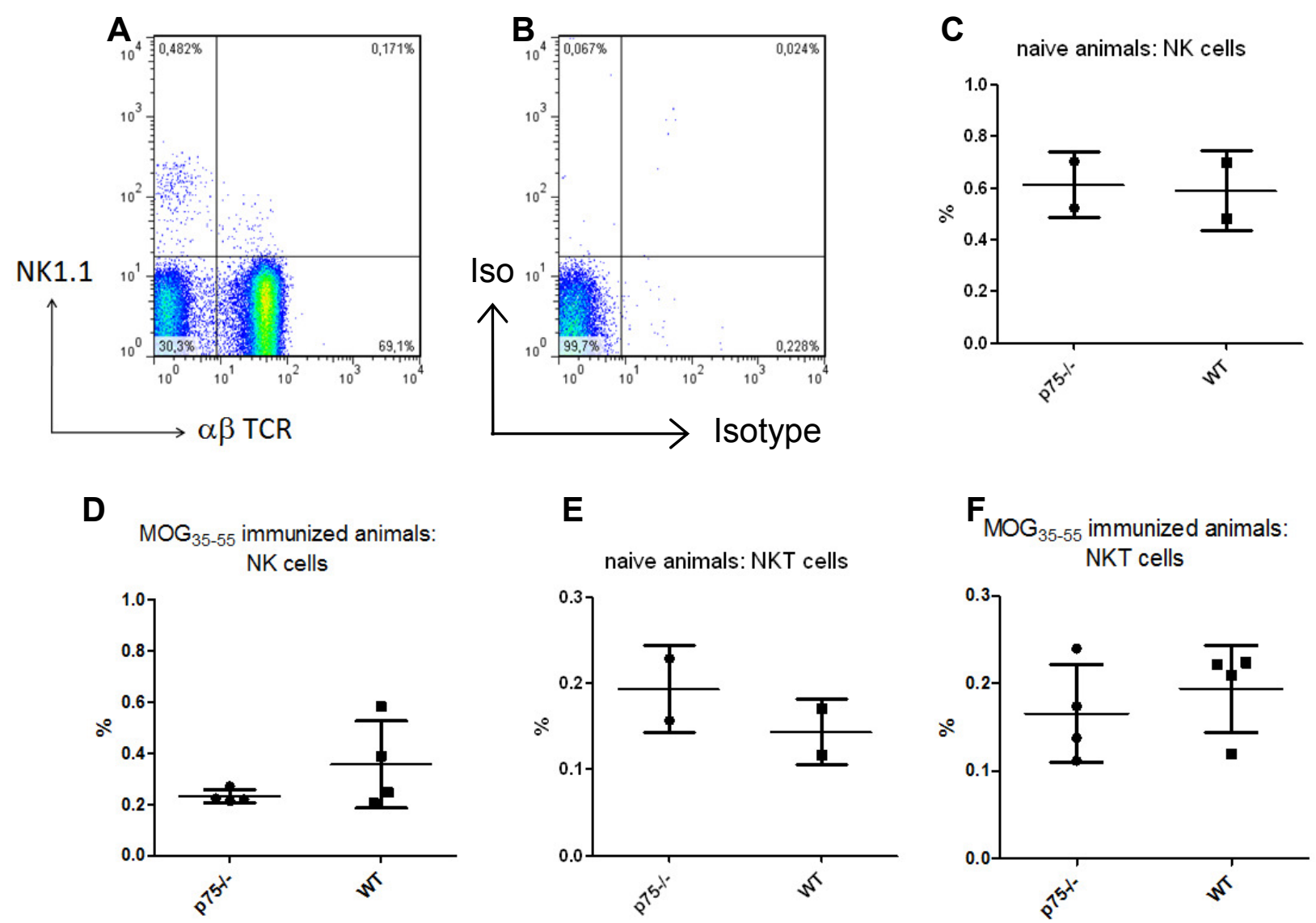

Fig. 3.16 I Flow cytometric analysis of NK cell and NK T cell populations in naïve and immunized lymph nodes.

A representative NK1.1/ $\alpha \beta$ TCR flow cytometry dot plot of lymph node cells is depicted in A, the isotype control panel is shown in B. NK (C, D) and NK T cells $(E, F)$ are expressed as percentage of total lymphocytes and did not differ between the genotypes in naive lymph nodes $(C, E)$ nor after immunization with MOG $_{35-55}(D, F)$.

The relative numbers of NK cells $\left(\mathrm{NK} 1.1^{\mathrm{hi}} \alpha \beta \mathrm{TCR}^{-}\right)$were similar in $\mathrm{p} 75^{\mathrm{NTR}}-/-$ and $\mathrm{wt}$ mice in naïve and immunized animals. (Fig. 3.16 C, D). Whereas the percentage of NK cells dropped after immunization (Fig 3.16 C, D), the frequency of NK T cells remained stable (Fig. 3.16 E, F). 
$\mathrm{p} 75^{\mathrm{NTR}}-/-$ and wt mice had comparable frequencies of NK T cells (NK1.1 ${ }^{\text {int }} \alpha \beta \mathrm{TCR}^{\mathrm{int}}$ ) in lymph nodes before and after immunization (Fig. 3.16 E, F).

Regulatory $\mathrm{T}$ cells $\left(\mathrm{T}_{\text {regs }}\right)$ were assessed due to their prominent function in regulating the proliferation and cytokine secretion of effector $\mathrm{T}$ cells. FoxP3, a forkhead/winged helix transcription factor is essential for the development and control of $\mathrm{T}_{\text {regs }}$ and can be detected with an intracellular staining as shown in Fig. 3.17.

A

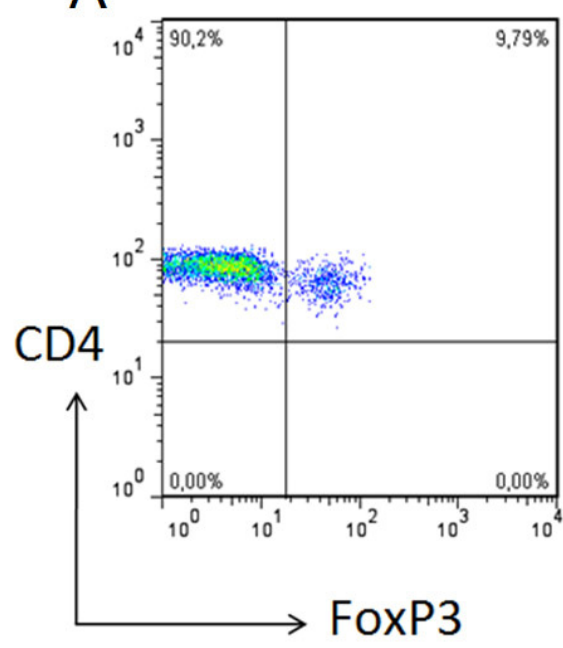

C

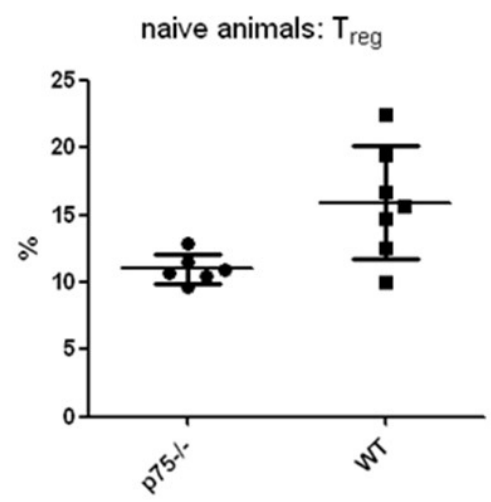

B

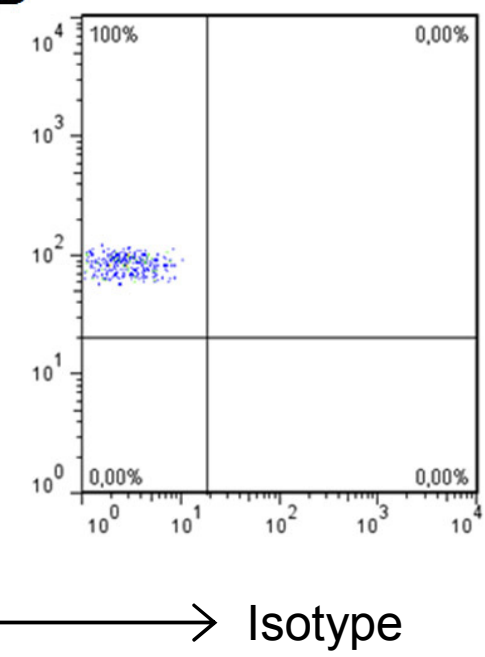

D MOG $35-55$ immunized animals: $T_{\text {reg }}$

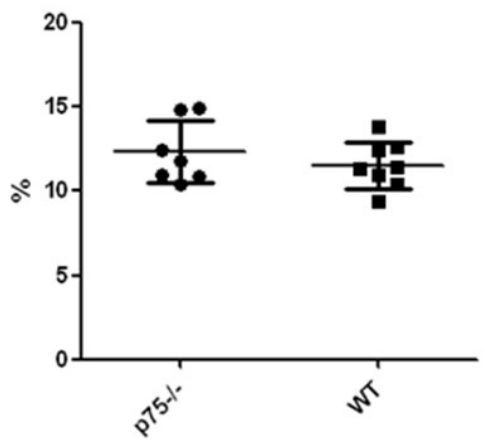

Fig. 3.17 | Flow cytometric analysis of the $T_{\text {reg cell }}$ population in naïve and immunized lymph nodes.

A representative intracellular staining against FoxP3 is shown in $A$ with the isotype control depicted in B. The cells analyzed for FoxP3 were previously gated on CD4 $T$ cells. The percentage of $\mathrm{FoxP3}^{+}$ cells refers therefore to the total number of CD4 positive $T$ cells and did not differ between the genotypes in naive lymph nodes (C) or after immunization with MOG $_{35-55}$ (D).

$\mathrm{p} 75^{\mathrm{NTR}}$ deficient mice had less $\mathrm{FoxP}^{+} \mathrm{T}$ regulatory cells in naive lymph nodes compared to wild type controls (p75 ${ }^{\mathrm{NTR}}-/-11.03+/-1.09$, wt $15.94+/-4.18$; p $=0,04$ ) (Fig. $3.17 \mathrm{C}$ ) but this difference did not persist after immunization with $\mathrm{MOG}_{35-55}\left(\mathrm{p} 75^{\mathrm{NTR}}-/-\right.$ $12.31+/-1.85$, wt 11.54 +/- 1.37; p =0,4) (Fig. 3.17 D). 
Finally, we analyzed the number and frequency of B cells in $\mathrm{p} 75^{\mathrm{NTR}}$ deficient mice by using an antibody against CD19.
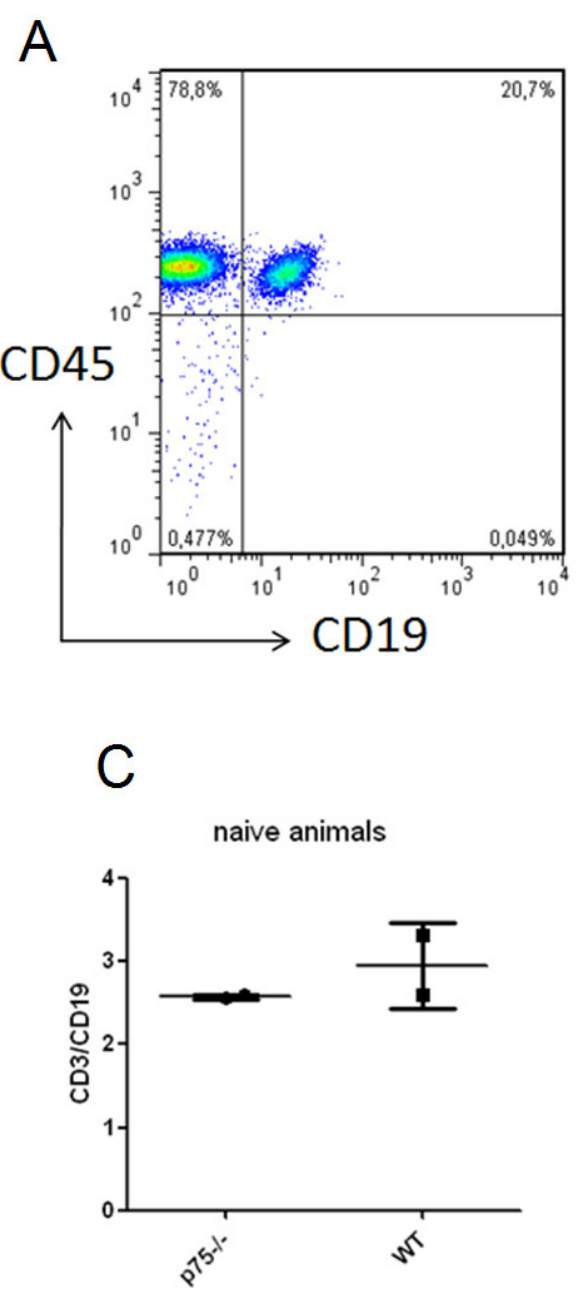

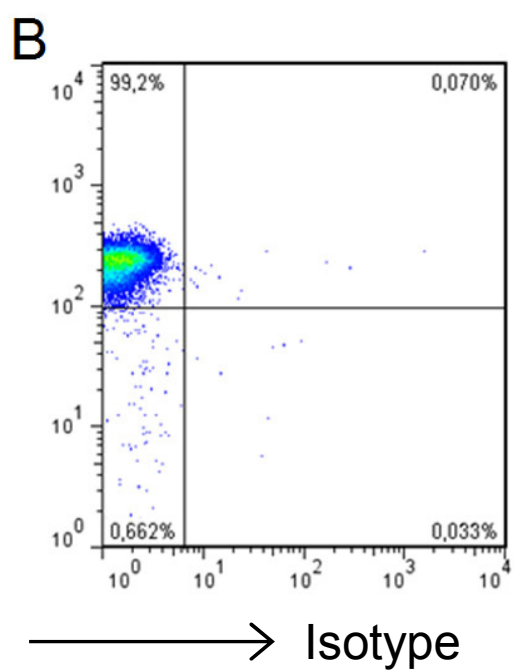

D

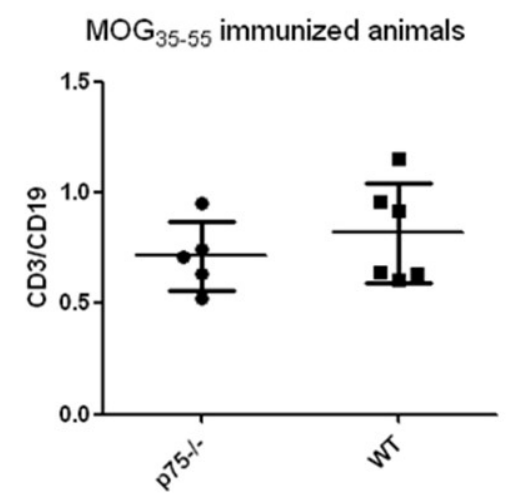

Fig. 3.18 I Flow cytometric analysis of the $B$ cell population in naïve and immunized lymph nodes.

A representative CD45/CD19 flow cytometry dot plot of lymph node cells is depicted in A. The cells were previously gated on the lymphocyte subpopulation by their FSC/SSC properties. B shows the isotype control. The ratio CD3/CD19 ratio did not differ between the genotypes in naive lymph nodes (C) nor after immunization with MOG $_{35-55}$ (D).

The ratio of T cells to B cells in naïve (p75 $5^{\mathrm{NTR}}-/-2.58+/-0.03$, wt $\left.2.91+/-0.51\right)$ and immunized lymph nodes ( $\mathrm{p} 75^{\mathrm{NTR}}-/-0.72+/-0.16$, wt $0.82+/-0.22$ ) was similar in $\mathrm{p} 75^{\mathrm{NTR}}-/-$ and wt animals (Fig. 3.18). Surprisingly, after immunization with $\mathrm{MOG}_{35-55}$ the $\mathrm{CD} 3 / \mathrm{CD} 19$ ratio decreased considerably. 


\subsubsection{Immunization response of lymph node cells to $\mathrm{MOG}_{35-55}$}

\subsection{No difference in the expression of $T$ cell activation and maturation markers in naïve and immunized lymph nodes of $\mathrm{p} 5^{\mathrm{NTR}}-/-$ and wt mice}

Next, we analyzed the activation status of CD4 T cells before and after immunization with $\mathrm{MOG}_{35-55}$ in the respective genotypes. We differentiated naïve T cells (CD44 ${ }^{\text {lo }}, \mathrm{CD} 62 \mathrm{~L}^{\text {hi }}$ ) from effector T cells $\left(\mathrm{CD} 44^{\mathrm{hi}}, \mathrm{CD} 6 \mathrm{~L}^{\mathrm{lo}}\right)$ with antibodies directed against CD44 and CD62L. A typical dot plot is depicted in Fig. 3.19. The percentage of CD4 T cells with an effector phenotype increased from around $4 \%$ to $8-9 \%$ at day 7 post immunization in both genotypes comparably (Fig 3.19).
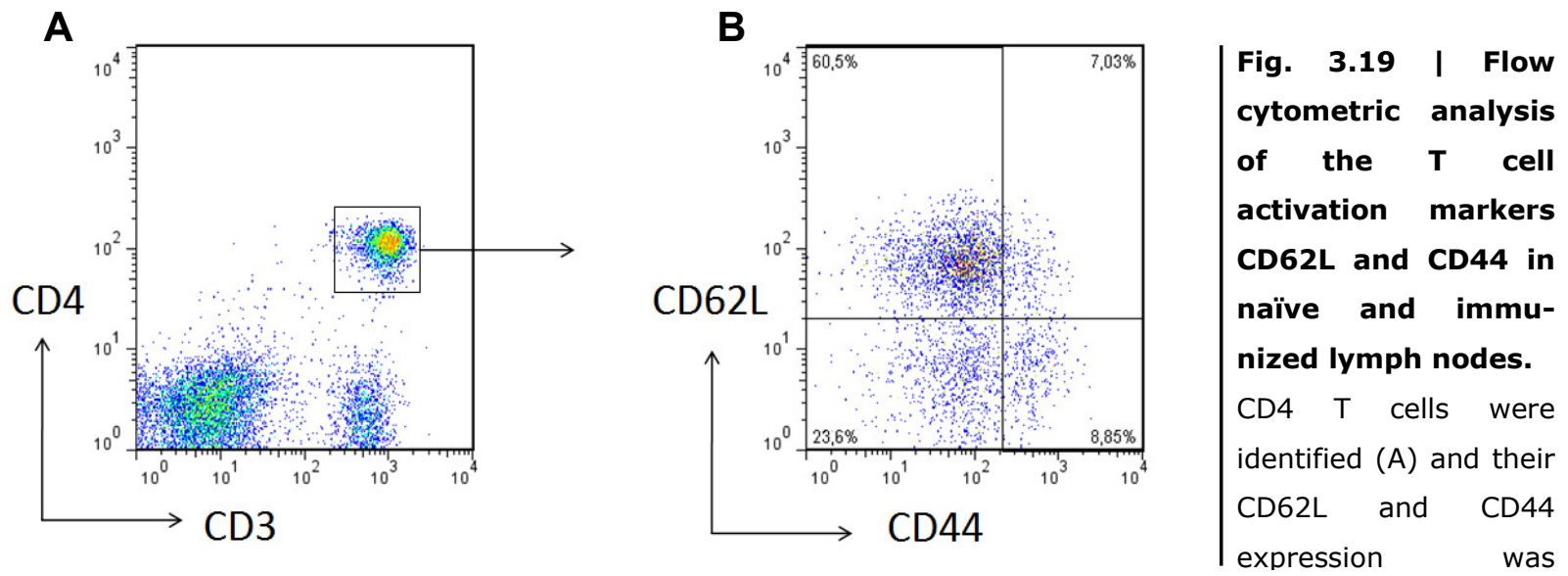

\begin{tabular}{|c|c|c|c|c|c|}
\hline & \multicolumn{2}{|c|}{$\mathrm{CD} 44^{1 \circ} \mathrm{CD} 6 \mathrm{~L}^{\mathrm{hi}}$} & \multicolumn{2}{|c|}{ CD44 $4^{\text {hi }}$ CD62L ${ }^{\text {lo }}$} & \multirow{4}{*}{$\begin{array}{l}\text { analyzed (B). The percentage of CD4 T cells } \\
\text { with an effector phenotype was significantly } \\
\text { higher at } d 7 \text { after immunization compared to } \\
\text { naïve mice }(n=2) \text {, but both genotypes } \\
\text { generated comparable CD4 effector } \\
\text { phenotype frequencies after MOG } \text { MO-55 }_{35} \\
\text { immunization. }\end{array}$} \\
\hline & wt & p75 ${ }^{\text {NTR }}-/-$ & wt & p75 $5^{\text {NTR }}-/-$ & \\
\hline Day 0 & $84.7+/-1.8$ & $84.4+/-0.8$ & $4.9+/-0.9$ & $4+/-0.4$ & \\
\hline Day 3 & $56.2+/-3.4$ & $60.4+/-3$ & $6.1+/-0.4$ & $4+/-0.1$ & \\
\hline Day 7 & $66.3+/-9.3$ & $60.5+/-0.4$ & $8.3+/-2.3$ & $8.9+/-0.1$ & \\
\hline
\end{tabular}


In naïve animals around 5\% of all CD4 T cells were positive for CD69, an early $\mathrm{T}$ cell activation marker. The percentage of CD69 positive CD4 T cells increased to $20.1 \%$ in wild type animals and $17.1 \%$ in $\mathrm{p} 75^{\mathrm{NTR}}$ deficient animals following immunization with $\mathrm{MOG}_{35-55}$ (Fig. 3.20).

A

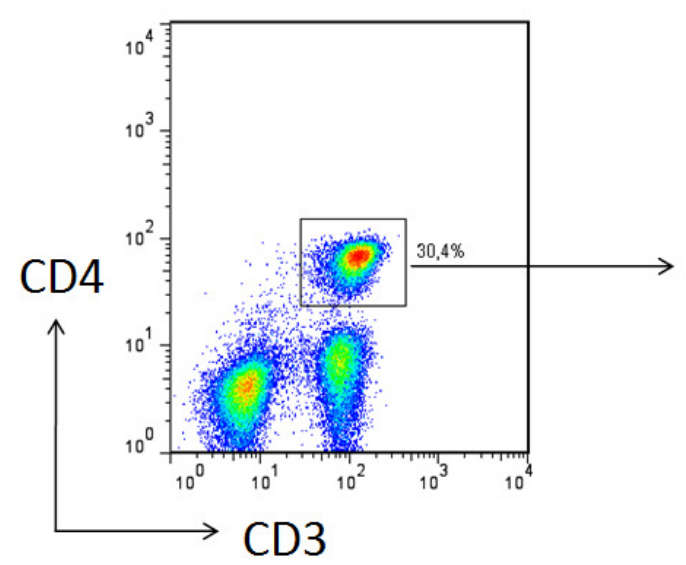

$\mathrm{CD}^{+} \mathrm{CD}^{+} 9^{+}$

\begin{tabular}{c|cc}
\cline { 2 - 3 } \multicolumn{2}{c}{ wt } & p75 \\
\hline Day 0 & $5.7+/-0.9$ & $5.3+/-0.1$ \\
Day 3 & $14.2+/-2,5$ & $15,4+/-0,9$ \\
Day 7 & $20.1+/-1$ & $17.1+/-3.4$
\end{tabular}

B

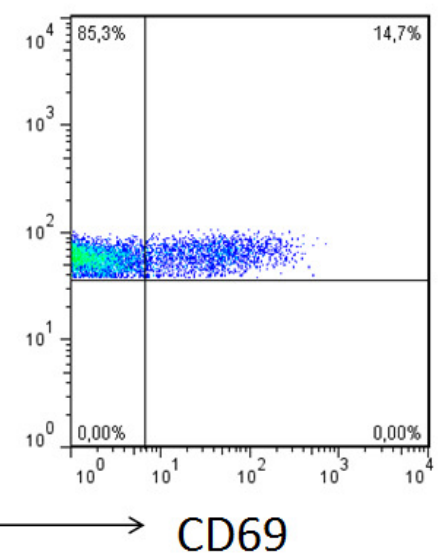

C

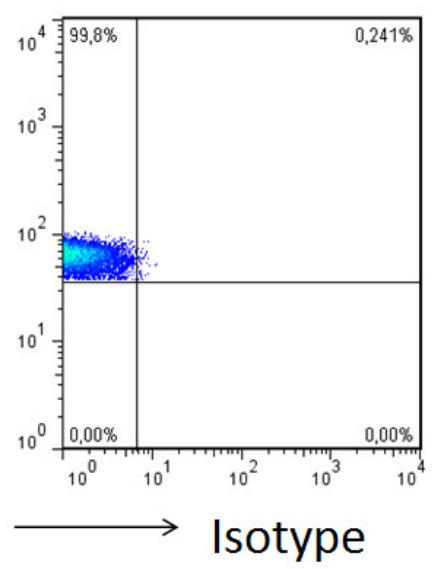

Fig. 3.20 | Flow cytometric analysis of the $\mathbf{T}$ cell activation marker CD69 in naïve and immunized lymph nodes.

A representative CD4/CD69 flow cytometry dot plot is depicted in B. First, CD4 T cells were identified by antibodies against CD4 and CD3 (A) and CD69 expression was subsequently analyzed on the CD4 T cell population (B). Isotype control staining for CD69 is shown in C. The number of CD69 positive CD4 $T$ cells increased after immunization in both genotypes comparably. $(n=2)$.

CD69 is expressed as one of the earliest activation markers by T cells. In non-inflamed lymph nodes the expression was moderate ( $5.5 \%$ ) (Fig. 3.20). After $\mathrm{MOG}_{35-55}$ immunization the number of $\mathrm{CD} 69^{+} \mathrm{T}$ cells increased ( $\sim 15 \%$ at dpi $3, \sim 18.5 \%$ at dpi 7$)$. The frequencies did not differ between $\mathrm{p} 75^{\mathrm{NTR}}$-/- and wt mice in naïve nor in immunized lymph nodes. 


\subsection{T cell adhesion molecules naïve and immunized lymph nodes of $\mathrm{p}^{\mathrm{NTR}} \mathrm{N}-/-$ and wt mice}

We analyzed adhesion molecules on CD4 $\mathrm{T}$ cells, which play a role in the $\mathrm{T}$ cell recruitment to the CNS. These included LFA-1 (CD11a/CD18), which is relevant for the transendothelial migration of encephalitogenic T cells to the CNS (Laschinger et al., 2002) and VLA-4 (CD29/CD49d) (Yednock TA et al.Nature 1992), which is the target of natalizumab, an approved monoclonal antibody therapy for active relapsing multiple sclerosis. Whereas CD11a was constitutively expressed on all lymph node $\mathrm{T}$ cells (Fig. 3.21), a comparable upregulation of $\mathrm{CD} 29$ after $\mathrm{MOG}_{35-55}$ immunization could be observed in both genotypes and is depicted in Fig. 3.22.

A

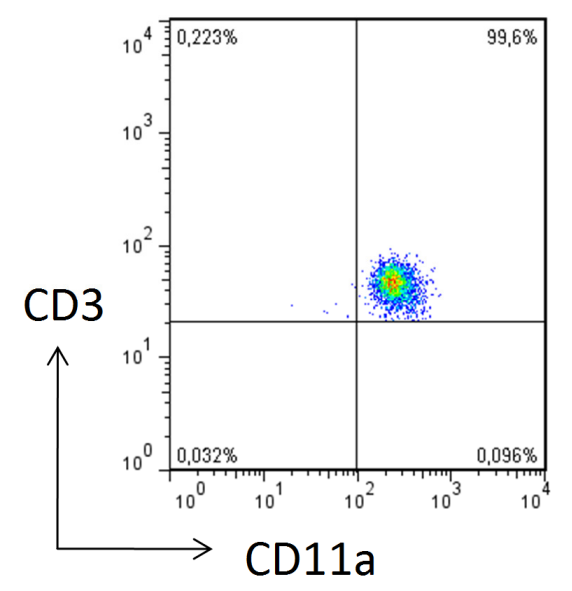

B

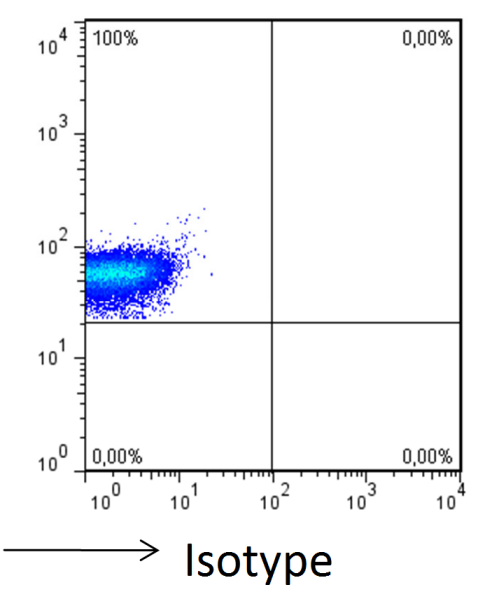

Fig. 3.21 I Flow cytometric analysis of the T cell adhesion molecule CD11a

A representative CD3/CD11a flow cytometry dot plot of lymph node cells is depicted in $A$. The cells were previously gated on CD3 T cells. B shows the isotype control. CD11a was constitutively expressed already in naïve animals and no further upregulation could be documented after immunization. $n=2$ 


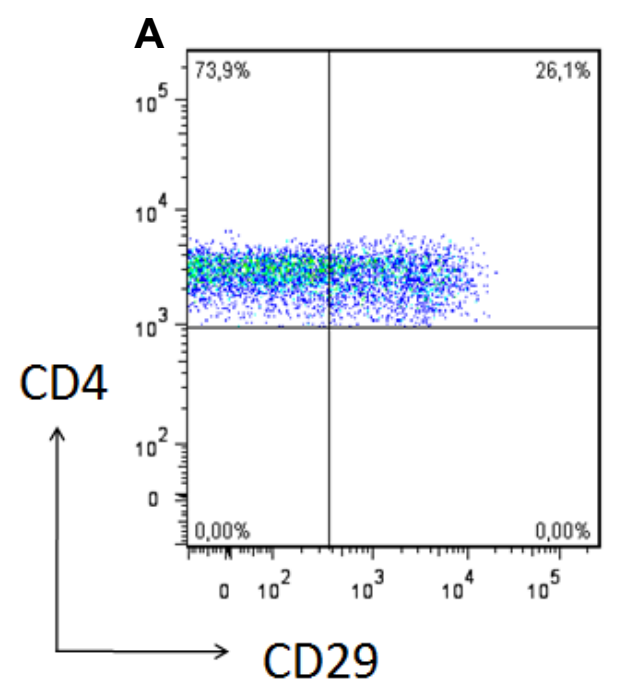

\begin{tabular}{c|cc}
\multicolumn{2}{c}{} & \multicolumn{2}{c}{ CD4 $^{+}$CD29 $^{+}$} \\
\cline { 2 - 3 } wt & p75 $^{\text {NTR }}-/-$ \\
\hline Day 0 & $3.9+/-0.5$ & $3+/-0.3$ \\
Day 3 & $13.7+/-7.4$ & $11.7+/-7.8$ \\
Day 7 & $22.8+/-4.8$ & $12.6+/-4.9$ \\
Day 10 & $29.8+/-5.2$ & $33.4+/-5.4$
\end{tabular}

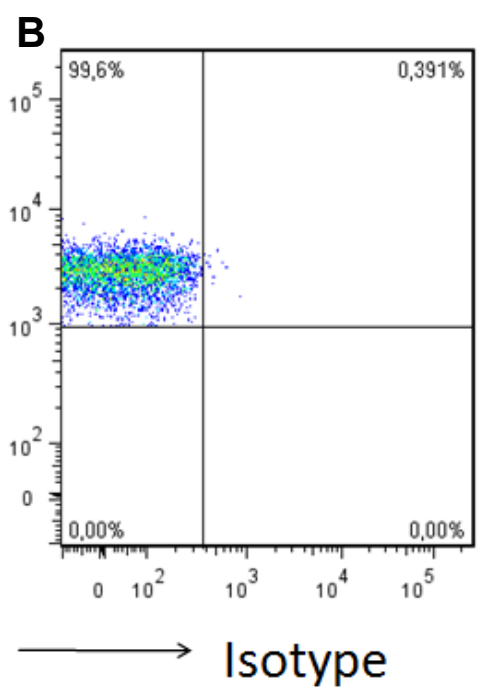

Fig. 3.22 | Flow cytometric analysis of the T cell adhesion molecule CD29

A representative CD4/CD29 flow cytometry dot plot of lymph node cells is depicted in $A$. The cells were previously gated on CD4 T cells. B shows the isotype control. CD29 is considerably upregulated after immunization. Whereas at day $7 \mathrm{p} 75^{\mathrm{NTR}}$ deficent mice have less CD4 T cells expressing CD29, at dpi 10 expression frequencies are comparable, suggesting that the difference at dpi 7 is not of biological relevance.

\subsection{Cytokine profile of $\mathrm{MOG}_{35-55}$ immunized $\mathrm{CD}^{+} \mathrm{T}$ cells in $\mathrm{p}^{\mathrm{TTR}}{ }^{\mathrm{NTR}}-\mathrm{-}^{-}$and $\mathrm{wt}$ mice}

Encephalitogenic CD4 $\mathrm{T}$ cells secrete $\mathrm{T}_{\mathrm{H}} 1$ or $\mathrm{T}_{\mathrm{H}} 17$ cytokines. We therefore determined the prototypic $\mathrm{T}_{\mathrm{H}} 1$ cytokine IFN $\gamma$ and the prototypic $\mathrm{T}_{\mathrm{H}} 17$ cytokine IL-17 after immunization with $\mathrm{MOG}_{35-55}$ on a single cell level by intracellular cytokine stainings. Regional lymph nodes were collected at dpi 3 and dpi 7 after immunization and the single cell suspensions were stimulated with PMA/Ionomycin at a concentration of $50 \mathrm{ng} / \mathrm{ml}$ in the presence of Golgi block for 6h. Unstimulated cells were kept on Golgi Block only. A representative flow cytometry dot plot is presented in Fig. 3.23 
A

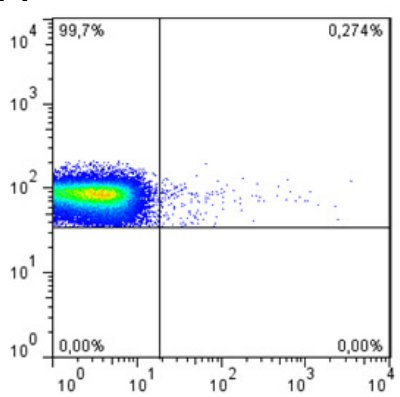

$\mathrm{B}$

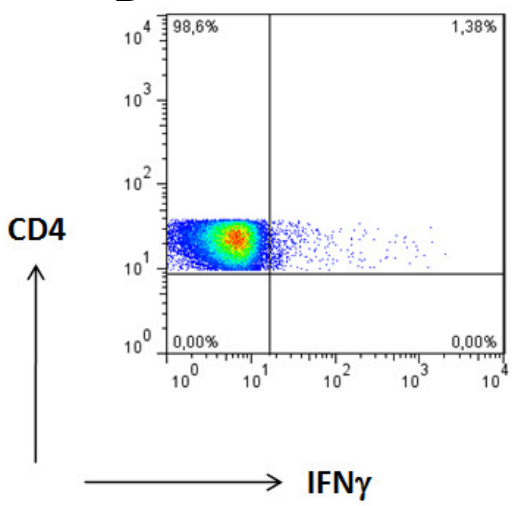

C

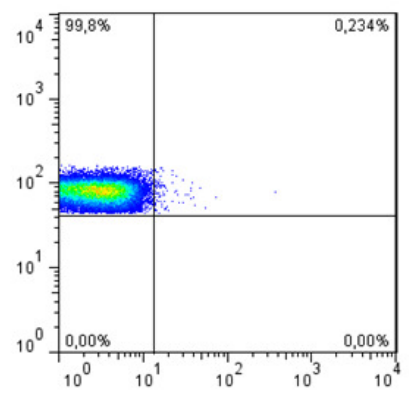

D

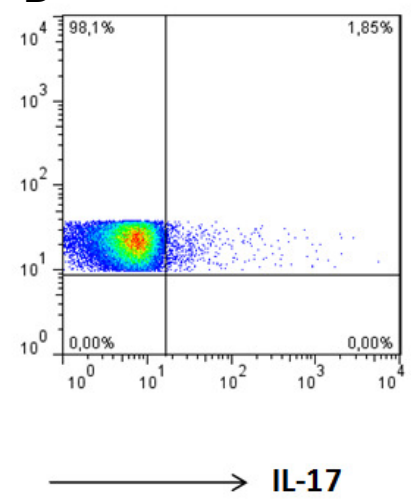

E

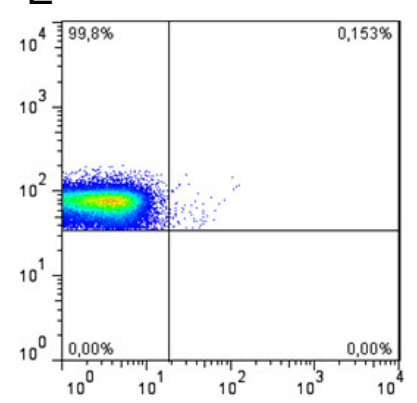

unstimulated

$\mathrm{F}$

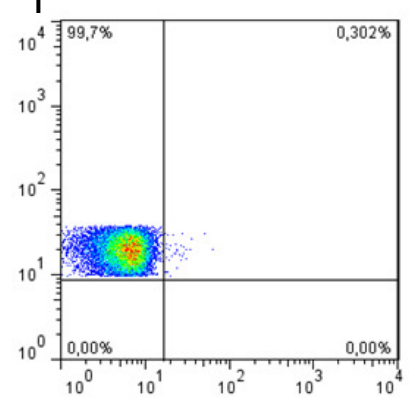

PMA

Fig. 3.23 | Flow cytometric analysis of IFN $\gamma$ and IL-17 producing CD4 ${ }^{+} \mathrm{T}$ cells in immunized lymph nodes with and without stimulation.

Representative CD4/IFN $\gamma$ and CD4/IL-17 flow cytometry dot plots of lymph node cells are depicted in A-D. The cells were previously gated on the lymphocyte subpopulation by their FSC/SSC properties and on CD4 ${ }^{+} \mathrm{T}$ cells. $\mathrm{E}$ and $\mathrm{F}$ show the isotype control.

The frequency of IFN $\gamma^{+} \mathrm{CD}^{+} \mathrm{T}$ cells as well as $\mathrm{IL}_{1} 7^{+} \mathrm{CD} 4^{+} \mathrm{T}$ cells was in the range of $1-2 \%$ after immunization with $\mathrm{MOG}_{35-55}$. Most $\mathrm{CD}^{+} \mathrm{T}$ cells produced either IFN $\gamma$ or IL17, cells producing both cytokines were extremely rare (data not shown). Whereas IFN $\gamma^{+} \mathrm{CD} 4^{+} \mathrm{T}$ cells can be detected as early as dpi 3 (Fig 3.24 E, F), there was an increase in the frequency of IL-17 producing T cells from dpi 3 to dpi 7 (Fig. $3.24 \mathrm{G}, \mathrm{H}$ ). $\mathrm{MOG}_{35-55}$ immunization resulted in comparable frequencies of $\mathrm{T}_{\mathrm{H}} 1$ and $\mathrm{T}_{\mathrm{H}} 17$ cells in both genotypes. 
no stimulation
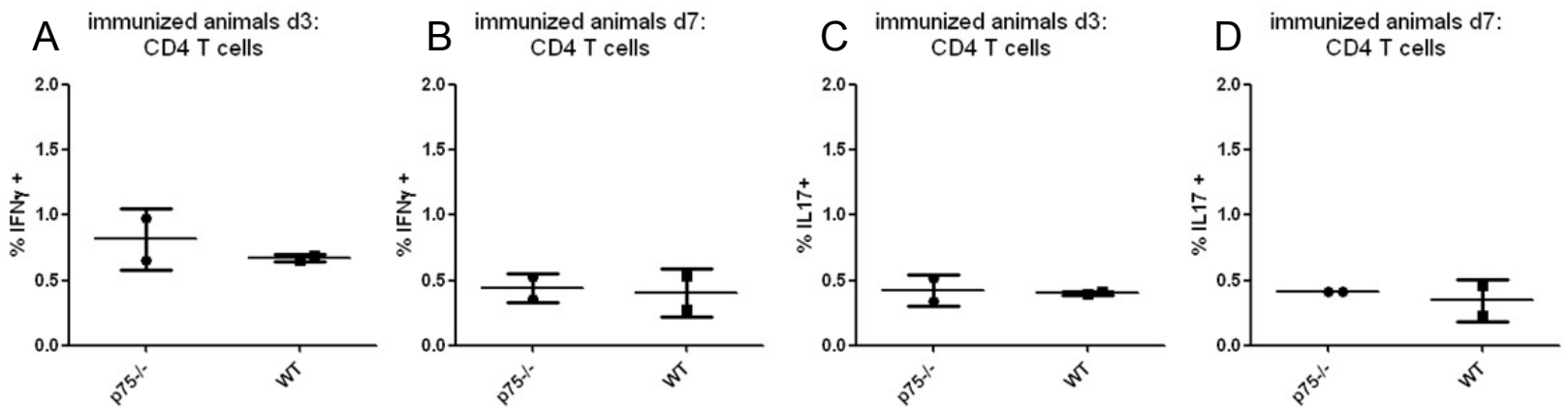

\section{PMA}

\section{$E$ immunized animals d3:} CD4 T cells

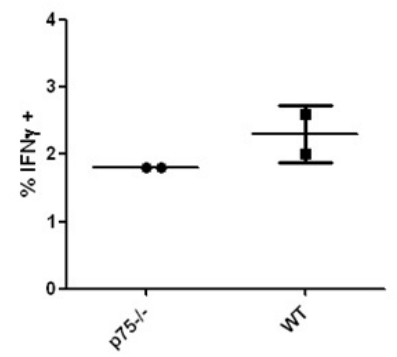

F immunized animals d7: CD4 $\mathrm{T}$ cells

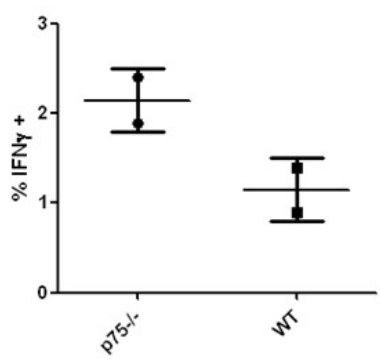

$G$ immunized animals d3: CD4 T cells

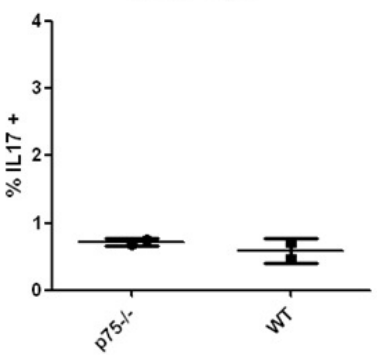

$\mathrm{H}$ immunized animals $\mathrm{d} 7$ : CD4 T cells

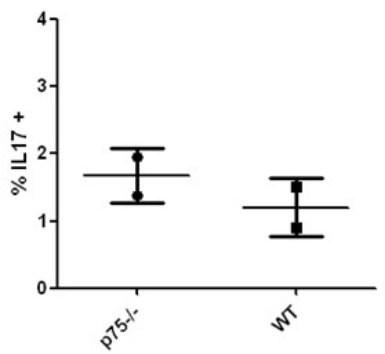

Fig. 3.24 | Frequencies of IFN $\gamma$ and IL-17 producing $\mathrm{CD4}^{+} \mathrm{T}$ cells in immunized lymph nodes with and without stimulation.

The number of IFN $\gamma$ producing $C D 4^{+}$T cells $(A, B, E, F)$ did not differ between the genotypes in unstimulated $(A$,

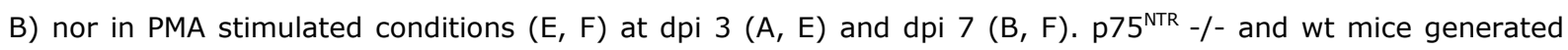
also similar frequencies of IL-17 producing CD4 ${ }^{+} T$ cells $(C, D, G, H)$. IL-17 production in $C D 4^{+} T_{\text {cells }}$ is depicted without stimulation (C, D) and after PMA stimulation $(G, H)$ at dpi $3(C, G)$ and dpi $7(D, H)$. Cytokine producing $\mathrm{CD}^{+}{ }^{+} \mathrm{T}$ cells are expressed as the fraction within the $\mathrm{CD} 4^{+} \mathrm{T}$ cell compartment $+/-\mathrm{SD}$.

IL- $17^{+} \mathrm{CD}^{+} \mathrm{T}$ cell frequencies did not increase over time at dpi 3 and dpi 7 in $\mathrm{MOG}_{35-55}$ immunized lymph nodes in both mouse strains (Fig 3.24 E, F). After stimulation of the T cells, IL-17 production was about 2-fold higher compared to unstimulated T cells (Fig. 3.24 G, H). T cells from time point dpi 7 (Fig. 3.24 F, H) responded more to stimulation than T cells from dpi 3 (Fig. 3.24 E, G). This shows that the cells are more susceptible to exogenous stimuli and have a more activated phenotype in comparison to dpi 3. Again, no significant differences between the two mouse strains analyzed were seen. 


\subsection{Similar numbers of IFN $\gamma$ and IL-17 producing $\gamma \delta$ T cells in lymph nodes of

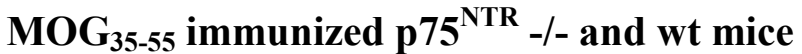

$\gamma \delta \mathrm{T}$ cells have come into focus due to their potential to restrain $\mathrm{T}_{\text {reg }}$ responses. We therefore analyzed IFN $\gamma$ and IL-17 production in the $\gamma \delta$ T cell subpopulation at dpi 3 and dpi 7 with and without PMA stimulation (Fig. 3.25).
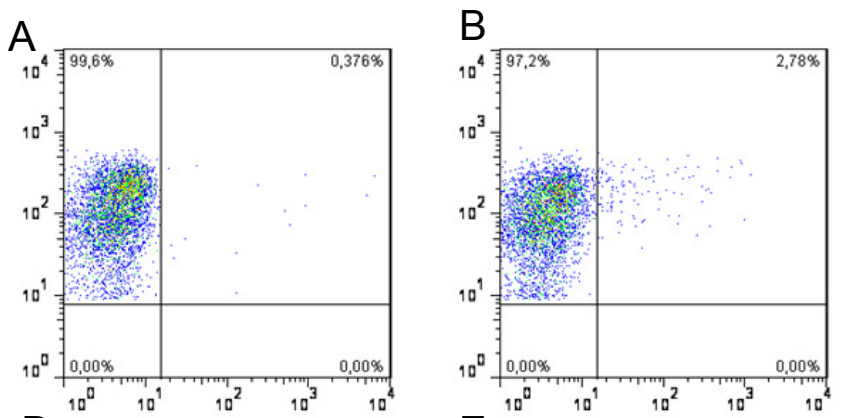

\section{$\mathrm{E}$}

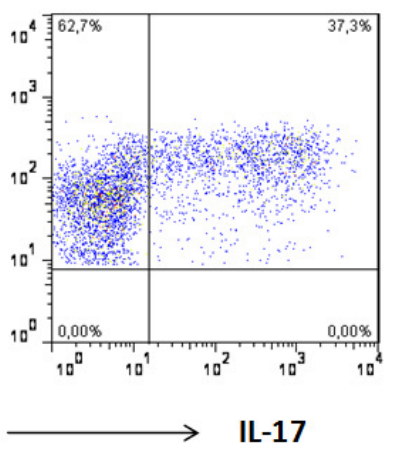

C

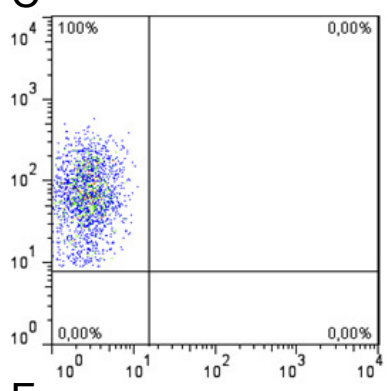

$\mathrm{F}$

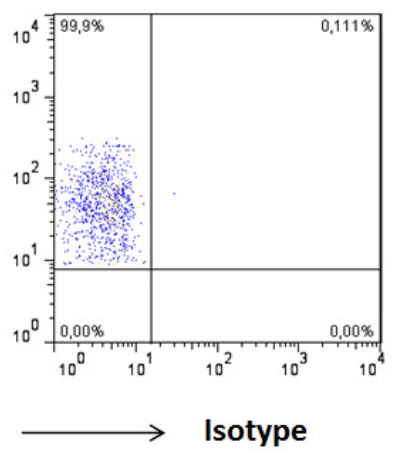

unstimulated

PMA

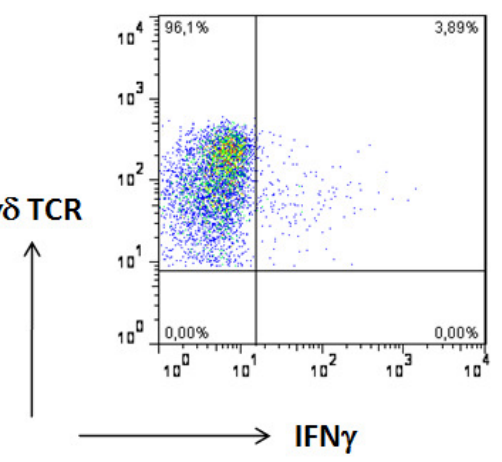

Fig. 3.25 | Flow cytometric analysis of IFN $\gamma$ and IL-17 producing $\gamma \delta$ T cells in immunized lymph nodes with and without stimulation.

Representative $\gamma \delta$ TCR/IFN $\gamma$ and $\gamma \delta$ TCR /IL-17 flow cytometry dot plots of lymph node cells are depicted in A, B, $D, E$. The cells were previously gated on the $\gamma \delta T$ cell population by antibodies directed against $\gamma \delta$ TCR and CD3. $\mathrm{C}$ and $\mathrm{F}$ show the isotype control stainings.

The numbers of IFN $\gamma^{+} \gamma \delta$ T cells were very low and did not significantly change from dpi 3 to dpi 7 (Fig. 3.26 A, B). After PMA treatment IFN $\gamma$ expression was about 15-fold increased at dpi 3 and dpi 7 (Fig. $3.26 \mathrm{E}, \mathrm{F}$ ). The frequency of IL-17 $7^{+} \gamma \delta \mathrm{T}$ cells increased from $\sim 1 \%$ (dpi 3) to $\sim 4 \%$ (dpi 7) (Fig. 3.26 C, D). After PMA stimulation, IL-17 ${ }^{+} \gamma \delta \mathrm{T}$ cell numbers were $\sim 10$-fold higher at dpi 3 and dpi 7 (Fig. $3.26 \mathrm{G}, \mathrm{H}$ ). The frequencies of $\gamma \delta \mathrm{T}$ cells secreting the given cytokines were comparable between the genotypes. 


\section{no stimulation}

A immunized animals d3: $\gamma \delta$ T cells

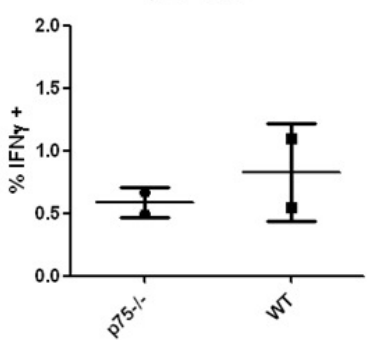

PMA

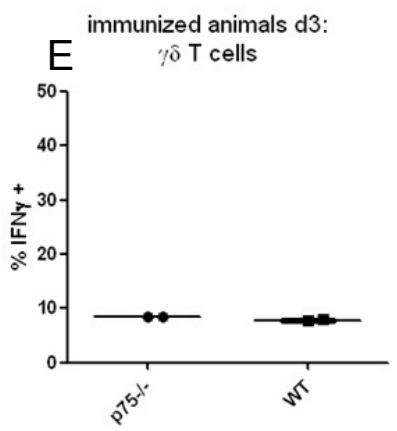

B immunized animals $d 7$ : $\gamma \mathrm{T}$ cells
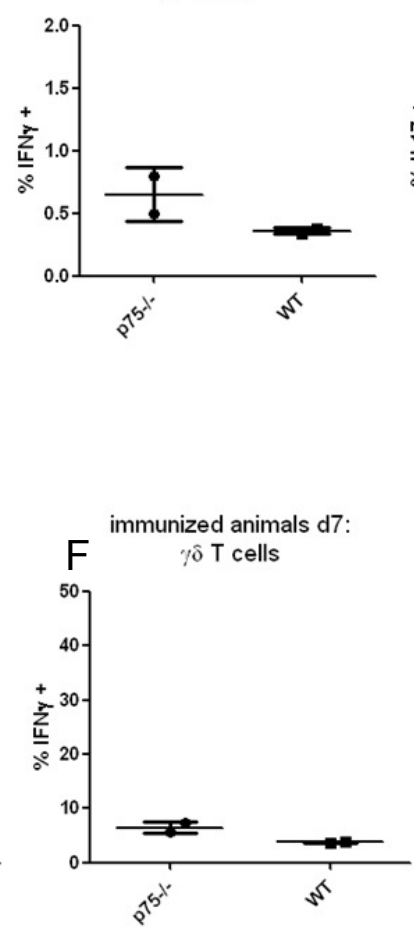

C immunized animals $\mathrm{d} 3$ : $\gamma \hat{\mathrm{T}} \mathrm{T}$ cells

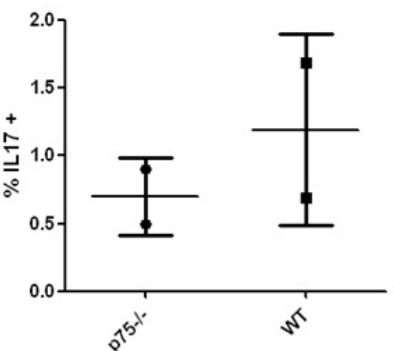

$G$ immunized animals $\mathrm{d} 3$ :

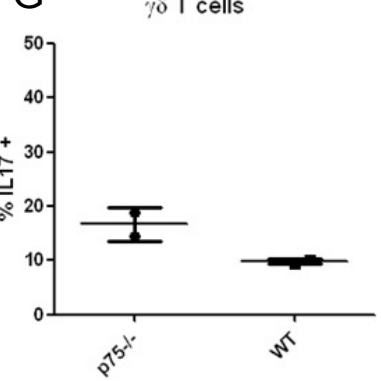

immunized animals $\mathrm{d} 7$ :

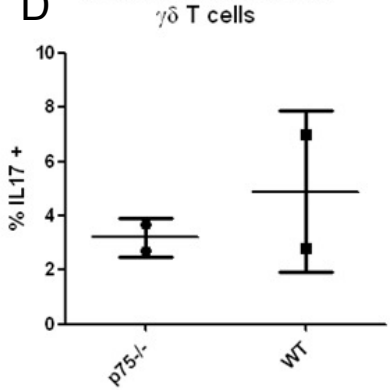

H immunized animals d7:

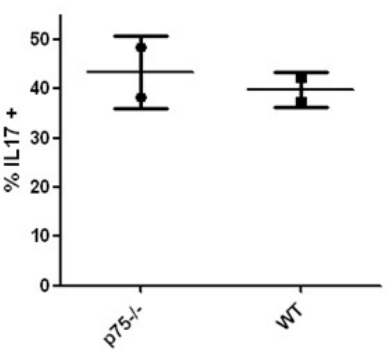

Fig. 3.26 | Frequencies of IFN $\gamma$ and IL-17 producing $\gamma \delta \mathrm{T}$ cells in immunized lymph nodes with and without stimulation.

The number of IFN $\gamma$ producing $\gamma \delta$ T cells $(A, B, E, F)$ did not differ between the genotypes in unstimulated $(A, B)$ nor in PMA stimulated conditions $(E, F)$ at dpi $3(A, E)$ and dpi $7(B, F)$. No difference in the number of IL-17 producing $\gamma \delta \mathrm{T}$ cells $(\mathrm{C}, \mathrm{D}, \mathrm{G}, \mathrm{H})$ between $\mathrm{p} 75^{\mathrm{NTR}}-/$ - and wt mice without stimulation $(\mathrm{C}, \mathrm{D})$ and after PMA stimulation $(G, H)$ at dpi $3(C, G)$ and dpi $7(D, H)$ was observed.

\subsection{No difference in numbers of macrophages expressing MHC class II and $\mathrm{T}$ cell costimulatory molecule CD80 in lymph nodes of naïve and immunized $\mathrm{p}^{\mathrm{NTR}}$-/- and wt animals}

I furthermore analyzed the population of antigen presenting macrophages $\left(\mathrm{CD} 45^{+}\right.$ $\mathrm{CD}_{11 \mathrm{~b}^{+}} \mathrm{MHC}$ class $\mathrm{II}^{+}$) and their expression of the co-stimulatory molecule CD80 (Fig. 3.27). 
A

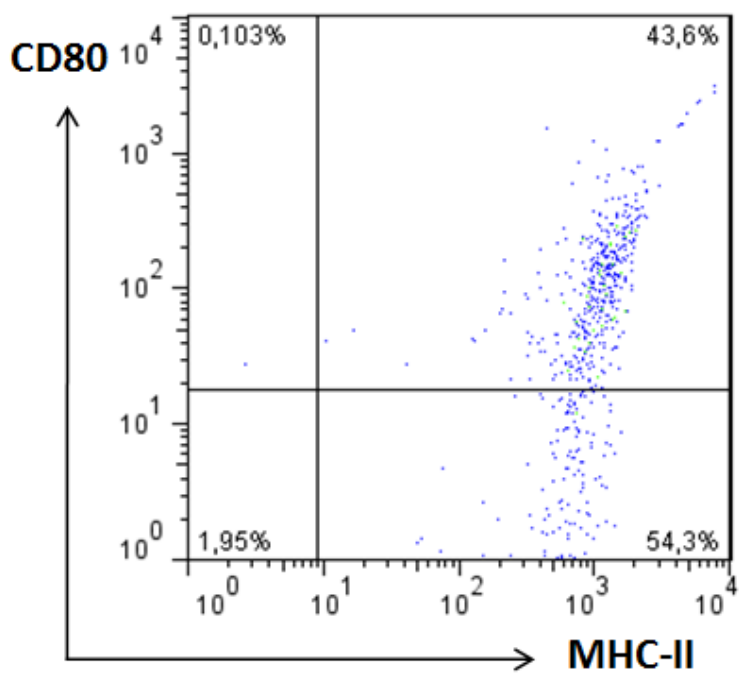

C immunized animals: $\mathrm{CD} 80+\mathrm{MHCll}+$

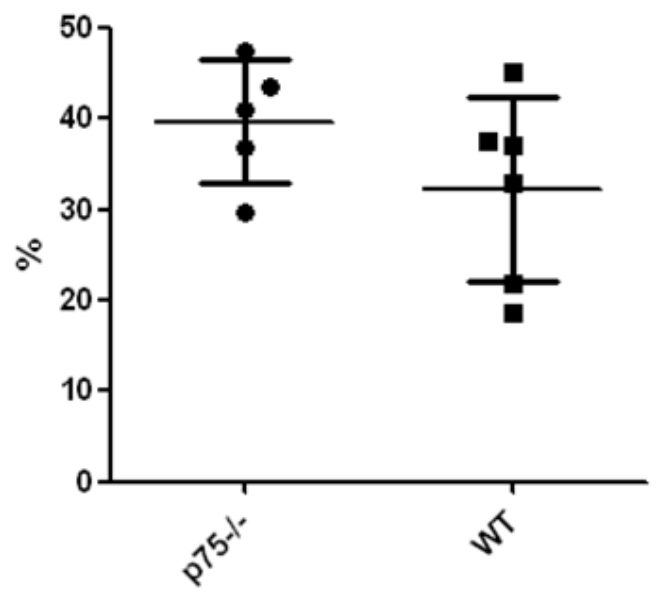

B

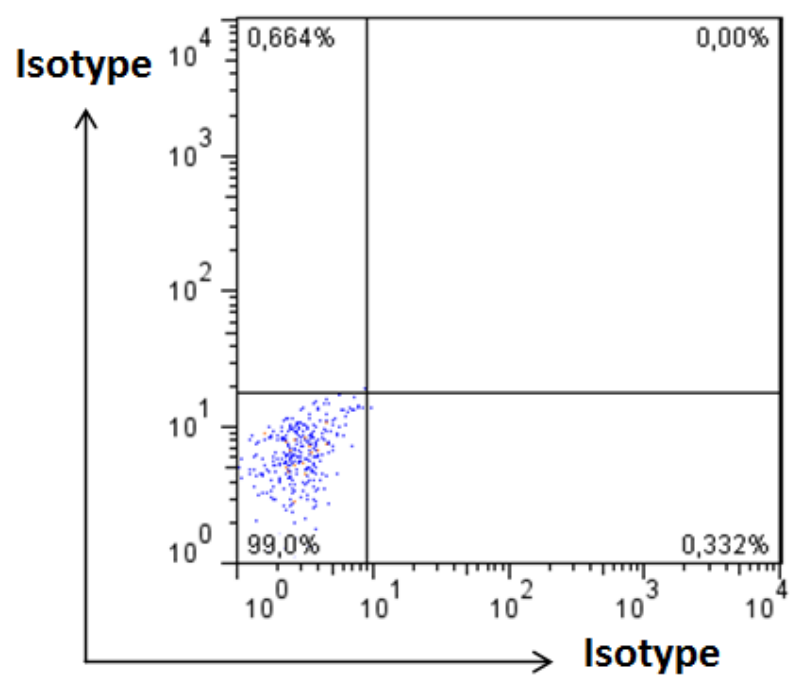

Fig. 3.27 | Flow cytometric analysis of antigen presenting macrophages in immunized lymph nodes.

A representative CD80/MHC class II flow cytometry dot plot of lymph node cells is depicted in $A$. The cells were previously gated on $\mathrm{CD}_{4} 5^{+} \mathrm{CD} 11 \mathrm{~b}^{+}$cells. $\mathrm{B}$ shows the isotype control. The number of $\mathrm{CD} 80^{+} \mathrm{MHC}$ class $\mathrm{II}^{+}$macrophages did not differ between the genotypes in $\mathrm{MOG}_{35-55}$ immunized lymph nodes (C).

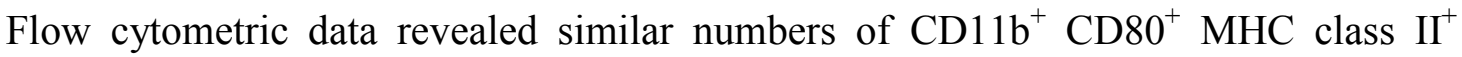
macrophages within the lymph nodes of immunized p $75^{\mathrm{NTR}}-/-$ and wt mice (Fig 3.27). We further distinguished dendritic cells within the $\mathrm{CD}_{1} 1 \mathrm{~b}^{+}$population by antibodies against CD11c and found similar percentages and cell numbers expressing MHC-II and CD80 between the genotypes (data not shown).

The percentage of $\mathrm{MHC}$ class $\mathrm{II}^{+}$cells within the $\mathrm{CD} 11 \mathrm{~b}^{+}$compartment was already high in naïve lymph nodes $(96 \%)$ and did not change after immunization with $\mathrm{MOG}_{35-55}$ (93\%) (Fig. 3.28 A, C). However, the median fluorescence intensity for MHC class II increased significantly, suggesting that MHC class II expression was upregulated by immunization. In naïve lymph nodes, a very small fraction of $\mathrm{CD} 11 \mathrm{~b}^{+}$cells expressed $\mathrm{CD} 80^{+}$ (Fig. 3.28 B) and this fraction increased to around $40 \%$ after $\mathrm{MOG}_{35-55}$ immunization 
(Fig. $3.28 \mathrm{D})$. No differences between $\mathrm{p} 75^{\mathrm{NTR}}-/-$ and wt animals with respect to antigen presenting cells were found.

A

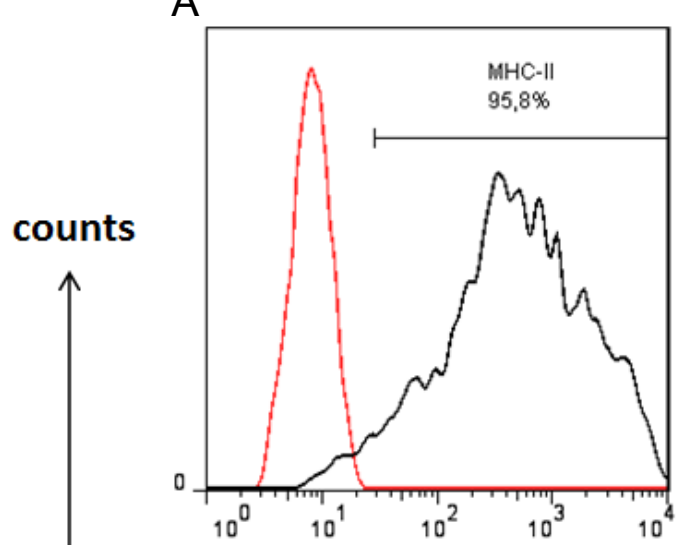

C

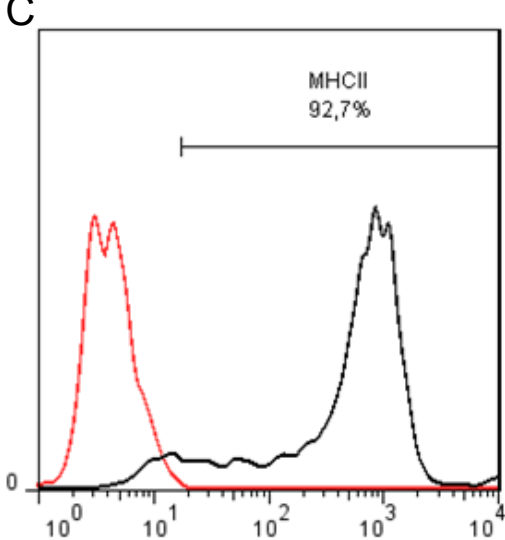

MHC class II
B

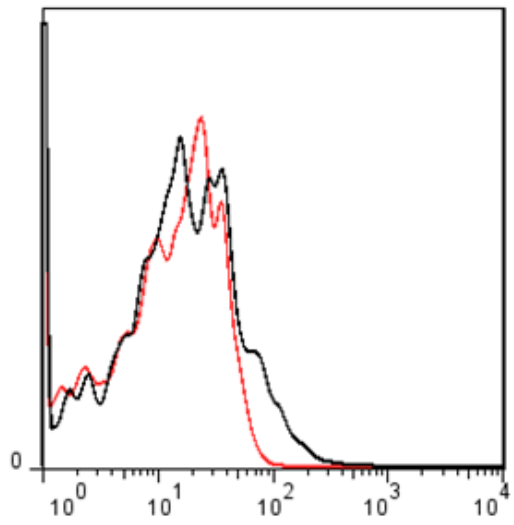

naive

D

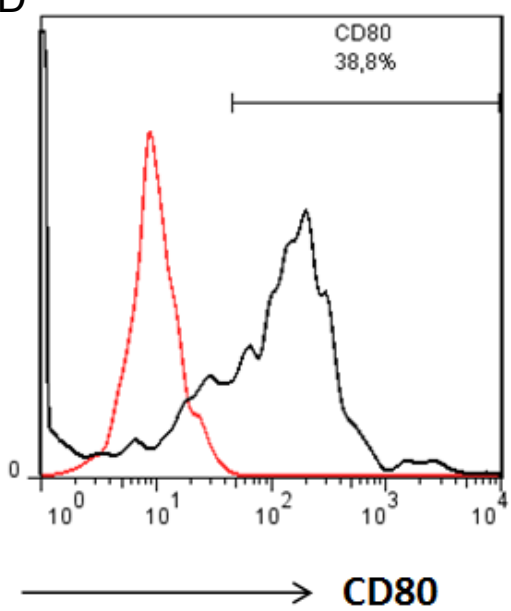

immunized

Fig. 3.28 | Flow cytometric histograms for MHC class II and CD80 expression by CD11b ${ }^{+}$cells in naïve and immunized lymph nodes.

Representative MHC class II (A, C) and CD80 (B, D) flow cytometry histograms of naïve (A, B) and immunized lymph node cells $(C, D)$ are shown. The cells were previously gated on $C D 45^{+} C D 11 b^{+}$cells. The percentage of $\mathrm{MHC}$ class $\mathrm{II}^{+}$cells within the $\mathrm{CD} 11 \mathrm{~b}^{+}$compartment did not change after $\mathrm{MOG}_{35-55}$ immunization ( 95\%) (A, C). However, there is a clear increase in median fluorescence intensity of MHC class II after immunization, suggesting upregulation of this molecule. In naïve lymph nodes, only a minimal fraction of $C D 11 \mathrm{~b}^{+}$cells was positive for CD80 (B). After immunization, this fraction increased to around $40 \%$ (D). The red line represents the isotype control. $n=5$ 


\subsection{No difference in the cytokine/chemokine production of lymph node cells of MOG $_{35-55}$ immunized $\mathrm{p}^{\mathrm{NTR}}$-/- and wt mice}

Cytokine and chemokine concentrations were also measured by ELISA in the supernatant of restimulated lymph node cells taken from animals 10 days after $\mathrm{MOG}_{35-55}$ immunization (Fig. 3.29). Comparable cytokine concentrations were found.
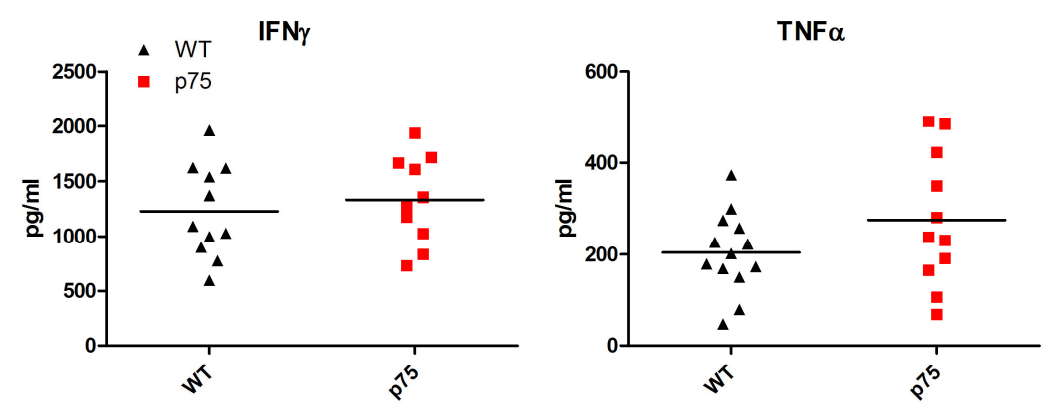

IL-10
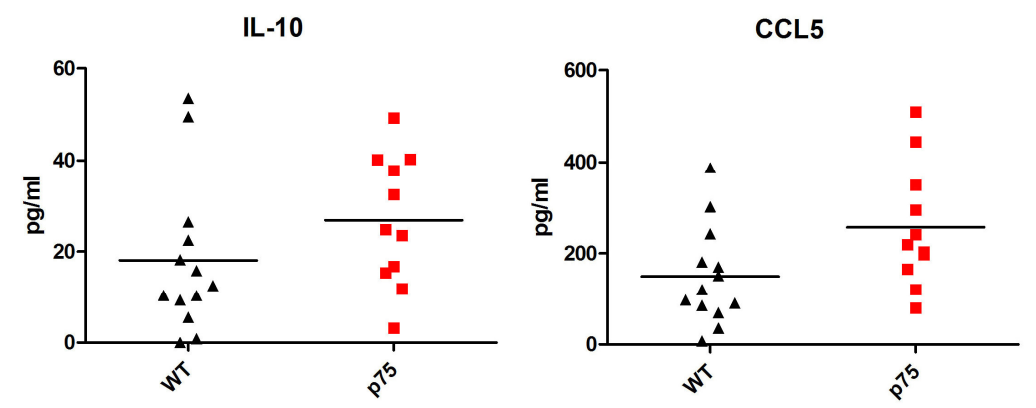

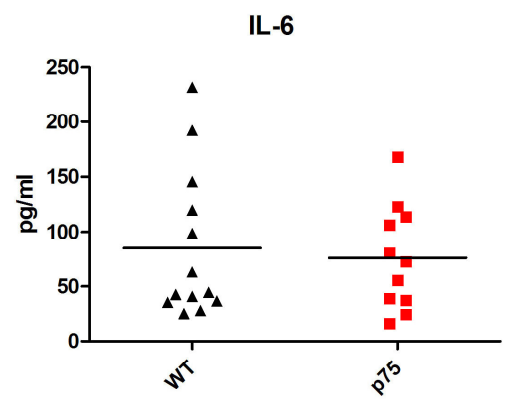

Fig. 3.29 | ELISA analysis of lymph node cells (dpi 10) after MOG $_{35-55}$ restimulation.

High levels of proinflammatory IFN $\gamma$, moderate levels of TNF $\alpha$, IL-6, CCL5, and low levels of antiinflammatory IL-10 were observed. No differences between wt and $p 75^{\mathrm{NTR}}-/$ - cells were found.

In summary, an extensive immunological workup failed to detect differences between $\mathrm{p} 75^{\mathrm{NTR}}$ deficient animals and wild type controls. 


\section{2 $\quad \mathrm{p75}^{\mathrm{NTR}}$ deficiency has no effect on $\mathrm{T}$ cell proliferation and antigen presentation to $T$ cells.}

The role of $\mathrm{p} 75^{\mathrm{NTR}}$ deficiency for $\mathrm{T}$ cell proliferation was determined by proliferation assays. At dpi 10 lymph node cells with and without a functional $\mathrm{p} 75^{\mathrm{NTR}}$ gene were restimulated in vitro with $\mathrm{MOG}_{35-55}$. The medium was supplemented with radioactive ${ }^{3} \mathrm{H}$ thymidine. After $3 \mathrm{~d}$, counts per minute were measured showing how much ${ }^{3} \mathrm{H}$ thymidine was incorporated into the DNA by de novo synthesis. Since only antigen specific T cells respond to $\mathrm{MOG}_{35-55}$ restimulation, most of the proliferation activity observed can be ascribed to $\mathrm{T}$ cells. $\mathrm{p} 75^{\mathrm{NTR}}$ deficiency in $\mathrm{CD}^{+} \mathrm{T}$ cells had no effect on antigen specific $\mathrm{T}$ cell proliferation (Fig. $3.30 \mathrm{~A}$ ).

To test whether APCs derived from $\mathrm{p} 75^{\mathrm{NTR}}$-/- and wt mice differ in their respective capacity to stimulate $\mathrm{MOG}_{35-55}$ specific wt $\mathrm{T}$-cells, $\mathrm{T}$ cell clone cells were restimulated using APCs from $\mathrm{p} 75^{\mathrm{NTR}}$-/- and wt spleens. T cells showed similar proliferation activity. Therefore, $\mathrm{p} 75^{\mathrm{NTR}}$ deficiency plays no role in antigen presentation by APCs to T cells (Fig. $3.30 \mathrm{~B}$ ).
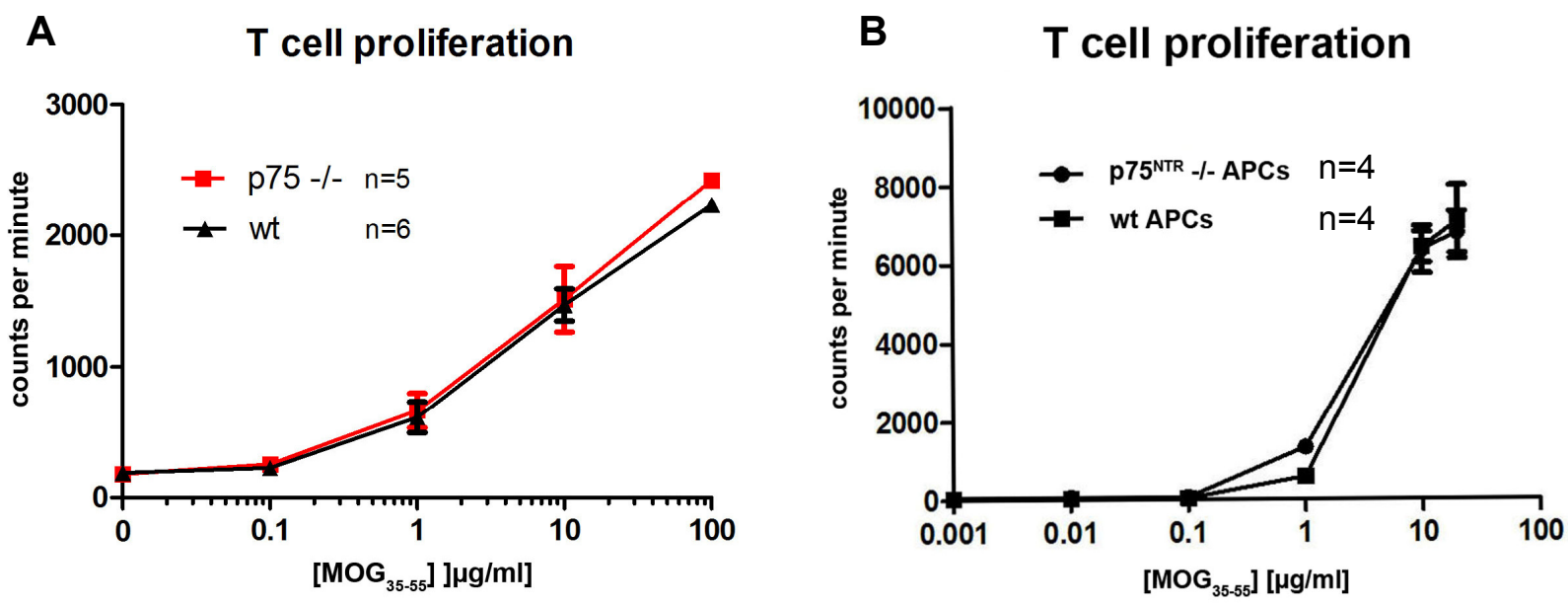

Fig. 3.30 | $\mathrm{T}$ cells proliferation after $\mathrm{MOG}_{35-55}$ restimulation.

Lymph nodes were collected at dpi 10 from actively immunized $\mathrm{p} 75^{\mathrm{NTR}}$-/- and wt mice and in vitro restimulated with $\mathrm{MOG}_{35-55}$ (A). p75 ${ }^{\mathrm{NTR}}$ deficiency on $\mathrm{T}$ cells had no effect on $\mathrm{T}$ cell proliferation. $\mathrm{MOG}_{35-55}$ specific wt $\mathrm{T}$ cells were also restimulated using APCs derived from $p 75^{\mathrm{NTR}}$ and wt mice (B). p $75^{\mathrm{NTR}}$ deficiency in APCs had no effect on T cell proliferation upon restimulation. 


\subsubsection{No $\mathrm{p}^{\mathrm{NT}} \mathrm{N}^{\mathrm{NTR}}$ expression by $\mathrm{T}_{\mathrm{H}} 1$ cells}

To test whether $\mathrm{p} 75^{\mathrm{NTR}}$ is expressed by the $\mathrm{MOG}_{35-55}$ specific $\mathrm{T}_{\mathrm{H}} 1$ cell clone used in this study, $\mathrm{p} 75^{\mathrm{NTR}}$ expression was measured after LPS, PMA (two concentrations), and CD3/CD28 stimulation at different time points

\begin{tabular}{|c|ccc|}
\hline T cell clone & 3h & 6h & 24h \\
\hline unstim. & bdl & bdl & bdl \\
CD3/CD28 & bdl & bdl & bdl \\
PMA 5 & bdl & bdl & bdl \\
PMA 50 & bdl & bdl & bdl \\
NGF & bdl & bdl & bdl \\
\hline
\end{tabular}

Tab. 3.1 | No p75 ${ }^{\text {NTR }} \quad$ expression by $T_{H} 1$ cell clone. p $75^{\text {NTR }}$ transcripts in $T_{H} 1$ cells were never detected by TaqMan qRT-PCR. $(n=3)$

by TaqMan qRT-PCR analysis (Tab. 3.1). No p $75^{\mathrm{NTR}}$ gene transcripts were detected. Also, p $75^{\text {NTR }}$ expression was not modulated by the presence of NGF. The high levels of CCL5 produced by our $\mathrm{T}$ cell clone after $\mathrm{CD} 3 / \mathrm{CD} 28$ as well as PMA stimulation did not change when NGF was applied (three different concentrations) (data not shown). Therefore, it could be ruled out that $\mathrm{p} 75^{\mathrm{NTR}}$ deficiency has a direct effect in $\mathrm{T}$ cells. However, since $\mathrm{T}$ cell responses are dependent on the stimulation by other cell populations (e.g., DCs, B cells, endothelia, pericytes), they could be affected indirectly by $\mathrm{p} 75^{\mathrm{NTR}}$ deficiency.

\section{3 $\mathrm{p}^{\mathrm{NTR}}$ deficiency has no effect on NO, ROS, and cytokine/chemokine production in bone marrow derived macrophages}

To obtain a pure, non-prestimulated macrophage population, hematopoietic stem cells from the bone marrow were differentiated to macrophages by incubation with L929 medium. The mature immune cells had a distinct macrophage, but not granulocyte phenotype (Fig. 3.31 and Fig. 3.32).

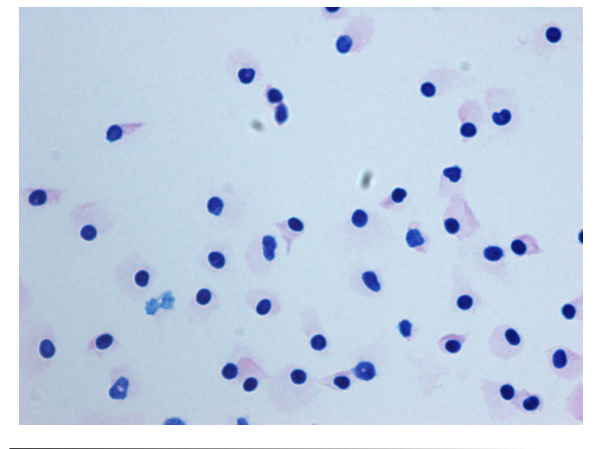

Fig. 3.31 | Macrophage morphology of BMDMs.

GIEMSA staining of BMDMs shows macrophages, but not granulocytes. 
wt

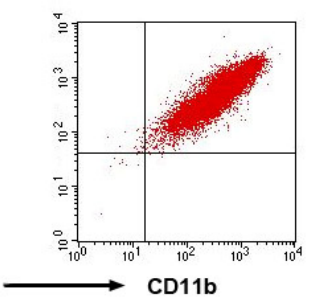

p75 ${ }^{\mathrm{NTR}}-/-$

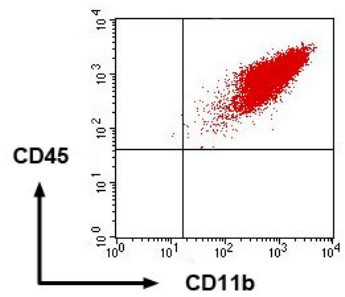

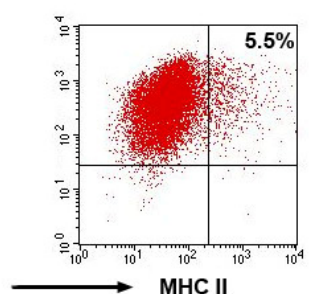
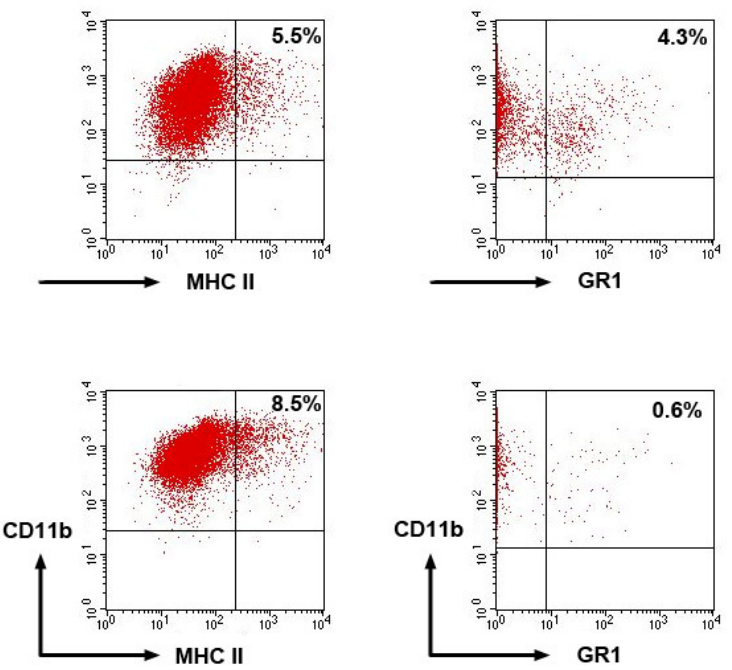

Fig. 3.32 I Flow cytometric analysis of BMDM showed a distinct macrophage phenotype.

BMDMs were $\mathrm{CD} 45^{+} \mathrm{CD} 11 \mathrm{~b}^{+}$and only a small percentage expressed MHC class II. Only very few cells carried the granulocyte marker GR1.

\subsubsection{No effect of $\mathrm{p}^{\mathrm{NTR}}$ deficiency on NO release by BMDMs}

BMDMs were stimulated by the TLR-4 ligand LPS and the TLR-2 ligand Zymosan. NO release was indirectly detected by its reduction products nitrite and nitrate using the Griess reaction. No differences between $\mathrm{p} 75^{\mathrm{NTR}}-/-$ and wt BMDMs could be found (Fig. 3.33).

A

$$
\text { NO - production }
$$
after LPS stimulation

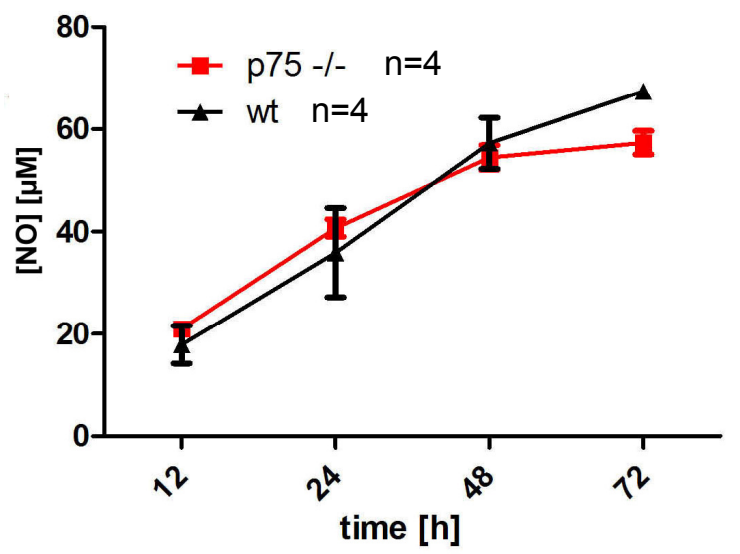

NO - production

B after Zymosan stimulation

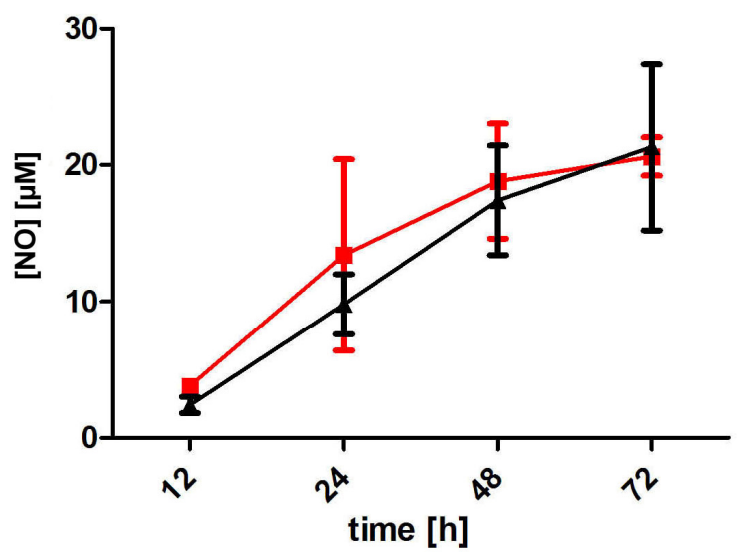

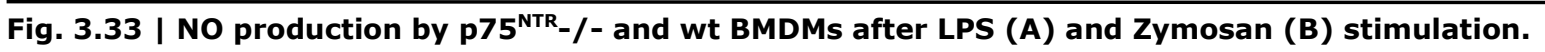
No differences in NO release after TLR4 activation by LPS (A) and after TLR2 activation by Zymosan (B) between $\mathrm{p} 75^{\mathrm{NTR}}$-/- and wt BMDMs were found. 


\subsubsection{ROS production of $\mathrm{p}^{\mathrm{NTR}}-/-$ and wt BMDMs}

To examine if $\mathrm{p} 75^{\mathrm{NTR}}$ deficiency leads to altered ROS production by BMDMs, cells were prestimulated under various conditions. After stimulation with and without PMA and Zymosan, intracellular ROS were directly bound by nitroblue tetrazolium (NBT) which binds both $\mathrm{H}_{2} \mathrm{O}_{2}$ and $\mathrm{O}^{2-}$.

Highest ROS levels were measured after Zymosan stimulation. ROS production of unstimulated, PMA, and Zymosan stimulated BMDM did not differ significantly between p $75^{\mathrm{NTR}}$-/- and wt cells (Fig 3.34). ROS production was always increased when the cells were prestimulated with LPS, IFN $\gamma$, or fibrinogen.

\section{ROS production}

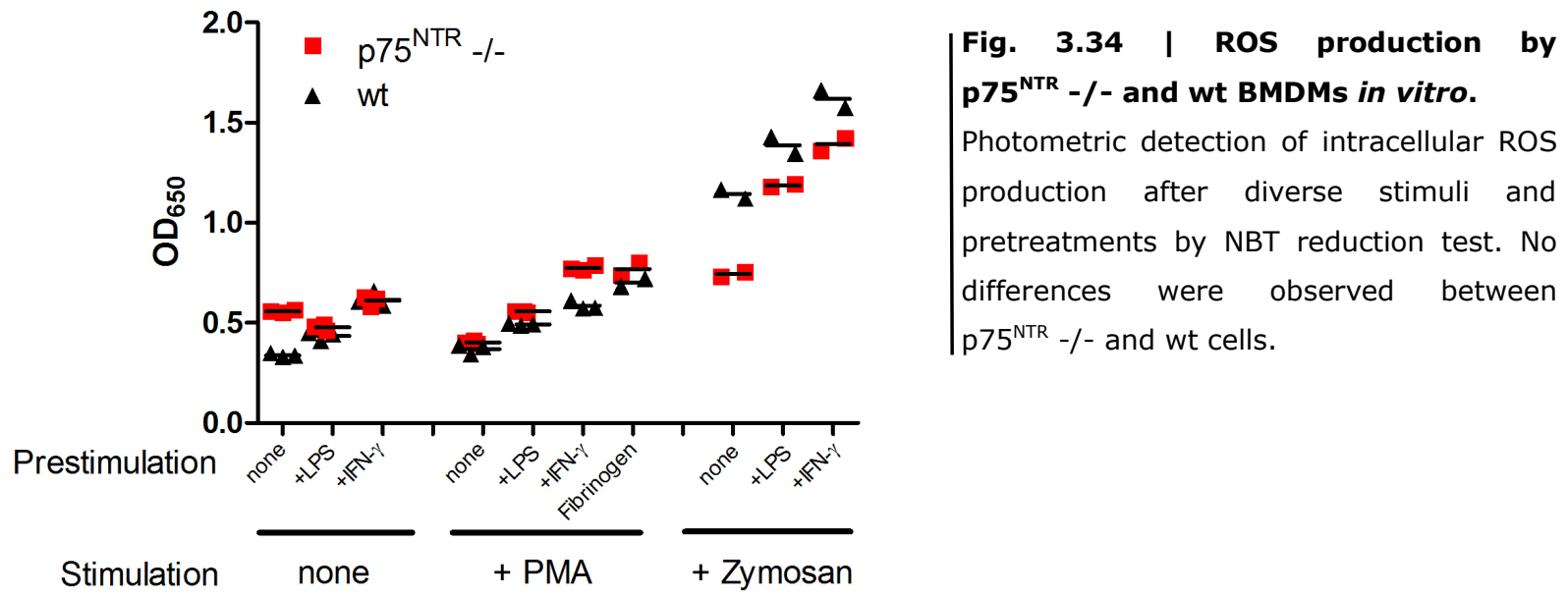

\subsubsection{Cytokine/chemokine production of $\mathrm{p}^{\mathrm{NT}} \mathrm{N}^{\mathrm{NTR}}$-/- and wt BMDMs}

Secretion of TNF $\alpha$, IL-6, and CCL5 was measured by ELISA after IFN $\gamma$, LPS, and fibrinogen stimulation (Fig. 3.35). No differences in the amount of TNF $\alpha$, IL-6 and CCL5 production could be found. In general, LPS stimulation had the greatest effect on BMDM activation, whereas IFN $\gamma$ and fibrinogen induced production of only small amounts of cytoand chemokines. 

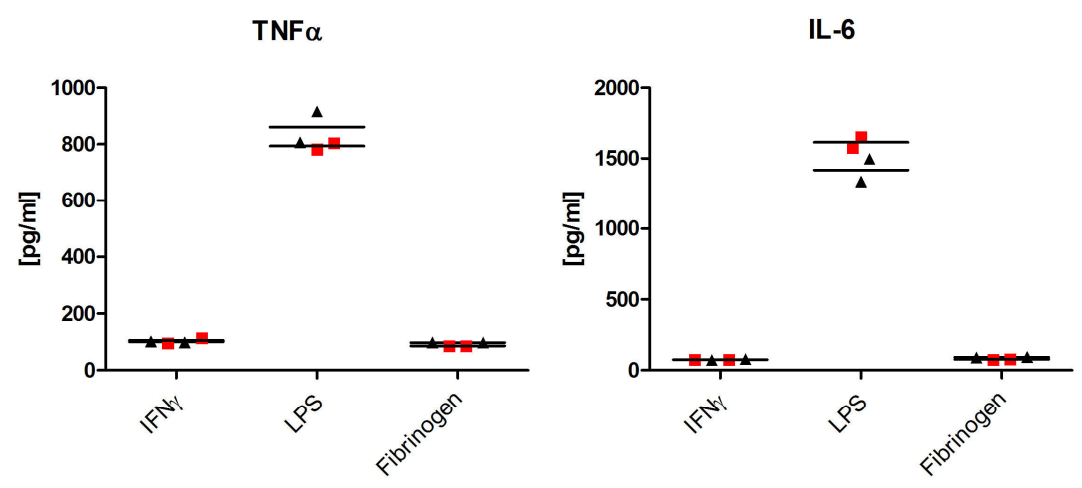

Fig. 3.35 | Cytokine/ chemokine release of p75 NTR $-/$ - and wt BMDM in vitro.

LPS had the strongest activation capacity for BMDMs. Similar values for TNF $\alpha$, IL-6 and CCL5 were found in $\mathrm{p} 75^{\mathrm{NTR}}-/$ - and wt BMDM.

CCL5

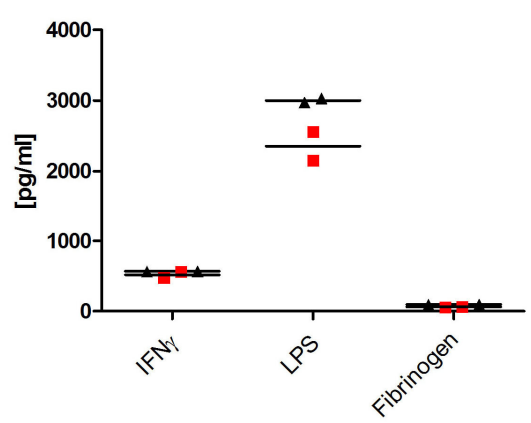

\section{4 $\quad \mathrm{p}^{\mathrm{NTR}}$ expression in naïve lymph nodes and after priming with MOG $_{35-55}$}

To study which immune cell types of the lymph node express $\mathrm{p} 75^{\mathrm{NTR}}$ under naïve conditions and after active immunization, cell populations were separated by FACS sorting and the amount of mRNA transcripts for $\mathrm{p} 75^{\mathrm{NTR}}$ was determined by TaqMan qRT-PCR. Time points were naive, dpi 3, dpi 6, and dpi 14 after immunization with $\mathrm{MOG}_{35-55}$ peptide.

Only in B cells a constitutive expression of $\mathrm{p} 75^{\mathrm{NTR}}$ was found under naïve as well as priming conditions (Tab. 3.2). In the conditions examined, $\mathrm{p} 75^{\mathrm{NTR}}$ was never expressed by any of the examined $\mathrm{T}$ cell types $\left(\mathrm{CD} 4^{+}, \mathrm{CD} 4^{+}\right.$effector, $\left.\mathrm{CD} 8^{+}, \gamma \delta, \mathrm{NK} \mathrm{T}\right), \mathrm{NK}$ cells, $\mathrm{CD} 11 \mathrm{~b}^{+}$ $\mathrm{CD}_{11 \mathrm{c}^{+}}$(macrophages, neutrophils), and $\mathrm{CD} 11 \mathrm{~b}^{-} \mathrm{CD} 11 \mathrm{c}^{+}$(DCs, neutrophils) cells. These findings are in accordance with our data revealing no $\mathrm{p} 75^{\mathrm{NTR}}$ expression by a CD4 $4^{+} \mathrm{T}_{\mathrm{H}} 1 \mathrm{~T}$ cell clone and by microglia after various stimuli in vitro (Tab. 3.1, Tab. 3.3). Constitutive expression of $\mathrm{p} 75^{\mathrm{NTR}}$ by B cells and no expression by $\mathrm{T}$ cells were shown before by Torcia et al., 1996. 


\begin{tabular}{|c|c|c|c|c|c|c|}
\hline & & \multicolumn{2}{|c|}{ dpi 3} & \multicolumn{2}{c|}{ dpi $\mathbf{6}$} & dpi 14 \\
$\Delta$ CT values & naive & MOG & CFA & MOG & CFA & MOG \\
\hline B cells & 2,44 & 1,315 & 1,13 & 5,86 & 6,2 & 5,51 \\
CD4+ T cells & bdl & bdl & bdl & bdl & bdl & bdl \\
CD4+ Effector T cells & nd & nd & nd & bdl & bdl & bdl \\
CD8+ T cells & bdl & bdl & bdl & bdl & bdl & bdl \\
$\gamma \delta$ T Zellen & bdl & nd & nd & nd & nd & nd \\
NK T cells & bdl & bdl & bdl & bdl & bdl & bdl \\
NK cells & bdl & bdl & bdl & bdl & bdl & bdl \\
CD11c ${ }^{+}$ & bdl & bdl & bdl & bdl & bdl & bdl \\
CD11b+ CD11c & bdl & bdl & bdl & bdl & bdl & bdl \\
\hline
\end{tabular}

Tab. $\quad 3.2 \quad$ I $\quad \mathbf{p 7 5}^{\mathrm{NTR}}$ expression in lymph nodes after priming with MOG $_{35-55}$.

Constitutive expression of p $75^{\text {NTR }}$ by $B$ cells in naïve and primed lymph nodes. No expression by $\mathrm{CD}^{+}, \mathrm{CD}^{+}$ effector, $\mathrm{CD}^{+}, \gamma \delta, \mathrm{NK} \mathrm{T,} \mathrm{NK}$, $\mathrm{CD} 11 \mathrm{~b}^{+} \mathrm{CD} 11 \mathrm{c}^{+}$, and $\mathrm{CD} 11 \mathrm{~b}^{-}$ $\mathrm{CD} 11 \mathrm{c}^{+}$cells. bdl = below detection limit; nd $=$ not determined, $n=2$ 


\subsection{Active EAE in bone marrow chimeras}

To further elucidate whether the observed increase in axonal damage after active immunization is derived from a (subtle) immune phenotype or an inherent enhanced vulnerability of the CNS, a bone marrow chimera system was established (Fig. 2.1). p75 $5^{\mathrm{NTR}}$-/- and wt mice were whole-body irradiated with 11.5 gray. This results in a complete destruction of the immune system, except for non-dividing memory $\mathrm{T}$ and $\mathrm{B}$ cells. Irradiated $\mathrm{p} 75^{\mathrm{NTR}}-/-$ mice were reconstituted with wt bone marrow and vice versa. This results in chimeras that have a complete, functioning $\mathrm{p} 75^{\mathrm{NTR}}$ gene in all cells of the body except immune cells (irradiated wt mice reconstituted with $\mathrm{p} 75^{\mathrm{NTR}}-/-$ bone marrow), and chimeras in which only immune cells express a functioning $\mathrm{p} 75^{\mathrm{NTR}}$ but no other cells (irradiated p $75^{\mathrm{NTR}}$-/- mice reconstituted with wt bone marrow). By using this system we were able to separate effects of local $\mathrm{p} 75^{\mathrm{NTR}}$ deficiency in the CNS (wt $\rightarrow \mathrm{p} 75^{\mathrm{NTR}}-/-$ ) and in the immune system $\left(\mathrm{p} 75^{\mathrm{NTR}}-/-\rightarrow \mathrm{wt}\right)$. Control groups were $\mathrm{p} 75^{\mathrm{NTR}}-/-\rightarrow \mathrm{p} 75^{\mathrm{NTR}}-/-$ and wt $\rightarrow$ wt.

\subsubsection{Effects of irradiation on immune cell infiltration and cytokine/chemokine production in the CNS}

To first assess the effects of the irradiation procedure on immune cell infiltration and cytokine production in the spinal cord and brain, irradiated and reconstituted animals (wt $\rightarrow$ wt and $\left.\mathrm{p} 75^{\mathrm{NTR}}-/-\rightarrow \mathrm{p} 75^{\mathrm{NTR}}-/-\right)$ were compared at d16 after irradiation to age-matched, naïve mice. Spinal cords (Fig. 3.36) and brains (Fig. 3.37) were prepared for TaqMan qRT-PCR analysis of cell lineage markers and cytokine/chemokine transcripts. Measurements of naïve and irradiated and $\mathrm{p} 75^{\mathrm{NTR}}-/-$ and wt CNS tissues were performed simultaneously. The $\Delta \mathrm{CT}$ value shows the number of cycles required to detect the first signal significantly above the background noise. The lower the $\Delta \mathrm{CT}$ value, the higher the specific mRNA amounts.

The expression of the macrophage/microglia surface marker CD68 and the T cell marker CD4 was not elevated in irradiated mice. TNF $\alpha$ and the chemokines CCL2 and CCL5 were slightly (2-fold) upregulated. CXCL10 was the only gene examined that was significantly modulated. There, fluorescence intensities of specific transcripts were 2-3 cycles earlier above background noise in irradiated CNS tissue than in naïve CNS tissues, which 
equates a 4-6-fold upregulation. Neither $\mathrm{p} 75^{\mathrm{NTR}}$ itself nor Troy, another apoptosis inducing receptor of the same family, were regulated. No differences between $\mathrm{p} 75^{\mathrm{NTR}}-/-$ and wt mice were observed.
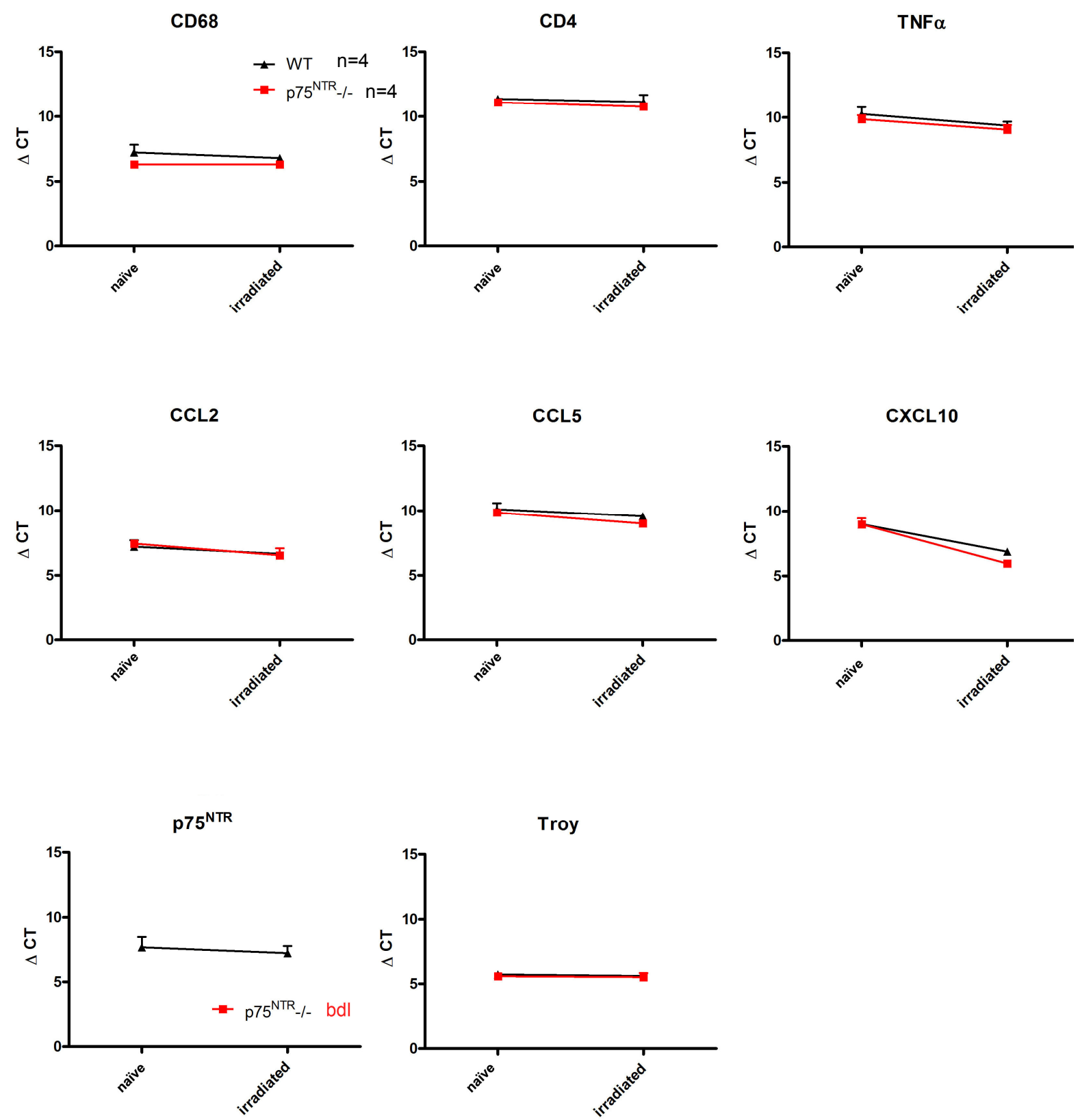

Fig. 3.36 | Expression of inflammation related genes in naïve and irradiated spinal cords.

No infiltration or proliferation/activation of macrophages/microglia (CD68) or T cells (CD4) was observed after irradiation. CXCL10 transcript levels were increased 4-6-fold (2-3 cycles). TNF $\alpha$, CCL2 and CCL5 were only slightly upregulated (2-fold, equates 1 cycle). p $75^{\text {NTR }}$ and Troy were not regulated. No differences between p75 NTR -/- (red) and wt (black) mice were observed. The lower the $\triangle \mathrm{CT}$ value, the higher the mRNA amount. 
Very similar values for the expression of these genes were found in the brains of the same naïve or irradiated animals.
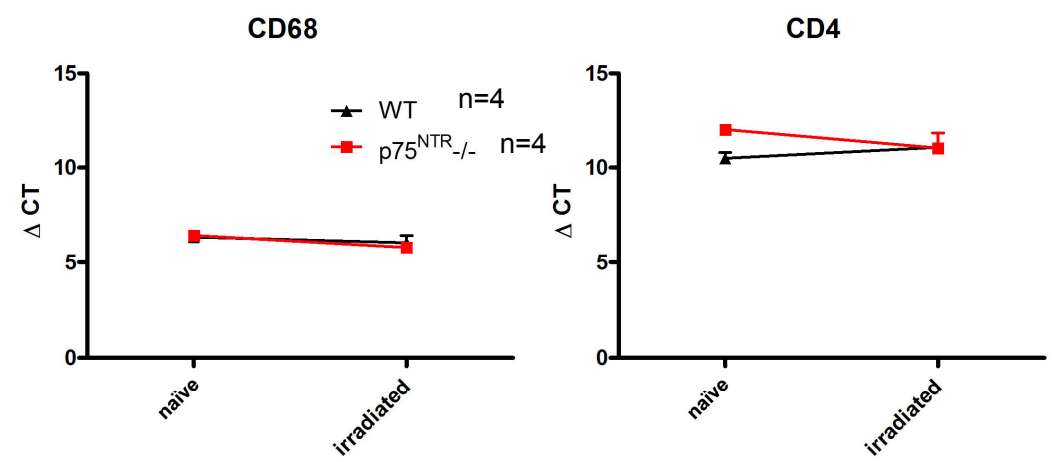

CCL2

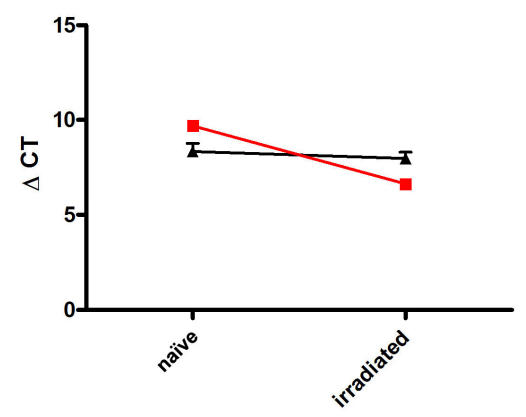

$\mathrm{p} 75^{\mathrm{NTR}}$

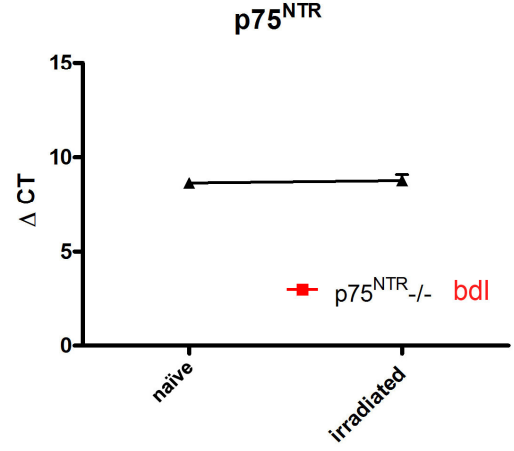

CCL5

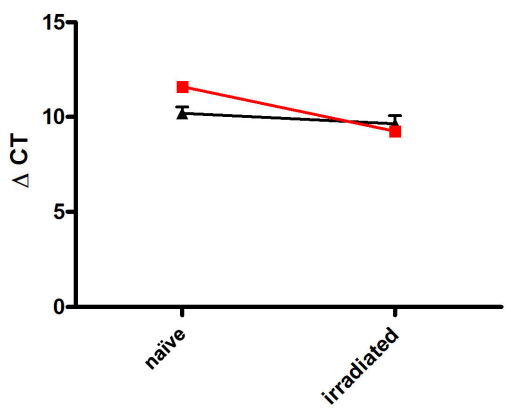

Troy

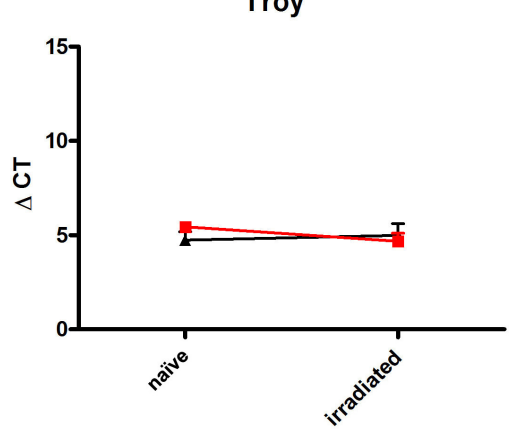

TNF $\alpha$

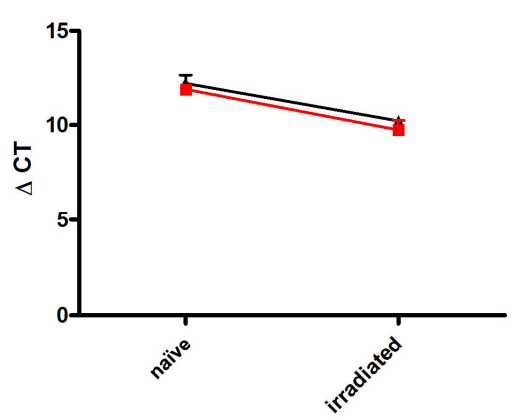

CXCL10

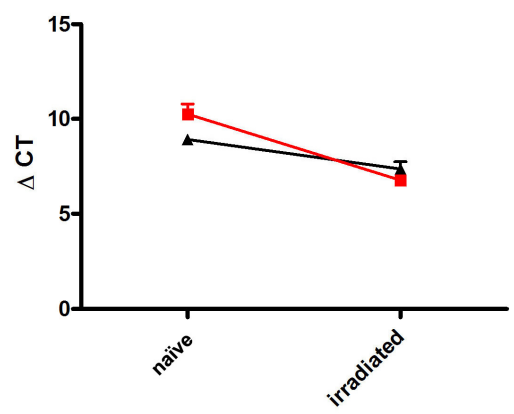

\section{Fig. 3.37 | Expression of inflammation related genes in naïve and irradiated brains.}

No infiltration or proliferation of macrophages/microglia (CD68) or T cells (CD4) took place after irradiation. CXCL10 transcription was increased 4-6-fold (2-3 cycles). TNF $\alpha$, CCL2 and CCL5 were only slightly upregulated (2-fold, equates 1 cycle). p $75^{\mathrm{NTR}}$ and Troy were not regulated. No differences between p $75^{\mathrm{NTR}}-/-$ (red) and wt (black) mice were found. The lower the $\triangle \mathrm{CT}$ value, the higher the mRNA amount. 


\subsubsection{Effects of irradiation on the infiltration of macrophages and $T$ cells into the CNS}

Similarly, on the histological level no cell infiltrations were found within the irradiated CNS (data not shown). Numbers of Mac- $3^{+}$macrophages/microglia were similar in naïve and irradiated spinal cords. Only very few $\mathrm{CD} 4^{+} \mathrm{T}$ cells were observed, but no differences between naïve and irradiated tissue and between $p 75^{\mathrm{NTR}}-/-$ and wt mice were found. To specifically detect immune cells infiltrating from the periphery, mice were reconstituted with transgenic actin-GFP expressing bone marrow cells. Overall numbers of $\mathrm{GFP}^{+}$immune cells were similar in naïve and irradiated mice as well as in $p 75^{\mathrm{NTR}}-/$ - and wt mice (data not shown).

Thus, we could exclude any significant microglia activation and cyto-/chemokine production in the brain and spinal cord of $\mathrm{p} 75^{\mathrm{NTR}}-/-$ and wt mice after irradiation.

\subsubsection{Reconstitution efficiency of bone marrow chimeras}

To test to which degree the irradiation had destroyed the hematopoietic stem and immune cells, and to which degree a repopulation of the immune system by the transplanted cells had occurred, flow cytometric and immunohistochemical analyses were performed. For flow cytometric analysis a congenic mouse strain was used that expresses CD45.1.

When $\mathrm{p} 75^{\mathrm{NTR}}-/-$ mice $\left(\mathrm{CD} 45.2^{+}\right)$receive bone marrow from wts $\left(\mathrm{CD} 45.1^{+}\right)$(wt $\rightarrow$ p $75^{\mathrm{NTR}}-/-$ ), immune cells should be $\mathrm{CD} 45.1^{+} 8$ weeks after reconstitution. Vice versa, when wt mice $\left(\mathrm{CD} 45.1^{+}\right)$are reconstituted with $\mathrm{p} 75^{\mathrm{NTR}}-/-$ bone marrow $\left(\mathrm{CD} 45.2^{+}\right)\left(\mathrm{p} 75^{\mathrm{NTR}}-/-\rightarrow\right.$ wt), the majority of the immune cells should express CD45.2. Fig. 3.38 A shows that almost all leukocytes in the peripheral blood of $\mathrm{p} 75^{\mathrm{NTR}}-/$ - mice expressed CD45.1 after reconstitution with wt $\left(\mathrm{CD} 45.1^{+}\right)$bone marrow. Similarly, almost all immune cells in wt $\left(\mathrm{CD} 45.1^{+}\right)$mice expressed CD45.2 after reconstitution with $\mathrm{p} 75^{\mathrm{NTR}}-/-\left(\mathrm{CD} 45.2^{+}\right)$bone marrow (Fig. 3.38 B). The reconstitution efficiency in our system was between $90 \%$ and $98 \%$ in all the experiments. 
A

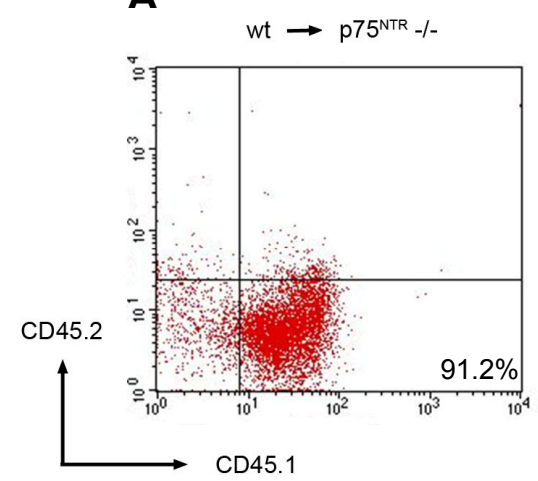

B

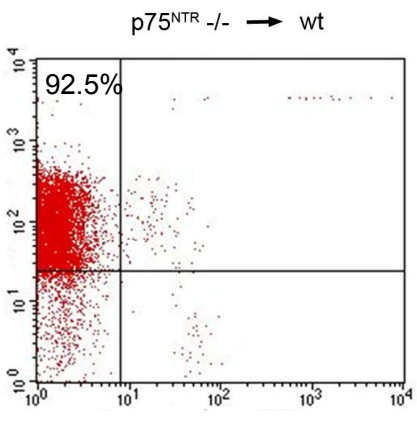

isotype

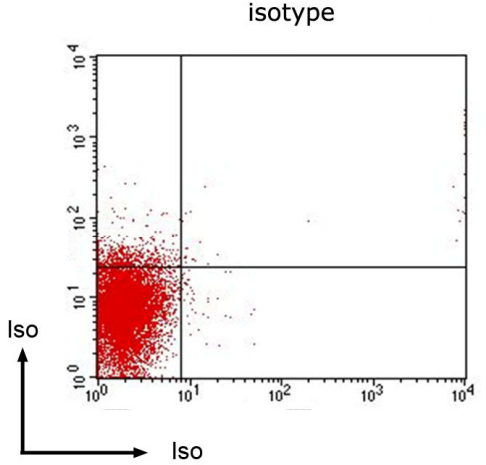

Fig. 3.38 | Flow cytometric analysis of $\mathrm{CD}^{+} 5^{+}$immune cells in the peripheral blood in bone marrow chimeras 8 weeks after reconstitution.

Wt CD 45. $1^{+}$bone marrow was received by CD45.2+ $775^{\mathrm{NTR}}-/-$ mice (wt $\rightarrow$ p $75^{\mathrm{NTR}}-/-$ ) (A). p75 $5^{\mathrm{NTR}}-/-\mathrm{CD}^{4} 5.2^{+}$ bone marrow was received by $\mathrm{CD} 45.1^{+}$wt mice $\left(\mathrm{p} 75^{\mathrm{NTR}}-/-\rightarrow \mathrm{wt}\right)(\mathrm{B})$. The reconstitution efficiency was above $90 \%$ in both groups.

A

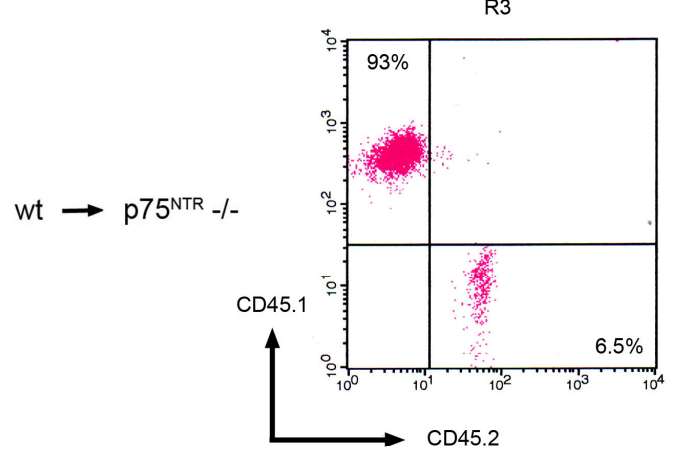

B

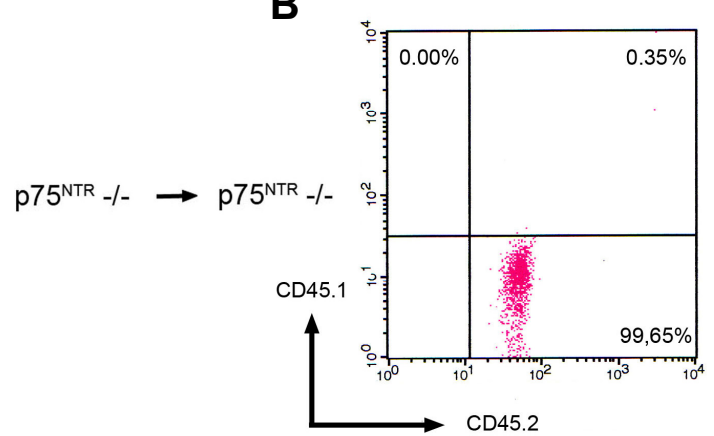

$B$ cells

R5
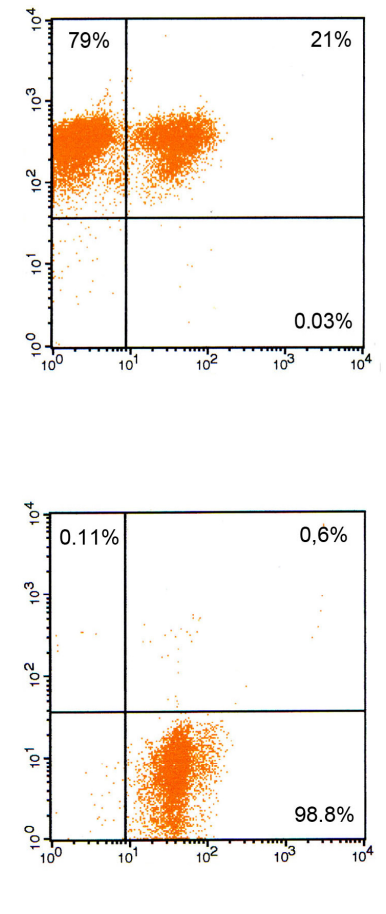

Gates
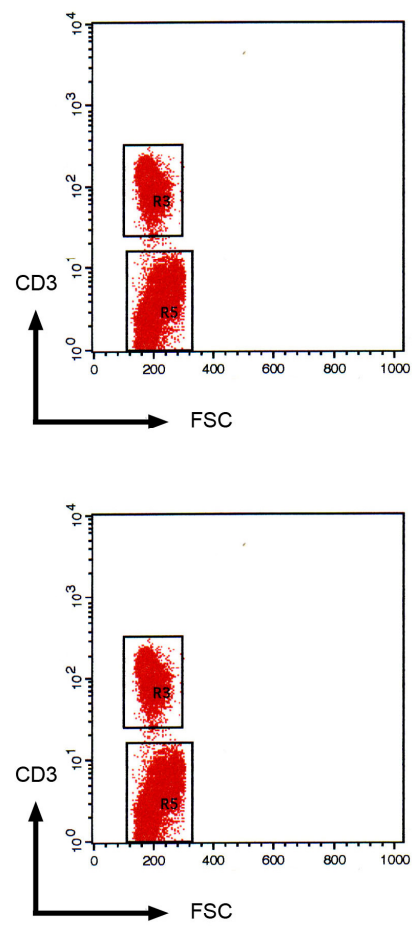

Fig. 3.39 | Flow cytometric analysis for blood $\mathrm{T}$ and $\mathrm{B}$ cells in bone marrow chimeras.

Reconstitution efficiency of $T$ cell population was $93 \%(A)$. It is very likely that the rest of the $T$ cells $(6.5 \%)$ are non-dividing memory $T$ cells. A control group ( $p 75^{\mathrm{NTR}}-/-\rightarrow \mathrm{p} 75^{\mathrm{NTR}}-/-$ ) shows specific binding of the antibodies and successful chimera generation (B). 
To determine the reconstitution efficiency of immune cell subsets, $\mathrm{T}$ and $\mathrm{B}$ cells populations were also analyzed separately (Fig. 3.39 A). For that purpose, all lymphocytes were gated and separated in $\mathrm{CD}^{+} \mathrm{T}$ cells and $\mathrm{CD} 3^{-} \mathrm{B}$ cells. In wt $\rightarrow \mathrm{p} 75^{\mathrm{NTR}}-/-$ chimeras $6.5 \%$ of all $\mathrm{T}$ cells were $\mathrm{CD} 45.2^{+}$. This population represents a non-dividing memory $\mathrm{T}$ cell subset that survived irradiation. The majority of $\mathrm{T}$ cells, however, (93\%) were derived from the reconstituted bone marrow $\left(\mathrm{CD} 45.1^{+}\right)$. In a control group $\left(\mathrm{p} 75^{\mathrm{NTR}}-/-\rightarrow \mathrm{p} 75^{\mathrm{NTR}}-/-\right) \sim 99 \%$ of the $\mathrm{T}$ and $\mathrm{B}$ cells were CD45.2 ${ }^{+}$(Fig. $3.39 \mathrm{~B}$ ).

A $\quad$ wt $\rightarrow$ p75 $75^{\text {NTR }}-/-$

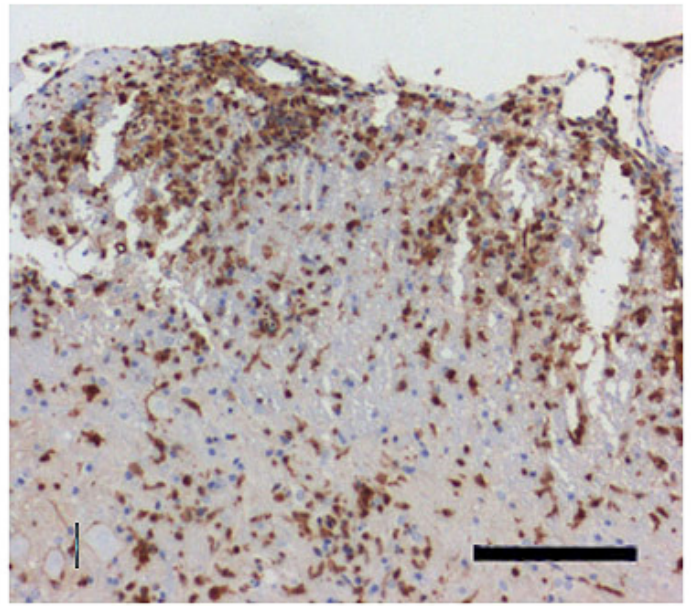

C $\quad$ P75 ${ }^{\mathrm{NTR}}-/-\rightarrow \mathrm{p} 75^{\mathrm{NTR}}-/-$

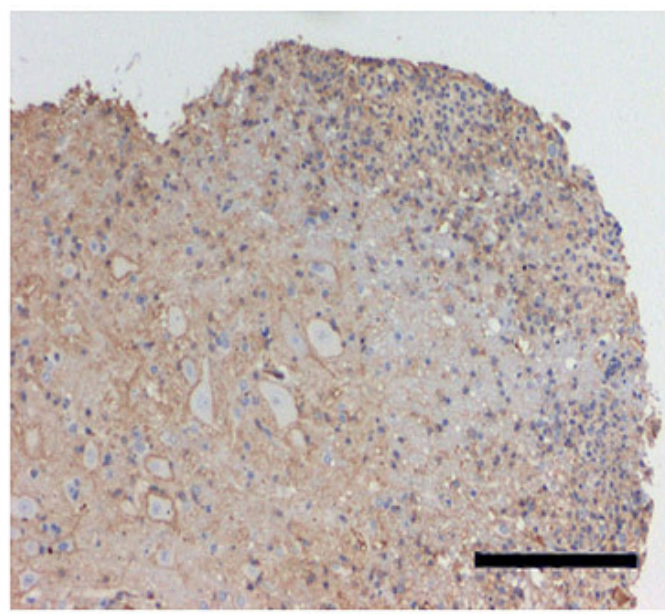

B $\quad$ p75 ${ }^{\mathrm{NTR}}-/-\rightarrow \mathrm{wt}$

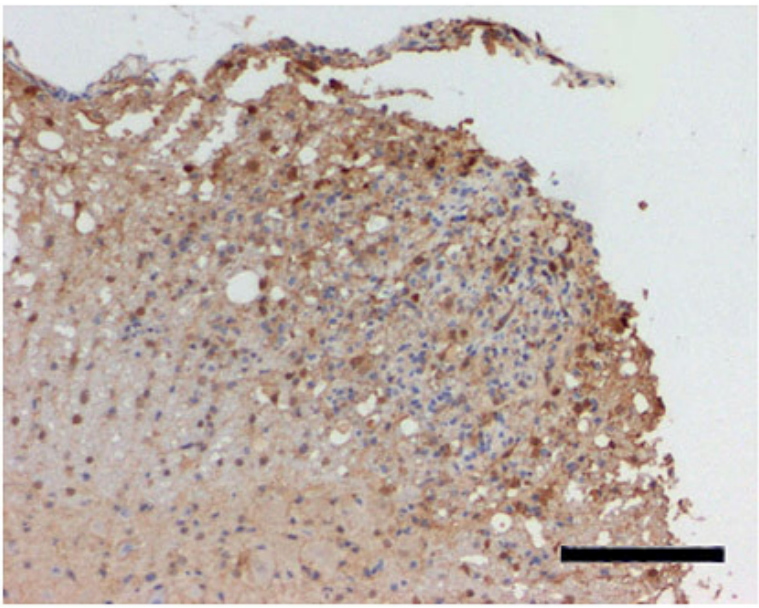

D wt $\rightarrow$ wt

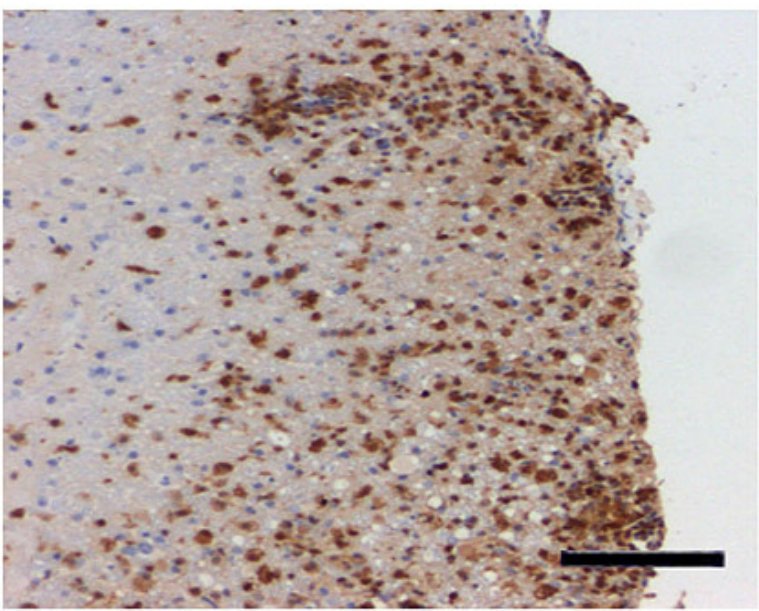

Fig. 3.40 | Visualization of chimerism: Immunohistochemical analysis of spinal cord sections at the peak of disease after active immunization.

Immunohistochemical staining of GFP (brown) detects only infiltrating immune cells in wt $\rightarrow$ p75 $5^{\text {NTR }}-/-(A)$, all CNS residential cells but no infiltrating cells in p $75^{\mathrm{NTR}}-/-\rightarrow$ wt $(\mathrm{B})$, no cells at all in the control group p75 $5^{\mathrm{NTR}}-/-$ $\rightarrow \mathrm{p} 75^{\mathrm{NTR}}-/-(\mathrm{C})$ and all cells in GFP $\rightarrow$ GFP wt mice (D). Scale bars $=50 \mu \mathrm{m}$ (A, B, D), $200 \mu \mathrm{m}$ (C) 
The bone marrow chimerism can be visualized by immunhistochemistry for GFP in mouse spinal cord sections after EAE induction. For these experiments, wt mice were not carrying the congenic CD45.1 marker but expressed GFP under the actin promoter. After active immunization at peak of disease the infiltrating $\mathrm{GFP}^{+}$immune cells are clearly distinguishable from the residential $\mathrm{GFP}^{-} \mathrm{CNS}$ cells in wt $\rightarrow$ p75 $5^{\mathrm{NTR}}-/-$ chimeras (Fig. $3.40 \mathrm{~A}$ ). Vice versa, in $\mathrm{p} 75^{\mathrm{NTR}}-/-\rightarrow$ wt chimeras the infiltrating immune cells are $\mathrm{GFP}^{-}$ and all other cells are $\mathrm{GFP}^{+}$(Fig. $3.40 \mathrm{~B}$ ). The control groups show that no cell is $\mathrm{GFP}^{+}$ $\left(\mathrm{p} 75^{\mathrm{NTR}}-/-\rightarrow \mathrm{p} 75^{\mathrm{NTR}}-/-\right)($ Fig. $3.40 \mathrm{C})$ or all cells are $\mathrm{GFP}^{+}(\mathrm{wt} \rightarrow \mathrm{wt})$, respectively (Fig. 3.40 D).

\subsubsection{Significantly reduced incidence and less severe disease course in wt $\rightarrow$ wt chimeras in the acute stage after active immunization}

The active immunization of the bone marrow chimeras was performed to examine the question, whether the lack of $\mathrm{p} 75^{\mathrm{NTR}}$ on immune or CNS resident cells is responsible for the more severe disease observed in $\mathrm{p} 75^{\mathrm{NTR}}$-/- after active immunization.

When active EAE was induced in bone marrow chimeras by immunization with $\mathrm{MOG}_{35-55}$, wt $\rightarrow$ wt chimeras suffered from a significantly milder disease course (Fig. 3.41 A). From the beginning on, p75 ${ }^{\mathrm{NTR}}-/-\rightarrow$ p $75^{\mathrm{NTR}}-/-(\mathrm{p}<0.01)$ and $\mathrm{p} 75^{\mathrm{NTR}}-/-\rightarrow$ wt $(\mathrm{p}<0.05)$ chimeras had higher scores. Compared to these two groups, wt $\rightarrow \mathrm{p} 75^{\mathrm{NTR}}-/-$ chimeras showed a trend towards a milder disease course. However, no statistically significant difference between the groups wt $\rightarrow$ p $75^{\mathrm{NTR}}-/-$ and wt $\rightarrow$ wt were found. The onset was also delayed in wt $\rightarrow$ wt. A trend towards higher cumulative scores in $\mathrm{p} 75^{\mathrm{NTR}}-/-\rightarrow$ p $75^{\mathrm{NTR}}$-/- chimeras was found $(\mathrm{p}=0.06)$ (Fig. $\left.3.41 \mathrm{~B}\right)\left(\mathrm{p} 75^{\mathrm{NTR}}-/-\rightarrow\right.$ p $75^{\mathrm{NTR}}-/-17.2+/-5.6$, $\mathrm{wt} \rightarrow \mathrm{p} 75^{\mathrm{NTR}}-/-14.5+/-6.3, \mathrm{p} 75^{\mathrm{NTR}}-/-\rightarrow$ wt $13.7+/-7.2, \mathrm{wt} \rightarrow$ wt $\left.9+/-3.9\right)$. 

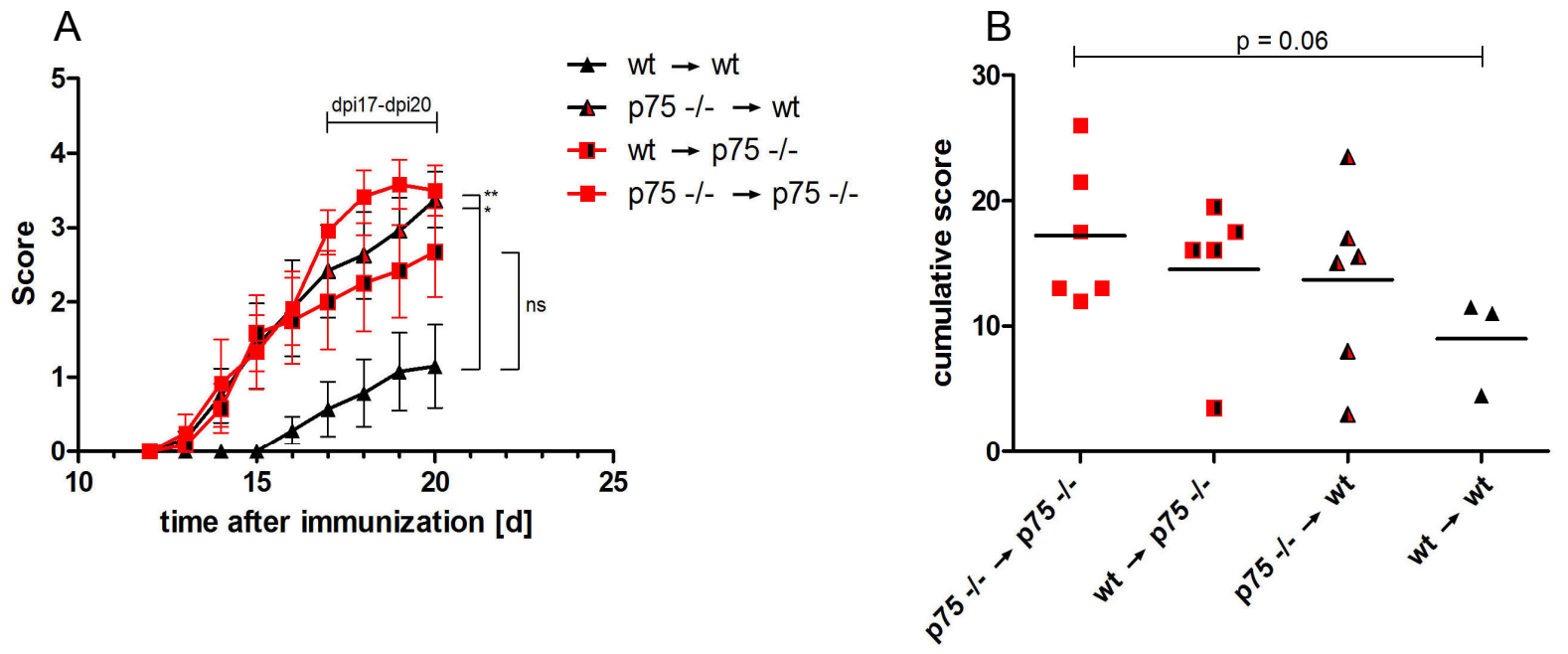

Fig. 3.41 | Acute disease course (A) and cumulative scores (B) after active immunization of bone marrow chimeric mice.

p75 $75^{\text {NTR }}-/-\rightarrow$ p75 NTR $-/-$ and p75 NTR $-/-\rightarrow$ wt chimeras showed significantly higher disease scores than wt $\rightarrow$ wt (A). The onset of disease was delayed in wt $\rightarrow$ wt. The cumulative scores of the $p 75^{\mathrm{NTR}}-/-\rightarrow \mathrm{p} 75^{\mathrm{NTR}}-/-$ chimeras were higher when compared to wt $\rightarrow$ wt $(B)$.

$100 \%$ of all $\mathrm{p} 75^{\mathrm{NTR}}-/-\rightarrow \mathrm{p} 75^{\mathrm{NTR}}-/-$ and $\mathrm{p} 75^{\mathrm{NTR}}-/-\rightarrow$ wt chimeras developed EAE. This is a significant difference in incidence when compared to $83.3 \%$ in wt $\rightarrow \mathrm{p} 75^{\mathrm{NTR}}-/-$ and $42.86 \%$ in wt $\rightarrow$ wt (Fig. 3.42) $(\mathrm{p}<0.05)$.

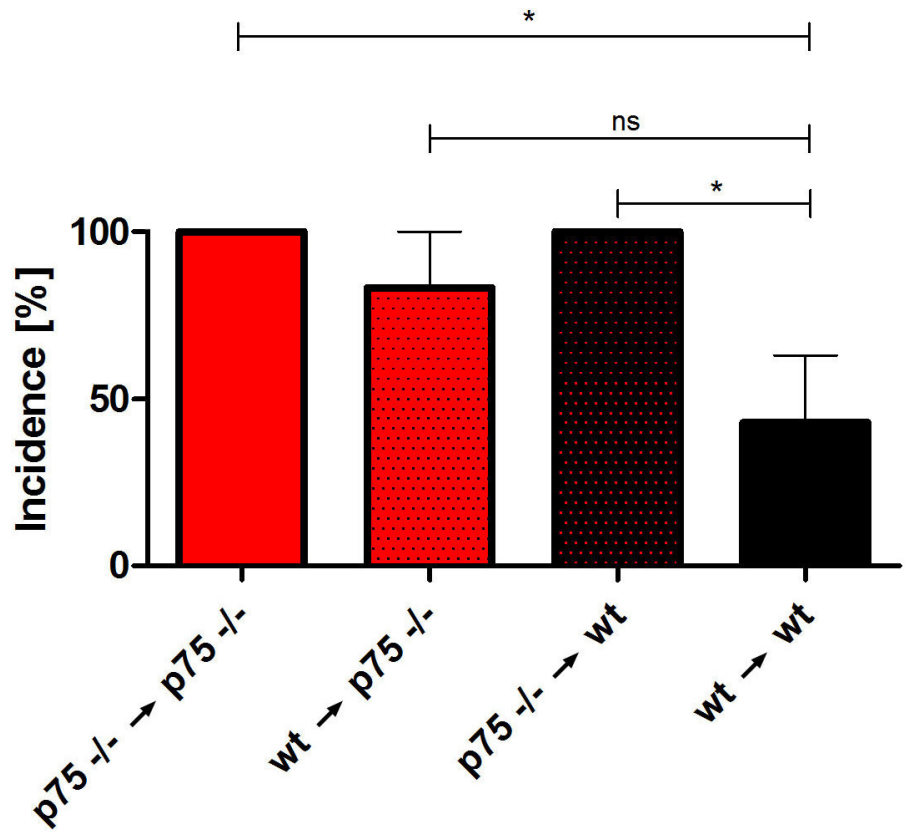

Fig. 3.42 I EAE Incidence in bone marrow chimeric mice after active immunization with MOG $_{35-55}$

p75 $75^{\text {NTR }}-/-\rightarrow$ p75 $5^{\text {NTR }}-/-$ and p75 $5^{\text {NTR }}-/-\rightarrow$ wt showed significantly higher incidence than wt $\rightarrow \mathrm{p} 75^{\mathrm{NTR}}-/-$ and wt $\rightarrow$ wt chimeras. 
In summary, mice with a p $75^{\mathrm{NTR}}$-/- immune system display more severe EAE; however, also mice with $\mathrm{p} 75^{\mathrm{NTR}}$ deficiency in the CNS develop severe EAE. These data suggest that $\mathrm{p} 75^{\mathrm{NTR}}$ plays a role in both, the immune system as well as the CNS.

\subsubsection{Histopathological disease correlates in bone marrow chimeric mice}

Wt $\rightarrow$ wt chimeras had less inflammatory infiltrates per spinal cord cross section (inflammatory index) $\left(9.2+/-3.2\right.$ infiltrates/cross section) than $\mathrm{p} 75^{\mathrm{NTR}}-/-\rightarrow \mathrm{p} 75^{\mathrm{NTR}}-/-(12.5$ $+/-2.1$ infiltrates/cross section) (wt $\rightarrow \mathrm{p} 75^{\mathrm{NTR}}-/-10.5+/-1.2$ infiltrates/cross section, p $75^{\mathrm{NTR}}-/-\rightarrow$ wt $7.6+/-1.4$ infiltrates/cross section) (Fig. 3.43). However, no significant difference was found $(\mathrm{p}>0.05)$.

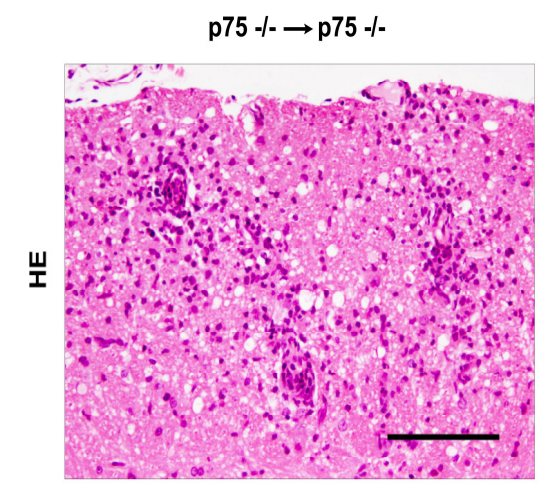

p75 $-1-\rightarrow$ wt

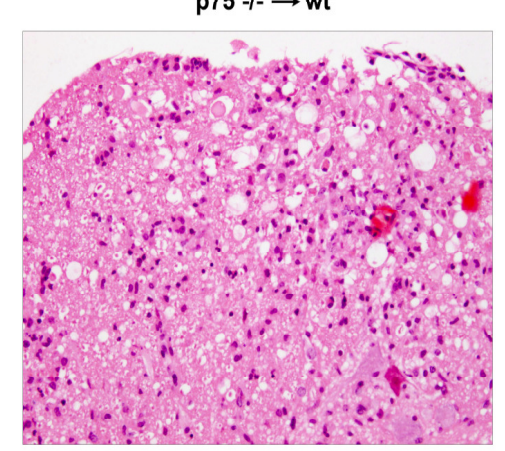

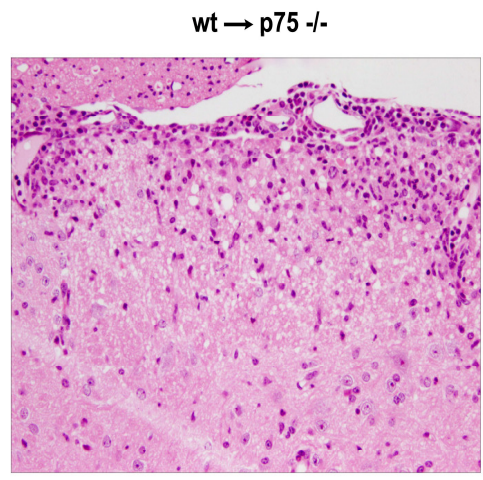

$w t \rightarrow w t$

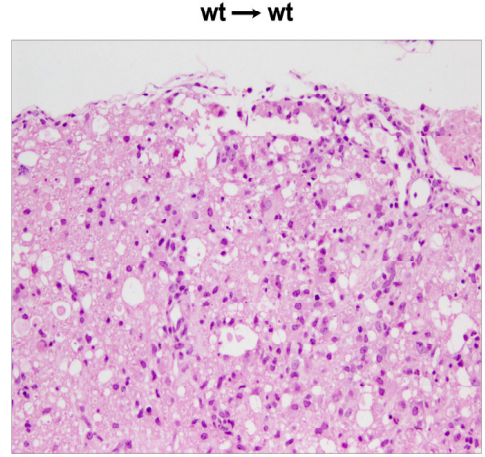

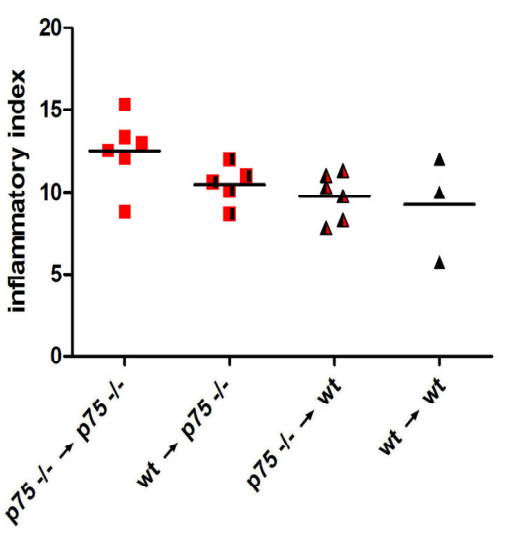

Fig. 3.43 I Inflammatory index in the acute stage after active immunization of bone marrow chimeric mice.

Slightly lower mean number of infiltrations per spinal cord cross section in wt $\rightarrow$ wt chimeras compared to p75 NTR $-/-\rightarrow$ p75 NTR $-/-$. 
In this very acute disease stage demyelinated areas in the white matter of the spinal cord mainly reflect the dense infiltrations of immune cells, which displace the myelin. No difference in the percentage of demyelinated white matter was observed between the groups $\left(\mathrm{p} 75^{\mathrm{NTR}}-/-\rightarrow \mathrm{p} 75^{\mathrm{NTR}}-/-9.02+/-1.75 \%\right.$, wt $\rightarrow \mathrm{p} 75^{\mathrm{NTR}}-/-8.16+/-1.27 \%$, p $75^{\mathrm{NTR}}-/-\rightarrow \mathrm{wt}$ $7.62+/-3.48 \%$, wt $\rightarrow$ wt $9.6+/-3.24 \%$ ) (Fig. 3.44).
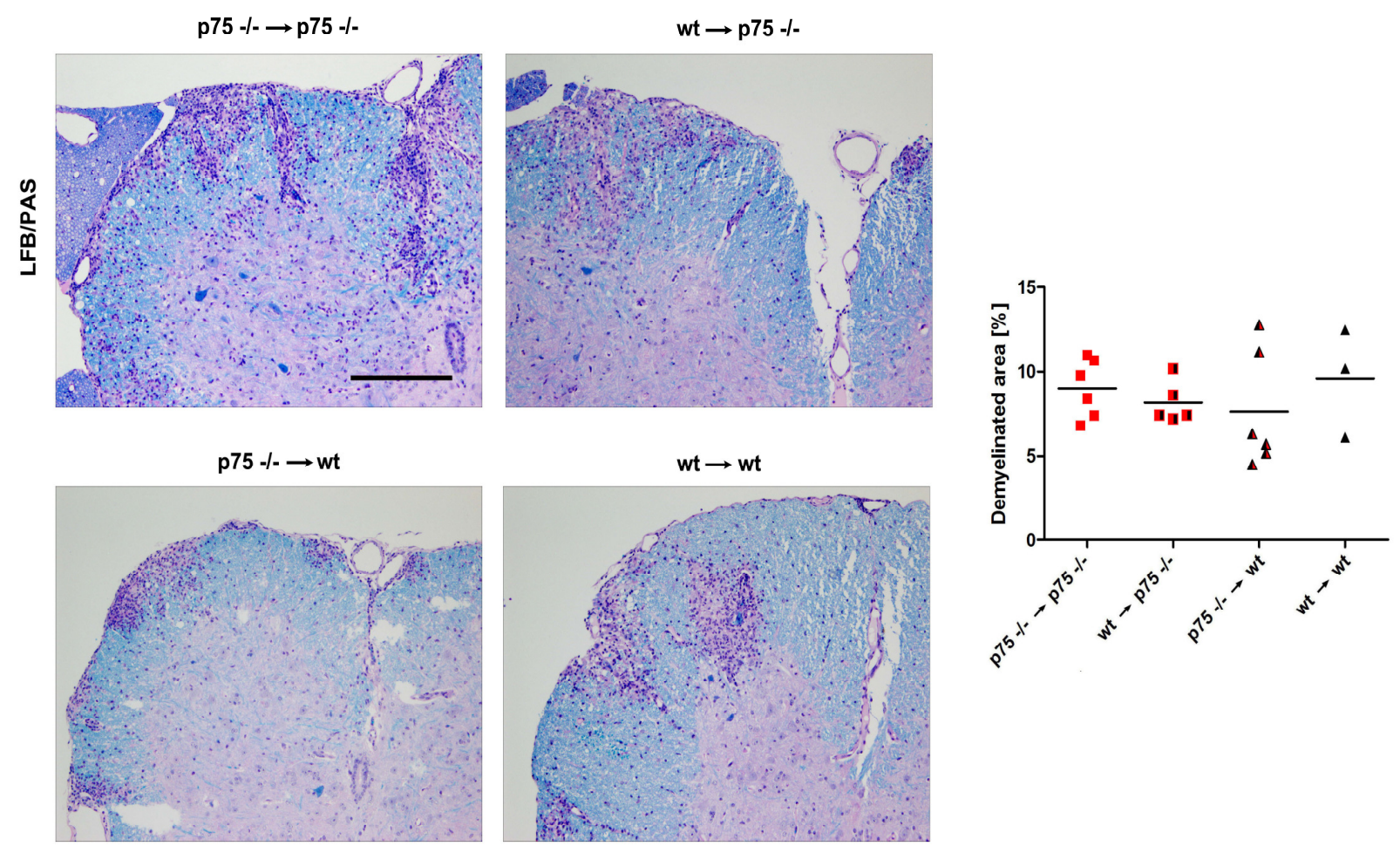

Fig. 3.44 | Demyelinated area in spinal cords of chimeras in the acute disease stage after active immunization.

No difference in white matter demyelination in the spinal cord was found. The graph displays the percentage of demyelinated white matter.

Axons in $\mathrm{p} 75^{\mathrm{NTR}}$ deficient animals suffered from more pronounced early axonal damage indicated by APP accumulation in the acute disease stage (Fig. 3.45). Wt $\rightarrow$ wt (501 $+/-212$ spheroids $\left./ \mathrm{mm}^{2}\right)$ and $\mathrm{p} 75^{\mathrm{NTR}}-/-\rightarrow \mathrm{wt}\left(513+/-273\right.$ spheroids $\left./ \mathrm{mm}^{2}\right)$ chimeras had the lowest numbers of $\mathrm{APP}^{+}$spheroids per $\mathrm{mm}^{2}$. No significant difference between these two groups was found $(\mathrm{p}=0.95) . \mathrm{p} 75^{\mathrm{NTR}}-/-\rightarrow \mathrm{p} 75^{\mathrm{NTR}}-/-\left(978+/-214\right.$ spheroids $\left./ \mathrm{mm}^{2}\right)$ and wt $\rightarrow$ p $75^{\mathrm{NTR}}-/-\left(1031+/-268\right.$ spheroids $\left./ \mathrm{mm}^{2}\right)$ chimeras attained the highest numbers. Again, no difference between the latter two groups was observed $(\mathrm{p}=0.74)$. However, both chimera groups with wt CNS show significantly lower early axonal damage when compared to the two 
other chimera groups with $\mathrm{p} 75^{\mathrm{NTR}}$ deficiency within the CNS $(\mathrm{p}<0.03)$. p $75^{\mathrm{NTR}}-/-\rightarrow \mathrm{wt}$ chimeras had relatively high disease scores while relatively few axonal damage; wt $\rightarrow$ p $75^{\mathrm{NTR}}$-/- chimeras had also relatively high scores but more damaged axons. These findings indicate an increased vulnerability of $\mathrm{p} 75^{\mathrm{NTR}}$ deficient CNS axons under inflammatory conditions.

In combination with the data obtained from the active immunization experiments, these results suggest that $\mathrm{p} 75^{\mathrm{NTR}}$ deficiency plays a role in both, the CNS and the immune system to aggravate the inflammatory disease phenotype. Without functional $\mathrm{p} 75^{\mathrm{NTR}}$, immune cells could generate a more aggressive inflammatory response, as suggested by the severe ealry disease course in $\mathrm{p} 75^{\mathrm{NTR}}-/-$ mice. On the other hand, $\mathrm{p} 75^{\mathrm{NTR}}$ deficiency within the CNS (in neurons, oligodendrocytes, microglia, or astrocytes) results in increased axonal damage.
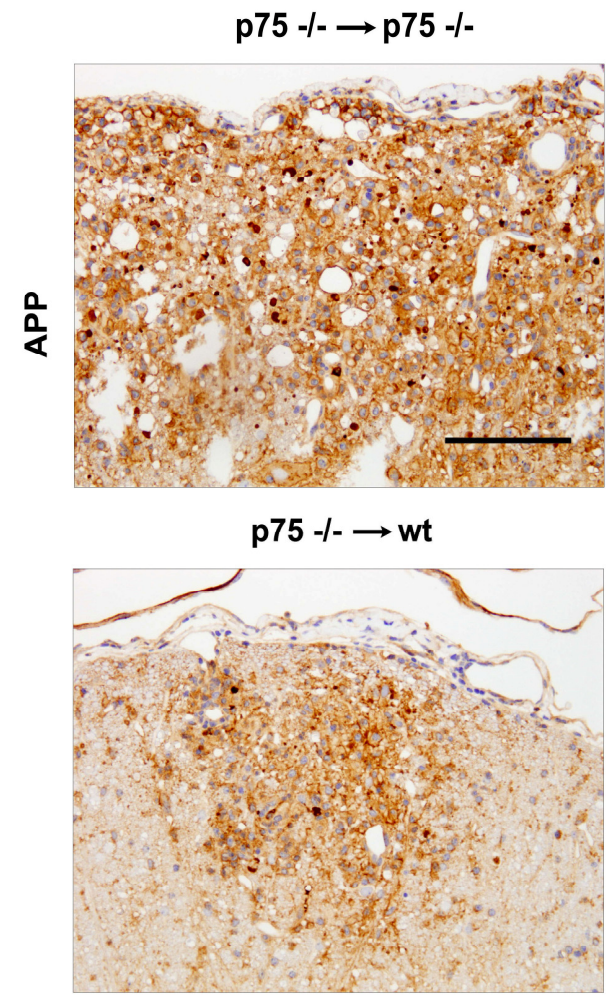

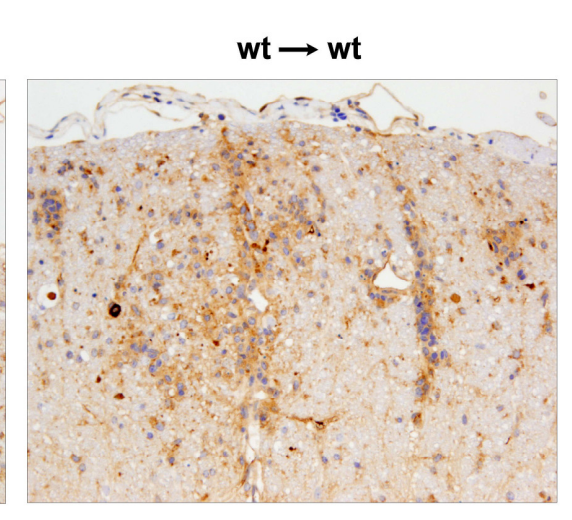

$w t \rightarrow p 75-/-$

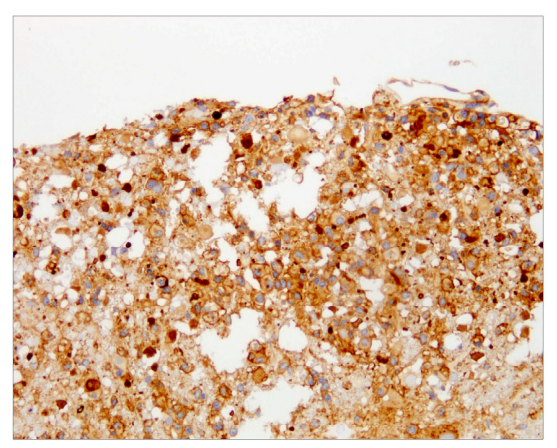

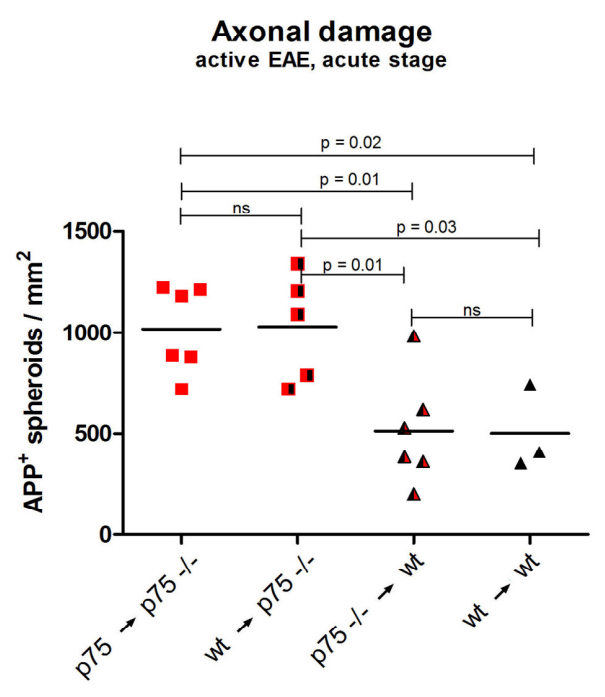

Fig. 3.45 I Early axonal damage in bone marrow chimeric mice in the acute disease stage after active immunization.

$\mathrm{p} 75^{\mathrm{NTR}}-/-\rightarrow \mathrm{p} 75^{\mathrm{NTR}}-/-$ and $w \mathrm{t} \rightarrow \mathrm{p} 75^{\mathrm{NTR}}$-/- chimeras suffer from significantly more early axonal damage than p $75^{\mathrm{NTR}}-/-$ $\rightarrow$ wt and wt $\rightarrow$ wt chimeras. 


\subsection{Induction of EAE by adoptive transfer of encephalitogenic T cells in $\mathrm{p}^{\mathrm{NTR}}-/-$ and wt mice}

To address the question if the increased disease severity in $\mathrm{p} 75^{\mathrm{NTR}}-/-$ mice results from events during priming in peripheral lymph nodes or the spleen before disease onset, EAE was induced by adoptive transfer of an encephalitogenic $\mathrm{MOG}_{35-55}$ specific $\mathrm{CD} 4^{+} \mathrm{T}$ cell clone. In contrast to active EAE induction by immunization, adoptive transfer completely circumvents de novo stimulation and proliferation of antigen-specific $\mathrm{T}$ cells. The T-cell clone expresses wt $\mathrm{p} 75^{\mathrm{NTR}}$.

\subsubsection{Similar disease onset and severity in the acute disease stage after adoptive transfer of $\mathrm{MOG}_{35-55}$ specific $\mathrm{CD4}^{+} \mathrm{T}$ cells}

Six days after adoptive transfer of $\mathrm{T}$ cells both mouse strains showed first clinical symptoms. No difference between $\mathrm{p} 75^{\mathrm{NTR}}$-/- and wt mice with regard to incidence $(100 \%$ each) (data not shown), disease onset, and severity (Fig. 3.46) were observed at any time point $(p=0.38)$. The mice were sacrificed at the peak of disease (dpi 11) for histological analysis.

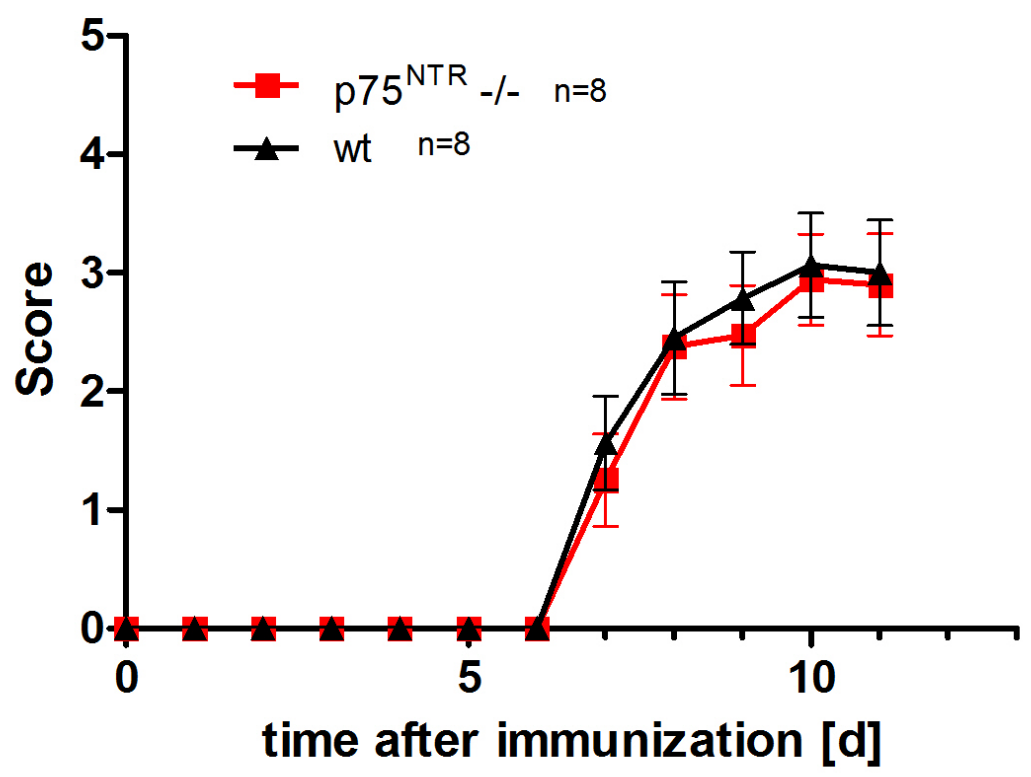

Fig. 3.46 | Disease course in the acute disease phase after the transfer of MOG $_{35-55}$ specific CD4+ $T$ cells in $p 75^{\mathrm{NTR}}-/-$ and wt animals.

Similar disease onset and severity during the acute stage in $\mathrm{p} 75^{\mathrm{NTR}}-/$ - and $\mathrm{wt}$ mice. The mice were sacrificed at the peak of disease (dpi 11) for histological analysis. 


\subsubsection{Similar quantity and quality of inflammation in the acute disease stage after adoptive transfer of a $\mathrm{CD4}^{+} \mathrm{T}$ cell clone}

To determine whether the similar disease course is also reflected on the histological level with regard to immune cell infiltration and tissue damage, immunohistochemical stainings of spinal cord sections were analyzed. No differences in the mean number of inflammatory infiltrates per spinal cord cross section were found at the peak of disease in p $75^{\mathrm{NTR}}$-/- and wt mice (Fig 3.47 A) (p75 ${ }^{\mathrm{NTR}}-/-2.7+/-1$ infiltrates/spinal cord cross section, wt $2.7+/-1$. infiltrates/spinal cord cross section, $\mathrm{p}=0.97$ ).

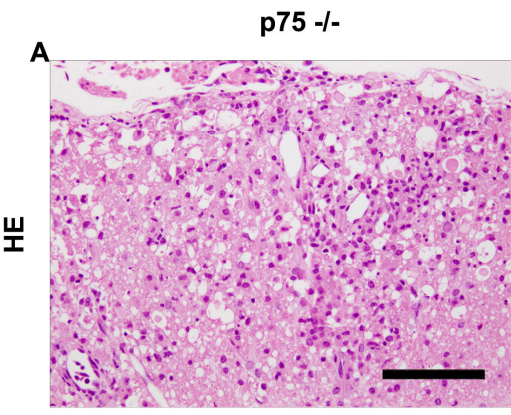

B

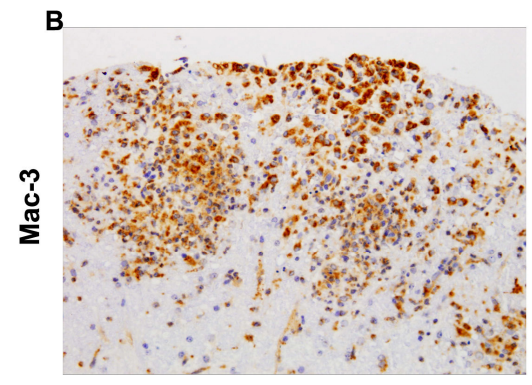

C
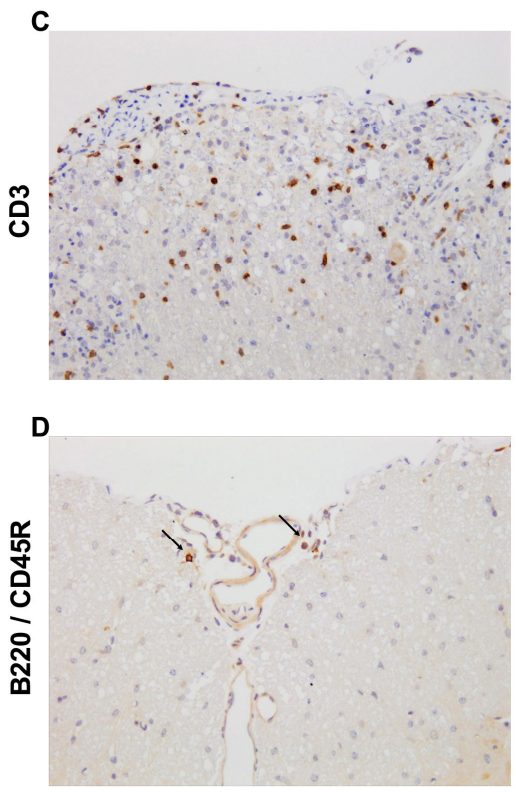

wt
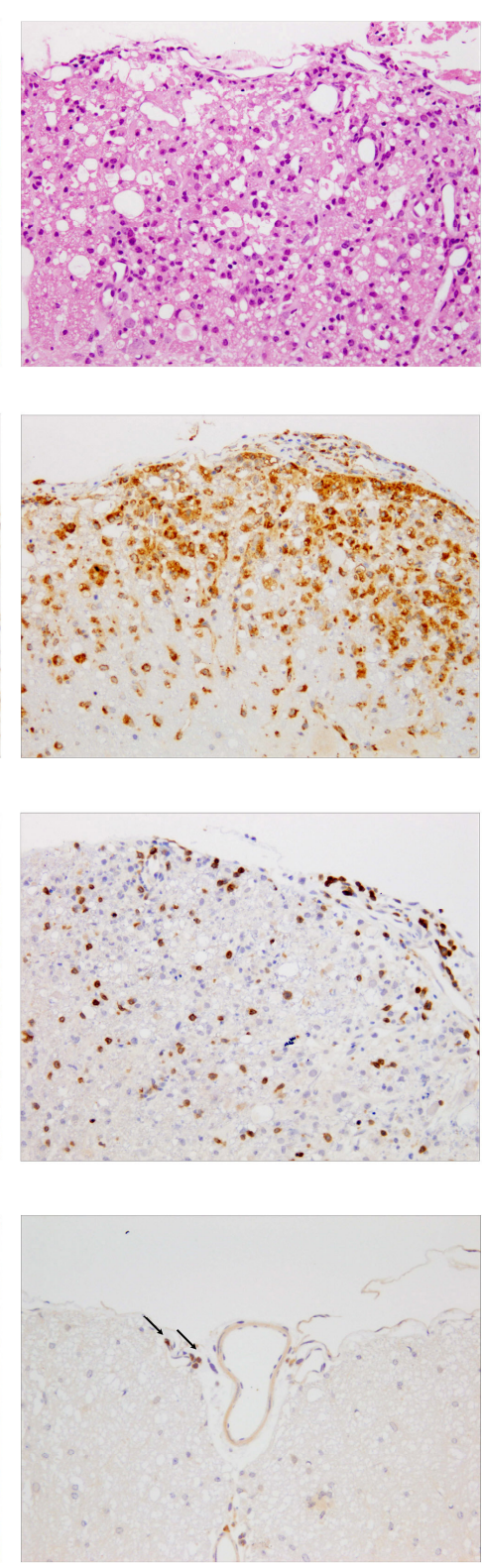
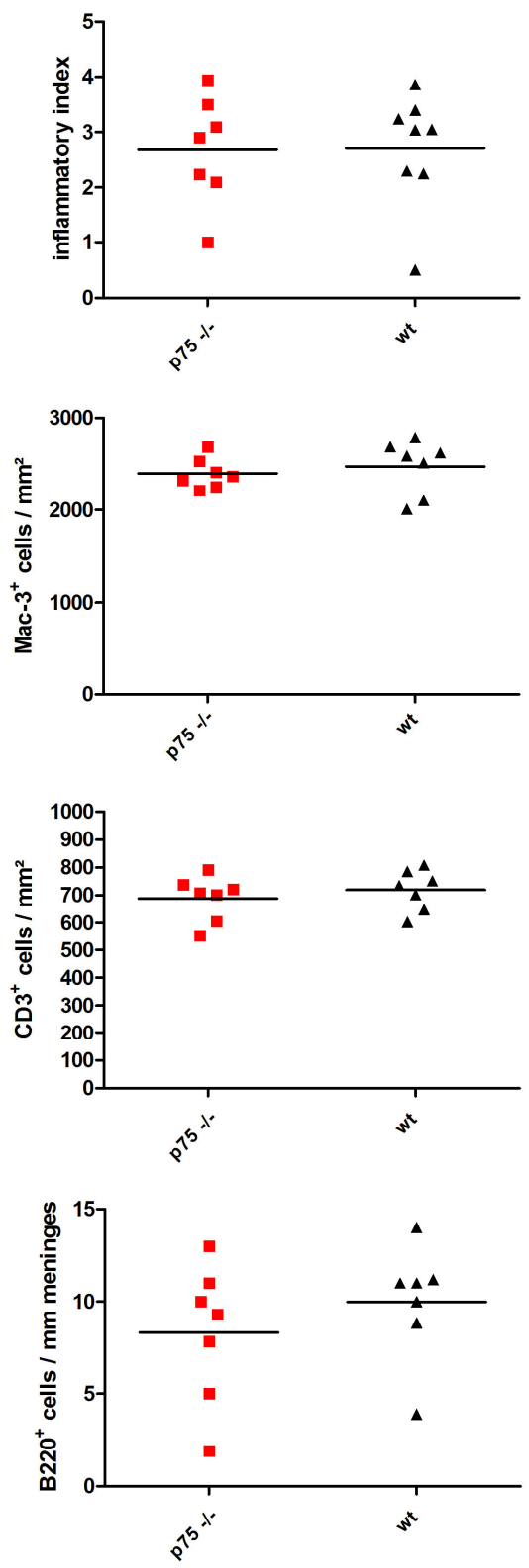

Fig 3.47 I Inflammatory infiltration in the acute disease stage after adoptive transfer of $\mathrm{CD4}^{+} \mathrm{T}^{-}$ cells.

HE (A) and immunohistochemical stainings (B-D) of spinal cord cross sections show similar numbers of inflammatory infiltrates (A), Mac- $3^{+}$macrophages/microglia (B), infiltrating $\mathrm{CD}^{+} \mathrm{T}^{+}$cells $(\mathrm{C})$ and B220/CD45R ${ }^{+}$B cells (D). Scale bars $=100 \mu \mathrm{m}$ 
Also, no differences in the cellular composition of the infiltrates were observed with respect to macrophage/microglia numbers (Fig. 3.47 B) $\left(\mathrm{p} 75^{\mathrm{NTR}}-/-2396+/-165\right.$ cells $/ \mathrm{mm}^{2}$, wt $2472+/-298$ cells $/ \mathrm{mm}^{2}, \mathrm{p}=0.57$ ), infiltration of T cells (Fig. $\left.3.47 \mathrm{C}\right)\left(\mathrm{p} 75^{\mathrm{NTR}}-/-688+/-82\right.$ cells $/ \mathrm{mm}^{2}$, wt $720+/-73$ cells $/ \mathrm{mm}^{2}, \mathrm{p}=0.47$ ) and B cells (Fig $\left.3.47 \mathrm{D}\right)\left(\mathrm{p} 75^{\mathrm{NTR}}-/-8.29+/-\right.$ 3.77 cells $/ \mathrm{mm}$ meninges, wt $10+/-3.11$ cells $/ \mathrm{mm}$ meninges, $\mathrm{p}=0.38$ ). These similarities in the extent of inflammation are in accordance with the comparable disease course in both mouse strains.

To further also assess the quality of inflammation on the histological level, spinal cord slices were immunostained for S100A9, which reveals early activated macrophages, and iNOS to show NO producing cells. Spinal cord lesions in $\mathrm{p} 75^{\mathrm{NTR}}-/-$ mice showed similar

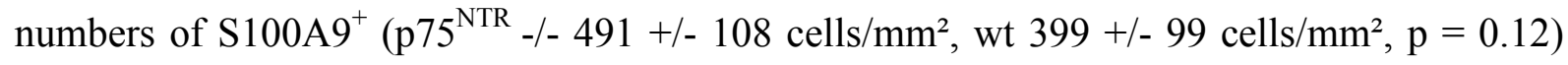
and iNOS $^{+}\left(\mathrm{p} 75^{\mathrm{NTR}}-/-1861+/-941\right.$ cells $/ \mathrm{mm}^{2}$, wt $2282+/-405$ cells $\left./ \mathrm{mm}^{2}, \mathrm{p}=0.31\right)$ macrophages/microglia as in wt mice (Fig. 3.48).
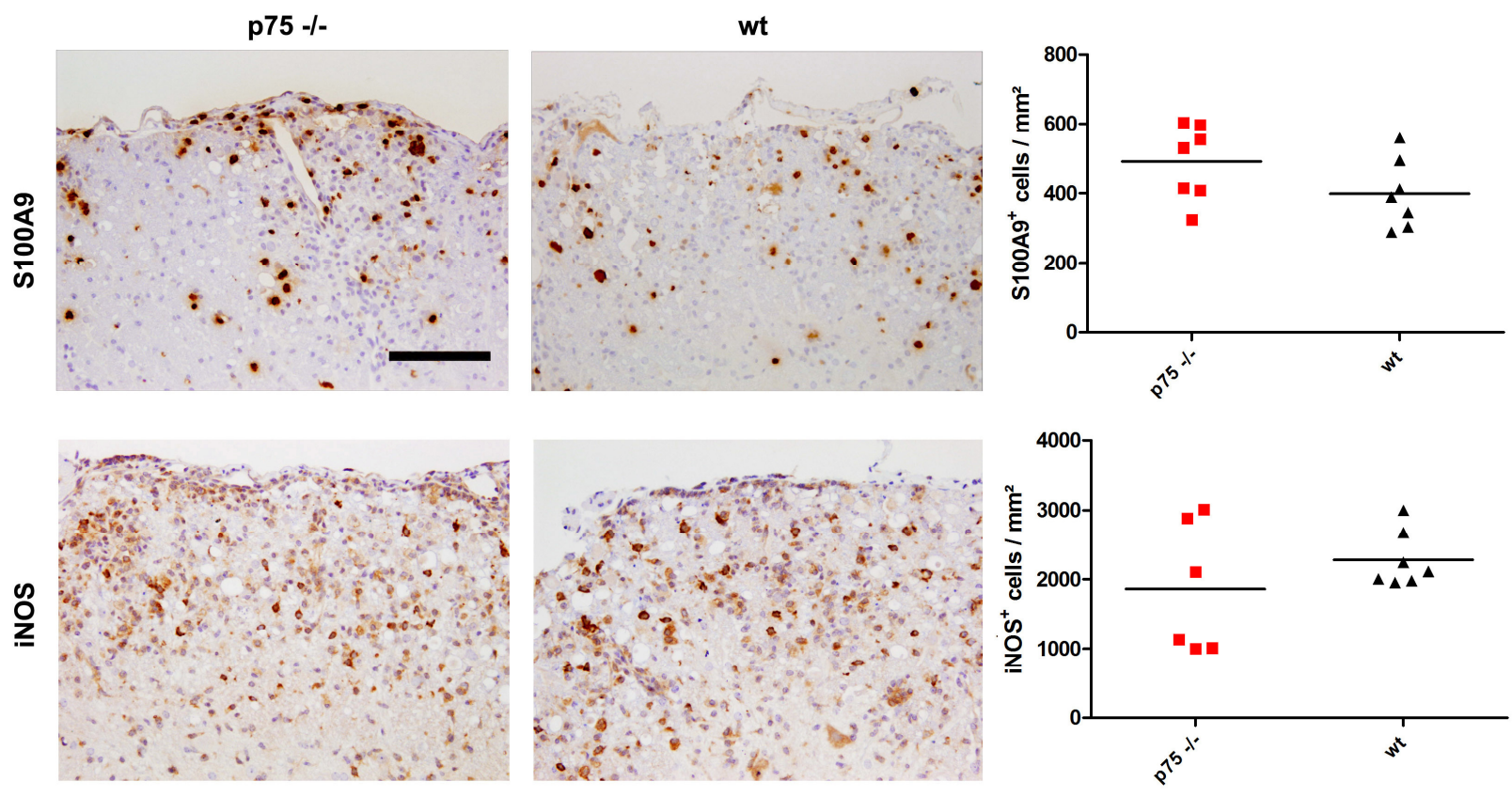

Fig. 3.48 | Early activated and NO producing macrophages /microglia at the peak of disease after adoptive transfer.

Immunohistochemical stainings of $\mathrm{S}_{100 \mathrm{~A}^{+}}$early activated macrophages and $\mathrm{iNOS}^{+} \mathrm{NO}^{\text {producing }}$ macrophages/microglia within lesions of the spinal cord showed no differences in lesional densities. 


\subsubsection{Increased axonal damage and loss in $p 75^{\mathrm{NTR}}-/-$ mice in the acute disease stage after adoptive transfer}

Axonal damage was assessed by APP immunostaining, and axonal loss by Bielschowsky silver impregnation. $\mathrm{APP}^{+}$axonal spheroids indicative of disturbed axonal transport occurred more often in spinal cord lesions of $\mathrm{p} 75^{\mathrm{NTR}}-/-$ mice (Fig. 3.49) (p75 $5^{\mathrm{NTR}}-/-$ $873+/-196$ spheroids $/ \mathrm{mm}^{2}$, wt $462+/-107$ spheroids $\left./ \mathrm{mm}^{2}, \mathrm{p}=0.0004\right)$. Axonal densities were decreased in $\mathrm{p} 75^{\mathrm{NTR}}-/-$ mice $\left(\mathrm{p} 75^{\mathrm{NTR}}-/-27.6+/-2.2 \%\right.$, wt $\left.33+/-1.5 \%, \mathrm{p}=0.0003\right)$.
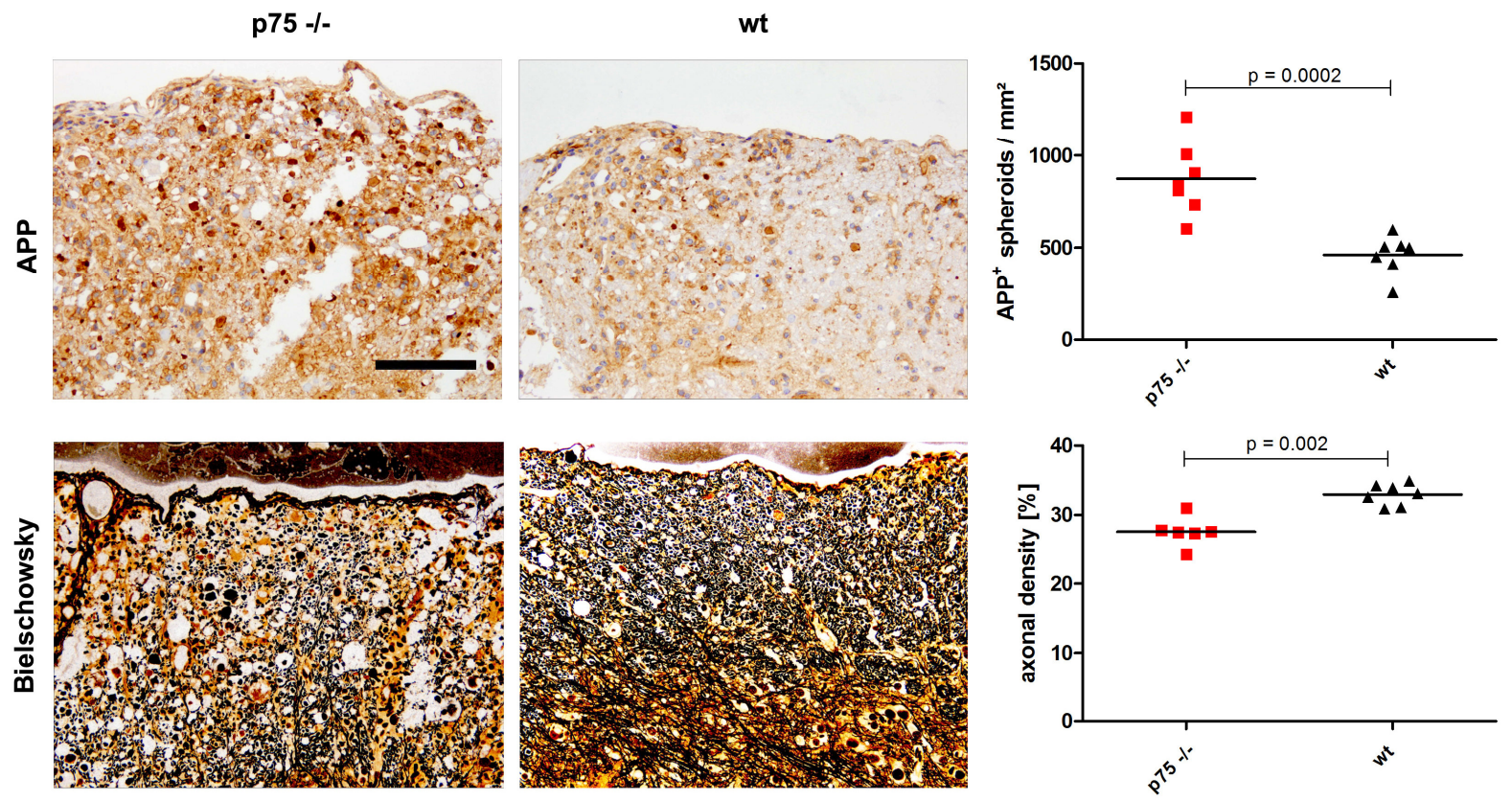

Fig. 3.49 | Axonal damage and loss in the acute disease stage after adoptive transfer.

Immunohistochemical staining for $\mathrm{APP}^{+}$axonal spheroids shows increased axonal damage in p75 $5^{\mathrm{NTR}}-/-$ mice. Bielschowsky silver impregnation reveals decreased axonal density within lesions of the spinal cord in p75 $5^{\mathrm{NTR}}-/-$ mice. Axonal densities are given as percentages of axonal density in the NAWM (set to $100 \%$ ). Scale bars = $50 \mu \mathrm{m}$

The increased axonal damage and loss while very similar disease onset, severity, quantity, and quality of inflammation in $\mathrm{p} 75^{\mathrm{NTR}}-/-$ mice suggests that $\mathrm{p} 75^{\mathrm{NTR}}$ on CNS resident cells (neurons, astrocytes, microglia, oligodendrocytes) is neuroprotective in CNS inflammation. However, an effect of $\mathrm{p} 75^{\mathrm{NTR}}$ on infiltrating immune cells could not be fully excluded by the immunohistological analysis (i.e. a more damaging immune reaction). Therefore, the quality of inflammation was further analyzed on the mRNA level by qRT-PCR. 


\subsubsection{No difference in the expression of inflammation related genes in the acute disease stage after adoptive transfer between $\mathrm{p}^{\mathrm{NTR}}$-/- and wt mice}

After EAE induction by adoptive transfer of $\mathrm{MOG}_{35-55}$ specific encephalitogenic $\mathrm{T}$ cells, spinal cords were collected at the peak of disease and total mRNA of inflammation related genes was determined by TaqMan qRT-PCR. Both, naïve and inflammed p $75^{\mathrm{NTR}}-/-$ and wt spinal cords were analyzed simultaneously and in direct comparison. The $\Delta \mathrm{CT}$ value represents the number of cycles needed to measure the first signal significantly above background. Therefore, the lower the $\Delta \mathrm{CT}$ value the higher the amount of specific mRNA within the sample. As expected, several genes were strongly upregulated in EAE at the peak of disease, such as IFN $\gamma$, TNF $\alpha$, IL-1, IL-6, iNOS, CCL2, CCL5, and CXCL10, reflecting an intense proinflammatory milieu (Fig. 3.50). Increased mRNA levels of CD4 and MHC class II reflect $\mathrm{T}$ cell and macrophage infiltration and activation. Other molecules, such as IL-17, macrophage colony stimulating factor (M-CSF), S100A8 (an marker for early activated macrophages and granulocytes), and MMP9 do not seem to play important roles in this phase of adoptive transfer EAE. Expression of the anti-inflammatory IL-10 was also increased at the peak of disease. The potential ligands for $\mathrm{p} 75^{\mathrm{NTR}}$, BDNF and NGF, were regulated only very little.

Expression levels of all analyzed genes were similar in $\mathrm{p} 75^{\mathrm{NTR}}-/-$ and wt mice, under naïve conditions as well as at the peak of disease. Consequently, to this point, the increased axonal damage in $\mathrm{p} 75^{\mathrm{NTR}}$-/- mice cannot be explained by differences in the quantity or the quality of inflammation. 

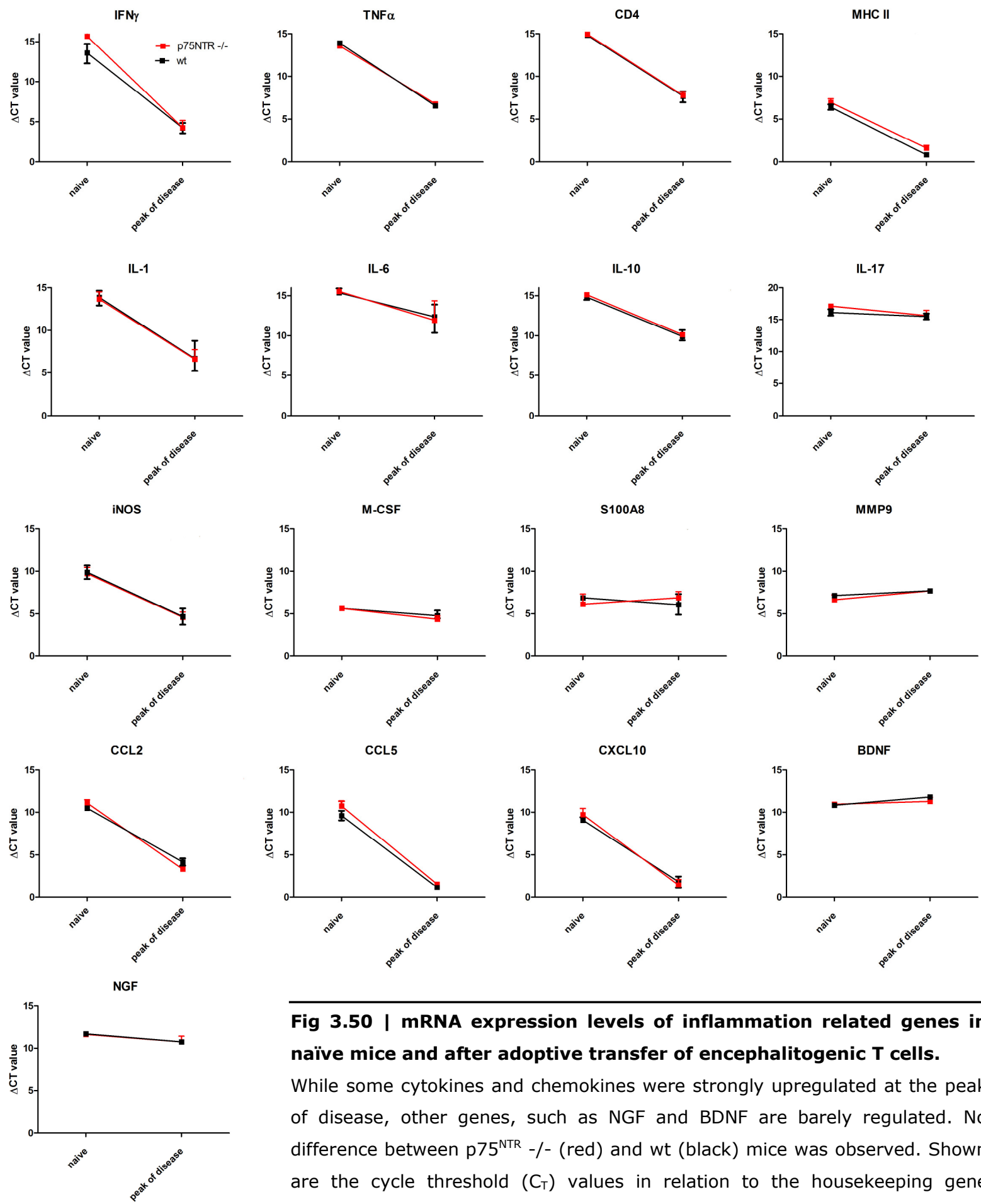

Fig 3.50 | mRNA expression levels of inflammation related genes in naïve mice and after adoptive transfer of encephalitogenic $T$ cells.

While some cytokines and chemokines were strongly upregulated at the peak of disease, other genes, such as NGF and BDNF are barely regulated. No difference between p75 NTR $-/$ - (red) and wt (black) mice was observed. Shown are the cycle threshold $\left(\mathrm{C}_{\mathrm{T}}\right)$ values in relation to the housekeeping gene GAPDH $\left(\Delta \mathrm{C}_{T}\right)$. The lower the $\Delta \mathrm{CT}$ value the higher the mRNA amount. 


\subsubsection{More severe disease course in $\mathrm{p}^{75^{\mathrm{NTR}}}-/-$ mice in the chronic disease stage after adoptive transfer of encephalitogenic $\mathbf{T}$ cells}

A "late chronic" EAE experiment ( $>50$ days of disease) was undertaken to examine the question whether the increased early axonal damage in $\mathrm{p} 75^{\mathrm{NTR}}-/-$ mice has effects on the disease severity and axonal density in the chronic stage. Therefore, EAE was induced by adoptive transfer of a $\mathrm{CD} 4{ }^{+} \mathrm{T}$ cell clone and the mice were sacrificed at dpi 65 . Again, disease onset and peak were very similar in $\mathrm{p} 75^{\mathrm{NTR}}$-/- and wt mice (Fig. 3.51). However, from dpi 50 on daily clinical scores were significantly higher in $\mathrm{p} 75^{\mathrm{NTR}}-/-$ mice $(\mathrm{p}<0.0001)$.

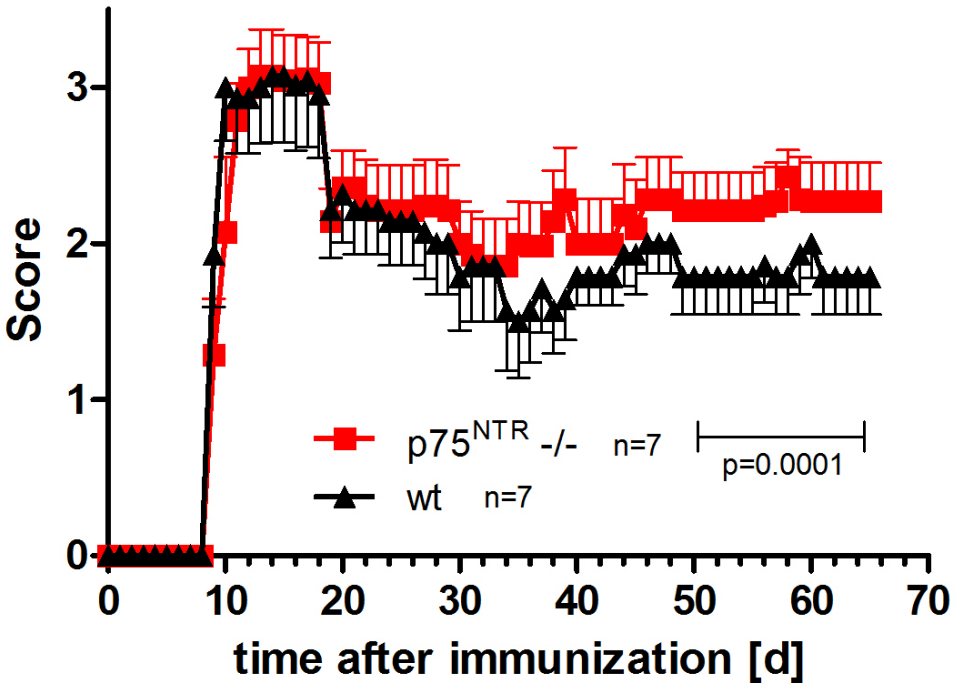

Fig. 3.51 Disease course
in the chronic stage after
adoptive transfer.
Similar course at onset and
peak of disease but
significantly more severe
disease in p75
50 onwards.

\subsubsection{Less $T$ cell infiltration in $\mathbf{p} 75^{\mathrm{NTR}}-/-$ mice in the chronic disease stage after adoptive transfer}

At dpi 65 after adoptive transfer the inflammatory spinal cord lesions were analyzed with regard to macrophage, $\mathrm{T}$ cell and $\mathrm{B}$ cell infiltration (Fig. 3.53). In the chronic disease stage fewer inflammatory cells were observed than at the peak of disease. No differences in the density of Mac- $3^{+}$macrophages/microglia (Fig. 3.52 A) $\left(\mathrm{p} 75^{\mathrm{NTR}}-/-406+/-50\right.$ cells $/ \mathrm{mm}^{2}$, wt $398+/-53$ cells $/ \mathrm{mm}^{2}, \mathrm{p}=0.76$ ) and meningeal B220/CD45R ${ }^{+}$B cells (Fig. $3.52 \mathrm{C}$ ) 
$\left(\mathrm{p} 75^{\mathrm{NTR}}-/-1.05+/-0.42\right.$ cells $/ \mathrm{mm}$ meninges, wt $0.81+/-0.44$ cells $/ \mathrm{mm}$ meninges, $\mathrm{p}=0.32$ ) were found between $\mathrm{p} 75^{\mathrm{NTR}}-/-$ and wt mice. Surprisingly, despite the fact that the disease course was more severe, significantly less $\mathrm{CD}^{+} \mathrm{T}$ cells were counted in $\mathrm{p} 75^{\mathrm{NTR}}-/-$ compared to wt mice at this time point (Fig. 3.52 B) $\left(\mathrm{p} 75^{\mathrm{NTR}}-/-58.8+/-25.7\right.$ cells $/ \mathrm{mm}^{2}$, wt $141.5+/-$ 32.7 cells $\left./ \mathrm{mm}^{2}, \mathrm{p}=0.0002\right)$.
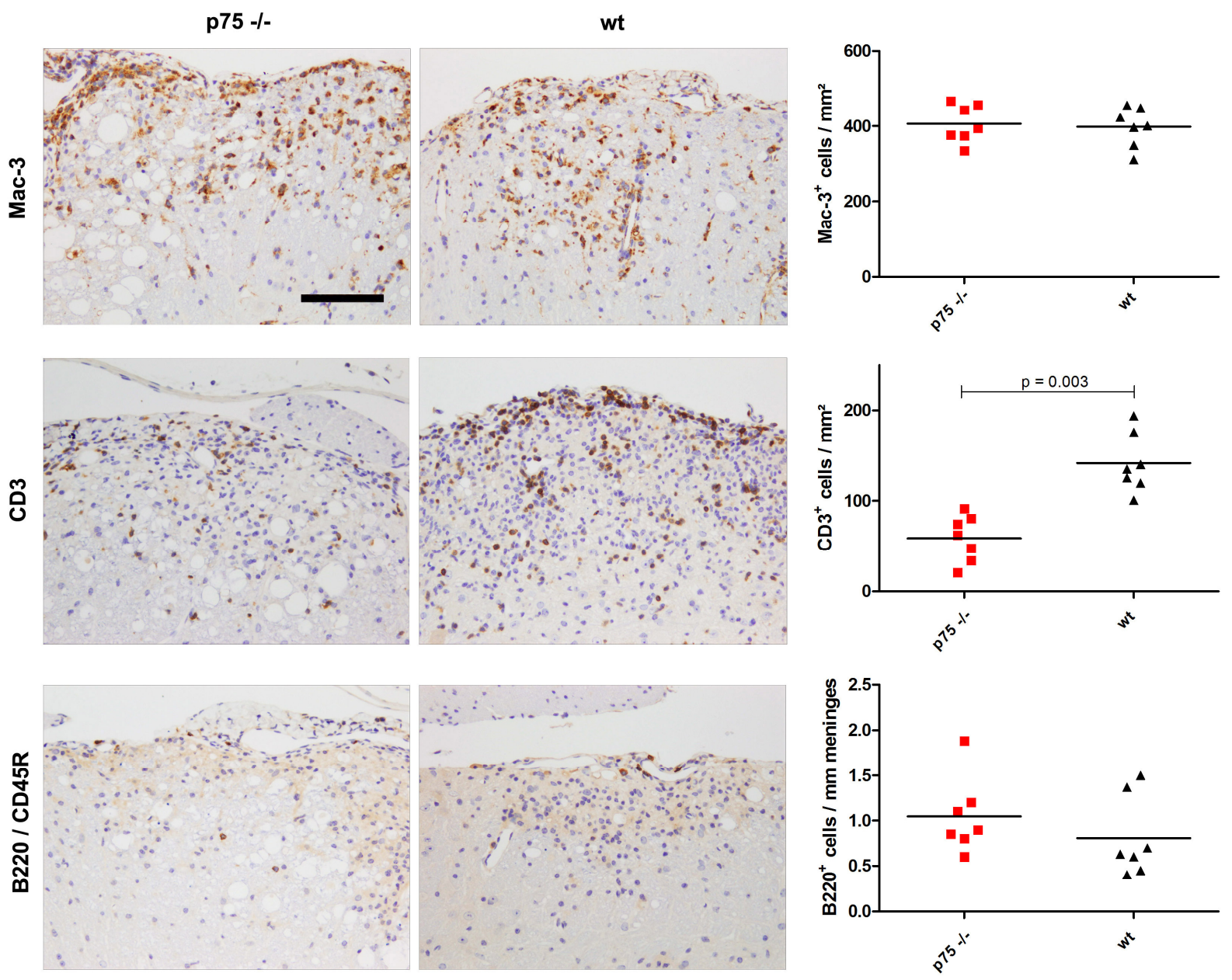

Fig. 3.52 Inflammation in the chronic disease stage after adoptive transfer.

Immunohistochemical stainings for Mac-3 (A), CD3 (B) and B220/CD45R (C) reveal similar numbers of macrophages/microglia and $B$ cells. Numbers of $T$ cells were increased in wt mice although less severe disease course was observed. Scale bars $=100 \mu \mathrm{m}(\mathrm{A}, \mathrm{B}), 50 \mu \mathrm{m}(\mathrm{C})$ 


\subsubsection{Similar extent of demyelination and oligodendroglial damage in p75 ${ }^{\mathrm{NTR}}-/-$ and wt mice in the chronic disease stage after adoptive transfer of encephalitogenic $T$ cells}

In this late chronic disease stage, the assessment of small perivascular, subpial or intraparenchymal inflammatory infiltrates (as performed in animals examined at the peak of disease) does not reflect the severity of tissue damage and disease. Instead, the extent of demyelinated lesions was assessed and given as percentage of the total white matter (Fig. $3.53 \mathrm{~A}) \quad\left(\mathrm{p} 75^{\mathrm{NTR}}-/-1.4+/-0.74 \%\right.$ demyelination of WM, wt $1.41+/-0.65 \%$ demyelination of WM, $\mathrm{p}=0.99$ ). Oligodendroglial damage was assessed by the density of $\mathrm{NogoA}^{+}$mature oligodendrocytes within lesions (Fig. 3.53 B) $\left(\mathrm{p} 75^{\mathrm{NTR}}-/-466+/-123\right.$ cells $/ \mathrm{mm}^{2}$, wt $330+/-112$ cells $/ \mathrm{mm}^{2}, \mathrm{p}=0.11$ ). No differences were found between $\mathrm{p} 75^{\mathrm{NTR}}-/-$ and wt mice.

A

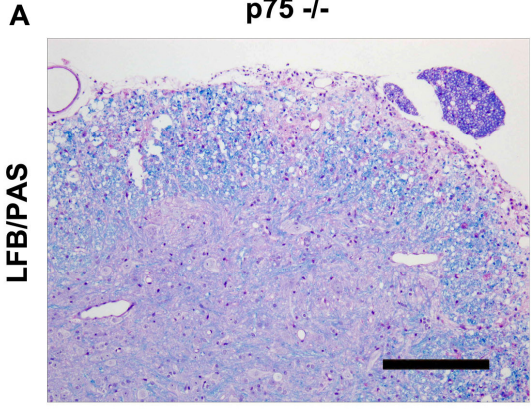

B

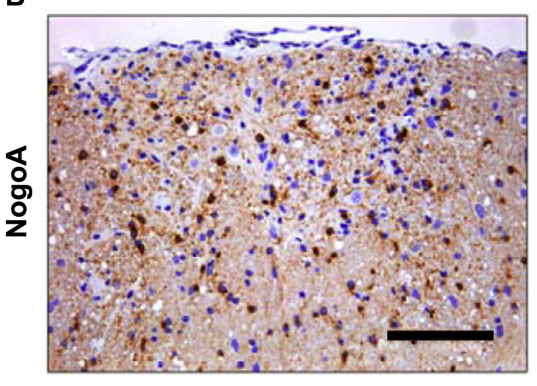

wt
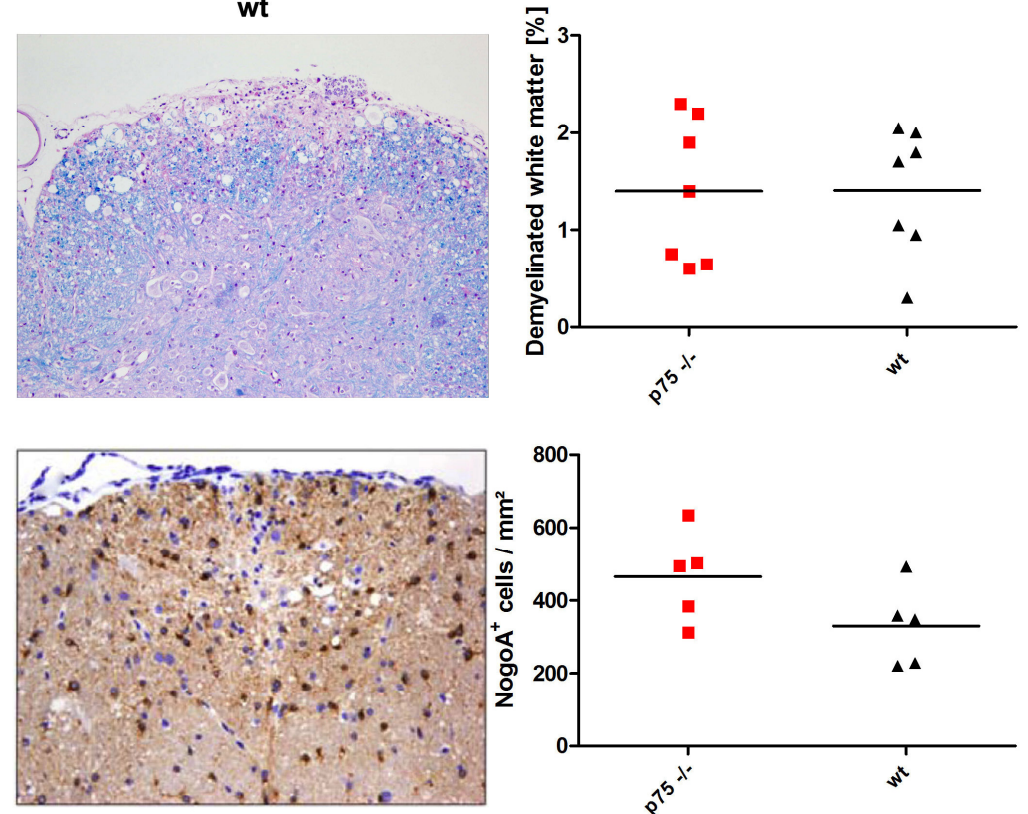

Fig. 3.53 | Demyelination in the chronic disease stage after adoptive transfer.

The percentage of the demyelinated area of the total white matter in spinal cord cross sections was calculated in LFB/PAS stained sections (A). Oligodencroglial damage was assessed by detection of mature oligodendrocytes expressing NogoA (B). No differences were observed between $p 75^{\mathrm{NTR}}$-/- and wt mice. Scale bars $=200 \mu \mathrm{m}(A), 100 \mu \mathrm{m}(B)$ 


\subsubsection{Increased axonal damage and loss in $p 75^{\mathrm{NTR}}-/-$ mice in the chronic disease stage after adoptive transfer}

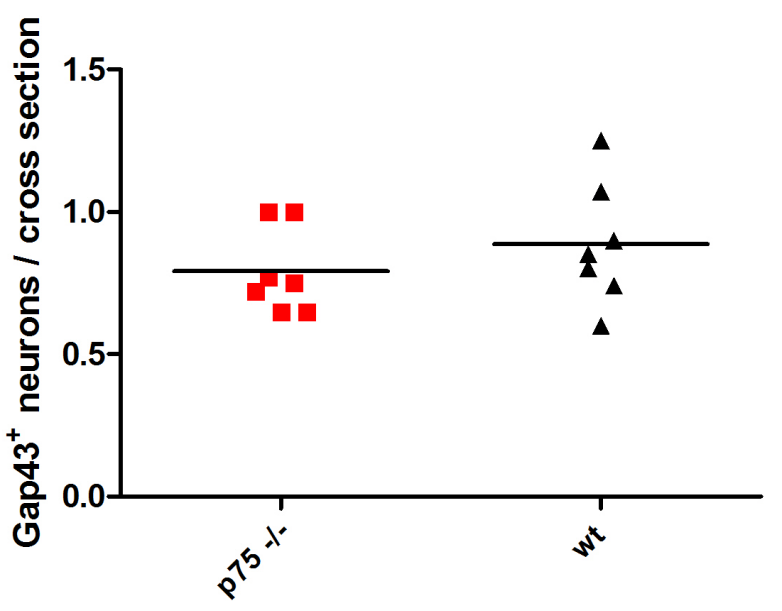

Fig. 3.54 | GAP43 $^{+}$neurons in the chronic disease stage after adoptive transfer.

No differences between $p 75^{\mathrm{NTR}}$-/- and wt mice were observed with regard to numbers of immunohistochemically detected Gap43 ${ }^{+}$neurons.
The capacity of neuroaxonal regeneration was assessed by immunostaining for Gap $43^{+}$neurons (Fig. 3.54). Only single $\mathrm{GAP}^{+} 3^{+}$neurons were observed. No differences between $\mathrm{p} 75^{\mathrm{NTR}}-/-$ and wt mice were found $\left(\mathrm{p} 75^{\mathrm{NTR}}-/-0.8+/-0.15\right.$ cells $/ \mathrm{mm}^{2}$, wt $0.89+/-0.22$ cells $/ \mathrm{mm}^{2}, \mathrm{p}=0.35$ ).
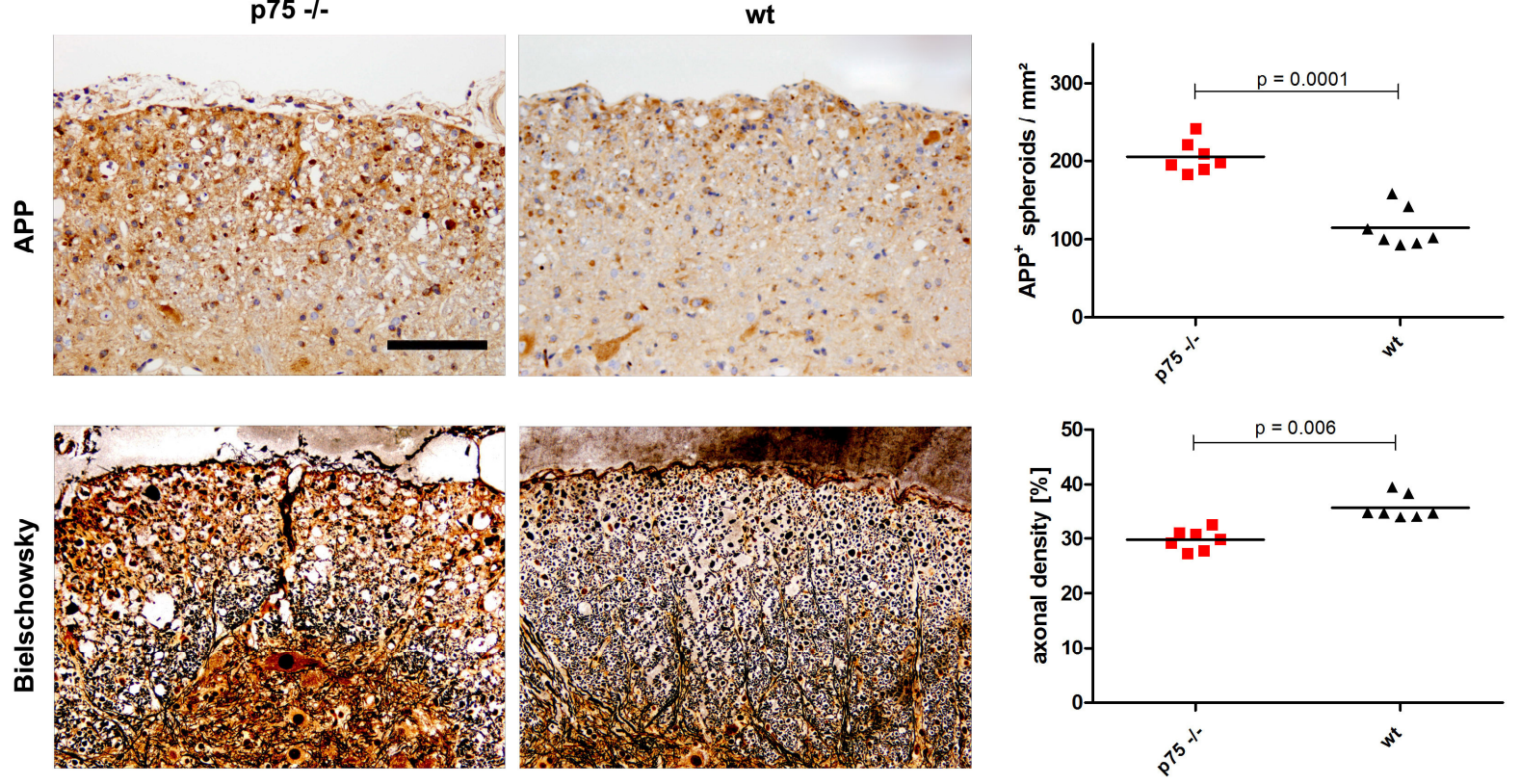

Fig. 3.55 | Axonal damage and loss in the chronic disease stage after adoptive transfer.

Immunohistochemical staining for APP revealed an increased degree of axonal damage in spinal cord lesions of p75 NTR $-/-$ mice. The relative axonal density in lesions was significantly lower in p75 ${ }^{\text {NTR }}$ deficient mice. Axonal densities are shown as percentages of axonal density in the NAWM (set to $100 \%$ ). Scale bars $=50 \mu \mathrm{m}$ 
The degree of axonal damage was determined by the density of $\mathrm{APP}^{+}$axonal spheroids within lesions; the degree of axonal loss by Bielschowsky silver impregnation (Fig. 3.55). Axonal damage (p75 $5^{\mathrm{NTR}}-/-205$ +/- 20 spheroids $/ \mathrm{mm}^{2}$, wt 115 +/- 25 spheroids $/ \mathrm{mm}^{2}$, $\mathrm{p}=0.000009)$ and loss $\left(\mathrm{p} 75^{\mathrm{NTR}}-/-29+/-1.8 \%\right.$, wt $\left.36+/-2.2 \%, \mathrm{p}=0.0001\right)$ were significantly increased in spinal cord lesions of $\mathrm{p} 75^{\mathrm{NTR}}-/-$ mice.

Having shown the similar quantity and quality of inflammation in the acute and chronic disease stage after adoptive transfer, the more severe axonal damage and loss at both time points in $\mathrm{p} 75^{\mathrm{NTR}}-/-$ mice suggested an important neuroprotective role for $\mathrm{p} 75^{\mathrm{NTR}}$ within the CNS, i.e. in neurons, astroglia, microglia, and oligodendroglia. Therefore, primary cell cultures of microglia and astrocytes were analyzed with regard to $\mathrm{p} 75^{\mathrm{NTR}}$ and cytokine/chemokine expression, ROS production, and modulation thereof by NGF.

\subsection{No $\mathrm{p}^{\mathrm{NTR}}$ expression in primary microglia cultures}

To analyze the role of $\mathrm{p} 75^{\mathrm{NTR}}$ deficiency in the CNS in more detail, primary microglia cultures from wt mice were used (kindly provided by Prof. Dr. Hanisch). No p75 $5^{\text {NTR }}$ expression was detected after LPS and PMA stimulation at different time points by TaqMan qRT-PCR (Tab. 3.3). Also, different NGF concentrations had no effect on $\mathrm{p} 75^{\mathrm{NTR}}$ expression and did not modulate the amount of CCL5 produced after LPS stimulation (data not shown).

Therefore, a direct modulation of microglia via $\mathrm{p} 75^{\mathrm{NTR}}$ during EAE can be ruled out.

\begin{tabular}{|c|ccc|c|c|c|}
\hline & & & & \multicolumn{4}{|c|}{ 24h } \\
microglia & 3h & 6h & 24h & +NGF 1 & +NGF 10 & +NGF 100 \\
\hline unstim. & bdl & bdl & bdl & bdl & bdl & bdl \\
LPS & bdl & bdl & bdl & bdl & bdl & bdl \\
PMA & bdl & bdl & bdl & bdl & bdl & bdl \\
NGF & bdl & bdl & bdl & nd & nd & nd \\
\hline
\end{tabular}

Tab. 3.3 | No p75 NTR expression in primary microglia cultures. No p75 ${ }^{\mathrm{NTR}}$ expression by microglia upon various stimuli at different time points. 


\subsection{Constitutive $\mathrm{p}^{\mathrm{NTR}}$ expression in primary astrocytes cultures}

To obtain a primary culture of astrocytes, after removing the meninges, single cell suspensions of the whole brain from $\mathrm{p} 0$ mice were disseminated in dishes. Oligodendrocytes

\begin{tabular}{|c|c|c|c|c|}
\hline astrocytes & $3 \mathrm{~h}$ & $6 \mathrm{~h}$ & $24 \mathrm{~h}$ & Tab. 3.4 I Constitutive \\
\hline unstim. & 6,96 & 6,55 & 6,79 & astrocyte \\
\hline PMA 5 & 6,35 & 6,31 & 7,37 & $\begin{array}{l}\text { cultures. } \\
\text { p75 }\end{array}$ \\
\hline PMA 50 & 5,60 & 5,03 & 8,19 & detected after all stimuli and \\
\hline NGF & 6,24 & 6,56 & 7,05 & \\
\hline
\end{tabular}

were shaken off and microglia were depleted by clodronate. $\mathrm{p} 75^{\mathrm{NTR}}$ expression, assessed by TaqMan qRT-PCR, was found in unstimulated and PMA stimulated conditions at all time points (Tab. 3.4). This constitutive $\mathrm{p} 75^{\mathrm{NTR}}$ expression was not regulated by NGF.

Therefore, the effect of $\mathrm{p} 75^{\mathrm{NTR}}$ deficiency on astrocytes was analyzed in more detail with regard to ROS and cytokine/chemokine production and its modulation by NGF.

\subsubsection{No difference in the ROS production by primary $p 75^{\mathrm{NTR}}$ deficient and wt astrocytes}

ROS production by primary $\mathrm{p} 75^{\mathrm{NTR}}$-/- and wt astrocytes cultures was measured in vitro after several pretreatments (LPS, IFN $\gamma$ ) and stimuli (PMA, Zymosan). Intracellular ROS were detected by the fluorescent dye $\mathrm{CM}-\mathrm{H}_{2}$ DCFDA. This molecule loses its membrane permeability upon ROS binding and is then trapped intracellularly. Arbitrary units for fluorescence intensity were measured over time (Fig. 3.56). Under none of the conditions examined differences between $\mathrm{p} 75^{\mathrm{NTR}}$ deficient and wt astrocytes could be found. Besides, pretreatment with LPS or IFN $\gamma$ as well as stimulation with PMA or Zymosan did not lead to an increase in ROS production compared to untreated unstimulated controls. 


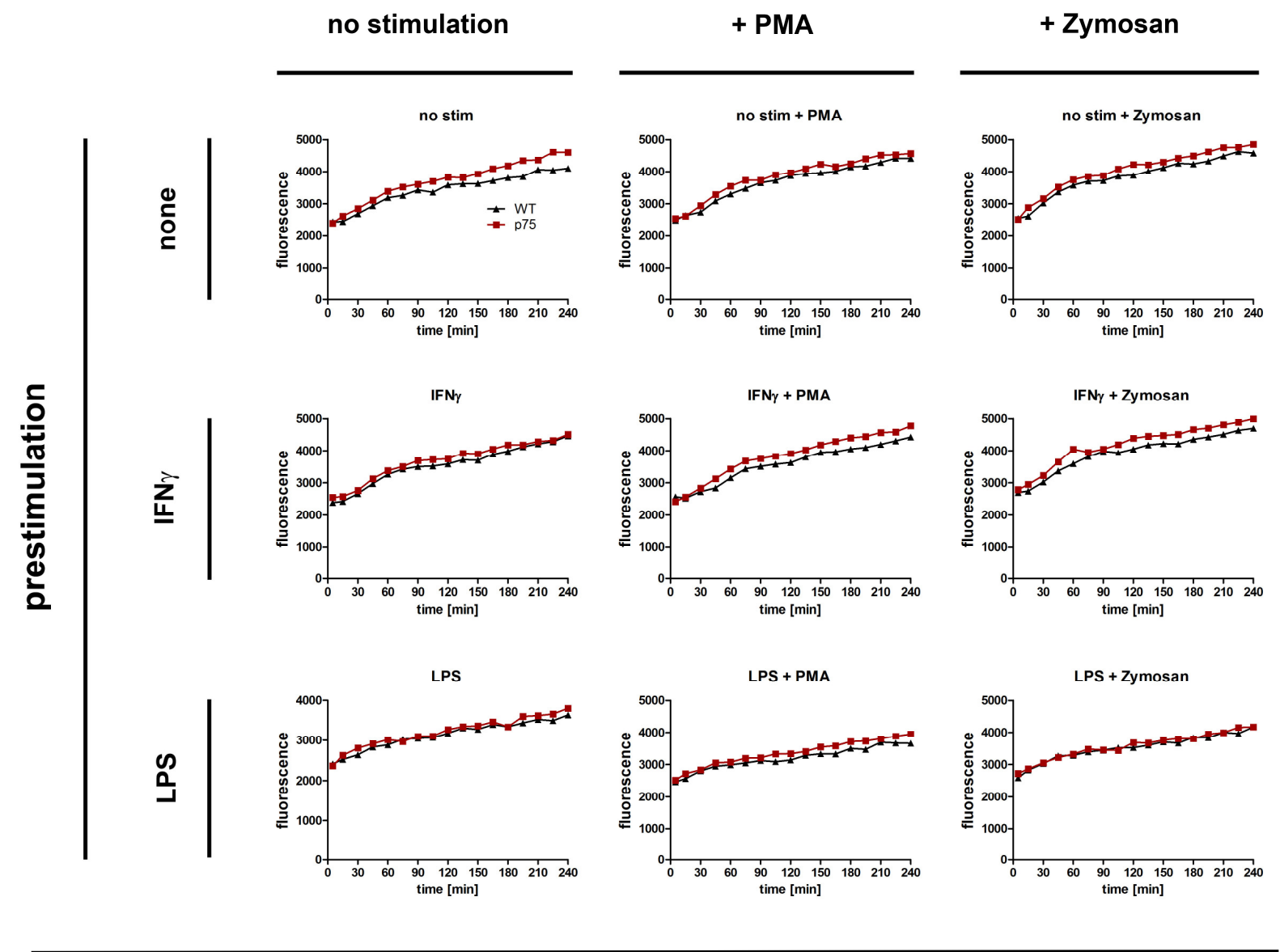

Fig. 3.56 | ROS production by p75 ${ }^{\mathrm{NTR}}$-/- and wt astrocytes in vitro.

ROS detection by CM- $\mathrm{H}_{2}$ DCFDA over time. Similar curves for $\mathrm{p} 75^{\mathrm{NTR}}$ deficient and wt astrocytes regardless of pretreatment (none, IFNg, LPS) and stimulus (none, PMA, Zymosan).

\subsubsection{No difference in the cytokine/chemokine production of $\mathbf{p}^{\mathrm{NTR}}$-/- and wt astrocytes}

TNF $\alpha$, IL-6, IL-10, and CCL5 levels in supernatants of p $75^{\mathrm{NTR}}-/-$ and wt astrocytes cultures were checked by ELISA after IFN $\gamma$ and LPS stimulation (Fig. 3.57). IL-10 levels of astrocytes were low after LPS stimulation, whereas TNF $\alpha$ levels were high. IFN $\gamma$ is no potent activator for cytokine / chemokine production. No differences between $\mathrm{p} 75^{\mathrm{NTR}}-/-$ and wt astrocytes were detected. 

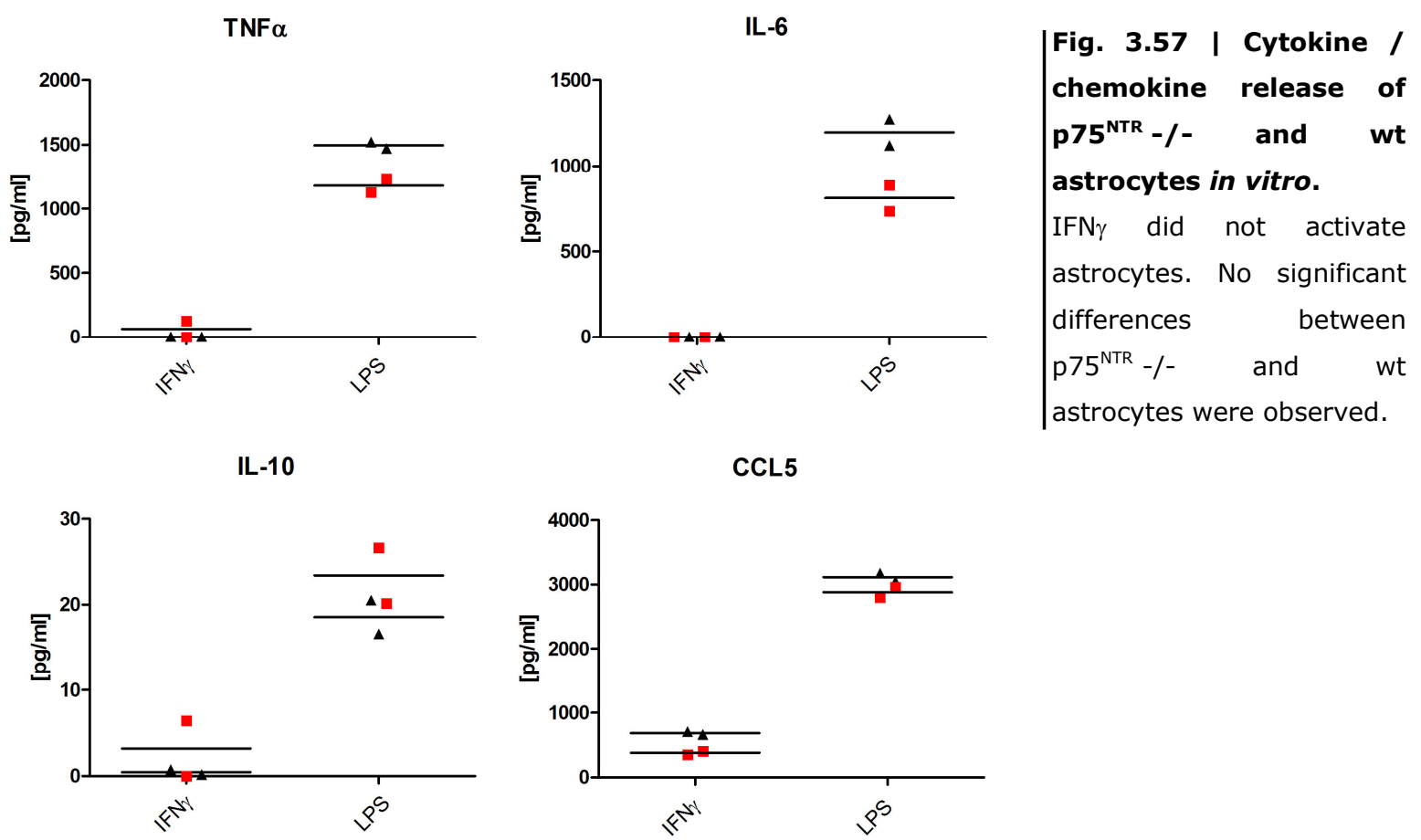


\section{Discussion}

\subsection{The role of $\mathbf{p} 75^{\mathrm{NTR}}$ in experimental CNS inflammation}

In the present study I examined the role of $\mathrm{p} 75^{\mathrm{NTR}}$ during EAE. EAE induction by active immunization with the $\mathrm{MOG}_{35-55}$ peptide in $\mathrm{C} 57 \mathrm{BL} / 6$ mice is the most common animal model for MS, because it mimics many pathological hallmarks of the disease, such as inflammation, demyelination, and axonal damage and loss. Copray et al. (2004) had shown before that $\mathrm{p} 75^{\mathrm{NTR}}$ deficient mice suffer from a more severe disease course than wild type mice. However, the underlying mechanisms remained unclear.

We induced EAE not only by active immunization with the $\mathrm{MOG}_{35-55}$ peptide, but also by adoptive transfer of a $\mathrm{MOG}_{35-55}$ specific $\mathrm{T}$ cell clone. Thereby, the generation of a peripheral immune response within the lymph nodes was completely circumvented. Using this technique helped us to dissect the role of $\mathrm{p} 75^{\mathrm{NTR}}$ during preclinical disease generation.

Furthermore, a bone marrow chimera system was used to separate the effect of $\mathrm{p} 75^{\mathrm{NTR}}$ deficiency in the immune system and in the CNS.

In this work I address the question why $\mathrm{p} 75^{\mathrm{NTR}}-/-$ mice get sicker, which cellular subsets express $\mathrm{p} 75^{\mathrm{NTR}}$ under pathological conditions and what inflammatory or CNSautonomous mechanisms are regulated by $\mathrm{p} 75^{\mathrm{NTR}}$ after active immunization or transfer of encephalitogenic T cells.

\subsubsection{More severe disease course in $\mathrm{p}^{\mathrm{NTR}}-/-$ mice after active immunization with MOG $_{35-55}$}

As the starting point of this project, I found that $\mathrm{p} 75^{\mathrm{NTR}}-/-$ mice suffer from a more severe disease course after active immunization with $\mathrm{MOG}_{35-55}$ compared to wt mice (Fig. 3.1). This is true from the very beginning on and extends into the chronic disease stage (dpi 31). Accordingly, in the chronic disease stage $\mathrm{p} 75^{\mathrm{NTR}}$ deficient mice showed increased demyelination and axonal loss. However, the degree of inflammation, with regard to numbers of macrophages/microglia and $\mathrm{T}$ cells within the lesions, was similar in $\mathrm{p} 75^{\mathrm{NTR}}-/-$ and $\mathrm{wt}$ 
mice. Furthermore, the number of acutely damaged axons, indicated by APP accumulation and hypophosporylation of neurofilaments $\left(\mathrm{SMI} 35^{+}\right)$did not differ between the genotypes, while axonal loss, assessed by Bielschowsky silver impregnation, was significantly increased in $\mathrm{p} 75^{\mathrm{NTR}}-/-$ mice. These findings are in accordance with Copray et al. (2004) who also found a more severe disease course in $\mathrm{p} 75^{\mathrm{NTR}}-/-$ mice while similar numbers of macrophages/microglia and $\mathrm{T}$ cells within the lesionscompared to wt animals

No differences in numbers of mature oligodendrocytes $\left(\operatorname{NogoA}^{+}\right)$(Fig. 3.3) were found in chronic lesions. This indicates that $\mathrm{p} 75^{\mathrm{NTR}}-/-$ mice did not suffer from a more severe disease course because of increased oligodendroglial damage.

In contrast to Copray et al. (2004), however, I found more B cells within the meninges in $\mathrm{p} 75^{\mathrm{NTR}}$-/- mice (Fig. 3.4). However, B cells and myelin specific antibodies are not considered important effectors in $\mathrm{MOG}_{35-55}$ induced EAE in $\mathrm{C} 57 \mathrm{BL} / 6$ mice. As such, we hypothesized that the B cells were attracted by the overall more severe inflammation in p $75^{\mathrm{NTR}}-/-$ mice. Nevertheless, B cells could play important roles in antigen presentation and activation of antigen specific T cells (Hjelmström et al., 1998 a; Hjelmström et al., 1998 b; Oliver et al., 2003).

The question arises here, whether the increased disease severity and axonal loss in $\mathrm{p} 75^{\mathrm{NTR}}$-/- mice, while similar numbers of macrophages/microglia and T cells within the lesions, is due to a more aggressive immune response or due to increased axonal vulnerability in $\mathrm{p} 75^{\mathrm{NTR}}-/-$ mice.

\subsubsection{Similar cellular composition of infiltrates and only minor differences in the quality of inflammation in $\mathbf{p 7 5}^{\mathrm{NTR}}-/-$ and wt mice}

Flow cytometric analysis of inflammatory cells extracted from inflamed spinal cords of actively immunized mice revealed similar numbers of cytotoxic $\mathrm{T}$ cells $\left(\mathrm{CD} 8^{+}\right)$, $\mathrm{T}$ helper cells $\left(\mathrm{CD} 4^{+}\right), \gamma \delta$ T cells $\left(\gamma \delta \mathrm{TCR}^{+}\right)$, NK cells $\left(\mathrm{NK} 1.1^{+} \mathrm{DX} 5^{+}\right)$, macrophages $\left(\mathrm{CD} 11 \mathrm{~b}^{+} \mathrm{CD} 45^{\mathrm{hi}}\right)$, microglia $\left(\mathrm{CD} 11 \mathrm{~b}^{+} \mathrm{CD} 45^{\mathrm{lo}}\right)$, and granulocytes $\left(\mathrm{CD} 11 \mathrm{~b}^{+}\right.$MHC class $\left.\mathrm{II}^{\mathrm{lo}}\right)$ at the peak of disease (score 3) (Fig. 3.8, Fig. 3.9 A, B, C) in p75 $5^{\mathrm{NTR}}-/-$ and wt mice. This is different to what has been reported by Küst et al. (2006) who found decreased numbers of macophages/microglia and neutrophils in lesions of $\mathrm{p} 75^{\mathrm{NTR}}$-/- mice, which stands in contrast to the increased disease course. Instead, Küst et al. showed increased T cell numbers in $\mathrm{p} 75^{\mathrm{NTR}}-/-$ lesions, which we 
could not confirm in our experiments. Quite similar to our approach, Küst et al. had compared score matched animals of $\mathrm{p} 75^{\mathrm{NTR}}-/-$ and wt mice at the peak of disease.

With regard to the quality of inflammation, I found similar expression levels of MHC class II by microglia and macrophages in p75 ${ }^{\mathrm{NTR}}-/-$ and wt mice (Fig. 3.9 D, E). Also, no significant differences in the mRNA amount of the cytokines/chemokines IL-1, IL-6, iNOS, CCL2, CCL5, and CXCL10 were measured (Fig. 3.11).

NGF was upregulated during EAE with highest amounts observed at the peak of disease (Fig. 3.12). This implies important regulatory functions of neurotrophins during EAE. However, I found no regulation at the level of the $\mathrm{p} 75^{\mathrm{NTR}}-/-$. At all time points the mRNA levels of NGF were lower in $\mathrm{p} 75^{\mathrm{NTR}}$-/- mice, which could indicate a lack of positive feedback loops. Also, in $\mathrm{p} 75^{\mathrm{NTR}}-/-$ mice, NGF was not as strongly regulated during EAE progression as seen in wt mice, similarly pointing towards positive feedback loops in NGF - p75 $5^{\mathrm{NTR}}$ interaction.

At the peak of disease no significant differences with regard to quantity and quality of inflammation within the spinal cord were found on the histological, cellular, and molecular levels (except for the number of meningeal B cells, as discussed above).

\subsection{The role of $p 75^{\mathrm{NTR}}$ in the naïve immune system and during peripheral immune priming after active immunization with MOG $_{35-55}$}

$\mathrm{p} 75^{\mathrm{NTR}}$-/- mice suffered from a more severe disease after active immunization with $\mathrm{MOG}_{35-55}$ right from the start (Fig. 3.1). This clinical difference was not observed, when EAE was induced by adoptive transfer, completely circumventing peripheral activation and proliferation of antigen specific $\mathrm{T}$ cells (Fig. 3.46, chapter 4.3). This strongly suggests that $\mathrm{p} 75^{\mathrm{NTR}}$ plays a role in the regulation of the immune response in peripheral lymph nodes after active immunization.

Naïve and immunized lymph nodes from $\mathrm{p} 75^{\mathrm{NTR}}-/-$ and $\mathrm{wt}$ mice were examined on the cellular, protein, and mRNA levels before disease onset. 


\subsubsection{Similar cellular composition and activation states of naïve and MOG- 35-55 immunized lymph nodes in $\mathrm{p}^{\mathrm{NTR}}$-/- and wt mice}

Frequencies of cytotoxic T cells $\left(\mathrm{CD}^{+}\right)$, T helper cells $\left(\mathrm{CD} 4^{+}\right)$(Fig. 3.14), $\gamma \delta \mathrm{T}$ cells $\left(\gamma \delta \mathrm{TCR}^{+}\right)\left(\right.$Fig. 3.15), NK T cells $\left(\mathrm{DX}^{+}, \mathrm{TCR}^{+}\right), \mathrm{NK}$ cells $\left(\mathrm{NK} 1.1^{+}, \mathrm{DX}^{+}\right)$(Fig. 3.16), regulatory $\mathrm{T}$ cells $\left(\mathrm{FoxP} 3^{+}\right)$(Fig. 3.17), and B cells $\left(\mathrm{CD}^{+} 9^{+}\right)$(Fig. 3.18) within naïve and $\mathrm{MOG}_{35-55}$ immunized lymph nodes showed no significant differences between $\mathrm{p} 75^{\mathrm{NTR}}-/-$ and wt mice.

Furthermore, no differences in the expression levels of adhesion molecules for trafficking into secondary lymphoid tissues $\left(\mathrm{CD}^{2} \mathrm{~L}^{+}\right.$) (Fig. 3.19) and target tissues (CD11a $\left.{ }^{+}\right)$ (Fig. 3.21), as well as early $\left(\mathrm{CD}^{+} 9^{+}\right.$) (Fig. 3.20) and late $\left(\mathrm{CD} 29^{+}, \mathrm{CD} 44^{+}\right.$) (Fig. 3.22, Fig. 3.19) activation markers were found by flow cytometric analysis. Cell numbers of

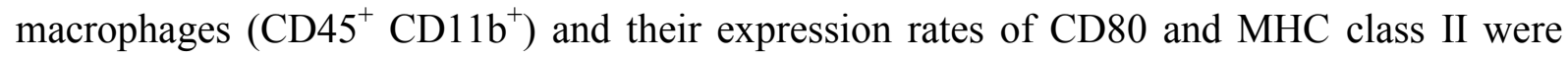
also similar (Fig. 3.27, Fig. 3.28). CD80 is a mandatory costimulatory molecule of the immunological synapse during antigen specific activation of $\mathrm{T}$ cells.

Also, no difference in the expression of cyto- and chemokines (IL-1, IL-6, CCL2, CCL5, CXCL10) and iNOS was found in p75 $5^{\mathrm{NTR}}-/-$ and wt animals neither in naïve lymph nodes nor after immunization with $\mathrm{MOG}_{35-55}$ on the mRNA level (Fig. 3.11). Furthermore, no differences in the production of cytokines/chemokines were observed on the protein level in $\mathrm{MOG}_{35-55}$ immunized lymph nodes of $\mathrm{p} 75^{\mathrm{NTR}}$-/- and wt mice (Fig. 3.29).

In summary, no significant differences with regard to immune cell populations and activations states thereof were found in naïve and immunized lymph nodes of $\mathrm{p} 75^{\mathrm{NTR}}-/-$ and wt mice that could explain the clinical difference between the strains in the acute stage of actively induced $\mathrm{MOG}_{35-55} \mathrm{EAE}$.

\subsubsection{No differences in the numbers of $\alpha \beta$ and $\gamma \delta T_{H} 1$ and $T_{H} 17$ cells with and without PMA stimulation in immunized lymph nodes}

At day 3 and 7 after active immunization with $\mathrm{MOG}_{35-55}$ the cell numbers of $\mathrm{T}_{\mathrm{H}} 1$ $\left(\mathrm{IFN} \gamma^{+}\right)$and $\mathrm{T}_{\mathrm{H}} 17\left(\mathrm{IL}-17^{+}\right)$cells were determined for $\alpha \beta\left(\mathrm{CD} 4^{+}\right)$and $\gamma \delta \mathrm{T}$ cells $\left(\gamma \delta \mathrm{TCR}^{+}\right)$, showing no significant differences between $\mathrm{p} 75^{\mathrm{NTR}}-/-$ and wt animals (Fig. 3.23-Fig. 3.26). 
Also, stimulation of these cells with PMA ex vivo, revealed similar frequencies of IFN $\gamma$ and IL-17 producing $\alpha \beta$ and $\gamma \delta$ T cells.

\subsubsection{No role for $\mathrm{p}^{\mathrm{NTR}}$ in antigen-specific $\mathrm{T}$ cell proliferation}

$\mathrm{MOG}_{35-55}$ specific $\mathrm{T}$ cells did not exhibit altered proliferation rates when lacking a functional $\mathrm{p} 75^{\mathrm{NTR}}$ (Fig. 3.30 A). Vice versa, p75 ${ }^{\mathrm{NTR}}$ deficient APCs stimulated wt $\mathrm{MOG}_{35-55}$ specific $\mathrm{T}$ cells as efficiently as wt APCs, leading to comparable $\mathrm{T}$ cell proliferation rates (Fig. 3.30 B). Thus, neither p75 ${ }^{\mathrm{NTR}}$ deficiency on T cells nor on APCs does have an effect on antigen specific $\mathrm{T}$ cell proliferation.

Furthermore, $\mathrm{p} 75^{\mathrm{NTR}}$ expression by $\mathrm{T}_{\mathrm{H}} 1$ cells was never detected in vitro by TaqMan qRT-PCR analysis (Tab. 3.1.).

\subsubsection{No role for $\mathrm{p}^{\mathrm{NTR}}$ in the production of proinflammatory mediators by bone marrow derived macrophages}

NO (Fig. 3.33), ROS (Fig. 3.34), and cytokine/chemokine (Fig. 3.35) production after various pre-treatments and stimuli in vitro did not differ between $\mathrm{p} 75^{\mathrm{NTR}}-/-$ and $\mathrm{wt}$ bone marrow derived macrophages. Thus, with regard to mediators of axonal damage like NO and ROS, a role for $\mathrm{p} 75^{\mathrm{NTR}}$ deficiency on macrophages, leading to a more aggressive inflammation, could be ruled out.

Furthermore, FACS sorted macrophages $\left(\mathrm{CD} 11 \mathrm{~b}^{+} \mathrm{CD} 11 \mathrm{c}^{+}\right)$from lymph nodes after immunization (dpi $3,6,14$ ) showed no $\mathrm{p} 75^{\mathrm{NTR}}$ expression in vivo measured by TaqMan $\mathrm{qRT}$ PCR Tab. 3.2). 


\subsubsection{Constitutive $\mathbf{p}^{\mathrm{NTR}}$ expression by $\mathrm{B}$ cells in lymph nodes in vivo}

Of all FACS sorted immune cell populations from naïve and immunized lymph nodes at different time points, only B cells showed relevant expression levels of $\mathrm{p} 75^{\mathrm{NTR}}$ in vivo by TaqMan qRT-PCR (Tab. 3.2). Effector T helper cells $\left(\mathrm{CD}^{+}\right)$, cytotoxic T cells $\left(\mathrm{CD} 8^{+}\right), \gamma \delta \mathrm{T}$ cells $\left(\gamma \delta \mathrm{TCR}^{+}\right), \mathrm{NK}$ T cells $\left(\mathrm{DX}^{+}, \mathrm{TCR}^{+}\right), \mathrm{NK}$ cells $\left(\mathrm{NK} 1.1^{+}, \mathrm{DX}^{+}\right), \mathrm{DCs}\left(\mathrm{CD} 11 \mathrm{c}^{+} \mathrm{CD} 11 \mathrm{~b}^{-}\right.$ ), and macrophages $\left(\mathrm{CD} 11 \mathrm{~b}^{+}, \mathrm{CD} 11 \mathrm{c}^{+}\right)$did not express $\mathrm{p} 75^{\mathrm{NTR}}$.

\subsection{Similar inflammation but more axonal damage in EAE induced by adoptive transfer}

By using the adoptive transfer technique, the peripheral activation of the immune system can be circumvented. After i.v. injection, the encephalitogenic $\mathrm{MOG}_{35-55}$ specific $\mathrm{T}_{\mathrm{H}} 1$ cell clone enters the CNS and causes CNS specific inflammation after a delay of around 6-7 days (Flügel et al., 2001 b). In contrast to EAE induction by active immunization, we could thereby exclude effects of $\mathrm{p} 75^{\mathrm{NTR}}$ deficiency on the so called "priming phase", the activation and proliferation of autoimmune $\mathrm{T}$ cells in secondary lymphoid organs.

Consequently, in early disease, the disease courses were very similar in both mouse strains after adoptive transfer (Fig. 3.46), whereas active immunization of $\mathrm{p} 75^{\mathrm{NTR}}$-/- mice led to increased disease scores right from the beginning (Fig. 3.1). This finding suggests an important role of $\mathrm{p} 75^{\mathrm{NTR}}$ during the priming phase. Quantitative histological analysis, showing comparable numbers of lesions and infiltrating immune cells ( $\mathrm{T}$ cells, macrophages, B cells) (Fig. 3.47), was in line with the similar disease course in the acute disease stage. Also, no differences in the quality of inflammation were found on the histological (numbers of $\mathrm{S} 100 \mathrm{~A}^{+}$early activated macrophages and iNOS expressing immune cells) (Fig. 3.48) and mRNA levels (cytokines, chemokines, inflammation related molecules) (Fig. 3.50).

Thus, despite the fact that we did not find any significant difference with regard to inflammation, $\mathrm{p} 75^{\mathrm{NTR}}-/-$ mice suffered from significantly more acute axonal damage and axonal loss (Fig. 3.49). We interpreted these results as a hint that $\mathrm{p} 75^{\mathrm{NTR}}$ might play neuroand/or axono-protective roles in the inflamed CNS. 
This hypothesis is supported by the more severe disease course of $\mathrm{p} 75^{\mathrm{NTR}}-/-$ mice in the chronic disease stage after adoptive transfer (Fig. 3.51). Again, the quantity of inflammation and demyelination was similar $\left(\mathrm{p} 75^{\mathrm{NTR}}-/-\right.$ spinal cords showed even less $\mathrm{T}$ cells) (Fig. 3.52, Fig. 3.53), but the degrees of axonal damage and loss were significantly increased in $\mathrm{p} 75^{\mathrm{NTR}}-/-$ mice (Fig. 3.55). Similar to the results obtained by active EAE induction, the levels of oligodendroglial damage were similar and therefore not contributing to the more severe disease course (Fig. 3.53).

Taken together, the similarities in the disease course as well as in the quantity and quality of inflammation in the early disease stage after adoptive transfer of encephalitogenic $\mathrm{T}$ cells contrast with increased axonal damage and loss in $\mathrm{p} 75^{\mathrm{NTR}}-/-$ mice, strongly suggesting a neuroprotective role for $\mathrm{p} 75^{\mathrm{NTR}}$ in CNS inflammation.

\subsubsection{Constitutive expression of $\mathrm{p}^{\mathrm{NTR}}$ by astrocytes, but not by microglia}

Since our in vivo EAE results hinted at a neuroprotective role of $\mathrm{p} 75^{\mathrm{NTR}}$ within the CNS, p $75^{\mathrm{NTR}}$ expression by different CNS cell types was assessed in vitro. Astrocytes were found to express p $75^{\mathrm{NTR}}$ constitutively (Tab. 3.4), whereas microglia did not Tab. 3.3). These findings are in line with previous publications (Hanbury et al., 2002; Oderfeld-Nowak et al., 2003). Therefore, astrocytes are candidates as mediators of the observed neuroprotection via $\mathrm{p} 75^{\mathrm{NTR}}$ after EAE induction. We can however rule out, that $\mathrm{p} 75^{\mathrm{NTR}}$ deficiency on astrocytes has effects on their ROS and cytokine/chemokine production in vitro (Fig. 3.56, Fig. 3.57). Also, CCL5 secretion by astrocytes revealed no modulation by NGF. Therefore, according to the results obtained so far, the inflammatory response of reactive astrocytes is not altered by $\mathrm{p} 75^{\mathrm{NTR}}$.

It is conceivable that astrocytes play alternative roles via $\mathrm{p} 75^{\mathrm{NTR}}$, e.g. in the protection from excitotoxicity or in the integrity of the blood brain barrier (BBB). Astrocytic foot processes are important functional components of the BBB. Copray et al. (2004) suggested a role of $\mathrm{p} 75^{\mathrm{NTR}}$ on the BBB integrity. However, they mainly considered an effect of $\mathrm{p} 75^{\mathrm{NTR}}$ on endothelial cells.

Future experiments will include an assessment of primary cell cultures of $\mathrm{p} 75^{\mathrm{NTR}}-/-$ and wt neurons with regard to their susceptibility to inflammatory mediators. A broad range of $\mathrm{p} 75^{\mathrm{NTR}}$ effects has been observed so far in neuronal cultures. For instance, neuroprotection 
by $\mathrm{p} 75^{\mathrm{NTR}}$ has been shown with regard to extracellular $\beta$-amyloid cytotoxicity (Zhang et al., 2003) and glutamate excitotoxicity (Kume et al., 2000; Culmsee et al., 2002).

Furthermore, inflammatory cells ( $\mathrm{T}$ cells, B cells and monocytes) secrete high amounts of neurotrophins upon antigen specific stimulation (Stadelmann et al., 2002; Kerschensteiner et al., 1999; Kerschensteiner et al., 2003; Moalem et al., 2000), which is likely to play a role in CNS inflammation.

\subsection{Dissecting the roles of $\mathrm{p}^{\mathrm{NTR}}$ in the immune system and the CNS: Active immunization of bone marrow chimeras}

To further separate the effects of $\mathrm{p} 75^{\mathrm{NTR}}$ deficiency within the immune system and the CNS, a bone marrow chimera system was used. In these chimeras only cells of the immune system or the CNS, respectively, had a functioning $\mathrm{p} 75^{\mathrm{NTR}}$.

We show on the molecular and histological levels that the irradiation procedure did not lead to immune cell infiltration of the CNS (Fig. 3.36 Fig. 3.37). Furthermore, cytokine/chemokine levels were not significantly increased except for CXCL10. This is in accordance with previous reports (Mildner et al., 2007). More importantly, no differences in the effect of CNS irradiation between $\mathrm{p} 75^{\mathrm{NTR}}-/-$ and wt mice were found.

\subsubsection{Increased axonal damage in chimeras deficient for $p 75^{\mathrm{NTR}}$ within the CNS}

wt $\rightarrow$ wt chimeras had a significantly milder disease course than $p 75^{\mathrm{NTR}}-/-\rightarrow$ wt and $\mathrm{p} 75^{\mathrm{NTR}}-/-\rightarrow \mathrm{p} 75^{\mathrm{NTR}}-/-$ animals. The latter tended to suffer from the most severe disease course. However, the disease courses of $\mathrm{p} 75^{\mathrm{NTR}}-/-\rightarrow$ wt and wt $\rightarrow \mathrm{p} 75^{\mathrm{NTR}}-/$ chimeras lay $^{\mathrm{N}}$ right between the control groups at an early time point of disease (dpi 20) (Fig. $3.41 \mathrm{~A}$ ). The cumulative score and inflammatory index were highest in $\mathrm{p} 75^{\mathrm{NTR}}-/-\rightarrow \mathrm{p} 75^{\mathrm{NTR}}-/-$ and lowest in wt $\rightarrow$ wt. p75 $5^{\mathrm{NTR}}-/-\rightarrow$ wt and wt $\rightarrow$ p $75^{\mathrm{NTR}}-/-$ chimeras lay in between. Only $50 \%$ of the 
wt $\rightarrow$ wt and $80 \%$ of wt $\rightarrow$ p $75^{\mathrm{NTR}}$-/- mice showed clinical signs, whereas all p $75^{\mathrm{NTR}}-/-\rightarrow$ wt and $\mathrm{p} 75^{\mathrm{NTR}}-/-\rightarrow \mathrm{p} 75^{\mathrm{NTR}}-/-$ chimeras developed EAE. Thus, a significantly lower disease incidence was found in animals with wt as compared to p75NTR-deficient immune systems. The more severe disease course early on of $\mathrm{p} 75^{\mathrm{NTR}}-/-\rightarrow$ wt compared to wt $\rightarrow$ wt and the lower incidence of wt $\rightarrow \mathrm{p} 75^{\mathrm{NTR}}-/-$ and $\mathrm{wt} \rightarrow$ wt chimeras can be viewed as an indicator for a role of $\mathrm{p} 75^{\mathrm{NTR}}$ during peripheral immune priming. As mentioned before, a down-modulatory role of regulatory $\mathrm{B}$ cells on $\mathrm{T}$ cells via $\mathrm{p} 75^{\mathrm{NTR}}$ is a promising hypothesis, since $\mathrm{B}$ cells constitutively express high levels of $\mathrm{p} 75^{\mathrm{NTR}}$.

Of note however, animals deficient for $\mathrm{p} 75^{\mathrm{NTR}}$ within the CNS (p75 $5^{\mathrm{NTR}}-/-\rightarrow$ $\mathrm{p} 75^{\mathrm{NTR}}$-/- and wt $\left.\rightarrow \mathrm{p} 75^{\mathrm{NTR}}-/-\right)$ suffered from significantly more early axonal damage than CNS wt mice (p75 $5^{\mathrm{NTR}}-/-\rightarrow \mathrm{wt}$ and $\mathrm{wt} \rightarrow \mathrm{wt}$ ), independent of the level of inflammation (Fig. 3.45). At this early disease stage the acute axonal damage measured by $\mathrm{APP}^{+}$spheroids does not correlate well with the disability score, since conduction block mediated by inflammatory cytokines is a more important contributor to the neurological symptoms (Bitsch et al., 2000; Rieckmann, 2005; Siffrin et al., 2010). However, the increased levels of acute axonal damage early on likely result in increased axonal loss in the chronic disease stage, in line with the increased disability observed in chronic actively induced and adoptive transfer EAE (Fig. 3.51, Fig. 3.55).

These findings strongly suggest a neuro- and/or axono-protective role of $\mathrm{p} 75^{\mathrm{NTR}}$ within the CNS. This is also supported by the comparable disease severity in the acute disease stage and increased severity in chronic disease after EAE induction by adoptive transfer in p $75^{\mathrm{NTR}}$-/- mice compared to wt mice (Fig. 3.51, chapter 4.3). In these experiments, the mounting of a peripheral immune response was completely circumvented and inflammatory CNS infiltration was the same in wt and $\mathrm{p} 75^{\mathrm{NTR}}$-/- mice. As such, this model allows for the direct assessment of the role of $\mathrm{p} 75^{\mathrm{NTR}}-/-$ in the CNS.

However, since $\mathrm{p} 75^{\mathrm{NTR}}-/-\rightarrow$ wt chimeras showed significantly increased scores compared to wt $\rightarrow$ wt mice, effects of $\mathrm{p} 75^{\mathrm{NTR}}$ deficiency within the immune system are also indicated. Furthermore, the increased disease severity in $\mathrm{p} 75^{\mathrm{NTR}}-/-$ mice at disease onset after active immunization (Fig. 3.1, chapter 4.1.1), but not after adoptive transfer, corroborates these findings.

Taken together, my data from active immunization experiments in bone marrow chimeras strongly hint at roles for $\mathrm{p} 75^{\mathrm{NTR}}$ in both, the CNS (neuroprotective) and the immune system (anti-inflammatory / down-modulatory). 


\subsection{Is $\mathrm{p}^{\mathrm{NTR}}$ relevant to the human inflammatory demyelinating disease, MS?}

The neurotrophin receptor $\mathrm{p} 75^{\mathrm{NTR}}$ attracted attention in the field of MS research, when increased levels of NGF were found in the cerebrospinal fluid of MS patients (Laudiero et al., 1992). Also, re-expression of $\mathrm{p} 75^{\mathrm{NTR}}$ by many different cell types in MS lesions was shown. Valdo et al. (2002) described $\mathrm{p} 75^{\mathrm{NTR}}$ expression by perivascular cells, reactive astrocytes, microglia / macrophages, and a subset of not otherwise specified inflammatory cells in chronic active lesions of MS patients. p $75^{\mathrm{NTR}}$ immunoreactivity was never co-localized with apoptotic cells. Thus, regulatory roles of neurotrophins and their receptors on supportive glia, but also on infiltrating immune cells during MS are suggested.

Furthermore, it has been shown that neurons of the CNS re-express $\mathrm{p} 75^{\mathrm{NTR}}$ under many pathological conditions (e.g. stroke, axonal transection, and also MS) (Ebadi et al., 1997; Dechant \& Barde, 2002).

Single nucleotide polymorphisms (SNPs) have been described before to modulate the outcome of and susceptibility to MS. Mirowska-Guzel et al. (2008) found two SNPs in the BDNF gene that increase the risk of MS. For one of the described SNPs, carriers developed first neurological signs of the disease earlier than controls. This could emerge from a modified binding affinity or signalling of BDNF via $\mathrm{p} 75^{\mathrm{NTR}}$ leading to reduced pro-survival signals to neurons. In the light of my results, showing a more severe disease course and increased axonal loss in the chronic disease stage in $\mathrm{p} 75^{\mathrm{NTR}}$-/- mice after adoptive transfer of $\mathrm{MOG}_{35-55}$ specific T cells, the $\mathrm{p} 75^{\mathrm{NTR}}$ deficiency could impede the pro-survival signal by BDNF.

Furthermore, a SNP in Exon 3 of the NGF gene of male patients with relapsingremitting MS was found, resulting in a single amino acid substitution in the NGF protein (Akkad et al., 2008). Exon 3 encodes exclusively the precursor form of NGF, proNGF. ProNGF is only bound by $\mathrm{p} 75^{\mathrm{NTR}}$, leading to cell death (Rabizadeh $\&$ Bredesen, 2003). This mutation could alter the proNGF-p $75^{\mathrm{NTR}}$-interaction (e.g., the affinity) or the subsequent signalling. In view of the increased disease severity in $\mathrm{p} 75^{\mathrm{NTR}}-/-$ mice after active immunization with $\mathrm{MOG}_{35-55}$ shown in this study, $\mathrm{p} 75^{\mathrm{NTR}}$ mediated signalling by proNGF could differ during the peripheral immune response. This in turn could result in a more severe inflammation.

Only little is known about the function of $\mathrm{p} 75^{\mathrm{NTR}}$ on neurons, glia cells, and peripheral immune cells during CNS inflammation. Detailed elucidation of expression patterns, inflammatory response modulations, and the capacity to induce apoptosis or survival signals, 
respectively, by $\mathrm{p} 75^{\mathrm{NTR}}$ could result in promising, novel treatments of MS. My study shows that B cells are potential targets for promising approches. I found a high constitutive expression of $\mathrm{p} 75^{\mathrm{NTR}}$ in $\mathrm{B}$ cells that is downregulated during peripheral disease generation. Therefore, an immunomodulatory role of $\mathrm{p} 75^{\mathrm{NTR}}$ in B cells is indicated that could possibly be modulated by artificial activation.

This study shows also a beneficial role of $\mathrm{p} 75^{\mathrm{NTR}}$ within the CNS. Neuroprotective properties of $\mathrm{p} 75^{\mathrm{NTR}}$ in neurons have been shown before (Hamanoue et al., 1999; Gentry et al., 2000; Rabizadeh \& Bredesen, 2003). Therefore, $\mathrm{p} 75^{\mathrm{NTR}}$ specific agonists could possibly prolong axonal survival and/or limit axonal loss, resulting in a milder disease course in the chronic disease stage.

Another interesting approach is the contribution of astrocytes via $\mathrm{p} 75^{\mathrm{NTR}}$ to the disease. I detected constitutively high expression levels of $\mathrm{p} 75^{\mathrm{NTR}}$ in astrocytes. Although, I can rule out effects of $\mathrm{p} 75^{\mathrm{NTR}}$ deficiency on astrocytic TNF $\alpha$, IL-6, IL-10, CCL5, and ROS release in vitro, it is conceivable that $\mathrm{p} 75^{\mathrm{NTR}}$ modulates the capacity of antigen presentation or the production of other cytokines/chemokines.

\subsection{Conclusions}

Taken together, we can rule out a major role of many different immune cell populations and inflammatory mediators, which do not contribute to the generation of a more aggressive inflammatory phenotype resulting in the more severe disease of $\mathrm{p} 75^{\mathrm{NTR}}-/-$ mice after active immunization with $\mathrm{MOG}_{35-55}$. This includes $\mathrm{T}$ helper cells, $\gamma \delta \mathrm{T}$ cells, cytotoxic T cells, $T_{\text {regs, }}$ NK T cells, NK cells, B cells, granulocytes, macrophages, and microglia in spinal cords and lymph nodes in the naïve state as well as during immune priming and disease. Also, $\mathrm{p} 75^{\mathrm{NTR}}$ does not play a role in antigen specific $\mathrm{T}$ cell proliferation, maturation, and activation, CD80 expression by macrophages, and MHC class II expression by macrophages and microglia. In line, significant differences for the key proinflammatory cytokines TNF $\alpha$, IFN $\gamma$, IL-1, and IL-6 and the chemokines CCL2, CCL5, and CXCL10 are also ruled out, as well as substantial differences in NO and ROS production. Furthermore, under the conditions examined, $\mathrm{p} 75^{\mathrm{NTR}}$ expression can be ruled out for T helper cells, $\gamma \delta \mathrm{T}$ cells, cytotoxic T cells, NK T cells, NK cells, DCs, macrophages, and microglia. This has been shown on histological, cellular, and molecular levels in vivo, ex vivo, and in vitro. 
To this point we have not found convincing evidence for substantial differences between $\mathrm{p} 75^{\mathrm{NTR}}-/-$ and $\mathrm{wt}$ mice in the naïve state or after immunization with regard to the quality and quantity of inflammation.

However, I show constitutive expression of $\mathrm{p} 75^{\mathrm{NTR}}$ on B cells, which is in accordance with Torcia et al., (1996). Also, p75 ${ }^{\mathrm{NTR}}$ expression was dowregulated in B cells after active immunization with $\mathrm{MOG}_{35-55}$. It is conceivable that $\mathrm{p} 75^{\mathrm{NTR}}$ deficiency in B cells leads to altered activation, antigen presentation, or expression of surface molecules. This, in turn, could affect the quality of activation of other cell subsets, like T cells or macrophages. Therefore, $\mathrm{p} 75^{\mathrm{NTR}}$ deficiency could indirectly affect non-p $75^{\mathrm{NTR}}$ expressing cell lineages. Additional experiments should elucidate the role of B cells during the generation of the peripheral immune response in $\mathrm{p} 75^{\mathrm{NTR}}$ deficient mice (chapter 4.7 ).

While $\mathrm{p} 75^{\mathrm{NTR}}$-/- animals suffered from a more severe disease course from the beginning on after active immunization with $\mathrm{MOG}_{35-55}$, the disease courses of $\mathrm{p} 75^{\mathrm{NTR}}-/-$ and wt mice were similar during disease onset after adoptive transfer of a $\mathrm{MOG}_{35-55}$ specific $\mathrm{T}$ cell clone. This indicates a down-modulatory role of $\mathrm{p} 75^{\mathrm{NTR}}$ during peripheral priming.

Despite the similar disease onset, however, $\mathrm{p} 75^{\mathrm{NTR}}$-/- mice subjected to adoptive transfer showed increased axonal damage and loss compared to wt. In addition, the similar disease course at onset but increased severity in the chronic disease stage in $\mathrm{p} 75^{\mathrm{NTR}}-/-$ mice after adoptive transfer of a $\mathrm{MOG}_{35-55}$ specific $\mathrm{T}$ cell clone indicates a role for $\mathrm{p} 75^{\mathrm{NTR}}$ within the CNS. An influence of $\mathrm{p} 75^{\mathrm{NTR}}$ deficiency on the quantity and quality of inflammation can be ruled out for the acute and chronic disease stage after adoptive transfer EAE. While microglia did not express $\mathrm{p} 75^{\mathrm{NTR}}$ in our study, astrocytes did. However, p $75^{\mathrm{NTR}}$ deficiency had no effect on cytokine, chemokine, and ROS production by astrocytes in vitro.

The more severe disease courses of $\mathrm{p} 75^{\mathrm{NTR}}-/-\rightarrow$ wt as well as wt $\rightarrow$ p $75^{\mathrm{NTR}}-/-$ bone marrow chimeras compared to wt $\rightarrow$ wt hint at a role of $\mathrm{p} 75^{\mathrm{NTR}}$ in both compartments, the immune and central nervous system. Also, increased axonal damage in $\mathrm{p} 75^{\mathrm{NTR}}-/-\rightarrow$ $\mathrm{p} 75^{\mathrm{NTR}}-/-$ and $\mathrm{wt} \rightarrow \mathrm{p} 75^{\mathrm{NTR}}-/-$ mice independent of the level of inflammation indicates an axonoprotective role for $\mathrm{p} 75^{\mathrm{NTR}}$ in the inflamed CNS.

In summary, the present study shows a role for $\mathrm{p} 75^{\mathrm{NTR}}$ in the immune system during the generation of the peripheral immune response, as well as in the CNS during EAE disease. Our data confine the range of possible functions of $\mathrm{p} 75^{\mathrm{NTR}}$ within the immune system and the CNS during EAE and emphasize the role of $\mathrm{p} 75^{\mathrm{NTR}}$ in B cells, astrocytes, and neurons. 


\subsection{Outlook}

With regard to the role of $\mathrm{p} 75^{\mathrm{NTR}}$ in the immune system, our data point to a regulatory role of B cells via $\mathrm{p} 75^{\mathrm{NTR}}$. In a recent publication, Matsushita et al. (2010) describe the role of a relatively newly discovered B cell subset $\left(\mathrm{B} 10\right.$ cells). This $\mathrm{CD} 1 \mathrm{~d}^{\text {hi }} \mathrm{CD}^{+} \mathrm{CD} 19^{\text {hi }}$ population produces anti-inflammatory IL-10 and exhibits regulatory roles during EAE initiation (Matsushita et al., 2008; Yanaba et al., 2008; Yanaba et al., 2009; Haas et al., 2010; Watanabe et al., 2010). Matsushita et al. (2010) also found that B10 cells do not directly influence $\mathrm{T}$ cell proliferation, which could be in accordance with our data showing similar $\mathrm{T}$ cell proliferation of $\mathrm{p} 75^{\mathrm{NTR}}$-/- and wt lymph node cells. However, they describe that B10 cells affect IFN $\gamma$ and TNF $\alpha$ production by $\mathrm{CD}^{+} \mathrm{T}$ cells. Further experiments could include in vitro analysis of primary B cell cultures, e.g. achieved by FACS or MACS sorting of lymph nodes or spleens. Possible differences in the subpopulation of regulatory B10 cells could be examined. Effects of $\mathrm{p} 75^{\mathrm{NTR}}$ by B cells could be elucidated in vivo by inducing EAE in B cell depleted $\mathrm{p} 75^{\mathrm{NTR}}$-/- and wt mice. This could be done by using a blocking CD19 or CD20 antibody or by reconstituting recombination activating gene (RAG) deficient mice with T cells only but not B cells. Furthermore, the use of B cell specific p75 $5^{\mathrm{NTR}}-/-$ will be helpful to assess the importance of $\mathrm{p} 75^{\mathrm{NTR}}$ as a modulator of $\mathrm{B}$ cell immune function.

A constitutive expression of $\mathrm{p} 75^{\mathrm{NTR}}$ on astrocytes, but no differences in TNF $\alpha$, IL-6, IL-10, CCL5, and ROS production were found between $\mathrm{p} 75^{\mathrm{NTR}}-/-$ and wt astrocytes after stimulation in vitro. Thus, it would be interesting to assess whether $\mathrm{p} 75^{\mathrm{NTR}}$ deficiency contributes to an altered secretion pattern of other cytokines/chemokines or to a difference in the ability of astrocytes to present antigens. Effects on the BBB integrity are also imaginable.

Another critical experiment includes neuronal cell cultures to directly elucidate the role of $\mathrm{p} 75^{\mathrm{NTR}}$ on neurons. Readouts with regard to apoptosis, excitotoxicity, axonal growth and dendritic branching as well as electrophysiological measurements would be useful, preferably after stimulation with inflammatory mediators or even immune cells.

Furthermore, experiments with hippocampal slice cultures from $\mathrm{p} 75^{\mathrm{NTR}}-/-$ and wt animals would be promising. The addition of cytokines/chemokines or $\mathrm{p} 75^{\mathrm{NTR}}-/-$ and $\mathrm{wt}$ immune cells would let us examine immune system-CNS-interactions directly in a controlled system. E.g., it would be very interesting to assess differences in axonal damage or loss in p75 $5^{\mathrm{NTR}}$-/- and wt hippocampal slices after antigen-specific $\mathrm{T}$ cell mediated inflammatory responses. This can be done by the addition to the culture medium of a $\mathrm{MOG}_{35-55}$ specific $\mathrm{T}$ cell clone or immunized lymph node cells from $\mathrm{p} 75^{\mathrm{NTR}}-/-$ and wt mice. It is also 
imaginable to sort out cell populations of interest of immunized $\mathrm{p} 75^{\mathrm{NTR}}-/-$ and wt lymph nodes by using the MACS system and add them to the slice culture. These experiments would help to dissect the roles of $\mathrm{p} 75^{\mathrm{NTR}}$ ex vivo and in vitro.

To further dissect the role of $\mathrm{p} 75^{\mathrm{NTR}}$ not only by adoptive transfer experiments and bone marrow chimeras, transgenic conditional knock-out approaches would be highly valuable, e.g. by inducing EAE in astrocyte, B cell or neuron-specific p $75^{\mathrm{NTR}}$ knock-out animals in vivo. 


\section{References}

Akkad DA, Kruse N, Arning L, Gold R, Epplen JT (2008)

"Genomic NGFB variation and multiple sclerosis in a case control study"

BMC Med Genet 9:107

Angeletti PU, Levi-Montalcini R, Caramia F (1971)

„Ultrastructural changes in sympathetic neurons of newborn and adult mice treated with nerve growth factor.

J Ultrastruct Res 36:24-36

Babbe H, Roers A, Waisman A, Lassmann H, Goebels N, Hohlfeld R, Friese M, Schröder R, Deckert M, Schmidt S, Ravid R, Rajewsky K (2000)

"Clonal expansions of $\mathrm{CD} 8(+) \mathrm{T}$ cells dominate the $\mathrm{T}$ cell infiltrate in active multiple sclerosis lesions as shown by micromanipulation and single cell polymerase chain reaction" J Exp Med 192: 393-404

\section{Balaguer D D G (1888)}

"Un caso de rabia paralítica"

Gaceta Médica Catalana 11, 45-57

Barres BA \& Raff MC (1994)

"Control of oligodendrocyte number in the developing rat optic nerve“

Neuron 12:935-42
Beattie MS, Harrington AW, Lee R, Kim JY, Boyce SL, Longo FM, Bresnahan JC, Hempstead BL, Yoon SO (2002)

"ProNGF induces p75-mediated death of oligodendrocytes following spinal cord injury"

Neuron 36(3):375-86

Ben Nun A, Wekerle H, Cohen IR (1981) "The rapid isolation of clonable antigenspecific $\mathrm{T}$ lymphocyte lines capable of mediating autoimmune encephalomyelitis" Eur J Immunol 11: 195-199

\section{Bertoglio JH (1983)}

"Monocyte-independent stimulation of human B lymphocytes by phorbol myristate acetate"

J Immunol 131(5):2279-81

Bitsch A, Schuchardt J, Bunkowski S, Kuhlmann T, Bruck W (2000)

"Acute axonal injury in multiple sclerosis. Correlation with demyelination and inflammation"

Brain 123 ( Pt6): 1174-1183

\section{Blakemore WF (1972)}

"Observations on oligodendrocyte degeneration, the resolution of status spongiosus and remyelination in cuprizone intoxication in mice" J Neurocytol. 1(4):413-26 
Blakemore WF \& Keirstead HS (1999)

"The origin of remyelinating cells in the central nervous system"

J Neuroimmunol 98, 69-76

Boltz-Nitulescu G, Wiltschke C, Holzinger C, Fellinger A, Scheiner O, Gessl A, Förster O (1987)

"Differentiation of bone marrow cells into macrophages under the influence of mouse L929 cell supernatant"

J Leukoc Biol 41(1):83-91

Bornstein MB, Miller A, Slagle S, Weitzman M, Crystal H, Drexler E, Keilson M, Merriam A, WassertheilSmoller S, Spada V, Weiss W, Arnon R, Jacobsohn I, Teitelbaum W, Sela M (1987) "A pilot trial of Cop 1 in exacerbatingremitting multiple sclerosis"

N Engl J Med. 317(7):408-14

Brück W (2005)

"Inflammatory demyelination is not central to the pathogenesis of multiple sclerosis“ J Neurol 252 [Suppl 5]: V/10-V/15

Casaccia-Bonnefil $\mathrm{P}$, Carter BD, Dobrowsky RT, Chao MV (1996)

"Death of oligodendrocytes mediated by the interaction of nerve growth factor with its receptor $\mathrm{p} 75$ "

Nature 383, 716-719
Casha S, Yu WR, Fehlings MG (2001)

"Oligodendroglial apoptosis occurs along degenerating axons and is associated with FAS and p75 expression following spinal cord injury in the rat"

Neuroscience 103(1):203-18

Chang A, Nishiyama A, Peterson J, Prineas J, Trapp BD (2000)

"NG2-positive oligodendrocyte progenitor cells in adult human brain and multiple sclerosis lesions"

J Neurosci. 20(17):6404-12

Chibante AM, Vaz MC, Vargas FS (2007) "IL-6 anti-inflammatory activity in pleural effusion post-coronary artery bypass graft surgery"

Rev Port Pneumol. (3):319-34

Copray S, Küst B, Emmer B, Lin MY, Liem R, Amor S, de Vries H, Floris S, Boddeke E (2004)

"Deficient p75 low-affinity neurotrophin receptor expression exacerbates experimental allergic encephalomyelitis in C57/BL6 mice“

J Neuroimmunol. 2004 148(1-2):41-53 
Copray JC, Küst BM, Mantingh-Otter I, Boddeke HW (2005)

" $p 75^{\text {NTR }}$ independent oligodendrocyte death in cuprizone-induced demyelination in $\mathrm{C} 57 \mathrm{BL} / 6$ mice"

Neuropathol. Appl. Neurobiol. 31(6):600-9

Culmsee C, Gerling N, Lehmann M, Nikolova-Karakashian M, Prehn JH, Mattson MP, Krieglstein J (2002)

"Nerve growth factor survival signaling in cultured hippocampal neurons is mediated through TrkA and requires the common neurotrophin receptor $\mathrm{P} 75$ "

Neuroscience 115(4):1089-108

Damarjian TG, Craner MJ, Black JA, Waxman SG (2004)

"Upregulation and colocalization of p75 and $\mathrm{Na}(\mathrm{v}) 1.8$ in Purkinje neurons in experimental autoimmune encephalomyelitis"

Neurosci Lett 369, 186-190

Dechant G, Barde YA (2002)

“The neurotrophin receptor p75(NTR): novel functions and implications for diseases of the nervous system“

Nat Neurosci 5(11):1131-6
De Stefano N, Bartolozzi ML, Guidi L, Stromillo ML, Federico A (2005)

"Magnetic resonance spectroscopy as a measure of brain damage in multiple sclerosis"

J Neurol Sci Jun 15; 233(1-2):203-8

De Stefano N, Filippi M (2007)

"MR spectroscopy in multiple sclerosis"

J Neuroimaging Apr; 17 Suppl 1:31S-35S

Dickensheets HL, Freeman SL, Smith MF, Donnelly RP (1997)

"Interleukin-10 upregulates tumor necrosis factor receptor type-II (p75) gene expression in endotoxin-stimulated human monocytes"

Blood 90(10):4162-71

Ding J, Hu B, Tang LS, Yip HK (2001)

"Study of the role of the low-affinity neurotrophin receptor $\mathrm{p} 75$ in naturally occurring cell death during development of the rat retina"

Dev Neurosci. 23(6):390-8

Driscoll BF, Kies MW, Alvord EC Jr (1975)

"Adoptive transfer of experimental allergic encephalomyelitis (EAE): prevention of successful transfer by treatment of donors with myelin basic protein"

J Immunol 114, 291-292 
Ebadi M, Bashir RM, Heidrick ML, Hamada FM, Refaey HE, Hamed A, Helal G, Baxi MD, Cerutis DR, Lassi NK (1997)

"Neurotrophins and their receptors in nerve injury and repair"

Neurochem Int 30(4-5):347-74

\section{Engelhardt B (2006)}

"Molecular mechanisms involved in T cell migration across the blood-brain barrier"

J Neural Transm 113: 477-485

\section{Engelhardt B (2008)}

"Immune cell entry into the central nervous system: involvement of adhesion molecules and chemokines"

J Neurol Sci 15;274(1-2):23-6

Ernfors P, Lee KF, Kucera J, Jaenisch R. (1994)

"Lack of neurotrophin-3 leads to deficiencies in the peripheral nervous system and loss of limb proprioceptive afferents"

Cell 77:503-12

Flügel A, Matsumuro K, Neumann $\mathrm{H}$, Klinkert WE, Birnbacher R, Lassmann H, Otten U, Wekerle H (2001 a)

"Anti-inflammatory activity of nerve growth factor in experimental autoimmune encephalomyelitis: inhibition of monocyte transendothelial migration" Eur J Immunol 31(1):11-22
Flügel A, Berkowicz T, Ritter T, Labeur M, Jenne DE, Li Z, Ellwart JW, Willem M, Lassmann H, Wekerle H (2001 b)

"Migratory activity and functional changes of green fluorescent effector cells before and during experimental autoimmune encephalomyelitis"

Immunity 14(5):547-60

Funakoshi H, Belluardo N, Arenas E, Yamamoto Y, Casabona A, Persson $\mathrm{H}$, et al (1995)

"Muscle-derived neurotrophin-4 as an activity-dependent trophic signal for adult motor neurons"

Science 268:1495-9

Geissmann F, Auffray C, Palframan R, Wirrig C, Ciocca A, Campisi L, NarniMancinelli E, Lauvau G (2008)

"Blood monocytes: distinct subsets, how they relate to dendritic cells, and their possible roles in the regulation of T-cell responses"

Immunol Cell Biol 86(5):398-408

Gentry JJ, Casaccia-Bonnefil P, Carter BD (2000)

"Nerve growth factor activation of nuclear factor kappaB through its $\mathrm{p} 75$ receptor is an anti-apoptotic signal in RN22 schwannoma cells" J Biol Chem 275, 7558-7565 
Giuliani A， D'Intino G， Paradisi M, Giardino L, Calzà L (2004)

"p75(NTR)-immunoreactivity in the subventricular zone of adult male rats: expression by cycling cells" J Mol Histol 35(8-9):749-58

Gold R, Linington C, Lassmann H (2006) "Understanding pathogenesis and therapy of multiple sclerosis via animal models: 70 years of merits and culprits in experimental autoimmune encephalomyelitis research" Brain, 129, 1953-1971

Haas KM, Watanabe R, Matsushita $\mathrm{T}$, Nakashima H, Ishiura $\mathrm{N}$, Okochi $\mathrm{H}$, Fujimoto M, Tedder TF (2010)

"Protective and pathogenic roles for B cells during systemic autoimmunity in NZB/W F1 mice"

J Immunol 184: 4789-4800

Halachmi E, Ben-Nun A, Lehmann D, Karussis D, Wekerle H, Berke G (1992)

"Delineation of tissue damage mechanisms in experimental autoimmune encephalomyelitis (EAE). I. Cell detachment and lysis induced by encephalitogenic CD4+ T lymphocytes"

J Autoimmun 5, 411-425
Hamanoue M, Middleton G, Wyatt S, Jaffray E, Hay RT, Davies AM (1999) "p75-mediated NF-kappaB activation enhances the survival response of developing sensory neurons to nerve growth factor"

Mol Cell Neurosci 14, 28-40

Hanbury R, Charles V, Chen EY, Leventhal L, Rosenstein JM, Mufson EJ, Kordower JH (2002)

"Excitotoxic and metabolic damage to the rodent striatum: role of the p75 neurotrophin receptor and glial progenitors"

J Comp Neurol. 444(4):291-305

Harrington AW, Kim JY, Yoon SO (2002)

"Activation of Rac GTPase by p75 is necessary for c-jun $\mathrm{N}$-terminal kinasemediated apoptosis"

J Neurosci. 22, 156-166

Hendriks JJ, Teunissen CE, de Vries HE, Dijkstra CD (2005)

"Macrophages and neurodegeneration"

Brain Res Brain Res Rev 48: 185-195 
Hjelmström P, Juedes AE, Ruddle $\mathrm{NH}$ (1998 a)

„Cytokines and antibodies in myelin oligodendrocyte glycoprotein-induced experimental allergic encephalomyelitis" Res Immunol 149(9):794-804; discussion $847-8,855-60$

Hjelmström P, Juedes AE, Fjell J, Ruddle NH (1998 b)

"B-cell-deficient mice develop experimental allergic encephalomyelitis with demyelination after myelin oligodendrocyte glycoprotein sensitization"

J Immunol 161(9):4480-3

Hofer MM \& Barde YA (1988)

"Brain-derived neurotrophic factor prevents neuronal death in vivo"

Nature 331:261-2

Hohlfeld R, Wekerle H (2001)

"Immunological update on multiple sclerosis"

Curr Opin Neurol 14, 299-304

Hory-Lee F, Russell M, Lindsay RM, Frank E (1993)

"Neurotrophin-3 supports the survival of developing muscle sensory neurons in culture"

Proc Natl Acad Sci 90:2613-7
Huang EJ \& Reichardt LF (2001)

"Neurotrophins: roles in neuronal development and function"

Annu Rev Neurosci 24, 677-736

Jung KM, Tan S, Landman N, Petrova K, Murray S, Lewis R, Kim PK, Kim DS, Ryu SH, Chao MV, Kim TW (2003)

"Regulated intramembrane proteolysis of the p75 neurotrophin receptor modulates its association with the TrkA receptor" J Biol Chem 278(43):42161-9

Jiang Y, Chen G, Zhang Y, Lu L, Liu S, Cao X (2007)

"Nerve growth factor promotes TLR4 signaling-induced maturation of human dendritic cells in vitro through inducible $\mathrm{p} 75^{\mathrm{NTR}} 1$ "

J Immunol 179(9):6297-304

Kaplan DR \& Miller FD (1997)

"Signal transduction by the neurotrophin receptors"

Curr Opin Cell Biol 9, 213-221 
Kerschensteiner M, Gallmeier E, Behrens

L, Leal VV, Misgeld T, Klinkert WE, Kolbeck R, Hoppe E, Oropeza-Wekerle RL, Bartke I, Stadelmann C, Lassmann H, Wekerle H, Hohlfeld R. (1999)

"Activated human $\mathrm{T}$ cells, B cells, and monocytes produce brain-derived neurotrophic factor in vitro and in inflammatory brain lesions: a neuroprotective role of inflammation?"

J Exp Med 189, 865-70

Kerschensteiner M, Stadelmann C, Dechant G, Wekerle H, Hohlfeld R (2003) "Neurotrophic cross-talk between the nervous and immune systems: implications for neurological diseases" Ann Neurol 53(3):292-304

Kim H, Li Q, Hempstead BL, Madri JA (2004)

"Paracrine and autocrine functions of brain-derived neurotrophic factor (BDNF) and nerve growth factor (NGF) in brainderived endothelial cells" J Biol Chem 279(32):33538-46

Kimata H, Yoshida A, Ishioka C, Mikawa H (1991)

"Stimulation of Ig production and growth of human lymphoblastoid B cell lines by nerve growth factor" Immunology 72, 451-452
Koritschoner R \& Schweinburg F (1925)

"Klinisch und experimentelle

Beobachtungen über Lähmungen nach

Wutschutzimpfung"

Z. Immunitats Forsh 42, 217-283

Korn \& Oukka (2007)

"Dynamics of antigen-specific regulatory T-cells in the context of autoimmunity" Semin Immunol 19: 272-278

Kornek B, Storch MK, Weissert R, Wallstroem E, Stefferl A, Olsson T, Linington C, Schmidbauer M, Lassmann H (2000)

"Multiple sclerosis and chronic autoimmune encephalomyelitis: a comparative quantitative study of axonal injury in active, inactive, and remyelinated lesions"

Am J Pathol 157: 267-276

Kume T, Nishikawa $\mathrm{H}$, Tomioka $\mathrm{H}$, Katsuki H, Akaike A, Kaneko S, Maeda T, Kihara T, Shimohama S (2000) “p75-mediated neuroprotection by NGF against glutamate cytotoxicity in cortical cultures"

Brain Res 852(2):279-89 
Küst B, Mantingh-Otter I, Boddeke E, Copray S (2006)

"Deficient p75 low-affinity neurotrophin receptor expression does alter the composition of cellular infiltrate in experimental autoimmune encephalomyelitis in C57BL/6 mice"

J Neuroimmunol 174(1-2):92-100

Labouyrie E, Parrens M, de Mascarel A, Bloch B, Merlio JP (1997)

"Distribution of NGF receptors in normal and pathologic human lymphoid tissues"

J Neuroimmunol 77, 161-173

Laschinger M, Vajkoczy P, Engelhardt B (2002)

"Encephalitogenic T cells use LFA-1 for transendothelial migration but not during capture and initial adhesion strengthening in healthy spinal cord microvessels in vivo"

Eur J Immunol 32(12):3598-606

Lassmann H, Brück W, Lucchinetti CF (2007)

"The immunopathology of multiple sclerosis: an overview"

Brain Pathol 17: 210-218

Laudiero LB, Aloe L, Levi-Montalcini R, Buttinelli C, Schilter D, Gillessen S, Otten U (1992)
"Multiple sclerosis patients express increased levels of beta-nerve growth factor in cerebrospinal fluid"

Neurosci Lett 147(1):9-12

Lee $\mathrm{KF}$, Li E, Huber LJ, Landis SC, Sharpe AH, Chao MV, Jaenisch R (1992)

"Targeted mutation of the gene encoding the low affinity NGF receptor p75 leads to deficits in the peripheral sensory nervous system"

Cell 69(5):737-49

Levi-Montalcini R, Skaper SD, Dal Toso R, Petrelli L, Leon A (1996)

"Nerve growth factor: from neurotrophin to neurokine"

Trends Neurosci 19(11):514-20

Lewin GR \& Barde YA (1996)

"Physiology of the neurotrophins"

Annu Rev Neurosci 19, 289-317

Lindert RB, Haase CG, Brehm U, Linington C, Wekerle $\mathrm{H}$, Hohlfeld R (1999)

"Multiple sclerosis: B- and T-cell responses to the extracellular domain of the myelin oligodendrocyte glycoprotein" Brain 122, 2089-2099 
Lindsten $\mathrm{T}$, Thompson $\mathrm{CB}$, Finkelman

FD, Andersson B, Scher I (1984)

"Changes in the expression of $\mathrm{B}$ cell surface markers on complement receptorpositive and complement receptor-negative B cells induced by phorbol myristate acetate"

J Immunol 132(1):235-9

Lomen-Hoerth C \& Shooter EM (1995)

"Widespread neurotrophin receptor expression in the immune system and other nonneuronal rat tissues"

J Neurochem 64, 1780-1789

Lovas G, Szilagyi N, Majtenyi K, Palkovits M, Komoly S (2000)

"Axonal changes in chronic demyelinated cervical spinal cord plaques"

Brain 123 ( Pt 2): 308-317

Lu B (2003)

"Pro-region of neurotrophins: role in synaptic modulation"

Neuron 39, 735-738

Lu B, Pang PT, Woo NH (2005)

"The yin and yang of neurotrophin action" Nat Rev Neurosci 6(8):603-14

Lublin FD \& Reingold SC (1996):

"Defining the clinical course of multiple sclerosis: Results of an international survey"

Neurology 46, 907-911
Lucchinetti C, Brück W, Parisi J, Scheithauer B, Rodriguez M, Lassmann H (2000)

"Heterogeneity of multiple sclerosis lesions: implications for the pathogenesis of demyelination"

Ann Neurol 47:707-717

Matsushita T, Yanaba K, Bouaziz JD, Fujimoto M, Tedder TF (2008)

"Regulatory B cells inhibit EAE initiation in mice while other $B$ cells promote disease progression"

J Clin Invest 118: 3420-3430

Matsushita T, Horikawa M, Iwata Y, Tedder TF (2010)

"Regulatory B Cells (B10 Cells) and Regulatory $\mathrm{T}$ Cells Have Independent Roles in Controlling Experimental Autoimmune Encephalomyelitis Initiation and Late-Phase Immunopathogenesis"

J Immunol 185;2240-2252

Meakin SO \& Shooter EM (1992)

"The nerve growth factor family of receptors"

Trends Neurosci 15, 323-331 
Mendel I, Kerlero de Rosbo N, Ben-Nun A (1995)

"A myelin oligodendrocyte glycoprotein peptide induces typical chronic experimental autoimmune encephalomyelitis in H-2b mice: fine specificity and $\mathrm{T}$ cell receptor $\mathrm{V}$ beta expression of encephalitogenic T cells"

Eur J Immunol 25(7):1951-9

Mi S, Lee X, Shao Z, Thill G, Ji B, Relton J, Levesque M, Allaire N, Perrin S, Sands B, Crowell T, Cate RL, McCoy JM, Pepinsky RB (2004)

"LINGO-1 is a component of the Nogo-66 receptor/p75 signaling complex"

Nat Neurosci 7(3):221-8

Mildner A, Schmidt $H$, Nitsche $M$, Merkler D, Hanisch UK, Mack M, Heikenwalder M, Brück W, Priller J, Prinz M (2007)

"Microglia in the adult brain arise from Ly-6ChiCCR2 ${ }^{+}$monocytes only under defined host conditions"

Nat Neurosci 10(12):1544-53

Mirowska-Guzel D, Mach A, Gromadzka G, Czlonkowski A, Czlonkowska A (2008) "BDNF A196G and C270T gene polymorphisms and susceptibility to multiple sclerosis in the Polish population. Gender differences“" J Neuroimmunol 193(1-2):170-2
Miyasaka M \& Dudler L (1984)

"Differentiation of ovine immature B cells upon exposure to phorbol myristate acetate"

Int Arch Allergy Appl Immunol 74(3):2813

Mukai J, Suvant P, Sato TA (2003)

"Nerve growth factor-dependent regulation of NADE-induced apoptosis“

Vitam Horm 66:385-402

Nacken W, Sopalla C, Pröpper C, Sorg C, Kerkhoff C (2000)

"Biochemical characterization of the murine S100A9 (MRP14) protein suggests that it is functionally equivalent to its human counterpart despite its low degree of sequence homology"

Eur J Biochem 267(2):560-5

Navikas V \& Link H (1996)

"Cytokines and the pathogenesis of multiple sclerosis"

J Neurosci Res 45, 322-33

Neumann $H$, Misgeld $T$, Matsumuro $K$, Wekerle H (1998)

"Neurotrophins inhibit major histocompatibility class II inducibility of microglia: involvement of the p75 neurotrophin receptor" Proc Natl Acad Sci U S A 95(10):5779-84 
Nykjaer A, Lee R, Teng KK, Jansen P, Madsen P, Nielsen MS, Jacobsen C, Kliemannel M, Schwarz E, Willnow TE, Hempstead BL, Petersen CM (2004)

"Sortilin is essential for proNGF-induced neuronal cell death"

Nature 427(6977):843-8

Oderfeld-Nowak B, OrzyłowskaSliwińska O, Sołtys Z, Zaremba M, Januszewski S, Janeczko K, Mossakowski M (2003)

"Concomitant up-regulation of astroglial high and low affinity nerve growth factor receptors in the CA1 hippocampal area following global transient cerebral ischemia in rat"

Neuroscience 120(1):31-40

Oertle T, van der Haar ME, Bandtlow CE, Robeva A, Burfeind P, Buss A, Huber AB, Simonen M, Schnell L, Brösamle C, Kaupmann K, Vallon R, Schwab ME (2003)

"Nogo-A inhibits neurite outgrowth and cell spreading with three discrete regions" J Neurosci 23(13):5393-406

Oliver AR, Lyon GM, Ruddle NH (2003)

"Rat and human myelin oligodendrocyte glycoproteins induce experimental autoimmune encephalomyelitis by different mechanisms in C57BL/6 mice" J Immunol 171(1):462-8

\section{Parker DC (1993)}

"T cell-dependent B cell activation"

Annu Rev Immunol 11, 331-340

Petermann F, Rothhammer V, Claussen MC, Haas JD, Blanco LR, Heink S, Prinz I, Hemmer B, Kuchroo VK, Oukka M, Korn T (2010)

" $\gamma \delta \mathrm{T}$ cells enhance autoimmunity by restraining regulatory $\mathrm{T}$ cell responses via an interleukin-23-dependent mechanism" Immunity 33(3):351-63

Rabizadeh S \& Bredesen DE (2003)

"Ten years on: mediation of cell death by thy common neurotrophin receptor $\mathrm{p} 75^{\mathrm{NTR},}$

Cytokine Growth Factor Rev. JunAug;14(3-4):225-39

Renganathan $\mathrm{M}$, Gelderblom $\mathrm{M}$, Black JA, Waxman SG (2003)

"Expression of Nav1.8 sodium channels perturbs the firing patterns of cerebellar Purkinje cells"

Brain Res 959(2):235-42

\section{Rieckmann P (2005)}

"Neurodegeneration and clinical relevance for early treatment in multiple sclerosis" Int MS J 12(2):42-51 
Rivers TM, Sprunt DH, Berry GP (1933)

"Observations on attempts to produce acute disseminated encephalomyelitis in monkeys"

J Exp Med. 58(1):39-53

Salehi AH, Roux PP, Kubu CJ, Zeindler C, Bhakar A, Tannis LL, Verdi JM, Barker PA (2000)

"NRAGE, a novel MAGE protein, interacts with the p75 neurotrophin receptor and facilitates nerve growth factor-dependent apoptosis"

Neuron 27(2):279-88

Sanders P \& De Keyser J (2007)

"Janus faces of microglia in multiple sclerosis"

Brain Res Rev 54: 274-285

Sheremata WA, Vollmer TL, Stone LA, Willmer-Hulme AJ, Koller M (1999)

"A safety and pharmacokinetic study of intravenous natalizumab in patients with MS"

Neurology 52(5):1072-4

Siffrin V, Radbruch H, Glumm R, Niesner R, Paterka M, Herz J, Leuenberger T, Lehmann SM, Luenstedt S, Rinnenthal JL, Laube G, Luche H, Lehnardt S, Fehling HJ, Griesbeck O, Zipp F (2010)
"In vivo imaging of partially reversible th17 cell-induced neuronal dysfunction in the course of encephalomyelitis"

Immunity 33(3):424-36

Singh AK, Wilson MT, Hong S, OlivaresVillagómez D, Du C, Stanic AK, Joyce S, Sriram S, Koezuka Y, Van Kaer L (2001) "Natural killer $\mathrm{T}$ cell activation protects mice against experimental autoimmune encephalomyelitis"

J Exp Med 194(12):1801-11

\section{Snider WD (1988)}

"Nerve growth factor enhances dendritic arborisation of sympathetic ganglion cells in developing mammals"

J Neurosci 8:2628-34

\section{Snider WD (1994)}

"Functions of the neurotrophins during nervous system development: what the knockouts are teaching us."

Cell 77:627-38

Soilu-Hänninen $M$, Epa R, Shipham K, Butzkueven H, Bucci T, Barrett G, Bartlett PF, Kilpatrick TJ (2000)

"Treatment of experimental autoimmune encephalomyelitis with antisense oligonucleotides against the low affinity neurotrophin receptor" J Neurosci Res 59, 712-721 
Sospedra M \& Martin R (2005)

"Immunology of multiple sclerosis"

Annu Rev Immunol 23: 683-747

Stadelmann C, Kerschensteiner M, Misgeld T, Brück W, Hohlfeld R, Lassmann H (2002)

"BDNF and gp145trkB in multiple sclerosis brain lesions: neuroprotective interactions between immune and neuronal cells?"

Brain 125(Pt 1):75-85

Teitelbaum D, Meshorer A, Hirshfeld T, Arnon R, Sela M (1971)

"Suppression of experimental allergic encephalomyelitis by a synthetic polypeptide"

Eur J Immunol 1(4):242-8

\section{Thoenen H (1995)}

"Neurotrophins and neuronal plasticity"

Science 270, 593-598

Tilg H, Trehu E, Atkins MB, Dinarello CA, Mier JW (1994)

"Interleukin-6 (IL-6) as an antiinflammatory cytokine: induction of circulating IL-1 receptor antagonist and soluble tumor necrosis factor receptor $\mathrm{p} 55$ " Blood, Vol83, No 1, pp 1 13-1 1
Torcia M, Bracci-Laudiero L, Lucibello M, Nencioni L, Labardi D, Rubartelli A, Cozzolino F, Aloe L, Garaci E (1996)

"Nerve growth factor is an autocrine survival factor for memory B lymphocytes"

Cell 85(3):345-56

Tsunoda I \& Fujinami RS (1996)

"Two models for multiple sclerosis: experimental allergic encephalomyelitis and Theiler's murine encephalomyelitis virus"

J Neuropathol Exp Neurol. 55(6):673-86

Valdo P, Stegagno C, Mazzucco S, Zuliani E, Zanusso G, Moretto G, Raine CS, Bonetti B (2002)

"Enhanced expression of NGF receptors in multiple sclerosis lesions"

J Neuropathol Exp Neurol 61(1):91-8

Volosin M, Song W, Almeida RD, Kaplan DR, Hempstead BL, Friedman WJ (2006) "Interaction of survival and death signaling in basal forebrain neurons: roles of neurotrophins and proneurotrophins"

J Neurosci 26(29):7756-66

Wang KC, Kim JA, Sivasankaran R, Segal

R, He Z (2002)

"p75 interacts with the Nogo receptor as a co-receptor for Nogo, MAG and OMgp"

Nature 420, 74-78 
Watanabe R, Ishiura N, Nakashima H, Kuwano Y, Okochi H, Tamaki K, Sato S, Tedder TF, Fujimoto M (2010)

"Regulatory B cells (B10 cells) have a suppressive role in murine lupus: CD19 and B10 cell deficiency exacerbates systemic autoimmunity"

J Immunol 184: 4801-4809

\section{Wekerle H (1991)}

"Immunopathogenesis of multiple sclerosis"

Acta Neurol (Napoli) 13(2):197-204

Welcher AA, Bitler CM, Radeke MJ, Shooter EM (1991)

"Nerve growth factor binding domain of the nerve growth factor receptor" Proc Natl Acad Sci 88, 159-163

\section{Weskamp G \& Otten U (1987)}

"An enzyme-linked immunoassay for nerve growth factor (NGF): a tool for studying regulatory mechanisms involved in NGF production in brain and in peripheral tissues"

J Neurochem 48(6):1779-86
Williams LR, Varon S, Peterson GM, Wictorin K, Fischer W, Bjorklund A, et al. (1986)

"Continuous infusion of nerve growth factor prevents basal forebrain neuronal death after fimbria fornix transaction" Proc Natl Acad Sci 83:9231-5

\section{Yan H \& Chao MV (1991)}

"Disruption of cysteine-rich repeats of the p75 nerve growth factor receptor leads to loss of ligand binding" J Biol Chem 266, 12099-12104

Yanaba K, Bouaziz JD, Haas KM, Poe JC, Fujimoto M, and Tedder TF (2008)

"A regulatory B cell subset with a unique CD1d ${ }^{\text {hi }} \mathrm{CD}^{+}$phenotype controls $\mathrm{T}$ celldependent inflammatory responses" Immunity 28: 639-650

Yanaba K, Bouaziz JD, Matsushita T, Tsubata T, Tedder TF (2009)

"The development and function of regulatory $B$ cells expressing IL-10 (B10 cells) requires antigen receptor diversity and TLR signals" J Immunol 182: 7459-7472 
Yednock TA, Cannon C, Fritz LC, Sanchez-Madrid F, Steinman L, Karin N (1992)

"Prevention of experimental autoimmune encephalomyelitis by antibodies against alpha 4 beta 1 integrin"

Nature 356(6364):63-6

Zhang B, Yamamura $\mathrm{T}$, Kondo $\mathrm{T}$, Fujiwara M, Tabira T (1997)

"Regulation of experimental autoimmune encephalomyelitis by natural killer (NK) cells" $J$ Exp Med 186(10):1677-87

Zhang Y, Hong Y, Bounhar Y, Blacker M, Roucou X, Tounekti O, Vereker E, Bowers WJ, Federoff HJ, Goodyer CG, LeBlanc A (2003)

“p75 neurotrophin receptor protects primary cultures of human neurons against extracellular amyloid beta peptide cytotoxicity"

J Neurosci 23(19):7385-94

Zhou P, Qiu J, L'Italien L, Gu D, Hodges

D, Chao CC, Schebye XM (2010)

"Mature B cells are critical to T-cellmediated tumor immunity induced by an agonist anti-GITR monoclonal antibody"

J Immunother 33(8):789-97 


\section{A Appendix}

\section{A.1 Common procedures}

$\underline{\text { Cell culture incubations }}$

If not other specified, all cells and cultures were long-term incubated at $37^{\circ} \mathrm{C}$ with $5 \%$ $\mathrm{CO}_{2}$ in a cell culture incubator.

\section{Cell washing}

Filled up the tube with specified medium or buffer, centrifugation at $290 \mathrm{~g}, 4^{\circ} \mathrm{C}, 6 \mathrm{~min}$, discarded the supernatant, and resuspension of the pellet in an appropriate amount of specified medium or buffer.

Determination of cell counts

Stained a cell suspension sample with $10 \%$ trypan blue in PBS (1:10) to reveal dead cells. Counted in a Neubauer counting chamber and extrapolated to total cell counts (cells/ml).

\section{A.2 Reagents: Solutions, buffers, emulsions}

$\underline{\text { astrocyte medium }}$

BME medium

100units/ml penicillin/streptomycin

$10 \% \quad$ NHS

$2 \mathrm{mM} \quad$ L-glutamine

Bielschowsky developer solution

$20 \mathrm{ml}$

$37 \%$ formalin

$0.5 \mathrm{~g}$

citric acid
2 drops $\quad 65 \%$ nitric acid

100ml distilled $\mathrm{H}_{2} \mathrm{O}$

$\underline{\text { citric acid buffer }}$

2.1g citric acid monohydrate

ad. $1000 \mathrm{ml} \quad \mathrm{H}_{2} \mathrm{O}$

$\mathrm{pH} \quad 6$ 
$\underline{\text { DAB solution }}$

$\begin{array}{ll}25 \mathrm{mg} & \text { DAB } \\ 20 \mu \mathrm{l} & 30 \% \mathrm{H}_{2} \mathrm{O}_{2} \\ \text { ad. } 50 \mathrm{ml} & \text { PBS }\end{array}$

ad. $50 \mathrm{ml} \quad$ PBS

ELISA wash buffer

$\begin{array}{ll}0.05 \% & \text { Tween } 20 \\ \text { ad. } 1000 \mathrm{ml} & \mathrm{H}_{2} \mathrm{O} \\ \text { pH } & 7.4\end{array}$

$\underline{\text { eosin solution }}$

$2 \mathrm{~g} \quad$ Eosin-G CertiStain

$198 \mathrm{ml} \quad 70 \%$ isopropanol

filtered

a little glacial acetic acid before use

$\underline{\text { FACS buffer }}$

$\begin{array}{ll}1 \% & \text { FCS } \\ \text { ad. } 1000 \mathrm{ml} & \text { PBS }\end{array}$

\section{FACS medium}

$2 \%$

FCS

$500 \mathrm{ml}$

DMEM (high glucose)
$\underline{\mathrm{HCl} \text { alcohol }}$

$175 \mathrm{ml}$ isopropanol

$2.5 \mathrm{ml} \quad 20 \%$ hydrochloric acid

$75 \mathrm{ml} \quad \mathrm{H}_{2} \mathrm{O}$

\section{$\underline{\text { LFB solution }}$}

$1 \mathrm{~g}$

LFB

$1000 \mathrm{ml} \quad 95 \% \mathrm{EtOH}$

$5 \mathrm{ml} \quad$ acetic acid

$\underline{\text { macrophage medium }}$

DMEM high glucose $(4.5 \mathrm{~g} / 1)$, + L-glutamine, + sodium pyruvate

$10 \% \quad$ FCS

$5 \% \quad$ NHS

100units/ml penicillin/streptomycin

$50 \mu \mathrm{M} \quad \beta$-mercaptoethanol

$\underline{\text { microglia medium }}$

DMEM high glucose $(4.5 \mathrm{~g} / \mathrm{l})$, + L-glutamine, + sodium pyruvate

$10 \% \quad$ FCS

100units/ml penicillin/streptomycin

MOG emulsion (per animal)

Griess reagent A

$\begin{array}{ll}0,1 \% & \text { naphtyl ethylene } \\ \text { in } & \mathrm{H}_{2} \mathrm{O}\end{array}$

$\underline{\text { Griess reagent B }}$

$1 \%$ sulphanilamide

$6 \% \quad \mathrm{H}_{3} \mathrm{PO}_{4}(85 \%)$

in $\mathrm{H}_{2} \mathrm{O}$

$\begin{array}{ll}200 \mu \mathrm{g} & \text { MOG }_{35-55} \\ 100 \mu \mathrm{l} & \text { PBS } \\ 100 \mu \mathrm{l} & \text { CFA } \\ 5 \mathrm{mg} / \mathrm{ml} & \text { killed mycobacteria tuber- } \\ & \text { culosis } \\ & \text { incomplete Freund's adju- } \\ 100 \mu \mathrm{l} & \text { vant }\end{array}$

emulsified by sonication 
$\underline{\text { PBS }}$

9.55g PBS

ad. $1000 \mathrm{ml} \mathrm{H}_{2} \mathrm{O}$
$\underline{T \text { cell clone freezing medium }}$

RPMI-1640 medium

40\% FCS HyClone

$20 \%$ dimethyl sulfoxide (DMSO)

$\underline{\text { PFA }}$

\begin{tabular}{|c|c|c|c|}
\hline $40 \mathrm{~g}$ & PFA & tail lysis buf & \\
\hline ad. $1000 \mathrm{ml}$ & PBS & $100 \mathrm{mM}$ & Tris \\
\hline heating up & to $60^{\circ} \mathrm{C}$ while constantly & $5 \mathrm{mM}$ & EDTA \\
\hline stirring to so & ve the PFA & $200 \mathrm{mM}$ & $\mathrm{NaCl}$ \\
\hline some drops & f $1 \mathrm{M} \mathrm{NaOH}$ until the PFA is & $0.2 \%$ & SDS \\
\hline solved & & $\mathrm{pH}$ & 8.5 \\
\hline pH 7.6 & & & \\
\hline & & $\underline{\mathrm{TBE}}$ & \\
\hline$\underline{\mathrm{T} \text { cell clone } 1}$ & nedium & $10.8 \mathrm{~g}$ & Tris \\
\hline RPMI-1640 1 & nedium & $5.5 \mathrm{~g}$ & boric acid \\
\hline $10 \%$ & FCS, HyClone & $4 \mathrm{ml}$ & $0.5 \mathrm{M}$ EDTA \\
\hline $1 \%$ & non-essential amino acids & ad. $1000 \mathrm{ml}$ & $\mathrm{H}_{2} \mathrm{O}$ \\
\hline $2 \mathrm{mM}$ & L-glutamine & & \\
\hline 100units/ml & penicillin/streptomycin & $\underline{\text { TBS }}$ & \\
\hline $1 \mathrm{mM}$ & sodium pyruvate (Na-P) & $9 g$ & $\mathrm{NaCl}$ \\
\hline $13 \mathrm{mM}$ & hydroxyethyl piperazine- & $50 \mathrm{ml}$ & $1 \mathrm{M}$ Tris/HCl \\
\hline & ethanesulfonic & ad. $1000 \mathrm{ml}$ & $\mathrm{H}_{2} \mathrm{O}$ \\
\hline & (HEPES) & $\mathrm{pH}$ & 7.6 \\
\hline
\end{tabular}

$50 \mu \mathrm{M} \quad \beta$-mercaptoethanol

\section{A.3 Chemicals / reagents manufacturers}

${ }^{3}$ H-thymidine

acetic acid

agarose

ammonium chloride

ammonium hydroxide
Sigma-Aldrich Chemie GmbH, Steinheim, Germany

Merck KgaA, Darmstadt, Germany

StarPure, StarLab GmbH, Ahrensberg, Germany

Pharm Lyse, 10x conc., BD Biosciences, Heidelberg, Germany

Merck KgaA, Darmstadt, Germany 
$\beta$-mercaptoethanol

BME

boric acid

$\mathrm{CD} 3 / \mathrm{CD} 28$

citric acid

clodronate

cloral hydrate

CM- $\mathrm{H}_{2}$ DCFDA

copper sulphate

DAB

DePeX

diethyl ether

DMEM

DMSO

DNA ladder

DNAse

dNTPs

EDTA

ELISA kit

Eosin-G CertiStain

ethidium bromide

EtOH absolute

FACS antibodies

Fc block

FCS (IHC)

FCS (T cell clone)

Fibrinogen

formalin

Giemsa
Sigma-Aldrich Chemie GmbH, Steinheim, Germany

Gibco, Invitrogen, Darmstadt, Germany

Roth, Karlsruhe, Germany

Dynabeads, Dynal Biotech, Invitrogen, Darmstadt, Germany

Merck KgaA, Darmstadt, Germany

Calbiochem, Merck KgaA, Darmstadt, Germany

Merck KgaA, Darmstadt, Germany

Invitrogen, Darmstadt, Germany

Merck KgaA, Darmstadt, Germany

Sigma-Aldrich Chemie GmbH, Steinheim, Germany

VWR international, Darmstadt, Germany

Sigma-Aldrich Chemie GmbH, Steinheim, Germany

High Glucose (4.5g/l), w/ L-Glutamine, sodium pyruvate, PAA, Cölbe, Germany

Sigma-Aldrich Chemie GmbH, Steinheim, Germany

gene ruler, Fermentas, St. Leon-Rot, Germany

DNase I, Roche, Mannheim, Germany

Fermentas, St. Leon-Rot, Germany

Roth, Karlsruhe, Germany

Quantikine Colorimetric Sandwich ELISA, R\&D Systems, Minneapolis, MN, USA

Merck KgaA, Darmstadt, Germany

Sigma-Aldrich Chemie GmbH, Steinheim, Germany

Merck KgaA, Darmstadt, Germany

BD Biosciences, Heidelberg, Germany

Beckman Coulter GmbH, Krefeld, Germany

eBioscience, NatuTec GmbH, Frakfurt, Germany

ImmunoTools, Friesoythe, Germany

BD Biosciences, Heidelberg, Germany

Biochrom AG, Berlin, Germany

HyClone, Thermo Fisher scientific GmbH, Schwerte, Germany

R\&D Systems, Minneapolis, MN, USA

Merck KgaA, Darmstadt, Germany

Merck KgaA, Darmstadt, Germany 
golgi stop

$\mathrm{H}_{2} \mathrm{O}_{2}$

$\mathrm{H}_{3} \mathrm{PO}_{4}$

HBSS

HEPES

IFA

IFN- $\gamma$

IL-2

isopropanol

L-glutamine

LFB

lithium carbonate

LPS

Mayer's hemalum

methanol

$\mathrm{MOG}_{35-55}$

mycobacteria tuberculosis

$\mathrm{NaCl}$

naphtyl ethylene

neomycin

NHS

nitric acid

nitroblue tetrazolium

non-essential amino acids

Paraffine

PBS

PBS (sterile)

PCR kit (genotyping)

penicillin/streptomycin

Percoll

periodic acid
BD Bioscience, Heidelberg, Germany

Merck KgaA, Darmstadt, Germany

Merck KgaA, Darmstadt, Germany

Gibco, Karlsruhe, Germany

Sigma-Aldrich Chemie GmbH, Steinheim, Germany

Sigma-Aldrich Chemie GmbH, Steinheim, Germany

R\&D Systems, Minneapolis, MN, USA

R\&D Systems, Minneapolis, MN, USA

Merck KgaA, Darmstadt, Germany

Gibco, Karlsruhe, Germany

BDH Laboratory supplies, VWR Int. Ltd., Poole, UK

Merck KgaA, Darmstadt, Germany

Sigma-Aldrich Chemie GmbH, Steinheim, Germany

Merck KgaA, Darmstadt, Germany

Merck KgaA, Darmstadt, Germany

amino acid sequence: MEVGWYRSPFSRVVHLYRNGK,

Institute of Medical Immunology, University Medical Center

Charité, Berlin, Germany

H37 RA, Difco Laboratories, Augsburg, Germany

Merck KgaA, Darmstadt, Germany

Merck KgaA, Darmstadt, Germany

Roth, Karlsruhe, Germany

PAA, Cölbe, Germany

Merck KgaA, Darmstadt, Germany

Sigma-Aldrich Chemie GmbH, Steinheim, Germany

Sigma-Aldrich Chemie GmbH, Steinheim, Germany

Paraplast Plus, Tyco Healthcare GmbH, Neustadt an der Donau, Germany

10x conc., Dulbecco, Biochrom AG, Berlin, Germany

Dulbecco, w/o $\mathrm{Mg}^{2+}, \mathrm{Ca}^{2+}$, PAA, Cölbe, Germany

GoTaq, Promega GmbH, Mannheim, Germany

Gibco, Karlsruhe, Germany

GE Healthcare, Uppsala, Sweden

Merck KgaA, Darmstadt, Germany 
PFA

PMA

poly-L-lysine

potassium hydroxide

POX

proteinase $\mathrm{K}$

PTX

Qiagen DNAse

Qiagen RNAlater

Qiagen RNeasy Mini Kit

qRT-PCR master mix

qRT-PCR TaqMan probes

reverse transcription

RPMI-1640

Schiff's solution

SDS

silver nitrate

sodium pyruvate $(\mathrm{Na}-\mathrm{P})$

sodium thiosulfate

sulfanilamid

sulphuric acid

tris

trypan blue $(0.4 \%)$

trypsin / EDTA

tween 20

xylol

Zymosan
Merck KgaA, Darmstadt, Germany

Sigma-Aldrich Chemie GmbH, Steinheim, Germany

Sigma-Aldrich Chemie GmbH, Steinheim, Germany

Merck KgaA, Darmstadt, Germany

Extravidin, Sigma-Aldrich Chemie GmbH, Steinheim, Germany

Roche, Mannheim, Germany

List Biological Laboratories, London, United Kingdom

RNase-free DNase set, Qiagen, Hilden, Germany

Qiagen, Hilden, Germany

Qiagen, Hilden, Germany

Applied Biosystems, Carlsbad, CA, USA

Applied Biosystems, Carlsbad, CA, USA

High Capacity cDNA Reverse transcription kit, Applied

Biosystems, Carlsbad, CA, USA

w/o L-glutamine, PAA, Cölbe, Germany

Merck KgaA, Darmstadt, Germany

Sigma-Aldrich Chemie GmbH, Steinheim, Germany

Roth, Karlsruhe, Germany

Sigma-Aldrich Chemie GmbH, Steinheim, Germany

Merck KgaA, Darmstadt, Germany

Merck KgaA, Darmstadt, Germany

Merck KgaA, Darmstadt, Germany

Roth, Karlsruhe, Germany

Sigma-Aldrich Chemie GmbH, Steinheim, Germany

Gibco, Karlsruhe, Germany

Merck KgaA, Darmstadt, Germany

Merck KgaA, Darmstadt, Germany

Sigma-Aldrich Chemie GmbH, Steinheim, Germany 


\section{A.4 Equipment / instrument manufacturers}

24-well plates (cell culture) Greiner Bio-One GmbH, Frickenhausen, Germany

96-well plates (qRT-PCR) Applied Biosystems, Carlsbad, CA, USA

cell harvester

MicroBeta FilterMate-96 Harvester, Perkin Elmer, Rodgau, Germany

cell irradiator

B +R Industrie-Elektronik GmbH, Bad Homburg, Germany

Cell Quest Pro 5.2

BD Biosciences, Heidelberg, Germany

cell strainer $(70+40 \mathrm{~nm})$

BD Biosciences, Heidelberg, Germany

cell $^{\wedge} \mathrm{F}$ program

Olympus Europa GmbH, Hamburg, Germany

centrifuge (cell culture)

5810 R, Eppendorf AG, Hamburg, Germany

cytospin

Shadon Cytospin 4, Thermo Fisher scientific GmbH, Schwerte, Germany

ELISA reader

Model 680, Biorad, Munich, Germany

FACS instrument

FACSCalibur, BD Bioscience, Heidelberg, Germany

FACS tubes

BD Bioscience, Heidelberg, Germany

fluorescence reader

Safire, Tecan, Mainz, Germany

gel rack \& power supply

SubCell GT \& PowerPack 300, Biorad, Munich, Germany

glass slides

Menzel, Braunschweig, Germany

incubator

Cellstar, Nunc GmbH, Wiesbaden, Germany

linear accelerator

Clinac 3, 600 C - 446, Varian Medical Systems, Palo Alto, CA, USA

microtome

Leica, Wetzlar, Germany

microwave

Bosch, Gerlingen-Schillerhöhe, Germany

NanoDrop

ND-1000, Thermo Fisher scientific GmbH, Schwerte, Germany

Neubauer counting chamber Brand GmbH \& Co KG, Wertheim, Germany

PCR cycler

Thermocycler T3, Biometra, Göttingen, Germany

Qiagen QiaShredder

Qiagen, Hilden, Germany

qRT-PCR cycler

StepOne Plus, Applied Biosystems, Carlsbad, CA, USA

scintillation counter

Wallac MicroBeta TriLux, Perkin Elmer, Rodgau, Germany

sonicator

SonoPuls, Bandelin Electronics, Berlin, Germany

Teflon coated pot

Roth, Karlsruhe, Germany

tissue processor

TP 1020, Leica, Wetzlar, Germany

WinMDI 2.9

TSRI, La Jolla, CA, USA 


\section{Acknowledgements}

First and foremost I would like to thank my supervisor and mentor Prof. Dr. med. Christine Stadelmann-Nessler not only for her excellent guidance but also for giving me the chance to work independently. I am deeply grateful for the opportunity to work in her laboratory, for her scientific expertise, her patience, and for her being always receptive to my questions, problems, and needs.

I am also very thankful to Dr. med. Stefan Nessler for great theoretical and practical support.

I appreciate working in the Institute of Neuropathology that is integrated in the University Medical Center and other scientific facilities in Göttingen. This provides great opportunities for using sophisticated equipment and for intellectual exchange. Therefore, many thanks go to the director of the institute, Prof. Dr. med. Brück, for given me the chance to learn so many valuable techniques.

I like to thank my thesis committee Prof. Dr. rer. nat. Fuchs, Prof. Dr. med. Simons, and Prof. Dr. med. Brück for their critical and supporting comments on my progress reports and for their precious time.

Many thanks go to our cooperation partners Dr. Patrick Vollmar and Prof. Dr. med. Hemmer at the Department of Neurology, Technical University, Munich, for great support in RNA analysis.

I am also very thankful to ...

... our laboratory assistants Katja, Brigitte, Heidi, Angela, and Uta for training me in the beginning and relieving me of many tasks.

... the Department of Animal Experiments under the direction of Dr. med. vet. Kimmina, especially to Nina Karbe for great and solid breeding of my mice. Thanks go also to Martina Radtke and Dr. med. vet. Schunck for taking care of my animals during the experiments.

... the Department of Radiation Therapy and Radiooncology under the direction of Prof. Dr. Dr. Hess, especially to Prof. Dr. med. Hille, for irradiating my mice, which was always very exciting.

... the Department of Transfusion Medicine under the direction of PD. Dr. med. Riggert and to the ladies at the front desk for always letting me irradiate my APCs no matter what time it was. 
Personal thanks go out to all members of the Institute of Neuropathology, especially to my friends and colleagues Angela, Amke, Christiane M, Christiane W, Claudia, Darius, Enrique, Jenni, Johanna, Jörg, Jutta, Mario, Ramona, Sebastian, Tanja, Tommy, and Wiebke. Thanks for the after hour pub meetings, barbeques, and the great time. Thank you, Cynthia and Chris, for your administrative support. Thank you, Rene, for exciting insights into your daily work.

Very personal thanks go out to my parents, Edith and Klaus, for their great support and love throughout my life. Thank you for always supporting my choices.

I am deeply grateful to Katharina for her endless patience, appreciation, love, and affection. 


\section{Curriculum vitae}

\section{Personal data}

Name

Date/Place of birth

Nationality

Contact
Tobias Dallenga

March 10, 1980 in Oldenburg, Germany

german

tobias.dallenga@gmx.net

\section{Education and Qualifications}

05/2007 - present

$10 / 2000-12 / 2006$

$1992-1999$
Institute of Neuropathology, University Medical Center Göttingen, Germany

Ph.D. student

Program of the DFG Research Center Molecular Physiology of the Brain (CMPB), Göttingen Graduate School for Neurosciences and Molecular Biosciences (GGNB)

\section{Carl-von-Ossietzky University, Oldenburg, Germany}

Studies in biology

Degree: Diploma, Grade: very good

Herbartgymnasium, Oldenburg, Germany

Abitur (A-levels) 


\section{Professional experience}

05/2007 - present

$09 / 2005-12 / 2006$

$01 / 2006-02 / 2006$

$11 / 2004-02 / 2005$
Institute of Neuropathology, University Medical Center Göttingen, Germany

Ph.D. thesis: "The Role of the p75 Neurotrophin Receptor in Experimental Inflammation of the Central Nervous System" Supervisor: Prof. Dr. med. Christine Stadelmann-Nessler

\section{Carl-von-Ossietzky University, Oldenburg, Germany}

Diploma thesis: "Morphological Characterization of the Retina in Connexin45 knock-out/Connexin 36 knock-in Mice" Supervisor: Prof. Dr. Ulrike Janssen-Bienhold

Carl-von-Ossietzky University, Oldenburg, Germany student assistant in the laboratory of Neuroanatomy

Institute for the Biosynthesis of Neural Structures, University Medical Center, Hamburg, Germany

Research internship

\section{Publications}

Dziedzic $\mathrm{T}^{*}$, Metz $\mathrm{I}^{*}$, Dallenga $\mathrm{T}^{*}$, König FB, Müller $\mathrm{S}$, Stadelmann C, Brück W (2010)

"Wallerian degeneration: a major component of early axonal pathology in multiple sclerosis"

Brain Pathol 20(5):976-85

* equal contribution 


\section{Talks}

2010

Dallenga T, Bittner A, Jäger W, Vollmar P, Oertel WH, Sommer N, Möller JC, Hemmer B, Nessler S, Stadelmann C

"The role of p75 neurotrophin receptor in axonal damage during CNS inflammation"

Ph.D. program CMPB, $2^{\text {nd }}$ Ph.D. students seminar, Göttingen, Germany

2009

Dallenga T, Bittner A, Jäger W, Vollmar P, Oertel WH, Sommer N, Möller JC, Hemmer B, Nessler S, Stadelmann C

"The role of p75-neurotrophin-receptor in axonal damage during CNS inflammation"

NeuroWind, Motzen, Germany

2009

Dallenga T, Bittner A, Jäger $\mathrm{W}$, Vollmar $\mathrm{P}$, Oertel $\mathrm{WH}$, Sommer N, Möller JC, Hemmer B, Nessler S, Stadelmann C

"The role of the p75 low affinity neurotrophin receptor in axonal damage during CNS inflammation"

German Society of Neuropathology and Neuroanatomy, Düsseldorf, Germany

\section{Poster presentations}

2010

Dallenga T, Bittner A, Jäger $\mathrm{W}$, Vollmar $\mathrm{P}$, Oertel $\mathrm{WH}$, Sommer N, Möller JC, Hemmer B, Nessler S, Stadelmann C

"The role of the $\mathrm{p} 75^{\mathrm{NTR}}$ in axonal damage during CNS inflammation"

NeuroWoche, Mannheim, Germany

Dallenga T, Bittner A, Jäger W, Vollmar P, Oertel WH, Sommer N, Möller JC, Hemmer B, Nessler S, Stadelmann C "The role of the $\mathrm{p} 75^{\mathrm{NTR}}$ in axonal damage during CNS inflammation“"

Inflammation in Brain Disease (NeurInfNet), Odense, Denmark 
Dallenga T, Bittner A, Jäger W, Vollmar P, Oertel WH, Sommer N, Möller JC, Hemmer B, Nessler S, Stadelmann C "The role of the $\mathrm{p} 75^{\mathrm{NTR}}$ in axonal damage during CNS inflammation“"

Ph.D. program GGNB Science Day, Göttingen, Germany

Dallenga T, Bittner A, Jäger W, Vollmar P, Oertel WH, Sommer N, Möller JC, Hemmer B, Stadelmann C, Nessler S "p $75^{\mathrm{NTR}}$-mediated axon protection in inflammatory CNS disease"

European Committee for Treatment and Research In Multiple Sclerosis (ECTRIMS), Düsseldorf, Germany

Dallenga $\mathbf{T}^{*}$, Escher $\mathrm{A}^{*}$, Nessler $\mathrm{S}$, Boretius $\mathrm{S}$, Brück $\mathrm{W}$, Lühder F, Stadelmann C

"MS-like cerebral inflammatory pathology in mice: A new experimental model for MS research"

Meeting of the German Neuroscience Society, Göttingen, Germany

* equal contribution

Tobias Dallenga, Wolfgang Jäger, Stefan Nessler, Christine Stadelmann

"The role of p75 neurotrophin receptor in axonal damage during CNS inflammation" Ph.D. program GGNB opening, Göttingen, Germany 